\title{
Evaluation of self-help computerised cognitive behavioural therapy for depression : Integrating clinical, economic and patient perspectives
}

Citation for published version (APA):

Gerhards, S. A. H. (2011). Evaluation of self-help computerised cognitive behavioural therapy for depression : Integrating clinical, economic and patient perspectives. [Doctoral Thesis, Maastricht University]. Datawyse / Universitaire Pers Maastricht. https://doi.org/10.26481/dis.20110113sg

Document status and date:

Published: 01/01/2011

DOI:

10.26481/dis.20110113sg

Document Version:

Publisher's PDF, also known as Version of record

Please check the document version of this publication:

- A submitted manuscript is the version of the article upon submission and before peer-review. There can be important differences between the submitted version and the official published version of record. People interested in the research are advised to contact the author for the final version of the publication, or visit the DOI to the publisher's website.

- The final author version and the galley proof are versions of the publication after peer review.

- The final published version features the final layout of the paper including the volume, issue and page numbers.

Link to publication

\footnotetext{
General rights rights.

- You may freely distribute the URL identifying the publication in the public portal. please follow below link for the End User Agreement:

www.umlib.nl/taverne-license

Take down policy

If you believe that this document breaches copyright please contact us at:

repository@maastrichtuniversity.nl

providing details and we will investigate your claim.
}

Copyright and moral rights for the publications made accessible in the public portal are retained by the authors and/or other copyright owners and it is a condition of accessing publications that users recognise and abide by the legal requirements associated with these

- Users may download and print one copy of any publication from the public portal for the purpose of private study or research.

- You may not further distribute the material or use it for any profit-making activity or commercial gain

If the publication is distributed under the terms of Article 25fa of the Dutch Copyright Act, indicated by the "Taverne" license above, 


\title{
Evaluation of self-help computerised cognitive behavioural therapy for depression
}

\author{
Integrating clinical, economic \\ and patient perspectives
}


(C) Sylvia A.H. Gerhards, Maastricht 2010

Production: Datawyse, Universitaire Pers Maastricht

Cover illustration: Geertje Claessen

Lay-out: S.A.H. Gerhards

ISBN 978-94-6159-021-3

This thesis was printed with financial supported of the RIAGG Maastricht.

The research in this thesis was performed at the Maastricht University School for Public Health and Primary Care (Caphri) and the department Clinical Psychological Science (CPS).

All rights reserved. No parts of this thesis may be repoduced or transmitted in any form or by any means, electronic or mechanical, including photoopying, recording or any information storage or retrieval system, without permission in writing from the author, or, when appropriate, from the publishers holding the copyright of the of the published article. 


\title{
Evaluation of self-help computerised cognitive behavioural therapy for depression
}

\author{
Integrating clinical, economic \\ and patient perspectives
}

\begin{abstract}
PROEFSCHRIFT
Ter verkrijging van de graad van doctor aan de Universiteit Maastricht op gezag van de Rector Magnificus, prof. mr. G.P.M.F. Mols, volgens het besluit van het College van Decanen, in het openbaar te verdedigen op donderdag 13 januari 2011 om 16.00 uur

door
\end{abstract}

Sylvia Anna Huberte Gerhards

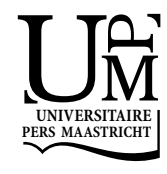




\section{Promotores}

Prof. dr. M.J.H. Huibers

Prof. dr. A. Arntz

Prof. dr. G.A.M. Widdershoven (VUmc Amsterdam / Universiteit Maastricht)

\section{Copromotor}

Dr. S.M.A.A. Evers

\section{Beoordelingscommissie}

Prof. dr. ir. C.P. van Schayck (voorzitter)

Prof. dr. J.J. van Busschbach (Erasmus MC Rotterdam)

Prof. dr. M. Peters

Prof. dr. F. Smit (Trimbos Instituut Utrecht)

Prof. dr. R. Vos 


\section{Table of contents}

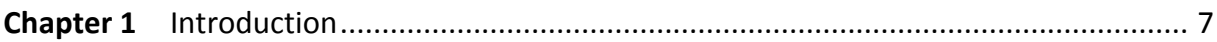

Part 1 Evaluation of online computerised cognitive-behavioural therapy......................... 19

Chapter 2 Clinical effectiveness of online computerised cognitive behavioural therapy without support for depression in primary care: a randomised trial

Chapter 3 Economic evaluation of online computerised cognitive behavioural therapy without support for depression in primary care: a randomised trial

Chapter 4 Improving adherence and effectiveness of computerised cognitive behavioural therapy without support for depression: a qualitative study on patient experiences

Chapter 5 Credibility and expectancy in online self-help depression treatment: impact on depression severity and quality of life

Part 2 Utility instruments in depression.

Chapter 6 The responsiveness of quality of life utilities to change in depression: a comparison of instruments (SF-6D, EQ-5D and DFD)

Chapter 7 Change in the course of depression severity (BDI-II) and quality of life utility (SF-6D): evidence for a temporal relation?

Chapter 8 Discrepancy in rating health-related quality of life of depression between patient and general population

Chapter 9 General conclusion and discussion

Summary

Samenvatting

Appendix 1 Clinical and cost-effectiveness of computerised cognitive behavioural therapy for depression in primary care: design of a randomised trial

Appendix 2 One-year follow-up results of unsupported online computerised cognitive behavioural therapy for depression in primary care: a randomised trial

Dankwoord 

Chapter 1

Introduction 


\section{Depression}

Depression is a common mental health problem in the general population. ${ }^{1}$ In Europe, prevalence estimates range from $3 \%$ to $10 \%{ }^{2,3}$ It is estimated that in the Netherlands $5.8 \%$ of the inhabitants aged 18 to 65 suffered from major depression in $1996,{ }^{1}$ and $6.2 \%$ in $2007 .{ }^{4}$ The lifetime prevalence was $15.4 \%$ in $1996^{1}$ and $18.7 \%$ in $2007 .{ }^{4}$ The DSM-IV lists the following symptoms of depression: depressed mood, loss of interest or pleasure, significant weight loss/gain or decrease/increase in appetite, insomnia or hypersomnia, fatigue or loss of energy, feeling of worthlessness, psychomotor agitation or retardation, concentration problems or indecisiveness, recurrent thoughts of death or suicidal ideation. ${ }^{5}$ For a diagnosis of major depression, the criteria are the presence of at least five symptoms during a two-week period, with at least one of the symptoms of depressed mood or loss of interest/pleasure. ${ }^{5}$ Consequently, the figures on depression prevalence would be even higher when including people with minor depressive symptoms as well.

\section{Burden of disease of depression}

Many studies have shown that depression has an important influence on the patient's quality of life through its impact on physical, social and emotional functioning and wellbeing. ${ }^{6-11}$ The global burden of disease study of the World Health Organisation ${ }^{12}$ even suggests unipolar depression to be the third largest contributor to the burden of disease world-wide in 2004: It was estimated that depression accounted for $4.3 \%$ of all disabilityadjusted life-years (DALYs) world-wide. ${ }^{12}$ This DALY is a measure which reflects the years of life lost from premature death combined with the years of life lived in less than full health due to the disorder. Prospects are that unipolar depression will be the leading cause of DALYs world-wide by $2030 .^{12}$ However, for middle- and high-income countries unipolar depression already achieved this first place in the estimates of $2004 .^{12}$

The high prevalence and burden of depression is reflected in depression-related costs. Cost-of-illness studies reveal that the economic burden of depression is considerable. ${ }^{13-18}$ In the Netherlands, it is estimated that depression accounted for $1.1 \%$ (or 773 million $€$ ) of total health care expenditures in $2005 .{ }^{18}$ Depression thus implies increased costs due to health care usage, but even more due to decreased productivity. ${ }^{14-16,19}$ It is estimated that in Europe, the total cost of depression is $1 \%$ of the total gross domestic product, although cost differences exist between countries. ${ }^{15}$

Depression thus is related with considerable costs and decreased quality of life. To reduce the burden and costs of depression, it is important that people suffering from depression are detected in an early stage and treated adequately.

\section{Undertreatment of depression}

The general practitioner (GP) is the major health care provider involved in the primary care treatment of depression. In the Dutch health care system the GP is seen as a gatekeeper, 
and consequently is a key figure in the detection and treatment of depression. ${ }^{20}$ Despite this, many depressed people remain undetected, ${ }^{21-23}$ which might partly be explained by not seeking professional help. ${ }^{24-27}$ Studies of the Netherlands, Australia, and the United States all estimate that about a third of the people with psychological disorders use some form of health care targeting their psychological problems, ${ }^{4}$ implying that a majority does not use these health care services. For depression, a study in the United States estimated that during a 12 -month period $51.6 \%$ of the people with a major depressive disorders received treatment, of which only $41.9 \%$ was treated adequately in either the specialty mental health sector or in the general medical sector (such as primary care). ${ }^{28}$ Thus, even when the depressive complaints are being recognized by the patient and the primary care provider, many patients do not receive the care they need. A first reason is that pharmacotherapy is not always an adequate treatment option. Many patients refuse medication or comply poorly. ${ }^{29}$ And although it can be effective in extremely depressed patients, there is only little evidence on the effectiveness of pharmacotherapy in mild to moderately depressed patients. ${ }^{30,31} \mathrm{~A}$ second reason why primary care patients do not always receive adequate care is that non-pharmacological treatment options in primary care are scarce or not feasible. ${ }^{32}$ Consequently, effective treatments are not offered to all depressed patients and many depressed patients in primary care remain untreated. ${ }^{27}$ As a result, only a limited group of depressed patients in primary care receives effective treatment.

\section{Computerised cognitive behavioural therapy}

An effective, acceptable, and feasible solution for depressed patients might be self-help computerised cognitive behavioural therapy (CCBT). ${ }^{33}$ CCBT is a program based on the principles of cognitive behavioural therapy (CBT). CBT has proven to be an effective treatment for depression. ${ }^{34,35}$ CCBT for primary care seems a promising alternative. It can be offered via the Internet, which makes it more easily accessible since clients can avoid the stigma experienced by seeing a therapist. ${ }^{36,37}$ Moreover, CCBT can be offered with differing degrees of professional support. ${ }^{37}$ Consequently, per-patient time and costs of CCBT can be expected to be lower, its availability can be expected to be less affected by the shortage of therapists, and thus CCBT can be offered to a larger group of people compared with faceto-face CBT. ${ }^{36-39}$ Furthermore, the number of referrals to secondary care by a GP can be reduced, and waiting lists for traditional CBT can become shorter. ${ }^{33,37}$ The National Institute of Health and Clinical Excellence (NICE, UK) already recommended the use of two CCBT software programs for depression and anxiety, ${ }^{40}$ and these programs are now in use in England, Wales and Northern Ireland. In the Netherlands, an online CCBT program is currently being used as part of an ongoing implementation study (www.kleurjeleven.nl).

\section{Efficiency and patient experiences with CCBT}

There is growing evidence on the effectiveness of CCBT for depression. ${ }^{33}$ However, a good evaluation of a health intervention should include more aspects besides its effectiveness, such as costs or social aspects. Health technology assessment (HTA) includes several do- 
mains of evaluation, as presented in the HTA flower (figure 1) based on Habema et al. ${ }^{41}$ Despite the number of trials, ${ }^{33,42-45}$ systematic reviews on CCBT for depression acknowledge that there is still little known on the efficiency ${ }^{33}$ (the 'costs and financing' in the HTAflower) and patient experiences ${ }^{46}$ (the 'ethical consequences' and 'social aspects' in the HTA flower) with CCBT. To our knowledge, only one study conducted an economic evaluation of CCBT for depression, showing that CCBT (delivered on a personal computer in the general practice) can be highly cost-effective compared with usual care by a GP in the UK setting. ${ }^{47}$ In their systematic review, Kalthenthaler et al. ${ }^{46}$ underline the importance of including qualitative studies alongside trials to determine patient acceptability. Moreover, a recent systematic review showed that a substantial part of study participants do not even start CCBT, while only little is known about the barriers to the uptake of CCBT. ${ }^{48}$ Previous qualitative research on depression treatment has focused on the patient experience of guided self-help in primary mental health care ${ }^{49}$ and of CBT delivered 'live' online by a psychologist. ${ }^{50}$ But to our knowledge, no previous research has studied the patient experience of pure self-help online CCBT for depression using qualitative research methods. Also, quantitative data on treatment expectancy and credibility might provide better insight into patient aspects through which CCBT might improve. Previous studies have found a relation between patients' treatment outcome expectancy and/or credibility for a wide range of conditions and treatment contexts. ${ }^{51-63}$ However, to our knowledge none of these studies focused on self-help or on an e-health intervention for depression. Consequently, there still remains a lot to be evaluated concerning CCBT for depression. In the current project, we will focus specifically on the clinical effectiveness, efficiency, patient experiences, and the role of credibility and expectancy in online CCBT delivered as pure self-help for depression.

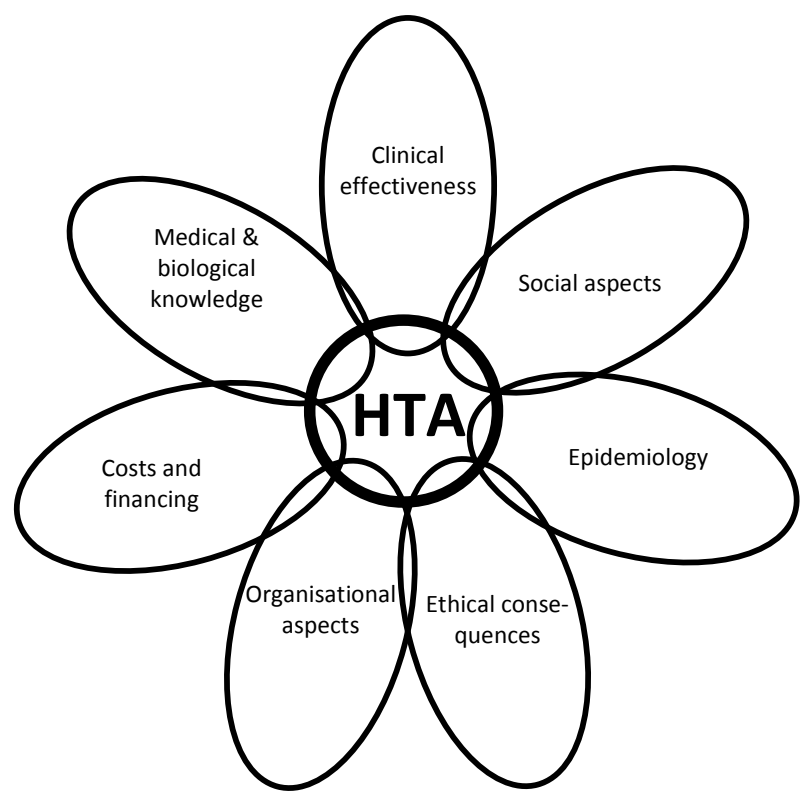

Figure 1: HTA flower (Source: adapted from Habbema et al., 1989) 


\section{Methodological aspects of evaluating quality of life utility with depression}

Economic evaluations assess the efficiency of an intervention and are used as a basis for resource allocation decisions. Often, generic health-related quality of life is one of the main outcome parameters in economic evaluation (i.e. cost-utility analysis). A utility theoretically can range from 0 (the worst imaginable condition: death) to 1 (perfect health). In costutility analyses, quality of life is included in a generic and not in a disease-specific manner: they target several health-related quality of life domains which are not necessarily related to the disorder at issue. This broad perspective facilitates comparisons between different disorders and interventions. ${ }^{64}$ Since cost-utility analyses are a base for policy decisions on resource allocation, it is important that these utilities correctly reflect health status changes supposed to be of influence on the subject's quality of life. And as mentioned above, depression has an important impact on several domains of quality of life, which consequently should be reflected in the utility.

However, there still exists uncertainty on the measurement of utility. There is no agreement on who should value the health state's quality of life: the general population, the patient, or some other rater group (e.g. health professionals) ${ }^{65}$ At one hand, one might argue that quality of life should be valued by a patient population; They really know what it is like to be in that health state, and consequently are the only ones who express the 'true' preference over different health states. ${ }^{66}$ On the other hand, a consensus panel of the United States Public Health Service recommended using valuations of a representative sample of the general population. In short, the Panel claims that, since the public bears the costs associated with health care decisions, they ought also to have some say in the determination of benefits. ${ }^{66,67}$ Although there can be discrepancies between the patient and general population valuation of quality of life, ${ }^{65}$ literature indicates that cost-utility studies increasingly rely on general population preferences. ${ }^{68}$

Nowadays, many cost-utility studies use multi-attribute utility methods whereby the patient only fills in a questionnaire on his health state, while numbers from the general population are used to value the patient's health state. For several questionnaires general population value sets are available (e.g. Euroqol 5D (EQ-5D), Short-Form 6D (SF-6D), Health Utility Index (HUI)). However, as suggested by McCrone et al., ${ }^{69}$ a likely limitation of the existing utility measures might be their large focus on physical health, which could imply that changes in quality of life through mental health care interventions might be less captured by these instruments as opposed to changes through physical health care interventions. The commonly used quality of life instruments might not be comprehensive enough to elicit quality of life in patients with depression. ${ }^{70}$

Summing up, questions arise whether there are differences between a patient or general population valuation of a health state, and whether the existing multi-attribute questionnaires are responsive to changes in a depression health state. If the utility does not correctly reflect the true quality of life (changes) of a disorder, this might result in over- or underestimation of the utility (changes), leading to incorrect policy information of a costutility analysis, and subsequently might imply (positive or negative) discrimination of a disorder, treatment, and/or patient group in resource allocation decisions. 


\section{Aim of the thesis}

The aim of this thesis is twofold. The objective of part 1 is to evaluate CCBT from a clinical, economic and patient perspective. The CCBT program evaluated here (named "Colour Your Life" (CYL, in Dutch Kleur je Leven)) is an online, multimedia, interactive computer program for depression and is offered as pure self-help. Part 2 aims to evaluate methods to derive quality of life utility in research on depression treatment.

\section{Data used in the thesis}

All data used in this thesis were collected within one research project. Trial participants were recruited through a process of random selection in the general population of the South of the Netherlands, an invitation letter, and online screening questionnaires. The participants included in the trial were randomly allocated to CCBT, treatment as usual by a GP (TAU) or a combination of both CCBT and TAU (COMBI). Follow-up data were gathered within a 12-month time horizon. Figure 2 shows the flow chart of trial participants, plus indicates which data are used within all the chapters of this thesis. More information on the recruitment procedures and data gathering within the research project can be found in appendix 1 of this thesis.

\section{Outline of the thesis}

The first part of this thesis focuses on CCBT for depression. Chapter 2 describes the clinical effectiveness of CCBT compared with TAU and COMBI based on data of our randomised trial. Since this study only includes the 6-month follow-up data, the clinical effectiveness study using the 12-month follow-up data is included in this thesis in appendix 2 . Chapter 3 presents the economic evaluation of these interventions, consisting of cost-effectiveness and cost-utility analyses. In chapter 4 patient experiences with the CCBT program are explored through qualitative interview data with CCBT users. Chapter 4 evaluates the impact of pre-treatment expectancy and credibility on depression severity and healthrelated quality of life utility outcomes for the interventions studied in our trial.

The second part of this thesis focuses on the derivation of utility in depression. Chapter 6 studies the responsiveness of utility instruments (i.e. SF-6D, EQ-5D and DFDu) to changes in depression. Chapter 7 explores whether there is a temporal relation between changes in the course of depression severity and quality of life utility. The last study, chapter 8, evaluates whether there is a discrepancy in the rating of health-related quality of life of depression between the patient and the general population.

In chapter 9, the findings of the different studies in this thesis are summarized, integrated, and discussed. Finally, suggestions are given for further improvement of the CCBT program. 


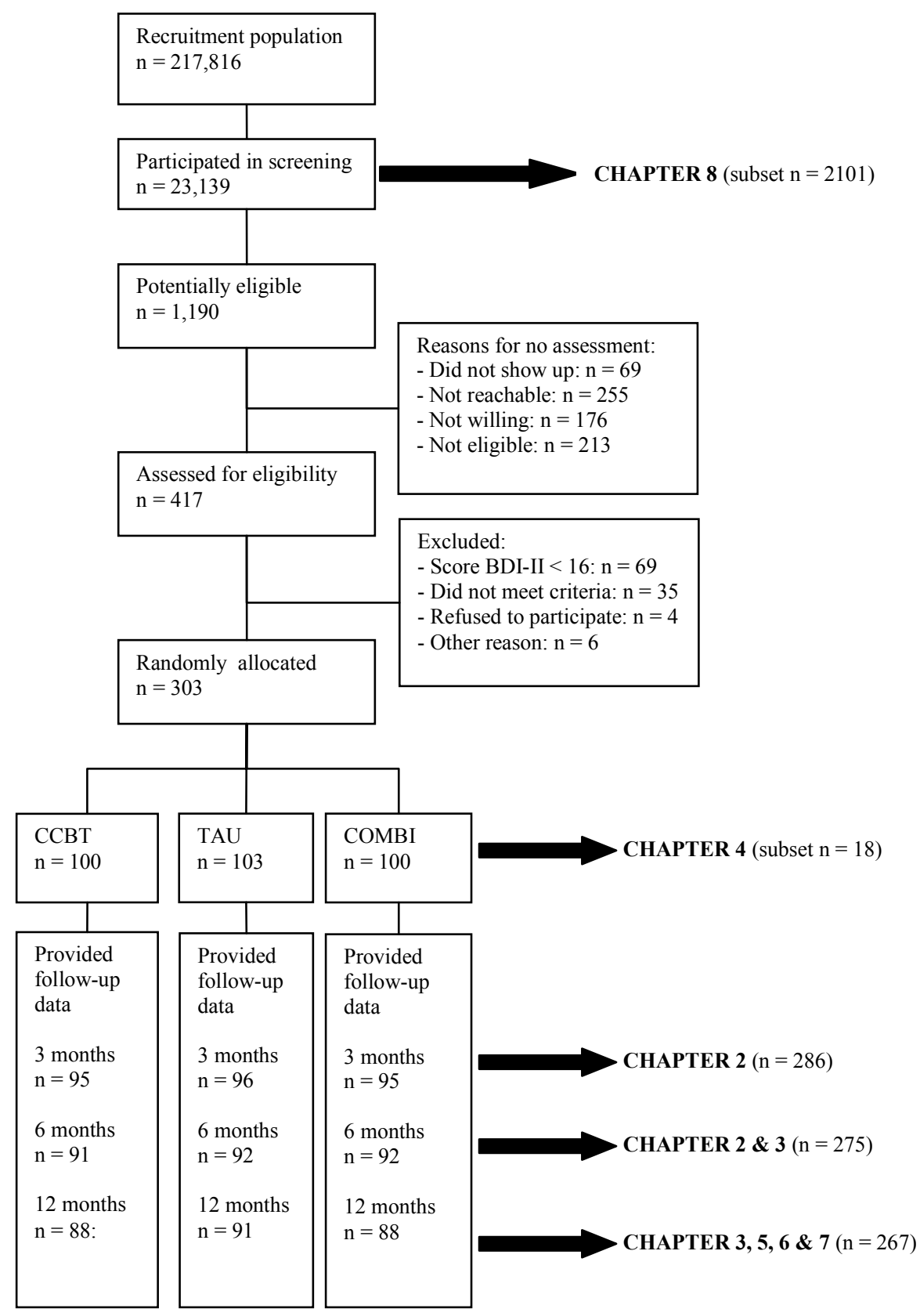

Figure 2: Flowchart indicating the data used in each thesis chapter 


\section{References}

1. Bijl RV, Ravelli A, van Zessen G. Prevalence of psychiatric disorder in the general population: Results of the Netherlands Mental Health Survey and Incidence Study (NEMESIS). Soc Psychiatry Psychiatr Epidemiol 1998;33(12):587-595.

2. Wittchen HU, Jacobi F. Size and burden of mental disorders in Europe-a critical review and appraisal of 27 studies. Eur Neuropsychopharmacol 2005;15:357-376.

3. Paykel ES, Brugha T, Fryers T. Size and burden of depressive disorders in Europe. Eur Neuropsychopharmacol 2005;15:411-423.

4. de Graaf R, ten Have M, van Dorsselaer S. De psychische gezondheid van de Nederlandse bevolking Nemesis-2: Opzet en eerste resultaten. Utrecht: Trimbos-instituut, 2010.

5. American Psychiatric Association. DSM-IV-TR. Diagnostic and Statistical Manual of Mental Disorders. 4th ed. Washington, DC: American Psychiatric Press, 2000.

6. ten Doesschate MC, Koeter MWJ, Bockting CLH, Schene AH, Group TDS. Health related quality of life in recurrent depression: A comparison with a general population sample. J Affect Disord 2010;120:126132.

7. Bijl RV, Ravelli A. Current and residual functional disability associated with psychopathology: findings from the Netherlands Mental Health Survey and Incidence Study (NEMESIS). Psychol Med 2000;30:657668.

8. Kruijshaar ME, Hoeymans N, Bijl RV, Spijker J, Essink-Bot ML. Levels of disability in Major Depression. Findings from the Netherlands Mental Health Survey and Incidence Study (NEMESIS). J Affect Disord 2003;77(1):53-64.

9. Creed F, Morgan R, Fiddler M, Marshall S, Guthrie E, House A. Depression and anxiety impair healthrelated quality of life and are associated with increased costs in general medical inpatients. Psychosomatics 2002;43(4):302-309.

10. Rapaport $\mathrm{MH}$, Clary C, Fayyad R, Endicott J. Quality-of-life impairment in depressive and anxiety disorders. Am J Psychiatry 2005;162(6):1171-1178.

11. Sobocki P, Ekman M, Agren H, Krakau I, Runeson B, Martensson B, et al. Health-related quality of life measured with EQ-5D in patients treated for depression in primary care. Value Health 2007;10(2):153160.

12. World Health Organization. The global burden of disease: 2004 update. Geneva, Switzerland: World Health Organization, 2008.

13. Slobbe LCJ, Kommer GJ, Smit JM, Groen J, Meerding WJ, Polder JJ. Kosten van Ziekten in Nederland 2003; Zorg voor euro's - 1 [Costs of illness in the Netherlands 2003]. Bilthoven: Rijksinstituut voor Volksgezondheid en Milieu, 2006.

14. Cuijpers P, Smit F, Oostenbrink J, de Graaf R, Ten Have M, Beekmand A. Economic costs of minor depression: a population-based study. Acta Psychiatr Scand 2007;115:229-236.

15. Sobocki P, Jönsson B, Angst J, Rehnberg C. Cost of Depression in Europe. J Ment Health Policy Econ 2006;9(2):87-98.

16. Stewart WF, Ricci JA, Chee E, Hanh SR, Morganstein D. Cost of lost productive work time among US workers with depression. JAMA 2003;289(23):3135-3144.

17. Luppa M, Heinrich S, Angermeyer MC, König HH, Riedel-Heller SG. Cost-of-illness studies of depression. A systematic review. J Affect Disord 2007;98:29-43.

18. Poos MJJC, Smit JM, Groen J, Kommer GJ, Slobbe LCJ. Kosten van Ziekte in Nederland 2005. Zorg voor euro's -8. Bilthoven: RIVM, 2008.

19. Simon GE, Barber C, Birnbaum HG, Frank RG, Greenberg PE, Rose RM, et al. Depression and work productivity: the comparative costs of treatment versus nontreatment. J Occup Environ Med 2001;43(1):1-9.

20. СВO. Multidisciplinaire richtlijn depressie: richtlijn voor de diagnostiek en behandeling van volwassen cliënten met een depressie [Multidisciplinary guideline depression: guideline for diagnostics and treatment of adult depression clients]. Utrecht: Trimbos-instituut, 2005.

21. Paykel ES, Tylee A, Wright A, Priest RG. The Defeat Depression Campaign: Psychiatry in the public arena. Am J Psychiatry 1997;154(6, suppl):59-65. 
22. Spijker J, Bijl RV, De Graaf R, Nolen WA. Care utilization and outcome of DSM-III-R major depression in the general population. Results from the Netherlands Mental Health Survey and Incidence Study (NEMESIS). Acta Psychiatr Scand 2001;104:19-24.

23. Tiemens BG, Ormel J, Simon GE. Occurrence, recognition, and outcome of psychological disorders in primary care. Am J Psychiatry 1996;153:636-644.

24. Oliver MI, Pearson N, Coe N, Gunnell D. Help-seeking behaviour in men and women with common mental health problems: cross-sectional study. Br J Psychiatry 2005;186:297-301.

25. Bebbington PE, Meltzer H, Brugha TS, Farrell M, Jenkins R, Ceresa $C$, et al. Unequal access and unmet need: neurotic disorders and the use of primary care services. Psychol Med 2000;30:1359-1367.

26. Angermeyer MC, Matschinger H, Riedel-Heller SG. What to do about mental disorder - help-seeking recommendations of the lay public. Acta Psychiatr Scand 2001;103:220-225.

27. Hirschfeld RM, Keller MB, Panico S, Arons BS, Barlow D, Davidoff F, et al. The National Depressive and Manic-Depressive Association consensus statement on the undertreatment of depression. JAMA 1997;277(4):333-340.

28. Kessler RC, Berglund P, Demler O, Join R, Korets D, Merikangas KR, et al. The epidemiology of major depressive disorder: Results from the national comorbidity survey replication (NCS-R). JAMA 2003;289(23):3095-3105.

29. Simon GE, VonKorff M, Heiligstein JH, Revicki DA, Grothaus L, Katon W, et al. Initial antidepressant choice in primary care: Effectiveness and cost of fluoxetine vs tricyclic antidepressants. JAMA 1996;275(24):1897-1902.

30. Kirsch I, Deacon BJ, Huedo-Medina TB, Scoboria A, Moore TJ, Johnson BT. Initial severity and antidepressant benefits: a meta-analysis of data submitted to the food and drug administration. PloS Medicine 2008;5(2):e45.

31. Kendrick T, Chatwin J, Dowrick C, Tuylee A, Moriss R, Peveler R, et al. Randomised controlled trial to determine the clinical effectiveness and cost-effectiveness of selective serotonin reuptake inhibitors plus supportive care, versus supportive care alone, for mild to moderate depression with somatic symptoms in primary care: the THREAD (THREshold for AntiDepressant response) study. Health Technol Assess 2009;13(22):1-159.

32. Bower P, Rowland N, Hardy R. The clinical effectiveness of counseling in primary care: A systematic review and meta-analysis. Psychol Med 2003;33(2):203-215.

33. Kaltenthaler E, Brazier J, De Nigris E, Tumur I, Ferriter M, Beverly C, et al. Computerised cognitive behaviour therapy for depression and anxiety update: a systematic review and economic evaluation. Health Technol Assess 2006;10(33):1-186.

34. Hollon SD, Stewart MO, Strunk D. Enduring effects for cognitive behavior therapy in the treatment of depression and anxiety. Annu Rev Psychol 2006;57:285-315.

35. Butler AC, Chapman JE, Forman EM, Beck AT. The empirical status of cognitive-behavioral therapy: A review of meta-analyses. Clin Psychol Rev 2006;26:17-31.

36. Gega L, Marks I, Mataix-Cols D. Computer-aided CBT self-help for anxiety and depressive disorders: experience of a London clinic and future directions. Journal of Clinical Psychology/In Session 2004;60(2):147-157.

37. Titov N. Status of computerized cognitive behavioural therapy for adults. Aust N Z J Psychiatry 2007;41(2):95-114.

38. Wright JH, Wright AS, Albano AM, Basco MR, Goldsmith $L$, Raffield T, et al. Computer-assisted cognitive therapy for depression: maintaining efficacy while reducing therapist time. Am J Psychiatry 2005;162:1158-1164.

39. Van den Berg S, Shapiro DA, Bickerstaffe D, Cavanagh K. Computerized cognitive-behaviour therapy for anxiety and depression: a practical solution to the shortage of trained therapists. J Psychiatr Ment Health Nurs 2004;11:508-513.

40. National Institute for Health and Clinical Excellence. Computerised cognitive behaviour therapy for depression and anxiety. Review of Technology Appraisal 51: NICE, 2006.

41. Habbema JDF, Casparie AF, Mulder JH, Rutten FFH. Medische Technology Assessment en gezondheidsbeleid. Alphen aan den Rijn: Samsom Stafleu, 1989. 
42. Spek V, Cuijpers P, Nyklícek I, Riper H, Keyzer J, Pop V. Internet-based cognitive behaviour therapy for symptoms of depression and anxiety: a meta-analysis. Psychol Med 2007;37(3):319-328.

43. Spek V, Cuijpers P, Nyklícek I, Smits N, Riper H, Keyzer J, et al. One-year follow-up results of a randomized controlled clinical trial on internet-based cognitive behavioural therapy for subthreshold depression in people over 50 years. Psychol Med 2008;38(5):635-639.

44. Spek V, Nyklícek I, Smits N, Cuijpers P, Riper H, Keyzer J, et al. Internet-based cognitive behavioural therapy for subthreshold depression in people over 50 years old: a randomized controlled clinical trial. Psychol Med 2007;37:1797-1806.

45. Warmerdam L, van Straten A, Twisk J, Riper H, Cuijpers P. Internet-based treatment for adults with depressive symptoms: Randomized controlled trial. J Med Internet Res 2008;10(4):e44.

46. Kaltenthaler E, Sutcliffe P, Parry G, Beverly C, Rees A, Ferriter M. The acceptability to patients of computerized cognitive behaviour therapy for depression: a systematic review. Psychol Med 2008;38(11):1521-1530.

47. McCrone P, Knapp M, Proudfoot J, Ryden C, Cavanagh K, Shapiro DA, et al. Cost-effectiveness of computerised cognitive-behavioural therapy for anxiety and depression in primary care: randomised controlled trial. Br J Psychiatry 2004;185:55-62.

48. Waller R, Gilbody S. Barriers to the uptake of computerized cognitive behavioural therapy: a systematic review of the quantitative and qualitative evidence. Psychol Med 2009;39(5):705-712.

49. Khan N, Bower P, Rogers A. Guided self-help in primary care mental health. Meta-synthesis of qualitative studies of patient experience. Br J Psychiatry 2007;191:206-218.

50. Beattie A, Shaw A, Kaur S, Kessler D. Primary-care patients' expectations and experiences of online cognitive behavioural therapy for depression: a qualitative study. Health Expect 2009;12:45-59.

51. Mondloch MV, Cole DC, Frank JW. Does how you do depend on how you think you'll do? A systematic review of the evidence for a relation between patients' recovery expectations and health outcomes. CMAJ Canadian Medical Association journal 2001;165(2):174-179.

52. Moses T, Leuchter AF, Cook I, Abrams M. What Shapes Depressed Individuals' Pre-Treatment Expectation in Antidepressant Clinical Trials? The Internet Journal of Mental Health 2007;3(2).

53. Meyer B, Pilkonis PA, Krupnick JL, Egan MK, Simmens SJ, Sotsky SM. Treatment Expectancies, Patient Alliance, and Outcome: Further Analyses From the National Institute of Mental Health Treatment of Depression Collaborative Research Program. J Consult Clin Psychol 2002;70(4):1051-1055.

54. Goossens ME, Vlaeyen JW, Hidding A, Kole-Snijders A, Evers SM. Treatment expectancy affects the outcome of cognitive-behavioral interventions in chronic pain. The Clinical Journal of Pain 2005;21(1):18-26.

55. Ilardi SS, Craighead WE. The Role of Nonspecific Factors in Cognitive-Behavior Therapy for Depression. American Psychological Association 1994;1(2):138-156.

56. Greenberg RP, Constantino MJ, Bruce N. Are patient expectations still relevant for psychotherapy process and outcome? Clin Psychol Rev 2006;26:657-678.

57. Smeets RJEM, Beelen SPT, Goossens MEJB, Schouten EGW, Knottnerus JA, Vlaeyen JWS. Treatment Expectancy and Credibility Are Associated With the Outcome of Both Physical and Cognitive-behavioral Treatment in Chronic Low Back Pain. The Clinical Journal of Pain 2008;24 (4):305-315.

58. Delsignore A, Schnyder U. Control expectancies as predictors of psychotherapy outcome: A systematic review. British Journal of Clinical Psychology 2007;46:467-483.

59. Glass CR, Arnkoff DB, Shapiro SJ. Expectations and preferences. Psychotherapy 2001;38(4):455-461.

60. Cole DC, Mondloch MV, Hogg-Johnson S. Listening to injured workers: how recovery expectations predict outcomes - a prospective study. CMAJ Canadian Medical Association journal 2002;166(6):749754.

61. Holm LW, Carroll L, Cassidy JD, Skillgate E, Ahlbom A. Expectations for Recovery Important in the Prognosis of Whiplash Injuries. PLoS medicine 2008;5(5):1-8.

62. Krell HV, Leuchter AF, Morgan M, Cook IA, Abrams M. Subject Expectations of Treatment Effectiveness and Outcome of Treatment With an Experimental Antidepressant. The Journal of Clinical Psychiatry 2004;65(9):1174-1179.

63. Yee A, Adjei N, Do J, Ford M, Finkelstein J. Do Patient Expectations of Spinal Surgery Relate to Functional Outcome? Clin Orthop 2008;466(5):1154-1161. 
64. Drummond MF, Sculpher MJ, Torrance GW, O'Brien B, Stoddart GL. Methods for the Economic Evaluation of Health Care Programmes. Oxford: Oxford University Press, 2005.

65. de Wit GA, Bussbach JJV, De Charro FT. Sensitivity and perspective in the valuation of health status: Whose values count? Health Econ 2000;9:109-126.

66. Drummond M, McGuire A. Economic evaluation in health care: Merging theory with practice. New York: Oxford University Press, 2001.

67. Gold MR, Siegel JE, Russell LB, Weinstein MC. Cost-effectiveness in Health and Medicine. New York: Oxford University Press Inc, 1996

68. Brauer CA, Rosen AB, Greenberg D, Neumann PJ. Trends in the measurement of health utilities in published cost-utility analyses. Value Health 2006;9(4):213-218.

69. McCrone P, Patel A, Knapp M, Schene A, Koeter M, Amaddeo F, et al. A Comparison of SF-6D and EQ-5D Utility Scores in a Study of Patients with Schizophrenia. J Ment Health Policy Econ 2009;12:27-31.

70. Günther $\mathrm{OH}$, Roick $\mathrm{C}$, Angermeyer $\mathrm{MC}$, König $\mathrm{HH}$. The responsiveness of EQ-5D utility scores in patients with depression: A comparison with instruments measuring quality of life, psychopathology and social functioning. J Affect Disord 2008;105(81-91). 



\section{Part 1 \\ Evaluation of online computerised cognitive-behavioural therapy}





\section{Chapter 2}

\section{Clinical effectiveness of online computerised cognitive behavioural therapy without support for depression in primary care: a randomised trial}

de Graaf LE, Gerhards SAH, Arntz A, Riper H, Metsemakers JFM, Evers SMAA, Severens JL, Widdershoven G, Huibers MJH

Published in British Journal of Psychiatry 2009; 195: 73-80. 


\begin{abstract}
Background: Computerised cognitive behavioural therapy (CCBT) might offer a solution to the current undertreatment of depression.

Aims: To determine the clinical effectiveness of online, unsupported CCBT for depression in primary care.

Method: 303 depressed patients were randomly allocated to (a) the CCBT program Colour Your Life (CYL), (b) treatment as usual (TAU) by a GP, or (c) CCBT and TAU combined (COMBI). CYL is an online, multimedia, interactive CCBT program. No assistance was offered. We had a 6-month follow-up period.

Results: No significant differences in outcome between the three interventions were found in the intention-to-treat and per-protocol analyses.

Conclusion: Online, unsupported CCBT did not outperform usual care, and the combination of both did not have additional effects. Decrease in depressive symptoms in moderately to severely depressed patients was moderate in all three interventions. Online CCBT without support is not beneficial for all depressed patients.
\end{abstract}




\section{Background}

Although cognitive behavioural therapy (CBT) is an effective treatment for depression, ${ }^{1,2}$ many depressed patients in primary care remain untreated. ${ }^{3}$ An effective, acceptable, and feasible solution might be computerised CBT (CCBT). ${ }^{4}$ CCBT programmes can vary greatly in terms of technologies used and amount of additional support. To our knowledge, only one study so far investigated the efficacy of CCBT for depression in primary care. ${ }^{5}$ It was shown that CCBT (delivered on a computer in the general practice) is more effective than usual GP care. Nevertheless, the effectiveness of CCBT via the Internet in primary care remains to be evaluated as well as the effects of CCBT combined with usual GP care. In a randomised trial, we addressed these issues by examining the effectiveness of online, unsupported CCBT (i.e. Colour Your Life) for depression in primary care. In another study, this intervention was equally effective as group CBT in people over 50 years old with subthreshold depression. ${ }^{6}$ We hypothesise that CCBT will be superior to usual GP care, and that the combination of CCBT and usual GP care will be more effective than CCBT alone.

\section{Method}

\section{Study population and recruitment}

Participants were recruited in the general population by means of a large-scale Internetbased screening in the South of the Netherlands. A random selection of individuals was sent an invitation letter to complete an online screening questionnaire. Potentially eligible participants were invited to visit the research centre to assess final eligibility. Participants were eligible if they met the following criteria: age 18 to 65; access to the Internet at home; at least mild to moderate depressive complaints (Beck Depression Inventory II (BDI-II) score $\geq 16$ ); duration of depressive complaints 3 months or more; no current psychological treatment for depression; no continuous antidepressant treatment for at least 3 months prior to entry; fluent in Dutch language; no alcohol and/or drug dependence; and no severe psychiatric co-morbidity. To determine DSM-III-R axis I diagnoses the computerised Composite International Diagnostic Interview (CIDI-auto) ${ }^{8}$ was used. Full details of the study method have been described elsewhere (see appendix 1 in this thesis). ${ }^{9}$

\section{Procedure}

After informed consent was obtained, participants were randomly allocated to: (1) online CCBT without support (i.e. Colour Your Life), (2) treatment as usual (TAU) by a GP, (3) and online, unsupported CCBT and TAU combined. Baseline assessment took place at the research centre before randomization on a computer. All follow-up assessments took place at home via the Internet. Preceding an upcoming assessment point, participants received an email alert. Individuals received financial compensation for Internet use (i.e. €25). 


\section{Interventions}

The CCBT program, named Colour Your Life $(C Y L),{ }^{10}$ is an online, multimedia, interactive computer program for depression. CYL is based on the principles of CBT and on the Dutch version of the 'coping with depression course' of Lewinsohn. ${ }^{11,12}$ CYL consists of eight 30minute sessions and a ninth booster session, although the duration of sessions can vary among users. At the end of each session homework-assignments are given. Participants were advised to complete one session per week. Participants were given log in codes by the researchers at inclusion and they accessed CYL at home. No assistance was offered. CYL was originally developed for people over 50 -years old ${ }^{6}$ and was adapted for an adult population (18 to 65 years) for the current study.

TAU was delivered by the patient's own GP who was advised to follow the guideline described by the Dutch College of General Practitioners. ${ }^{13}$ TAU can include four to five biweekly consultations and antidepressant treatment if indicated.

For each patient, it was assessed whether the interventions received were according to 'protocol'. Adherence to CYL was defined as being exposed to all essential steps of the intervention, which was operationalised as having completed five or more sessions. TAU adherence was defined as receiving at least four consultations or antidepressant medication. $\mathrm{COMBI}$ adherence was defined as a combination of both.

\section{Outcomes}

The primary outcome measure was the severity of depression as measured with the Beck Depression Inventory Second Edition (BDI-II), high scores indicating severe depression (range 0-63). ${ }^{7,14,15}$

Secondary outcomes included the following measures. General psychological distress was measured with the Symptom Check-List 90 (SCL-90). Scores range from 90 (no distress) to 450 (very severe distress). ${ }^{16,17}$ The Work and Social Adjustment Scale (WSAS) was used to assess impairment in social functioning attributable to depression. ${ }^{18} \mathrm{~A}$ high score is indicative of severe impairment (score range 0-40). The 36-item short-form Health Survey (SF-36) was used to assess specific features of quality of life. ${ }^{19-21}$ We used the two most relevant subscales: role limitations caused by emotional problems and general mental health. High scores indicate high levels of quality of life (score range 0-100). The intensity of dysfunctional beliefs was assessed with the Dysfunctional Attitude Scale form A (DAS-A). ${ }^{22}$ We used a 17 -item version, ${ }^{23}$ with a score range of 17 to 119 . The higher the score, the more dysfunctional attitudes an individual reports.

Additional measures included a self-developed health care use questionnaire, which measured self-reported use of GP care, antidepressant medication, and specialist care.

All outcomes were assessed at baseline and at three months of follow-up. In addition, the BDI-II and the DAS-A-17 were also assessed at two months and six months of follow-up. The health care use questionnaire was assessed monthly. 


\section{Sample size}

Power calculations were based on elementary head-to-head comparisons of CCBT versus usual care and CCBT versus combination treatment (t-test). We calculated that a sample size of 84 participants per group was needed to detect a change score of 5 (SD 5.25) on the BDI-II (power 90\%, alpha 0.05). Adjusting for potential study withdrawal (20\%), we estimated that 100 participants per group were needed.

\section{Data analysis}

Preliminary tests for distribution and outliers were performed. Skewness and Kurtosis did not indicate substantial deviations from normality for all outcomes. The analyses were based on the intention-to-treat principle (i.e. those who provided follow-up data irrespective of treatment-adherence). Only intermittent missing data were imputed $(n=5)$ by calculating the mean of the values of a previous and a subsequent time point. Missing data due to lost to follow-up were not replaced by imputed values. We tested all effects at the $p<.05$ level (two-tailed). All analyses were carried out using SPSS (version 15.0.1 for Windows).

First, to test the main hypotheses, repeated-measures analyses of variance (ANOVAs) were performed. In case of significant time by group interactions, contrasts were conducted comparing changes from baseline to each subsequent time point for each pair of groups separately. Then, we computed improvement effect sizes for BDI-II scores for each time point according to Cohen's d statistic, ${ }^{24}$ defined as $\left(\mathrm{Mt}_{0}-\mathrm{Mt}_{\mathrm{k}}\right) / \mathrm{sd}_{(\mathrm{Mt0}-\mathrm{Mtk})}$. Between group effect sizes were determined by calculating the difference in improvement effect sizes between two groups. Next, we determined the proportion of patients who made clinically meaningful changes on the BDI-II using the methodology of Jacobson and Truax. ${ }^{25}$ This approach is based on two components: (1) reliable change (RC), i.e. a decrease of 9 points, and (2) clinically significant change (CSC), i.e. a score below 12 . Chi-square tests were used to test the frequency differences in RC, CSC, and RS+CSC between the three groups. Based on the RC+CSC proportions, the number needed to treat (NNT) was calculated. ${ }^{26}$ Finally, we conducted per-protocol analyses for treatment adherers only, using repeated measures ANOVA's for the BDI-II scores.

\section{Results}

\section{Flowchart and participants}

Figure 1 presents the flow of the participants. Recruitment took place from December 2005 to June 2007. Follow-up ended December 2007. 303 depressed participants were enrolled in the study. At six months of follow-up, data were available for 275 participants (attrition rate 9.2\%). Reasons for lost-to-follow up were: too time consuming $(n=8)$, personal circumstances or medical illness other then a mental disorder $(n=5)$, and no reason was given $(n=15)$. There seemed to be no baseline differences between participants who completed all assessments and those who were lost-to-follow-up (lowest p-value=.10). Baseline characteristics of all participants are shown in table 1, stratified according to intervention 
group. Randomisation was successful; the characteristics are fairly similar in all three groups, although gender did not seem equally distributed across the groups.

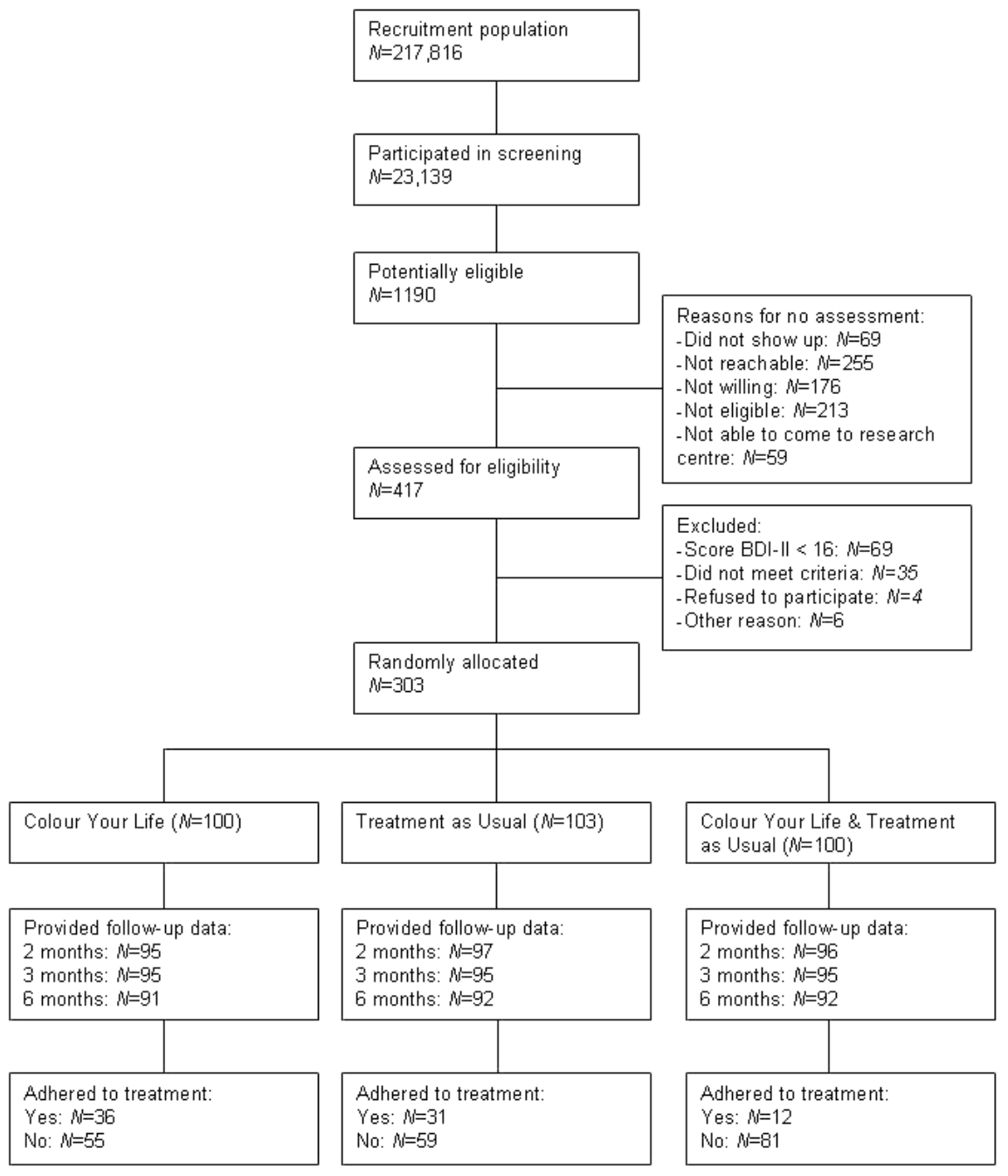

Figure 1: Flow of the participants. 
Table 1: Baseline characteristics of the total sample

\begin{tabular}{|c|c|c|c|c|}
\hline \multicolumn{2}{|l|}{ Variable } & $\begin{array}{l}\text { CCBT } \\
(\mathrm{N}=100)\end{array}$ & \multirow{2}{*}{$\begin{array}{l}\text { TAU } \\
(\mathrm{N}=103) \\
46(44.7)\end{array}$} & \multirow{2}{*}{$\begin{array}{l}\text { COMBI } \\
(\mathrm{N}=100) \\
37(37.0)\end{array}$} \\
\hline Male sex, nr (\%) & & $48(48.0)$ & & \\
\hline Age (18 -65), M (SD) & & $44.3(11.8)$ & $45.1(12.2)$ & $45.2(10.9)$ \\
\hline \multirow[t]{3}{*}{ Education $^{\text {a }}$ : } & Low, $\mathrm{nr}(\%)$ & $18(18.6)$ & $16(16.2)$ & $17(17.5)$ \\
\hline & Medium, nr (\%) & $55(56.7)$ & $55(55.6)$ & $52(53.6)$ \\
\hline & High, nr (\%) & $24(24.7)$ & $28(28.3)$ & $28(28.9)$ \\
\hline Partner, yes, nr (\%) & & $72(73.5)$ & $73(72.3)$ & $71(73.2)$ \\
\hline Employed, yes, $\mathrm{nr}(\%)^{\mathrm{c}}$ & & $67(72.0)$ & $64(76.2)$ & $69(73.4)$ \\
\hline \multirow[t]{3}{*}{ Depressive episode: } & No, nr (\%) & $22(22.0)$ & $18(17.5)$ & $21(21.0)$ \\
\hline & First, nr (\%) & $48(48.0)$ & $45(43.7)$ & $39(39.0)$ \\
\hline & Recurrent, nr (\%) & $30(30.0)$ & $40(38.8)$ & $40(40.0)$ \\
\hline
\end{tabular}

Note. CCBT, computerised cognitive behavioural therapy; TAU, treatment as usual by a general practitioner; COMBI, combined treatment of both CCBT and TAU.

a data unavailable: CCBT $(n=3), \operatorname{TAU}(n=4)$, and COMBI $(n=3) ;{ }^{b}$ data unavailable: CCBT $(n=2), \operatorname{TAU}(n=2)$, and $\operatorname{COMBI}(n=3) ;{ }^{c}$ data unavailable: CCBT $(n=7)$, TAU $(n=17)$, and COMBI $(n=6)$.

\section{Outcome of the interventions}

Table 2 depicts the means and standard deviations of the clinical outcomes at follow-up. There were no significant group by time interactions on the primary outcome measure as well as most secondary outcomes (all $p>$.29). Only a significant interaction effect was found for the WSAS $(\mathrm{p}=.03)$. Contrasts revealed that $C O M B I$ resulted in a significant greater reduction on the WSAS compared to CCBT alone $\left(F_{1,188}=5.63, p=.02\right)$ and TAU alone $\left(F_{1,188}=4.35, p=.04\right)$. Since gender could have confounded the outcomes, we corrected for this in ancillary analyses by adding gender to the model as between-group factor. This did not result in a significant outcome for the BDI-II (group $x$ time: $F_{6,536}=0.94, p=.47$ ) nor was there a significant interaction between group and gender $\left(F_{2,270}=0.47, p=.63\right)$. We, therefore, omitted this correction from all further analyses. 
Table 2: Mean scores (SD) for all outcome measures in the intention-to-treat population: results from repeated measures ANOVA

\begin{tabular}{|c|c|c|c|c|c|c|c|}
\hline Outcome & $\begin{array}{l}\text { Time } \\
\text { point }\end{array}$ & CCBT & TAU & COMBI & Time & Group & $\begin{array}{l}\text { Time } x \\
\text { group }\end{array}$ \\
\hline \multirow[t]{8}{*}{ BDI-II } & baseline & 28.2 & 27.9 & 27.4 & $\mathrm{~F}_{3,271}=71.13 * *$ & $F_{2,273}=0.75$ & $F_{6,542}=1.22$ \\
\hline & & (7.7) & $(7.5)$ & (8.2) & & & \\
\hline & 2 months & 20.6 & 22.1 & 21.7 & & & \\
\hline & & (10.4) & $(10.2)$ & (10.1) & & & \\
\hline & 3 months & 20.4 & 21.4 & 19.1 & & & \\
\hline & & $(11.2)$ & (11.0) & (10.9) & & & \\
\hline & 6 months & 17.8 & 18.9 & 17.5 & & & \\
\hline & & $(10.6)$ & (11.8) & $(12.2)$ & & & \\
\hline \multirow[t]{8}{*}{ DAS-A-17 } & baseline & 62.2 & 62.6 & 61.9 & $\mathrm{~F}_{3,270}=17.17 * *$ & $F_{2,272}=0.30$ & $F_{6,540}=0.52$ \\
\hline & & $(16.8)$ & (17.6) & (17.4) & & & \\
\hline & 2 months & 61.5 & 63.9 & 62.2 & & & \\
\hline & & $(16.7)$ & $(16.3)$ & (18.7) & & & \\
\hline & 3 months & 59.0 & 60.4 & 57.9 & & & \\
\hline & & (17.5) & (17.0) & (20.0) & & & \\
\hline & 6 months & 56.6 & 59.0 & 58.3 & & & \\
\hline & & $(15.2)$ & (18.3) & (19.6) & & & \\
\hline \multirow[t]{4}{*}{ SCL90 } & baseline & 182.9 & 179.9 & 180.0 & $F_{1,282}=1.14$ & $F_{2,282}=0.32$ & $F_{2,282}=0.33$ \\
\hline & & $(43.4)$ & (41.9) & (40.0) & & & \\
\hline & 3 months & 181.5 & 178.06 & 174.7 & & & \\
\hline & & $(53.8)$ & $(46.6)$ & $(50.7)$ & & & \\
\hline \multirow[t]{4}{*}{ SF-36 RL } & baseline & 29.7 & 34.0 & 33.7 & $\mathrm{~F}_{1,278}=6.41^{*}$ & $F_{2,278}=1.12$ & $F_{2,278}=0.71$ \\
\hline & & $(36.4)$ & (35.8) & (36.8) & & & \\
\hline & 3 months & 35.1 & 40.1 & 45.3 & & & \\
\hline & & $(37.2)$ & (38.9) & (41.8) & & & \\
\hline SF-36 & baseline & 44.7 & 44.5 & 45.1 & $\mathrm{~F}_{1,278}=46.20 * *$ & $F_{2,278}$ & $F_{2,278}=0.67$ \\
\hline \multirow[t]{3}{*}{$\mathrm{GMH}$} & & (13.7) & (13.9) & (14.3) & & $=0.19$ & \\
\hline & 3 months & 50.4 & 51.9 & 52.8 & & & \\
\hline & & $(16.5)$ & (15.7) & (17.5) & & & \\
\hline \multirow[t]{4}{*}{ WSAS } & Baseline & 19.3 & 18.4 & 19.1 & $\mathrm{~F}_{1,282}=11.26 * *$ & $F_{2,282}=1.11$ & $F_{2,282}=3.61^{*}$ \\
\hline & & $(7.2)$ & $(6.7)$ & (7.7) & & & \\
\hline & 3 months & 18.6 & 17.7 & 15.8 & & & \\
\hline & & (8.7) & $(7.8)$ & (7.5) & & & \\
\hline
\end{tabular}

Note. CCBT, computerised cognitive behavioural therapy; TAU, treatment as usual by a general practitioner; COMBI, combined treatment of both CCBT and TAU; BDI-II, Beck Depression Inventory II; SCL-90, Symptom Checklist 90; SF36, 36-item short-form health survey (GMH, general mental health subscale; RL, role limitations due to emotional problem subscale); WSAS, Work and Social Adjustment Scale; DAS-A-17, 17-item Dysfunctional Attitude Scale form A.

* $p<0.05 ; * * p<0.001$ 


\section{Effect sizes}

Regarding the magnitude of the effects, as can be seen in table 3 , all three groups had medium to large improvement effect sizes, whereas, between-group effect sizes were trivial. Small negative between-group effects sizes were also found, indicating an effect in the opposite direction as hypothesized.

Table 3: Improvement and between-group effect sizes based on the BDI-II in the intention-to-treat population

\begin{tabular}{lllllll}
\hline & \multicolumn{3}{l}{ Improvement effect size } & \multicolumn{4}{c}{ Between-group effect size } \\
Time point & 1. CCBT & 2. TAU & 3. COMBI & 1 v 2 & 3 v 2 & 3 v 1 \\
\hline 2 months & 0.71 & 0.63 & 0.57 & 0.08 & -0.06 & -0.14 \\
3 months & 0.71 & 0.69 & 0.74 & 0.02 & 0.05 & 0.03 \\
6 months & 0.86 & 0.81 & 0.89 & 0.05 & 0.08 & 0.03 \\
\hline
\end{tabular}

Note. CCBT, computerised cognitive behavioural therapy; TAU, treatment as usual by a general practitioner; COMBI, combined treatment of both CCBT and TAU; BDI-II, Beck Depression Inventory II. Improvement effect size $=(\mathrm{Mt0}-\mathrm{Mtk}) / \mathrm{sd}\left(\mathrm{Mt0} \mathrm{M}_{\mathrm{Mtk}}\right)$. Between group effect sizes = difference in improvement effect sizes between two groups.

\section{Reliable and clinical change}

Table 4 shows the proportion of participants in each group who showed a reliable change, a clinically significant change, and both for each time-point. There were no significant differences between the three groups (all p>.12). In figure 2 the percentage of patients with both a reliable change and a clinically significant change are graphically shown. We calculated the number needed to treat (NNT) with TAU as the reference group. At six months the NNT were 72 and 25 , respectively for CCBT and COMBI.

Table 4: Proportion of patients in the intention-to-treat population showing reliable and/or clinically significant change based on the BDI-II

\begin{tabular}{llllll}
\hline Outcome & Time point & CCBT & TAU & COMBI & $\chi^{2}(\mathrm{df}=2)$ \\
\hline RC & 2 months & $36(37.1 \%)$ & $30(30.9 \%)$ & $30(31.3 \%)$ & 1.06 \\
& 3 months & $35(36.8 \%)$ & $33(34.7 \%)$ & $43(45.3 \%)$ & 2.48 \\
CSC & 6 months & $45(49.5 \%)$ & $44(47.8 \%)$ & $54(58.1 \%)$ & 2.25 \\
& 2 months & $24(24.7 \%)$ & $16(16.5 \%)$ & $16(16.7 \%)$ & 2.76 \\
& 3 months & $22(23.2 \%)$ & $18(18.8 \%)$ & $28(29.5 \%)$ & 3.06 \\
RC+CSC & 6 months & $26(28.6 \%)$ & $29(31.5 \%)$ & $33(35.5 \%)$ & 1.02 \\
& 2 months & $23(23.7 \%)$ & $13(13.4 \%)$ & $14(14.6 \%)$ & 4.32 \\
& 3 months & $21(22.1 \%)$ & $16(16.7 \%)$ & $24(25.3 \%)$ & 2.15 \\
\hline
\end{tabular}

Note. CCBT, computerised cognitive behavioural therapy; TAU, treatment as usual by a general practitioner; COMBI, combined treatment of both CCBT and TAU; BDI-II, Beck Depression Inventory II; RC, reliable change (i.e. decrease of 9 points); CSC, clinically significant change (i.e. a score below 12). 


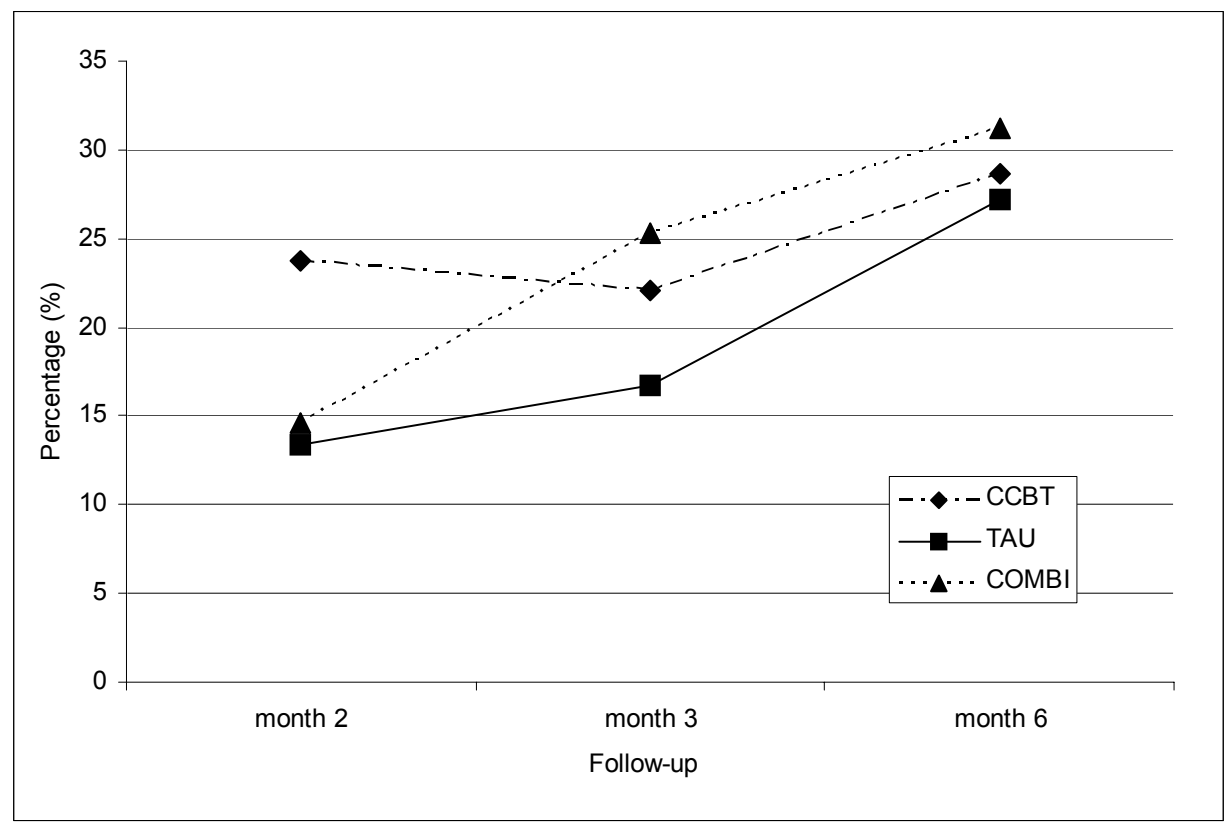

Figure 2: Percentage of patients in the intention-to-treat population with reliable and clinically significant change (RC+CSC).

Note. CCBT, computerised cognitive behavioural therapy; TAU, treatment as usual by a general practitioner, COMBI, combined treatment of both CCBT and TAU. 


\section{Treatment received}

In table 5, treatment adherence and the use of health care services are shown for each group during six months after baseline. As was expected, there were some significant differences between the three groups $(p<.05)$. More patients in TAU and COMBI visited their GP for depressive complaints compared with those in the CYL alone group. Concerning the use of $\mathrm{CYL}$, more patients in the COMBI group completed the last session compared to the CCBT alone group. Furthermore, more patients in the TAU group received specialist mental health care than in the other groups, and they received it earlier in time. Finally, only a small proportion of patients in each group received an adequate dosage of treatment.

Table 5: Treatment adherence and consumption of mental health care during six months of follow-up in the intention-to-treat population

\begin{tabular}{|c|c|c|c|}
\hline Variable & CCBT & TAU & COMBI \\
\hline \multicolumn{4}{|l|}{ Use of GP care ${ }^{a}$} \\
\hline Depression related GP contact, $\mathrm{nr}(\%)$ & $25(28.7 \%)$ & $66(73.3 \%)$ & $67(73.3 \%)^{* *}$ \\
\hline \multicolumn{4}{|l|}{ Details of those who visited the GP } \\
\hline Number of contacts, M (SD) & $4.7(4.5)$ & $3.7(3.4)$ & $2.9(3.3)$ \\
\hline Prescription of antidepressants, M (SD) & $8(32.0 \%)$ & $25(37.9 \%)$ & $17(25.4 \%)$ \\
\hline \multicolumn{4}{|l|}{ Use of other mental health care $^{a}$} \\
\hline Use of antidepressants, nr (\%) & $12(13.8 \%)$ & $24(26.7 \%)$ & $23(25.0 \%)$ \\
\hline Specialist mental health care, $\mathrm{nr}(\%)$ & $17(23.6 \%)$ & $33(36.7 \%)$ & $22(23.9 \%)^{*}$ \\
\hline \multicolumn{4}{|c|}{ Details of those who received specialist mental health care } \\
\hline Month of first contact, M (SD) & $3.4(1.7)$ & $2.0(1.1)$ & $2.5(1.5)^{*}$ \\
\hline Number of contacts, M (SD) & $7.8(6.2)$ & $7.5(6.3)$ & $7.3(5.2)$ \\
\hline \multicolumn{4}{|l|}{ Use of the CYL program } \\
\hline Completed first session, $\mathrm{nr}(\%)$ & $72(72.0 \%)$ & - & $76(76.0 \%)$ \\
\hline Completed last session, $\mathrm{nr}(\%)$ & $14(14.0 \%)$ & - & $26(26.0 \%)^{*}$ \\
\hline Number of sessions, M (SD) & $3.4(3.0)$ & - & $4.0(3.4)$ \\
\hline \multicolumn{4}{|l|}{ Protocol compliance } \\
\hline Adequate dosage of TAU, $\mathrm{nr}(\%)$ & - & $31(34.4 \%)$ & $26(28.3 \%)$ \\
\hline Adequate dosage of $\mathrm{CYL}, \mathrm{nr}(\%)$ & $36(36.0 \%)$ & - & $47(47.0 \%)$ \\
\hline Overall treatment compliance, $\mathrm{nr}(\%)$ & $36(36.0 \%)$ & $31(34.4 \%)$ & $12(12.9 \%)^{* *}$ \\
\hline
\end{tabular}

Note. CCBT, computerised cognitive behavioural therapy; TAU, treatment as usual by a general practitioner, COMBI, combined treatment of both CCBT and TAU; CYL, Colour Your Life (CCBT program). Adequate dosage of $\mathrm{TAU}=$ at least four consultations or antidepressant prescription; adequate dosage of $\mathrm{CYL}=$ at least five sessions. Chi-square tests for categorical variables and t-tests / ANOVA's for continuous variables were used.

${ }^{a}$ Data unavailable: CCBT $(n=13)$, TAU $(n=13)$, and COMBI $(n=8)$.

${ }^{*} \mathrm{p}<0.05 ;{ }^{* *} \mathrm{p}<0.001$.

\section{Per-protocol analyses}

First, we compared the outcomes on the BDI-II only for those who adhered to the treatment. Group by time interaction was not statistically significant $\left(F_{6,148}=0.85, p=.53\right)$. We repeated these analyses using a less strict definition of adherence in the COMBI group, i.e. adherence was defined as either an adequate dosage of CYL or an adequate dosage of TAU $(n=59)$. Again no significant interaction effect was obtained $\left(F_{6,242}=1.67, p=.13\right)$. 
Next, we compared the BDI-II scores between those who adhered to the treatment protocol and those who did not within each intervention group. None of these within-group tests revealed statistically significant adherence by time interaction effects (CCBT: $F_{3,87}=0.59$, $p=.62 ;$ TAU: $F_{3,86}=2.03, p=.12 ;$ COMBI: $F_{3,89}=0.76, p=.52$ ). When we used the less strict definition of adherence in the COMBI group, a small effect, albeit clinically neglectable, for adherence by time interaction was obtained $\left(F_{3,88}=2.70, p=.05\right)$. Contrasts revealed no differences between those who adhered to the treatment and those who did not for each change score ( $p$ 's $>.30)$.

\section{Sub-group analyses}

Since initial depressive severity was high (as can be concluded from the baseline BDI-II scores in table 2), we conducted ancillary subgroup analyses. First, subgroups were formed according to the initial median score on the BDI-II for the total group; low scores $=B D I<27$, and high scores $=\mathrm{BDI}-\mathrm{II}>27$. No statistically significant group by time interaction effects were found in each subgroup ( $B D \mid<27: F_{6,262}=1.27, p=.27$; $B D I>27: F_{6,270}=1.15, p=.34$ ). Second, subgroups were formed based on the presence or absence of a major depressive episode (MDE). In the no MDE subgroup, the group by time interaction was not statistically significant $\left(F_{6,84}=1.02, p=.42\right)$, while a significant interaction was obtained in the MDE group $\left(F_{6,448}=2.25, p=.04\right)$. Contrasts revealed only a significant effect for change from baseline to 3 months of follow-up in favour of the COMBI group compared to the TAU alone group $\left(F_{1,161}=6.03, p=.02\right)$.

\section{Discussion}

\section{Main results}

In contrast to our hypotheses, the findings suggest that there are no meaningful differences between CCBT, TAU, and COMBI during six months of follow-up in terms of depressive severity, quality of life, dysfunctional beliefs, and general psychological distress. Although we found medium improvement effect sizes in depressive severity for all interventions, the between-group effect sizes were rather small or even negative. Moreover, per-protocol analysis between and within groups revealed no differences between the interventions either. Finally, we found that treatment adherence was low in all interventions. It should be noted that at three months, a significant effect was found for social functioning in favour of the combination treatment. We are reluctant to interpret this effect given the high number of statistical tests we performed.

\section{Previous studies}

To be able to compare the effects of CCBT in our study with previous ones, we calculated the usual Cohen's d (i.e. dividing the pre-post difference by the pooled standard deviation) for the 2-month follow-up period. Our improvement effect size for CYL ( $d=0.84)$ was 
smaller than in the previous study on CYL $(d=1.00)^{6}$ and than in the previous primary care study ( $d=1.27){ }^{5}$ The between-group effect size of CYL relative to TAU was smaller $(d=0.20)$ than found for CYL in a previous study $(d=0.55),{ }^{6}$ CCBT in primary care $(d=0.65),{ }^{5}$ online CCBT with support $(d=1.05),{ }^{27}$ and for CCBT with shortened face-to-face therapy $(d=1.14) .{ }^{28}$ Comparable effect sizes were found for bibliotherapy with minimal contact in primary care $(d=0.18),{ }^{29}$ and online CCBT without support $(d=0.22) .{ }^{30}$ It should be noted here that most of these studies used other comparison groups, making it difficult to directly compare the effects.

There are several reasons that may explain the small effects in our study. First of all, one might argue that the CYL itself was less effective than other CCBT programs. Results from the previous study using CYL seemed very promising for subthreshold depression in people over 50 years old. ${ }^{6,31}$ However, in their study, baseline assessment of the primary outcome was conducted after randomization, which could have violated their results.

Second, the way CCBT was offered might explain the different outcomes. Various technologies can be used, ranging from telephone-system to CD-ROMs, hi-tech computers, palmtops, and Internet. ${ }^{32-35}$ The latest interventions are highly sophisticated computer systems, which might stimulate and improve engagement and motivation. ${ }^{36}$ Although CYL makes full use of the current technologies, this might not have been enough to stimulate treatment adherence. We think that the lack of clinician support might account for the poor adherence and response to online, unsupported CCBT that we observed. Similar studies also showed a lack of response, ${ }^{30,37,38}$ while studies that offered some form of support reported more treatment adherence and larger effects to online CCBT for several psychological disorders. ${ }^{27,32,39-41}$ Poor treatment adherence in our study might thus have masked potential effects of the interventions, but our ancillary per-protocol analyses did not reveal differences between the treatment-groups either. We did observe a small trend in favour of the combination group as opposed to both mono-therapies for reliable change and clinically significant change, as well as for the subgroup with a major depressive episode. However, our combination group cannot be seen as supported self-help, since the GP was not directly involved in the CCBT intervention.

Third, the low effect sizes in all three interventions might be attributable to our study sample, which was more severely depressed than in previous studies. ${ }^{5,27}$ The mean starting levels on the BDI-II were even higher than generally seen in depressed, primary care patients. ${ }^{42}$ Chronicity might also have negatively influenced the outcome. ${ }^{43}$ Unfortunately, we do not have details on the exact duration of the current depressive episode. Moreover, because of our recruitment strategy our sample did not consist of active help-seekers, despite the high severity. This might have resulted in less motivated participants.

Finally, we should note that none of our interventions did particularly well. Clinical improvement was approximately $30 \%$ in all groups. Given the fact that the placebo-response rate for depression is generally high (i.e. $30-40 \%$ ), ${ }^{44,45}$ we might have observed the natural course of depression in the current study, although improvement was somewhat larger as seen in patients without treatment. ${ }^{46}$ 


\section{Implications}

Our findings might have several implications for the primary care treatment of depression. First, treatment might only be indicated for those who 'get stuck' in their depression, since depressive symptoms seem to improve over time without adhering to treatment, as was shown in the current study. Second, for more severely depressed patients online CCBT offered with some support might be more helpful. Third, this group of more severely depressed patients might also fare better in secondary mental health care, where they can receive psychotherapy or antidepressant medication for which larger effect sizes have been found relative to our effect size. ${ }^{47,48}$ Fourth, careful implementation of unsupported online self-help is warranted. Stepped-care and collaborative care models might be viable options. ${ }^{49,50}$ Fifth, if large differences in costs between the interventions exist, this might be a reason to choose one primary care treatment over the other. Only one study so far has conducted an economic evaluation of CCBT. ${ }^{51}$ It was shown that supported CCBT was both more effective and more costly compared with usual GP care. When willing to pay for an additional unit of effect, CCBT could be very cost-effective..$^{51}$ In a next paper, we will report the economic evaluation of CCBT without support in primary care. Finally, qualitative process evaluation and information on patients' experiences (e.g. treatment satisfaction) might also help to decide which treatment should be given to a patient. The acceptability by patients of CCBT both before and after treatment (e.g. expectancy, credibility, and satisfaction) has rarely been assessed in research. ${ }^{52}$ Taken together, more work needs to be done to optimise treatment adherence in CCBT, to determine the best way of providing online and unsupported CCBT in actual practice, and to determine for whom CCBT is best suited.

\section{Methodological considerations}

We feel that our results cannot be explained by clear methodological flaws. Our large sample size $(\mathrm{N}=303)$ provided us with sufficient power to detect significant differences between the interventions. Furthermore, we had a relatively low attrition rate, so we feel confident that no biases occurred due to missing data. Finally, we were able to recruit patients from the general population. Unlike in samples selected in general practices or clinics, no biases occurred due to help seeking behaviour of patients and illness recognition by physicians, which is often a problem in depression. ${ }^{53}$

Some limitations of the present study should also be noted. All our outcomes were measured online and one might question the equality of computerised questionnaires and paper-and-pen versions. However, there are sufficient indications that computerised and paper-and-pen questionnaires show similar construct validity. ${ }^{54-56}$ Furthermore, we relied on self-report measures at follow-up and, as a result, we have no information on actual diagnoses of depressive episodes at follow-up. Finally, it should be noted that the number of patients included is merely a fraction of the original recruitment population (i.e. $0.14 \%$ ), despite the high prevalence of depression in the community. ${ }^{57,58}$ Participants had to come to the research centre for an intake, which could have reduced the number of applicants, but could also have increased the compliance. Overall, the low response rate in the current 
study might be discouraging for the belief of many researchers that online CCBT can be disseminated to large parts of the general population. ${ }^{59}$

\section{Conclusion}

In the current study we were unable to confirm the previously reported high effectiveness of CCBT using online, unsupported Colour Your Life. Moreover, adding online CCBT to treatment as usual had no extra beneficial effects. These findings cannot merely be explained by the lack of treatment adherence, since per-protocol analyses showed no differences between the interventions either. It is entirely possible that we have observed natural, although not complete, recovery in a group moderately and severely depressed patients who showed a decrease in symptoms irrespective of the nature of the intervention they received. CCBT, offered online without any support, is not beneficial for all depressed patients. Adding therapist support to online CCBT or treatment in secondary mental health care might have yielded better results in this group of depressed patients.

\section{Acknowledgements}

We thank Annie Hendriks and Greet Kellens for their assistance during the study and Rosanne Janssen for the development of the infrastructure for online data-collection.

The trial is financed by ZonMw (Netherlands Organisation for Health Research and Development; project number 945-04-417), research institute EPP and research institute CAPHRI. Municipalities Eijsden, Meerssen, Sittard-Geleen, Valkenburg and Maastricht sponsored the study. 


\section{References}

1. Butler AC, Chapman JE, Forman EM, Beck AT. The empirical status of cognitive-behavioral therapy: A review of meta-analyses. Clin Psychol Rev 2006;26:17-31.

2. Hollon SD, Stewart MO, Strunk D. Enduring effects for cognitive behavior therapy in the treatment of depression and anxiety. Annu Rev Psychol 2006;57:285-315.

3. Hirschfeld RM, Keller MB, Panico S, Arons BS, Barlow D, Davidoff F, et al. The National Depressive and Manic-Depressive Association consensus statement on the undertreatment of depression. JAMA 1997;277(4):333-340.

4. Kaltenthaler E, Brazier J, De Nigris E, Tumur I, Ferriter M, Beverly C, et al. Computerised cognitive behaviour therapy for depression and anxiety update: a systematic review and economic evaluation. Health Technol Assess 2006;10(33):1-186.

5. Proudfoot J, Ryden C, Everitt B, Shapiro DA, Goldberg A, Mann A, et al. Clinical efficacy of computerised cognitive-behavioural therapy for anxiety and depression in primary care: randomised controlled trial. Br J Psychiatry 2004;185:46-54.

6. Spek V, Nyklícek I, Smits N, Cuijpers P, Riper H, Keyzer J, et al. Internet-based cognitive behavioural therapy for subthreshold depression in people over 50 years old: a randomized controlled clinical trial. Psychol Med 2007;37:1797-1806.

7. Van der Does AJW. De Nederlandse versie van de Beck Depression Inventory - second edition (BDI-II-NL): Handleiding [The Dutch version of the Beck Depression Inventory - second edition (BDI-II-NL): Manual]. Enschede: The Psychological Corporation, 2002.

8. Robins LN, Wing J, Ulrich Wittchen H, Helzer JE, Babor TF, Burke J, et al. The Composite International Diagnostic Interview. Arch Gen Psychiatry 1988;45(12):1069-1077.

9. de Graaf LE, Gerhards SAH, Evers SMAA, Arntz AR, Riper H, Severens JL, et al. Clinical and costeffectiveness of computerised cognitive behavioural therapy for depression in primary care: design of a randomised trial. BMC Public Health 2008;8:224.

10. Riper H, Kramer JJAM. Online zelfhulpcursus www.kleurjeleven.nl. Utrecht: Trimbos-institute, 2004.

11. Cuijpers $P$, Bonarius $M$, van den Heuvel $A$. De omgaan met depressie cursus: een handreiking voor begeleiders en organisatoren [The coping with depression course: a manual]. Utrecht: NcGv, 1995.

12. Lewinsohn PM, Antonuccio DO, Steinmetz JL, Teri L. The coping with depression course: a psychoeducational intervention for unipolar depression. Eugene, OR: Castalia Publishing, 1984.

13. Van Marwijk HWJ, Grundmeijer HGLM, Bijl D, van Gelderen MG, de Haan M, van Weel-Baumgarten EM, et al. NHG-standaard depressieve stoornis (in Dutch) [Depression guideline of the Dutch College of General Practitioners]. Huisarts Wet 2003;46:614-623.

14. Beck AT, Steer RA, Ball R, Ranieri WF. Comparison of Beck Depression Inventories-IA and -II in psychiatric outpatients. J Pers Assess 1996;67(3):588-597.

15. Arnau RC, Meagher MW, Norris MP, Bramson R. Psychometric Evaluation of the Beck Depression Inventory-II With Primary Care Medical Patients. Health Psychol 2001;20(2):112-119.

16. Arrindell WA, Ettema H. Dimensionele sctructuur, betrouwbaarheid en validiteit van de Nederlandse bewerking van de Symptom Checklist (SCL-90); gegevens gebaseerd op een fobische en een 'normale' populatie. Nederlands Tijdschrift voor de Psychologie 1981;36:77-108.

17. Derogatis LR, Rickels K, Rock AF. The SCL-90 and the MMPI: A Step in the Validation of a New Self-Report Scale. Br J Psychiatry 1976;128(280-289).

18. Mundt JC, Marks IM, Shear MK, Greist JH. The Work and Social Adjustment Scale: a simple measure of impairment in functioning. Br J Psychiatry 2002;180:461-464.

19. McHorney CA, Ware JE, Raczek AE. The MOS 36-item short form health survey (SF-36): II. Psychometric and clinical tests of validity in measuring physical and mental health constructs. Med Care 1993;31(3):247-263.

20. Ware JE, Sherbourne CD. The MOS 36-item short-form health survey (SF-36). I. Conceptual framework and item selection. Med Care 1992;30(6):473-483. 
21. Aaronson NK, Muller M, Cohen PD, Essink-Bot ML, Fekkes M, Sanderman R, et al. Translation, validation, and norming of the Dutch language version of the SF-36 Health Survey in community and chronic disease populations. J Clin Epidemiol 1998;51(11):1055-1068.

22. Weissman AN, Beck AT. Development and validation of the Dysfunctional Attitude Scale. 1978, Chicago, November.

23. De Graaf LE, Roelofs J, Huibers MJH. Measuring dysfunctional attitudes in the general population: the DAS-A revised. revision submitted.

24. Cohen J. Statistical power analysis for the behavioral sciences. Hillsdale, NJ: Erlbaum, 1988.

25. Jacobson NS, Truax P. Clinical significance: a statistical approach to defining meaningful change in psychotherapy research. J Consult Clin Psychol 1991;59(1):12-19.

26. Cook RJ, Sackett DL. The number needed to treat: a clinically useful measure of treatment effect. $\mathrm{Br} M e d$ J 1995;310:452-454.

27. Andersson G, Bergström J, Holländare F, Carlbring $P$, Kaldo V, Ekselius L. Internet-based self-help for depression: randomised controlled trial. Br J Psychiatry 2005;187:456-461.

28. Wright JH, Wright AS, Albano AM, Basco MR, Goldsmith $L$, Raffield T, et al. Computer-assisted cognitive therapy for depression: maintaining efficacy while reducing therapist time. Am J Psychiatry 2005;162:1158-1164.

29. Willemse GRWM, Smit F, Cuijpers P, Tiemens BG. Minimal-contact psychotherapy for sub-threshold depression in primary care. Br J Psychiatry 2004;185:416-421.

30. Spek V, Cuijpers P, Nyklícek I, Riper H, Keyzer J, Pop V. Internet-based cognitive behaviour therapy for symptoms of depression and anxiety: a meta-analysis. Psychol Med 2007;37(3):319-328.

31. Spek V, Cuijpers P, Nyklícek I, Smits N, Riper H, Keyzer J, et al. One-year follow-up results of a randomized controlled clinical trial on internet-based cognitive behavioural therapy for subthreshold depression in people over 50 years. Psychol Med 2008:1-5.

32. Christensen $\mathrm{H}$, Griffiths KM, Jorm AF. Delivering interventions for depression by using the internet: randomised controlled trial. Br Med J 2004;328(265).

33. Newman MG, Consoli AJ, Barr Taylor C. A palmtop computer program for the treatment of generalized anxiety disorders. Behav Modif 1999;23:597-619.

34. Osgood-Hynes DJ, Greist JH, Marks IM, Baer L, Heneman SW, Wenzel KW, et al. Self-administered psychotherapy for depression using a telephone-accessed computer system plus booklets: an open USUK study. J Clin Psychiatry 1998;59:358-365.

35. Proudfoot J, Goldberg A, Mann A, Everitt B, Marks I, Gray JA. Computerized, interactive, multimedia cognitive behavioral program for anxiety and depression in general practice. Psychol Med 2003;33:217227.

36. Cavanagh K, Shapiro DA. Computer treatment for common mental health problems. J Clin Psychol 2004;60(3):239-251.

37. Patten SB. Prevention of depressive symptoms through the use of distance technologies. Psychiatr Serv 2003;54:396-398.

38. Clarke G, Eubanks D, O'Connor E, DeBar LL, Kelleher C, Lynch F, et al. Overcoming Depression on the Internet (ODIN): A Randomised Controlled Trial of an Internet Depression Skills Intervention Program. $J$ Med Internet Res 2002;4(3):e14.

39. Carlbring P, Gunnarsdóttir M, Hedensjö L, Andersson G, Ekselius L, Furmark T. Treatment of social phobia: randomised trial of internet-delivered cognitive-behavioural therapy with telephone supportq. Br J Psychiatry 2007;190:123-128.

40. Clarke G, Eubanks D, Reid E, Kelleher C, O'Connor E, DeBar LL, et al. Overcoming depression on the internet (ODIN) (2): a randomized trial of a self-help depression skills program with reminders. J Med Internet Res 2005;7(2):e16.

41. Kenwright M, Marks I, Graham C, Franses A, Mataix-Cols D. Brief scheduled phone support from a clinician to enhance computer-aided self-help for obsessive-compulsive disorder: randomized controlled trial. J Clin Psychol 2005;190:123-128.

42. Vuorilehto M, Melartin TK, Rytsälä HJ, Isometsä E. Do characteristics of patients with major depressive disorder differ between primary and psychiatric care? Psychol Med 2007;37:893-904. 
43. Hamilton KE, Dobson KS. Cognitive therapy of depression: pretreatment patient predictors of outcome. Clin Psychol Rev 2002;22:875-893.

44. Walsh C, MacMillan H, Jamieson E. The relationship between parentalpsychiatric disorder and child physical and sexual abuse: findings from the Ontario Health Supplement. Child Abuse Negl 2002;26:1122.

45. Bialik RJ, Ravindran AV, Bakish D, Lapierre YD. A comparison of placebo responders and nonresponders in subgroups of depressive disorder. J Psychiatry Neurosci 1995;20(4):265-270.

46. Posternak MA, Miller I. Untreated short-term course of major depression: a meta-analysis of outcomes from studies using wait-list control groups. J Affect Disord 2001;66:139-146.

47. DeRubeis RJ, Hollon SD, Amsterdam JD, Shelton RC, Young PR, Salomon RM, et al. Cognitive therapy vs medications in the treatment of moderate to severe depression. Arch Gen Psychiatry 2005;62:409-416.

48. Dimidjian S, Hollon SD, Dobson KS, Schmaling KB, Kohlenberg RJ, Addis ME, et al. Randomized trial of behavioral activation, cognitive therapy, and antidepressant medication in the acute treatment of adults with major depression. J Consult Clin Psychol 2006;74(4):657-670.

49. Katon W, Von Korff M, Lin E, Walker E, Simon GE, Bush T, et al. Collaborative management to achieve treatment guidelines. Impact on depression in primary care. JAMA 1995;273(13):1026-1031.

50. Scogin FR, Hanson A, Welsh D. Self-Administered Treatment in Stepped-Care Models of Depression Treatment. J Clin Psychol 2003;59(3):341-349.

51. McCrone P, Knapp M, Proudfoot J, Ryden C, Cavanagh K, Shapiro DA, et al. Cost-effectiveness of computerised cognitive-behavioural therapy for anxiety and depression in primary care: randomised controlled trial. Br J Psychiatry 2004;185:55-62.

52. Kaltenthaler E, Sutcliffe P, Parry G, Beverly C, Rees A, Ferriter M. The acceptability to patients of computerized cognitive behaviour therapy for depression: a systematic review. Psychol Med 2008;38(11):1521-1530.

53. Paykel ES, Tylee A, Wright A, Priest RG. The Defeat Depression Campaign: Psychiatry in the public arena. Am J Psychiatry 1997;154(6, suppl):59-65.

54. Butcher JN, Perry J, Hahn J. Computers in Clinical Assessment: Historical developments, present status, and future challenges. J Clin Psychol 2004;60(3):331-345.

55. Butcher JN, Perry JN, Atlis MM. Validity and Utility of Computer-Based Test Interpretation. Psychological Assessment 2000;12(1):6-18.

56. Schulenberg SE, Yutrzenka BA. Equivalence of Computerized and Conventional Versions of the Beck Depression Inventory-II (BDI-II). Current Psychology 2001;20(3):216-230.

57. Bijl RV, Ravelli A, van Zessen G. Prevalence of psychiatric disorder in the general population: Results of the Netherlands Mental Health Survey and Incidence Study (NEMESIS). Soc Psychiatry Psychiatr Epidemiol 1998;33(12):587-595.

58. Kessler RC, Berglund P, Demler O, Jin R, Koretz D, Merikangas KR, et al. The epidemiology of major depressive disorder. Results from the National Comorbidity Survey Replication (NCS-R). JAMA 2003;289(23):3095-3105.

59. Andersson G, Cuijpers P. Pros and cons of online cognitive-behavioural therapy. Br J Psychiatry 2008;193:270-271. 


\section{Chapter 3}

\section{Economic evaluation of online computerised cognitive behavioural therapy without support for depression in primary care: a randomised trial}




\begin{abstract}
Background: Recently, we compared the clinical effectiveness of unsupported, online computerised cognitive behavioural therapy (CCBT) with treatment as usual (TAU), and a combination of CCBT and TAU (COMBI) for depression. Evidence on the cost-effectiveness and cost-utility of CCBT is still limited.

Aims: To assess the cost-effectiveness of CCBT compared with TAU and COMBI.

Method: Costs, depression severity and quality of life were measured during 12 months. Cost-effectiveness and cost-utility analyses were performed from a societal perspective. Uncertainty was dealt with by bootstrap replications and sensitivity analyses.

Results: Costs were lowest for the CCBT group. There are no significant group differences in effectiveness or quality of life. Cost-utility and cost-effectiveness analyses tend to be in favour of CCBT.

Conclusion: On balance, CCBT constitutes the most efficient treatment strategy, although all treatments showed low adherence rates and modest improvements in depression and quality of life.
\end{abstract}




\section{Background}

Major depression is a common mental health problem in the general population ${ }^{1}$ and is associated with substantial decreases in quality of life. ${ }^{2,3}$ Cost-of-illness studies reveal that the economic burden of depression is considerable. ${ }^{4-8}$ However, many depressed patients in primary care do not receive the care they need. There is only little evidence on the effectiveness of pharmacotherapy in mild to moderately depressed patients, ${ }^{9}$ while psychological treatments in primary care are scarce and costly. Consequently, effective treatments like cognitive behavioural therapy $(\mathrm{CBT})^{10,11}$ are not offered to all patients and many depressed patients in primary care remain untreated. ${ }^{12}$ An effective, acceptable, and feasible solution for depressed patients in primary care might be computerised CBT (CCBT). ${ }^{13}$ The National Institute of Health and Clinical Excellence recommended the use of two CCBT software programs for depression and anxiety, ${ }^{14}$ and these programs are now in use in England, Wales and Northern Ireland. In the Netherlands, an online CCBT program is currently being used as part of an ongoing implementation study (www.kleurjeleven.nl). However, evidence on the cost-effectiveness of CCBT is still limited. ${ }^{13}$ To our knowledge, only one study conducted an economic evaluation of CCBT for depression, showing that CCBT (delivered on a personal computer in the general practice) can be highly costeffective compared with usual care by a GP in the UK setting. ${ }^{15}$ In a recent study, we compared the clinical effectiveness of unsupported, online CCBT (i.e. Colour Your Life) with treatment as usual (TAU) by a GP, and a combination of both CCBT and TAU for depression (COMBI). ${ }^{16}$

In the present study, we assess the cost-effectiveness of these interventions, focusing on the research question: Is CCBT compared with TAU or COMBI for mild to moderate depression preferable in terms of cost-effectiveness from a societal perspective?

\section{Method}

\section{Design and participants}

In a randomised trial, 303 participants were recruited from the general population by means of a large-scale Internet-based screening in the South of the Netherlands. Inclusion criteria were: age 18 to 65 ; access to the Internet at home (for an optimal use of the CCBT program, a broad-band connection was required and no dial-up connection); at least mild to moderate depressive complaints (Beck Depression Inventory II (BDI-II) ${ }^{17}$ score $\geq 16$ ); duration of depressive complaints 3 months or more; no current psychological treatment for depression; no continuous antidepressant treatment for at least 3 months prior to entry; fluent in Dutch language; no alcohol and/or drug dependence; and no severe psychiatric co-morbidity (e.g. psychotic disorders). During a one-year follow-up period, participants were asked to fill in monthly Internet questionnaires. Further details of the study design have been described elsewhere (see appendix 1 in this thesis). ${ }^{16,18}$ 


\section{Interventions}

CCBT is based on the principles of cognitive behavioural therapy. The CCBT program in our trial (named "Colour Your Life" (CYL, in Dutch Kleur je Leven)) is an online, multimedia, interactive computer program for depression. ${ }^{19}$ The program consists of eight weekly sessions and a ninth booster session, including homework-assignments and a 'mood diary'. No professional assistance was offered. Patients could reach the program wherever they had a computer with Internet access.

The GP is the major health care provider involved in the primary care of depression. In the Dutch health care system the GP is seen as a gatekeeper, and a key figure in the detection and treatment of depression. ${ }^{20}$ Participants who received the TAU were advised to contact their own GP. After inclusion, the patients' GP received an information letter about the patient's participation in the study. In the letter, the GP was advised to follow the depression guideline as described by the Dutch College of General Practitioners. Usual care as such can consist of four to five biweekly consultations in combination with antidepressant treatment if indicated. In practice however, usual care is whatever the GP prescribes. ${ }^{21}$

Further details of the design of the trial, the interventions and the population can be found elsewhere. ${ }^{16,18}$

\section{Cost measures and valuation}

The economic evaluation was performed from the societal perspective. Costs were divided into the categories: health care sector costs, costs for patient and family, and productivity costs. ${ }^{22}$ Due to the impact depression can have on a patient's overall health status, functioning and well-being, it is often not clear whether the health care use or productivity loss is depression-related. We therefore included all related and unrelated costs in the analysis. Health care costs were measured by means of a monthly health care use questionnaire. Patients were asked to report the volumes of psychological, paramedical, medical, paid and informal care, participation in a self-help group, and alternative treatments received during the last month. CCBT usage was based on computer-registered login data of the CYL program.

The patient and family costs consisted of costs of travelling and lost time due to the intervention TAU and/or CCBT. The time spent by a patient on CCBT was tracked by means of the computer-registered login and logout data of the program. In the health care use questionnaire, the average duration of a GP consult was registered by the patient. For the time spent on psychological care received from a psychiatrist, we used mean time duration of 30 minutes per session. The time spent on a psychologist, social-psychiatric nurse or other mental health care professional was valued by 45 minutes per session. We assumed that patients used the TAU and CCBT program outside working hours, and therefore valued their time costs as leisure time. The number of GP consults informs on the number of travels from/to the GP, and was linked to the average travel distances to a GP in the Netherlands. ${ }^{23,24}$

Modules of the PROductivity and DISease Questionnaire (PRODISQ) were used to measure absenteeism, presenteeism and compensation mechanisms of absenteeism. ${ }^{25,26}$ Productiv- 
ity costs were based on the outcomes of the PRODISQ, and calculated according to the friction cost method. ${ }^{23,24,27}$

Costs for computer and Internet use were considered to be sunk costs and not included, as the inclusion criteria of the trial required that the participant has Internet access at home. For the costs of CYL we included $€ 50$ per user for the whole program and the entire intervention period (Heleen Riper, personal communication, December 8, 2008).

Dutch standard costs were used to value health care, patient and family, and productivity cost items. ${ }^{23,24}$ If for specific categories standard costs were unavailable, we used average tariffs. Medication costs were based on the Dutch Pharmacotherapeutic Compass. ${ }^{28}$ The standard costs and tariffs of health care practitioners were the integral costs, being all costs directly and indirectly attributable to the cost unit.

Costs are presented in Euros for the year 2007. Since the follow-up period lasts one year and no extrapolation over time was executed, discounting was not necessary. If needed, costs were indexed to the year 2007 by means of the consumer price indexes of the Dutch Central Bureau of Statistics.

\section{Outcome measures}

Depression severity was measured with the Beck Depression Inventory Second Edition (BDIII). The total score is the sum of the 21 items with a range of 0 (no depression) to 63 (severe depression). There has been support for the construct validity and reliability of the BDI-II in various samples. ${ }^{17,29,30}$

Quality of life was measured with the EuroQol EQ-5D ${ }^{31}$ and the Short Form 6D (SF-6D). ${ }^{32}$ The EQ-5D consists of five health state dimensions (mobility, self-care, usual activity, pain/discomfort and anxiety/depression) on which the respondent has to indicate his own health state. ${ }^{31,33}$ An advantage of the EuroQol is that it is short and that an overall utility score for population-based quality of life can be obtained, which facilitates comparisons with other interventions and health states in other disease areas. A utility refers to the preference that individuals or society may have for any particular set of health outcomes. It is indicated by a number between 0 (the worst imaginable condition: death) and 1 (perfect health). ${ }^{22}$ Standardised value sets are available to calculate the utility based on the EQ-5D. Because many studies in the Netherlands and internationally use the UK tariff, this study used both the UK tariff and Dutch tariff to value generic quality of life. ${ }^{34,35}$

The SF-6D is a utility instrument based on the health-related quality of life questionnaire 36-item short-form Health Survey (SF-36). ${ }^{32}$ The utility score is derived from 11 items of the SF-36 and is composed of six dimensions of health (physical functioning, role limitations, social functioning, pain, mental health, and vitality). The SF-6D utilities were derived by means of the UK tariff. ${ }^{36,37}$

The EQ-5D and SF-6D utility scores were used to calculate the quality adjusted life year (QALY) during the follow-up period by adjusting the length of time between each measurement moment by the respective utility value for this period. ${ }^{22}$ 


\section{Analysis}

All available data were used. Only intermittent missing data were replaced by mean imputation using the outcomes on the previous and next measurement moment of the patient. Only 8 participants had intermittent missing data. In all these cases, the number of missing moments was limited to one moment. Data of patients lost to follow-up were not imputed. For each patient, volumes of care, travels, lost time for receiving care and lost productivity hours were multiplied by the prices determined for each cost item. Costs during the followup period were calculated as the cumulative costs per patient at 12 months after baseline. The costs during the follow-up period of the three groups were compared by the nonparametric bootstrapping method with $95 \%$ confidence intervals in percentiles. By bootstrapping, samples of the same size as the original data are drawn with replacement from the observed data. ${ }^{38}$ The quality of life and severity of depression outcomes during followup were compared between the three groups using ANOVA, Kruskall-Wallis and $\chi^{2}$ tests at the $p<.05$ level. Baseline corrections for societal cost and QALY outcomes were performed by means of regression correction. . $^{39-41}$

The analysis consisted of a base-case cost-effectiveness and cost-utility analysis, and sensitivity analyses. In the base-cases, the primary outcome measure for the cost-effectiveness analysis was change from baseline score of depression severity measured by the BDI-II at 12 months, and for the cost-utility analysis the QALY at 12 months based on the EQ-5D using the UK-tariff. Costs in the base-case analysis are calculated according to the societal perspective.

Uncertainty of parameter estimates of the base-cases was dealt with by the sensitivity analyses. ${ }^{22}$ In the sensitivity analyses, the correction method for baseline differences in costs and utilities was varied by using no correction. ${ }^{39,40}$ Other aspects of sensitivity analyses were: varying the time horizon of the cost-effectiveness analysis from 12 to 6 months, varying the societal costs to healthcare costs, calculating productivity costs according to the human capital approach instead of the friction cost method, using the Dutch tariff to value the EQ-5D, varying the QALY outcome by using the SF-6D, and using the reliable change index of the BDI-II score as outcome measure. For the reliable change we used the methodology of Jacobson and Truax, ${ }^{42}$ which gives the proportion of patients with clinically meaningful changes at 12 months (i.e. a decrease of at least 9 points on the BDI-II since baseline). Due to uncertainty about the cost price of self-help online CCBT in real-world, this cost price was varied by estimating either one fixed price per package user $(€ 5, € 50$, and $€ 150$ ), and a price per lesson. Based on the price estimates per package, and an average number of 5 lessons completed by CCBT users, we varied this cost price by $€ 1$, $€ 10$ and $€ 30$ per lesson.

Because of the comparison of three strategies in this trial, an incremental approach is not feasible for analysing the cost-effectiveness data. Therefore the net benefit (NB) was used to present the cost-utility results in monetary units for each strategy. The NB is calculated by valuing the utility outcome in monetary values using the threshold willingness-to-pay for a QALY, minus the costs of the interventions. ${ }^{43}$

Non-parametric bootstrap re-sampling techniques were used to explore uncertainty around estimates of cost-effectiveness and cost-utility derived from the study sample. ${ }^{38}$ For each bootstrap iteration, using a range of cost-effectiveness thresholds it was decided which 
strategy had the highest NB, and for all iterations it was calculated which strategy had the highest probability of being most efficient. The resulting decision uncertainty is represented graphically by a cost-effectiveness acceptability curve (CEAC). ${ }^{22,44-46}$ Due to uncertainty on the monetary threshold per QALY, alternative values ranging from $€ 0$ to $€ 80,000$ were used in the cost-utility analysis. ${ }^{47}$ Since the value that society would place on a unit reduction in BDI-II depression score is unknown, its NB cannot be defined. ${ }^{15}$

Bootstrap analyses were carried out using Microsoft Office Excel 2003. All other analyses were carried out using SPSS version 15.0.1 for Windows.

\section{Results}

\section{Population}

Of the 303 eligible patients, 100 were assigned to CCBT, 103 to TAU, and 100 to COMBI treatment. After imputation of intermittent missings, data were available for 275 patients (91\%) at 6 months (CCBT $n=91$, TAU $n=92$, COMBI $n=92$ ) and 267 patients (88\%) at 12 months after baseline (CCBT $n=88$, TAU $n=91$, COMBI $n=88$ ). Baseline characteristics of patients lost to follow-up did not differ from participants who completed all assessments. ${ }^{16}$ Table 1 shows the baseline characteristics of all participants, stratified according to intervention group. The $C O M B I$ group had lower costs on all costs categories as opposed to CCBT and TAU. The TAU group showed highest costs on productivity loss, and consequently has higher total costs compared with CCBT and COMBI. The CCBT group had higher baseline healthcare costs and patient and family costs compared with the other patient groups.

\section{Costs}

The mean volumes of health care use and productivity loss per patient are presented in table 2. The uncorrected costs are shown in table 3 . Societal costs over the 12 months follow-up period were lowest for the CCBT group with $€ 9,457$ for CCBT, $€ 10,793$ for the COMBI group and $€ 11,244$ for TAU. Bootstrap replications revealed a mean difference in societal costs in favour of CCBT of respectively $€ 1,784$ when compared with TAU, and $€$ 1,340 compared with COMBI. Both health care costs and productivity costs were lowest in the CCBT group ( $€ 1,428$ and $€ 7,475$ ), and highest in the TAU group ( $€ 1,912$ and $€ 8,925$ ). On the other hand, patient and family costs are highest in the CCBT group ( $€ 553$ ) and lowest in the TAU group ( $€$ 408). The COMBI group takes an intermediate position on all cost categories with $€ 1,829$ health care costs, $€ 8,425$ productivity costs, and $€ 539$ patient and family costs. About $80 \%$ of the societal costs consist of costs due to productivity loss. 
Table 1: Baseline characteristics of the sample and group differences $(n=303)^{*}$

\begin{tabular}{|c|c|c|c|}
\hline \multirow[b]{2}{*}{ Variable } & CCBT & COMBI & TAU \\
\hline & $\mathrm{n}=100$ & $n=100$ & $\mathrm{n}=103$ \\
\hline Male sex, nr (\%) & $48(48.0)$ & $37(37.0)$ & $46(44.7)$ \\
\hline Age, $M(s d)$ & $44.3(11.8)$ & $45.2(10.9)$ & $45.1(12.2)$ \\
\hline \multicolumn{4}{|l|}{ Education, $\mathrm{nr}(\%)^{\mathrm{a}}$ : } \\
\hline - Low & $18(18.6)$ & $17(17.5)$ & $16(16.2)$ \\
\hline - $\quad$ Medium & $55(56.7)$ & $52(53.6)$ & $55(55.6)$ \\
\hline - High & $24(24.7)$ & 28 (28.9) & $28(28.3)$ \\
\hline Partner, yes, $\mathrm{nr}(\%)^{\mathrm{b}}$ & $72(73.5)$ & $71(73.2)$ & $73(72.3)$ \\
\hline Paid job, yes, nr (\%) & $53(53.0)$ & $63(63.0)$ & $68(66.0)$ \\
\hline $\begin{array}{l}\text { Depressive severity BDI-II } \\
\text { (range } 0-63), M(s d)\end{array}$ & $28.2(7.7)$ & $27.4(8.2)$ & $27.9(7.5)$ \\
\hline \multicolumn{4}{|l|}{ Quality of life, M (sd) } \\
\hline - EQ-5D, UK Dolan tariff, & $0.70(0.21)$ & $0.69(0.22)$ & $0.71(0.20)$ \\
\hline $\begin{array}{l}\text { EQ-5D, NL Lamers tariff, } \\
\text { (range }-0.33-1 \text { ) }\end{array}$ & $0.70(0.20)$ & $0.69(0.20)$ & $0.71(0.18)$ \\
\hline $\begin{array}{l}\text { - } \quad \text { SF-6D, U.K. Brazier tariff, } \\
\text { (range } 0.30-1 \text { ) }\end{array}$ & $0.67(0.08)$ & $0.66(0.09)$ & $0.67(0.08)$ \\
\hline \multicolumn{4}{|l|}{ Costs, $\mathrm{M}[95 \% \mathrm{Cl}]^{\mathrm{c}, \mathrm{d}}$} \\
\hline - Healthcare costs & $464[270,731]$ & $268[191,353]$ & $345[246,459]$ \\
\hline - $\quad$ Patient and family costs & $165[85,256]$ & $66[35,101]$ & $77[31,136]$ \\
\hline - $\quad$ Productivity costs & $2010[1375,2729]$ & $1954[1351,2605]$ & $2501[1879,3169]$ \\
\hline - $\quad$ Societal costs & $2640[1963,3402]$ & $2288[1702,2916]$ & $2922[2300,3568]$ \\
\hline
\end{tabular}

Note. CCBT, computerised cognitive behavioural therapy; TAU, treatment as usual by a general practitioner; COMBI, combined treatment of both CCBT and TAU; BDI-II, Beck Depression Inventory II.

* Analysis of the characteristics costs of all patients excluding the drop-outs from research questionnaires ( $C C B T \mathrm{n}=88$, TAU $\mathrm{n}=91, \mathrm{COMBI} \mathrm{n}=88$ ) revealed similar results. 


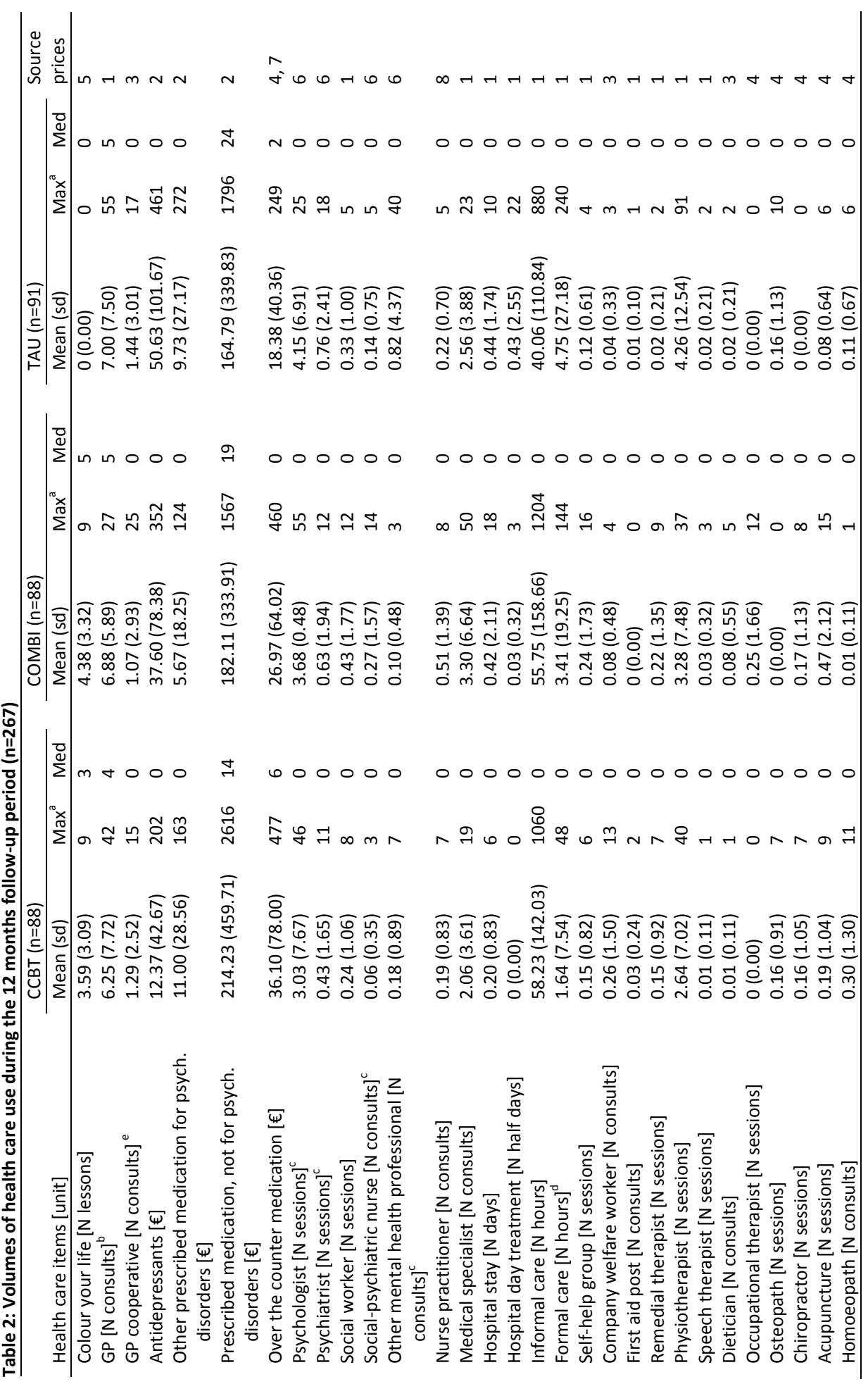




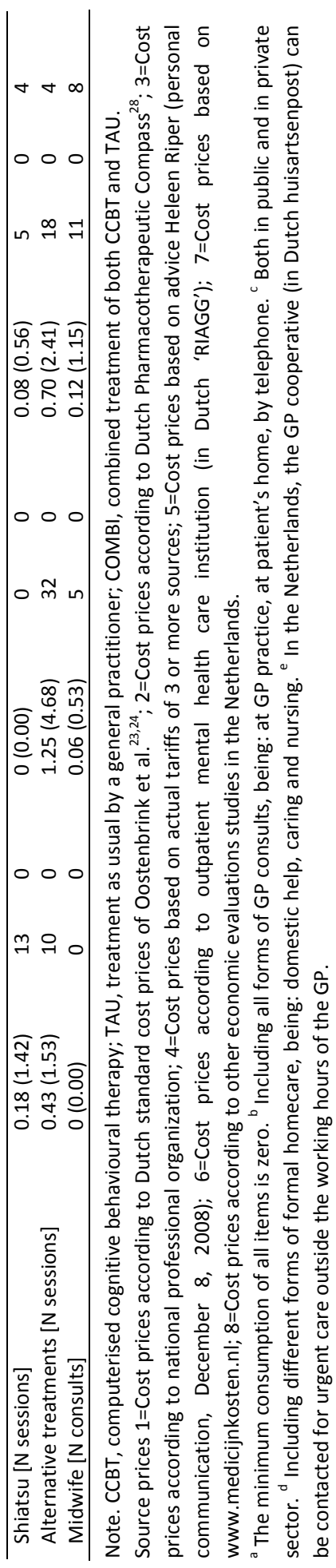


Table 3: Mean costs per cost type at 12 months after baseline $(\mathbf{n}=\mathbf{2 6 7})$

\begin{tabular}{llll}
\hline & Mean per group & & \\
& CCBT & COMBI & TAU \\
Cost type & $\mathrm{n}=88$ & $\mathrm{n}=88$ & $\mathrm{n}=91$ \\
\hline Healthcare costs [95\% CI] $^{*}$ & $1428[1121,1763]$ & $1829[1429,2261]$ & $1912[1515,2349]$ \\
GP care & 233 & 239 & 265 \\
Mental health care specialist & 329 & 401 & 474 \\
CYL program & 41 & 40 & 0 \\
Paramedical care & 68 & 97 & 106 \\
Medical specialist care & 264 & 422 & 328 \\
Hospital care & 88 & 189 & 293 \\
Antidepressants & 12 & 38 & 51 \\
Other prescribed and OTC & 261 & 215 & 193 \\
medication & & & \\
Paid home care & 47 & 84 & 137 \\
Alternative healers & 78 & 100 & 63 \\
Other care & 6 & 2 & 3 \\
Patient and family costs [95\% CI] & $553[321,834]$ & $539[284,859]$ & $408[236,634]$ \\
Travelling & 3 & 3 & 3 \\
Lost time $_{\text {Informal care }}$ & 39 & 46 & 53 \\
Productivity costs [95\% CI] & 511 & 489 & 352 \\
Absenteeism & $7475[5556,9430]$ & $8425[6063,10940]$ & $8925[6777,11007]$ \\
Presenteeism & 693 & 605 & 379 \\
Societal costs [95\% Cl] & 6782 & 7820 & 8546 \\
\hline
\end{tabular}

Note. CCBT, computerised cognitive behavioural therapy; TAU, treatment as usual by a general practitioner; COMBI, combined treatment of both CCBT and TAU; CYL, Colour Your Life (CCBT program); OTC medication, over the counter medication.

* The upper and lower confidence limits are the $2.5^{\text {th }}$ and $97.5^{\text {th }}$ percentile based on 5000 bootstrap replications.

Table 4 shows the mean costs per patient group of the different cost scenarios used in the base-case and sensitivity analyses. In all scenarios, CCBT has the lowest mean costs per patient. In the base-case analysis, costs are corrected for baseline cost differences. After regression correction for baseline differences, CCBT has the lowest societal costs during the 6-months $(€ 4,462)$ and 12-months $(€ 9,092)$ follow-up period. After 6 months the mean societal costs of TAU $(€ 5,113)$ are a little higher compared to the costs of COMBI $(€ 5,069)$. However, after 12 months COMBI has the highest costs (€ 10,534), while TAU takes an intermediate cost position $(€ 9,765)$ between COMBI and CCBT. As shown in table 4, varying the costs of CYL or the valuation method of the productivity costs, implies only minor changes in costs and in differences in costs between the patient groups. Varying the cost perspective from the societal to the health care costs, implies that the TAU group has highest baseline corrected costs $(€ 1,861)$, while costs of the COMBI group are a bit lower $(€ 1,797)$, and CCBT shows the lowest costs $(€ 1,366)$.

In the sensitivity analyses without correction for the baseline costs, the CCBT group remains the patient group with the lowest costs in all cost-varying scenarios, while TAU shows highest costs in all scenarios. 


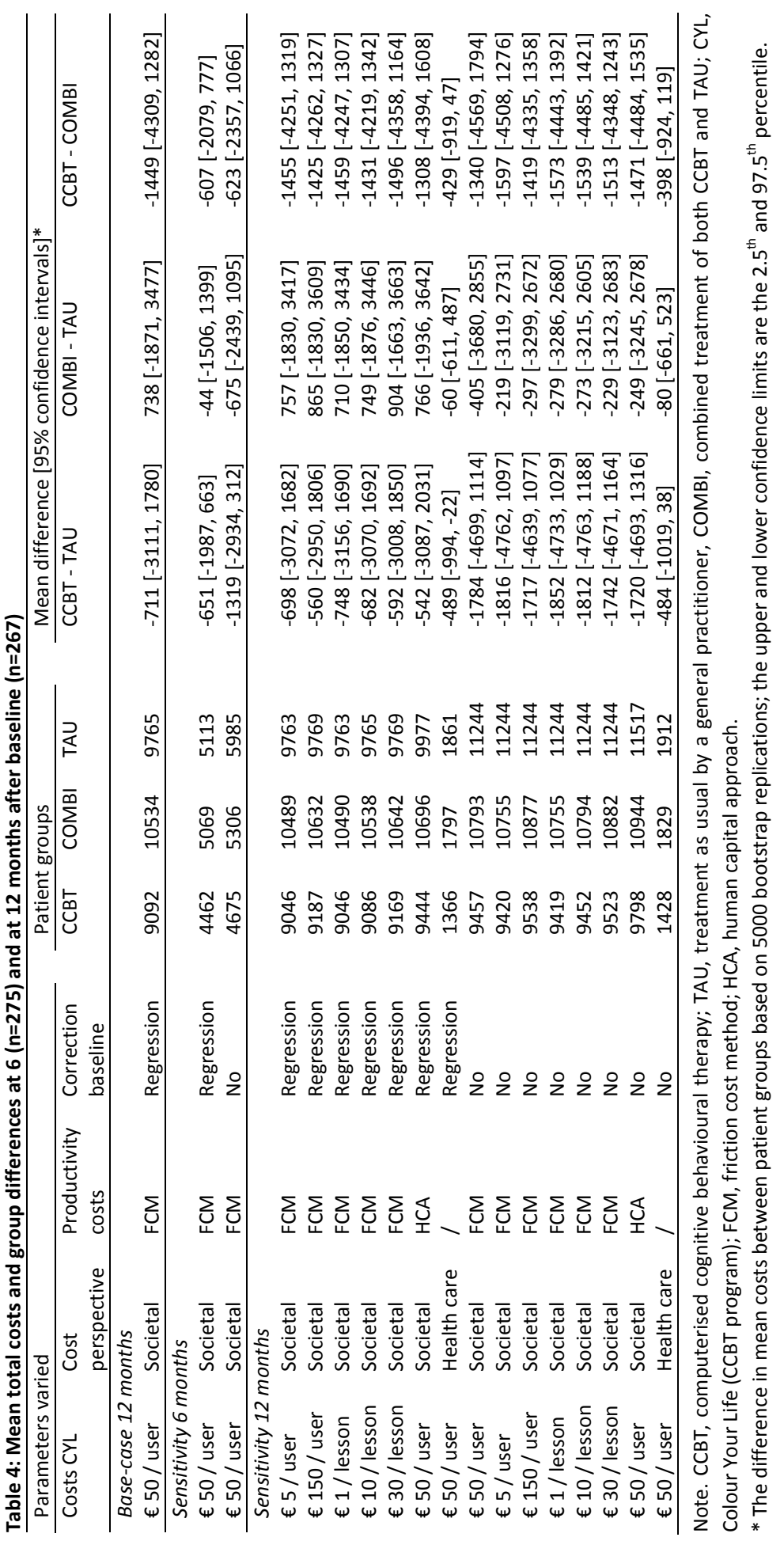




\section{Effects}

Table 5 reports no significant group differences in QALYs or clinical effectiveness outcomes. In the base-case analysis (baseline regression-corrected QALY using the UK-tariff to value the EQ-5D), results show a mean QALY of 0.71 for CCBT, 0.71 for COMBI and 0.72 for TAU. The mean QALY outcomes in all three patient groups remain about 0.70 , regardless of using a baseline correction or the type of QALY measure used. There seems to be not much improvement in terms of quality of life, as the mean QALYs during the 12-months follow-up period are very similar to the mean baseline utilities of about 0.70 per patient group.

The clinical effectiveness outcome does show an improvement during the 6 and 12 months follow-up period in all three patient groups. However, these improvements in effectiveness outcomes are rather minor improvements in depression. ${ }^{16}$ 


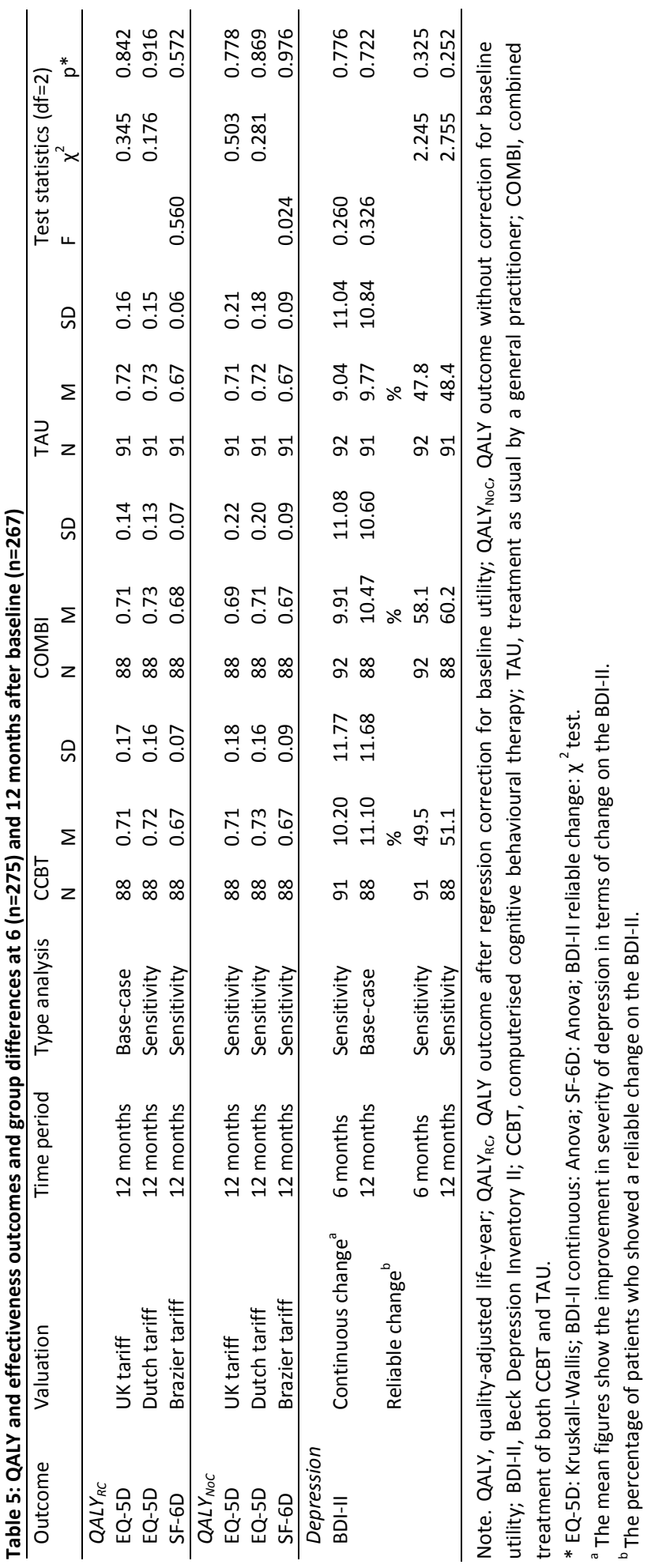




\section{Comparing costs and effects}

Figure 1 presents the CEACs of the base-case cost-utility analysis with the bootstrapped baseline-corrected societal costs and EQ-5D-based QALYs. CCBT tends to be the most optimal treatment compared to $\mathrm{COMBI}$ and TAU with a probability of about $65 \%$ of being the most efficient strategy at a threshold value of $€ 0$ per QALY, but diminishing towards a $40 \%$ probability when increasing the threshold value up to $€ 80,000$. Despite the $25 \%$ probability of TAU being the most efficient strategy at a threshold value of $€ 0$ per QALY, its probability increases up to about $40 \%$ when society's willingness to pay increases up to $€$ 80,000 per QALY, and consequently the choice between TAU and CCBT becomes almost indifferent at a threshold of $€ 80,000$. The COMBI treatment has the lowest chance of being the most efficient strategy, with probabilities varying from $10 \%$ to $20 \%$ at the presented threshold values per QALY.

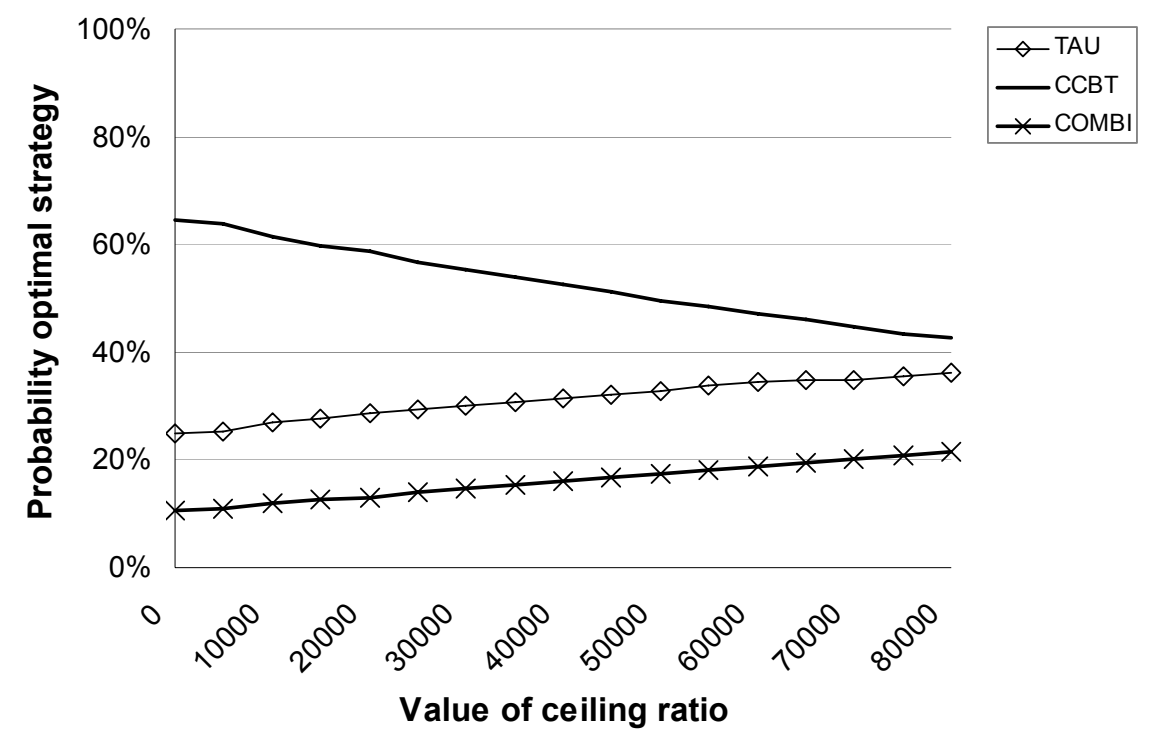

Figure 1: Base-case analysis. Cost-effectiveness acceptability curves of the cost-utility at 12 months followup

Note. CCBT, computerised cognitive behavioural therapy; TAU, treatment as usual by a general practitioner; COMBI, combined treatment of both CCBT and TAU. Costs = societal costs after regression correction for baseline costs; utility = quality-adjusted life-year (EQ-5D, UK tariff) after regression correction for baseline utilities.

Figure 2 shows the CEACs for the base-case cost-effectiveness analysis at 12 months followup using point changes on the BDI-II scale as outcome. As there is no guideline on the threshold value per point improvement on the BDI-II, the value of the ceiling ratio is varied up to an amount of $€ 40,000$ where the probabilities per treatment remain rather stable for higher thresholds. The CCBT treatment shows highest probabilities of about $60 \%$ of being the most efficient strategy, regardless of the threshold value for an improvement on the 
BDI-II scale. If one is willing to pay at least $€ 5,000$ per point improvement on the BDI-II scale, the TAU treatment is less favoured with probabilities about $10 \%$ of being the most optimal strategy, while COMBI shows probabilities about $30 \%$. Below the threshold value of $€ 5,000$, TAU has a probability between 25 to $13 \%$, while the COMBI treatment shows increasing probabilities of about $10 \%$ to $20 \%$.

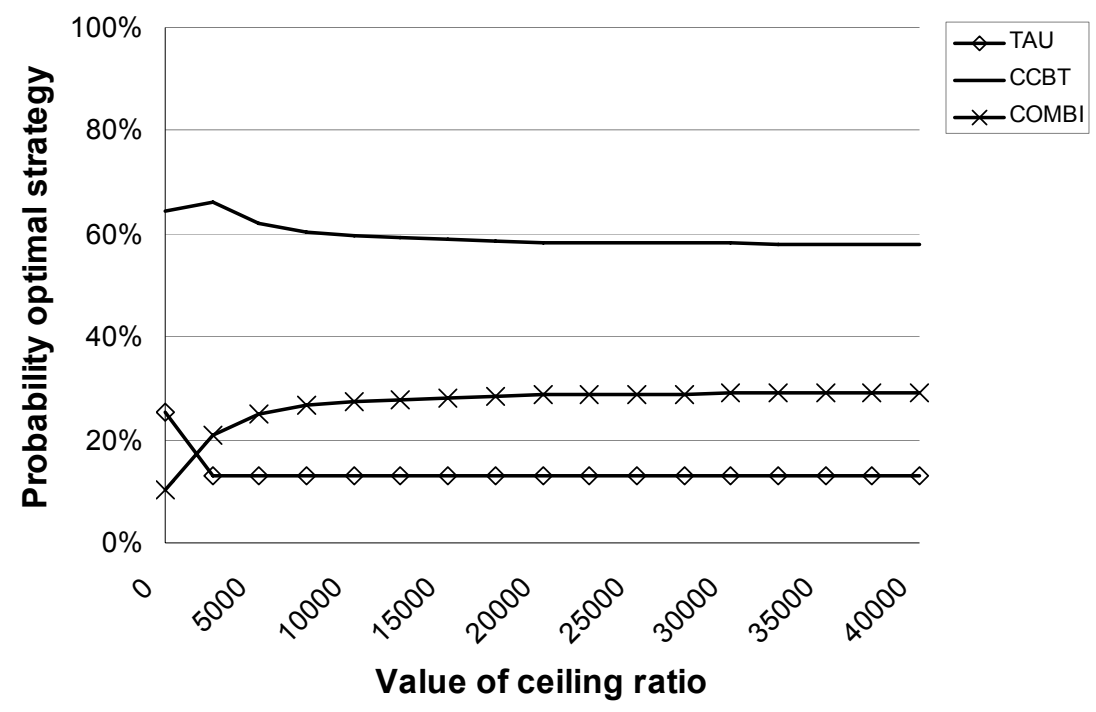

Figure 2: Base-case analysis. Cost-effectiveness acceptability curves of the cost-effectiveness at 12 months follow-up

Note. CCBT, computerised cognitive behavioural therapy; TAU, treatment as usual by a general practitioner; $\mathrm{COMBI}$, combined treatment of both CCBT and TAU. Costs = societal costs after regression correction for baseline costs; effectiveness = points improvement on the Beck Depression Inventory II.

\section{Sensitivity analyses}

Varying the outcome parameter of the base-case cost-utility scenario to either the regression-corrected QALY valued by the Dutch EQ-5D tariff or the SF-6D revealed similar results. Varying the regression-corrected societal costs by different cost calculations of CYL, or the productivity costs to the human capital approach, did not show much difference from the base-case analysis with QALY as outcome measure. CCBT is still the most favourable treatment in terms of cost-utility. However, as a consequence of not using baseline corrections, the TAU treatment turns out to have the lowest probability of being the most optimal choice. In this scenario, CCBT has a 70 to $80 \%$ probability of being the most efficient treatment given the varying threshold values up to $€ 80,000$, while COMBI and TAU each have a probability about $10-20 \%$.

The sensitivity analysis with most deviation from the base-case cost-utility analysis, is the scenario in which the health care cost perspective is used. Figure 3 shows CCBT is the most efficient strategy for treatment at the lower threshold values. But when increasing the 
ceiling on the value per QALY, the choice between the three treatment strategies becomes indifferent as all curves approach a probability of $30 \%$.

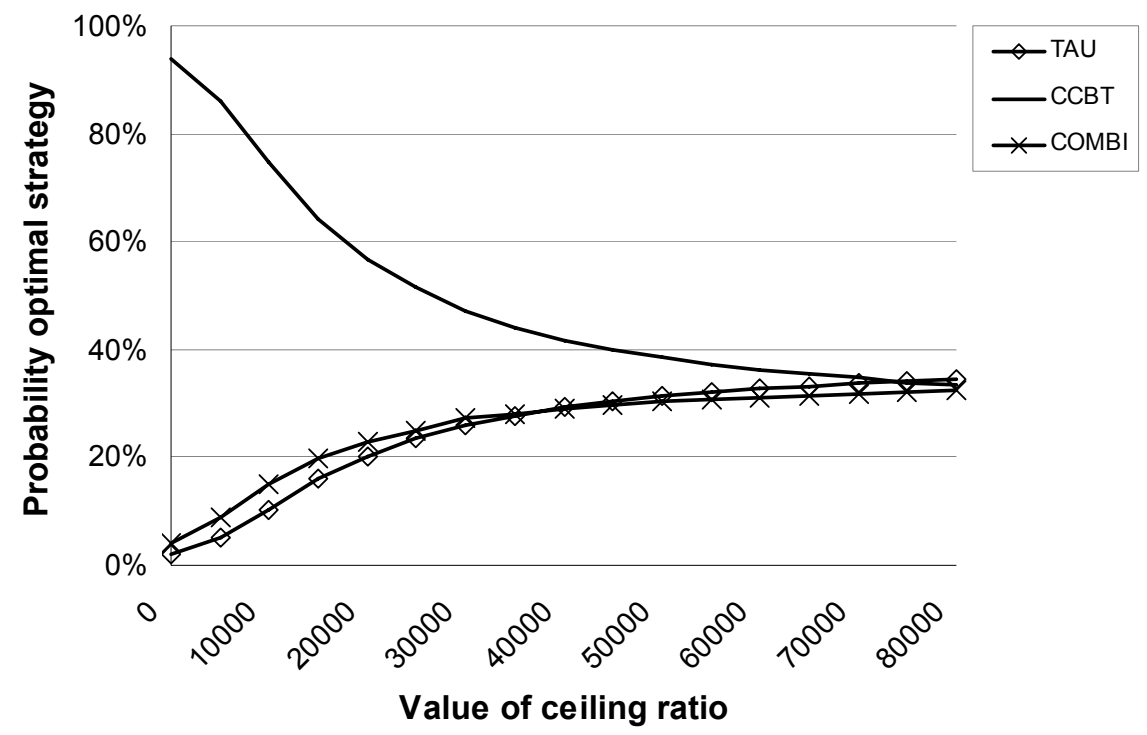

Figure 3: Sensitivity analysis. Cost-effectiveness acceptability curves of the cost-utility with healthcare costs at 12 months follow-up

Note. CCBT, computerised cognitive behavioural therapy; TAU, treatment as usual by a general practitioner; $\mathrm{COMBI}$, combined treatment of both CCBT and TAU. Costs = healthcare costs after regression correction for baseline costs; utility = quality-adjusted life-year (EQ-5D, UK tariff) after regression correction for baseline utilities.

When using clinical effectiveness as outcome measure, most of the sensitivity analyses resulted in minor differences from the CEACs of the base-case analysis at 12 months followup. The variations in societal cost calculation by using different cost for CYL, varying the productivity costs to the human capital approach, varying the use of baseline corrected costs, varying the cost perspective to the health care perspective or varying the time period by 6 months time period resulted in similar CEACs as the base-case analysis at 12 months follow-up. Only varying the outcome measure into the reliable change index of the BDI-II showed differences from the base-case analysis in which costs were related to the absolute change on the BDI-II. As presented in figure 4, CCBT is still the favoured treatment at the lower threshold values. However, the curve of COMBI shows a steeper increase. From a threshold value of $€ 7,000$ onwards, COMBI outperforms CCBT up to $80 \%$ chance of being the most optimal strategy, while CCBT decreases to $20 \%$ at higher threshold values for a patient with a reliable BDI-II change. 


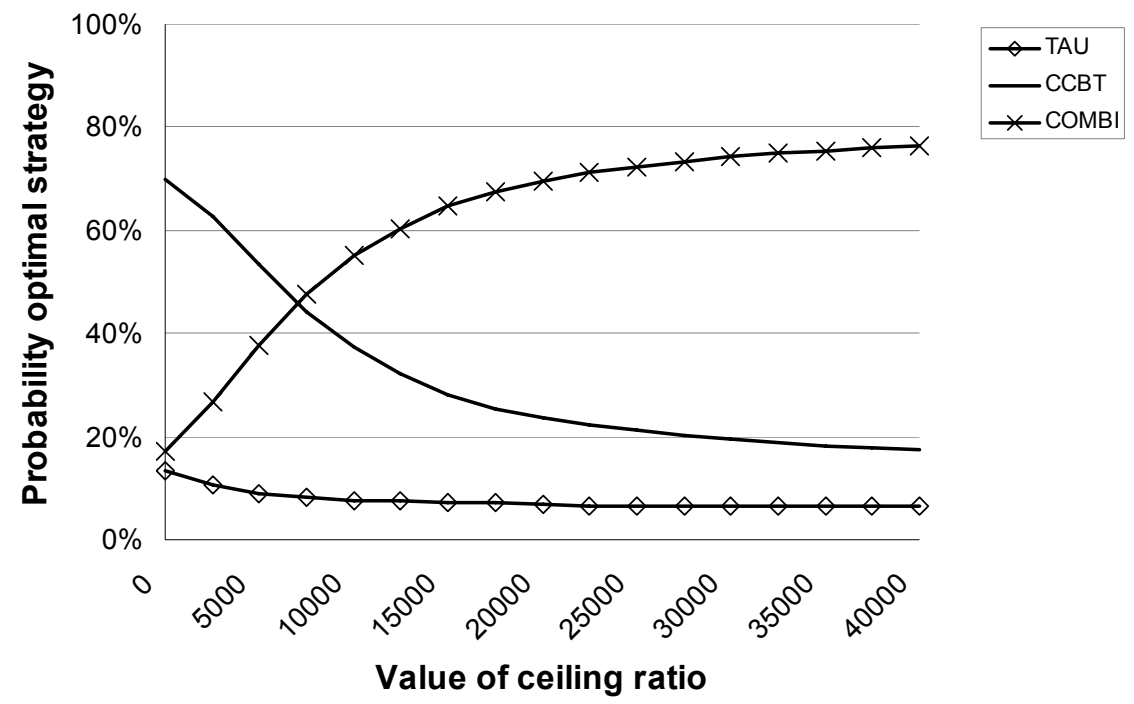

Figure 4: Sensitivity analysis. Cost-effectiveness acceptability curves of the reliable change on the BDI-II at 12 months

Note. CCBT, computerised cognitive behavioural therapy; TAU, treatment as usual by a general practitioner; COMBI, combined treatment of both CCBT and TAU; BDI-II, Beck Depression Inventory II. Costs = societal costs after regression correction for baseline costs; effectiveness = reliable change (i.e. 9 points improvement) on the Beck Depression Inventory II.

\section{Discussion}

\section{Main results}

At first glance, CCBT seems to be the most efficient treatment strategy, as in most costeffectiveness and cost-utility scenarios CCBT has the highest probability of being the most optimal treatment choice.

In all cost-utility analyses, the CCBT treatment turned out to be the most efficient strategy for treatment. The mean societal costs were lowest in this group, while cost-utility CEACs showed that CCBT has the highest probability of being the most efficient treatment strategy compared with $C O M B I$ and TAU. However, when increasing the threshold value for an additional QALY, the difference between CCBT versus TAU and COMBI decreases and in some analyses tends to indifference in the choice between the three treatments in terms of cost-utility.

With probabilities of about $60 \%$ of CCBT being the most efficient treatment choice, the cost-effectiveness analysis using the absolute change on the BDI-II also shows a preference for the CCBT treatment versus TAU and COMBI. However, when evaluating the reliable change on the BDI-II, the COMBI treatment outperforms CCBT at threshold values above $€$ 7,000 per patient achieving reliable change. 
Despite the outcomes of the economic evaluation, there are no statistically significant differences in effectiveness or QALY outcomes, and all three treatments do not seem to achieve much improvement in depression or quality of life during the 12-month follow-up period. However, changing the BDI-II outcome from absolute change to reliable change does have an impact on the cost-effectiveness outcomes. While the BDI-II decreases on average about 10 points per patient in all groups, using the cut-off score of 9 for the reliable change results in $60 \%$ of $\mathrm{COMBI}$ patients with reliable change, compared with about $51 \%$ and $48 \%$ for CCBT and TAU. Although not significant, this difference in reliable change on the BDI-II does seem to be relevant and in favour of the COMBI treatment. Given the high depressive severity of our sample, the differences in reliable change on the BDI-II might not seem surprising. For more severely depressed patients, combination treatments have been found to be superior to single treatments. ${ }^{48,49}$

\section{Previous studies}

Until now, only one study has been published on the cost-effectiveness of CCBT for depression. McCrone et al. ${ }^{15}$ performed a randomised trial in which supported CCBT was compared to usual care for anxiety and depression. In this study, the healthcare costs of CCBT were a little higher as opposed to the healthcare costs of TAU, while our study showed the reverse. This might be explained by differences in the type of intervention. In the study of McCrone, the CCBT program was supported and took place at the GP practice, consequently involving more healthcare costs. In accordance with our study, productivity costs of CCBT were lower compared with the productivity costs of TAU, resulting in TAU being more expensive compared with CCBT.

Contrary to our study, CCBT was clinically superior to TAU and showed higher effect sizes in the McCrone study. ${ }^{15,16}$ In their study, McCrone found that if society is willing to pay only a small amount for increased effectiveness, CCBT has a higher chance of being cost-effective compared with the TAU treatment. Both the McCrone and our study thus seem to be in favour of the CCBT treatment versus TAU in terms of cost-effectiveness.

\section{Methodological considerations}

In this study, we made several assumptions on the calculation and valuation of costs. First of all, the costs of CYL are estimates based on the actual costs of the program, and we decided to calculate costs only for those participants who at least once logged in to the program. Different views on the calculation of CYL costs per patient might exist. At the one hand, one might expect that a patient will have to pay for using the program, or for the time duration using the program. At the other hand, one may also argue that in real-life a patient would have to pay for receiving a login code for the program, regardless of his use of CYL. Moreover, the time costs of patients who followed CYL might have been underestimated. The time spent on CYL was based on the computer-registered login time, and does not include the time a patient might have spent by reflecting on the lessons' content or doing homework tasks offline. On the other hand, the computer-registrations might as well give an overestimation of time spent on CYL as one might as well do other things during the time logged in on CYL. Moreover, we opted not to account for costs of a computer and/or 
Internet. Reason for this is that patients who participated in the trial were required to have a computer at home with a broad-band Internet connection. Consequently, participating in the CYL program should not lead to any additional expenditure on computer or Internet. However, this also means that our study sample is limited to the population of Internet and computer users.

In the recording of cost data, one important difference is that the costs of CYL are based on computer-registered data, while costs of other health care items are based on patientreported care consumption. The latter method might as well have lead to an over- or underestimations of the health care use, as self-reports by patients can be vulnerable to recall error. ${ }^{50}$

In the base-case analysis, we used regression correction for the baseline costs and QALYs. Although utilities did not differ significantly among the patient groups, it is likely that the patient's baseline utility is highly correlated with the QALY outcome. As argued by Manca et al., ${ }^{40}$ controlling for baseline utility is advised to be standard practice in economic evaluations. As shown in our sensitivity analyses, the baseline correction did affect the outcomes of the costs, cost-effectiveness and cost-utility analyses. In the base-case analysis, COMBI is the patient group with highest costs during the 12 months follow-up (COMBI €10,534; TAU $€ 9,765$; CCBT $€ 9,092$ ), while in the sensitivity analysis without correction, it is the TAU treatment that shows the highest mean societal costs per patient (TAU $€ 11,244$; COMBI $€$ $10,793 ;$ CCBT $€ 9,457)$. Although CCBT remained the treatment with the highest probability of being most cost-effective, its probability in the base-case cost-utility analysis was much lower (about 65-40\%) than in the sensitivity cost-utility analysis without correction (70$80 \%$ ). The TAU group has a probability of about $25 \%$ to $40 \%$ in the base-case cost-utility analysis, while in the sensitivity analysis its probability is only about 10 to $20 \%$. These differences in corrected versus uncorrected costs and outcomes stress the importance of taking baseline outcomes into account in economic evaluations.

Evaluating the cost-effectiveness based on reliable change outcomes shows that COMBI outperforms CCBT from a certain point on. However, these outcomes should be considered with caution, as power calculations of the sample size were based on a mean difference in change scores of 5 on the BDI-II. ${ }^{18}$ The reliable change outcome refers to a change of 9 points on the BDI-II, to be able to find reliable differences between the intervention groups, a larger sample size might be required.

In our cost-utility analysis, we interpreted the results at varying monetary threshold values of a QALY up to $€ 80,000$. However, the exact threshold value is unknown, and there are no exact guidelines available in the Netherlands. Several studies on the threshold suggested values of $€ 10,000$ to $€ 27,000$ per QALY, ${ }^{51-53}$ while in general $€ 18,000$ is accepted as the threshold value per QALY for preventive care in the Netherlands. ${ }^{47,54}$ However, the Dutch Council for Public Health and Health Care recommends relating the threshold of the costs of a QALY to the burden of disease, with a limit of $€ 80,000$ per QALY for diseases with a maximum loss in health status. ${ }^{47}$ Despite the absence of a clear guideline, we assume that the chosen range of cost-utility thresholds in our study is broad enough to capture the relevant threshold values.

A last remark concerns the scope of costs included in the analysis. Because of the broad impact depression can have on a patient's life, we chose to include all health-related healthcare, productivity and patient and family costs in the analysis. However, since the 
costs are not limited to depression-related costs, resulting costs are probably an overestimation of the costs due to depression.

Despite the assumptions mentioned above, we believe that one of the strengths of our study is that the main findings were rather robust. In the sensitivity analyses, we tried to capture the uncertainty in the assumptions. Both the base-case analysis and the sensitivity cost-utility analyses indicated a preference for CCBT at a considerable range of costeffectiveness and cost-utility thresholds.

\section{Implications of the study characteristics}

In our sample, the adherence to treatment as well as the clinical effectiveness and change in quality of life were rather low. ${ }^{16}$ In this study, there was no control group receiving no care. One of the questions is whether the changes in clinical effectiveness or quality of life of our participants can be attributed to the treatment received-especially given the low adherence rates-, or whether they reflect the natural course of depression. In the absence of a no-treatment group, it is not clear whether the participants' depression and QALY changes differ from depressed people who do not receive treatment during a 12-month follow-up period. The low adherence to treatment could explain the small differences in costs between the three treatment groups. Possible explanations for the low effect of treatment and the low adherence rate have been suggested elsewhere. ${ }^{16}$

Moreover, BDI-II scores at baseline in our sample were higher than generally seen in depressed primary care patients. ${ }^{55}$ The interventions offered in our study might have been less suited for this patient group. A more intensive and/or supported treatment form might have been justified for this population, and might have generated better outcomes in terms of QALY and clinical effectiveness.

\section{Conclusion}

Differences in costs and outcomes of the three treatment groups are rather small. The costutility and cost-effectiveness analyses tend to be in favour of the CCBT treatment as opposed to the TAU and COMBI treatment. However, the low adherence rate and modest improvements in depression and quality of life outcomes, combined with the severity of depression of our study sample, raises questions on the suitability of this unsupported treatment form for this type of depressed patients.

\section{Acknowledgements}

We thank Annie Hendriks and Greet Kellens for their assistance during the study and Rosanne Janssen for the development of the infrastructure for online data-collection. Thanks to Fons Kessels, Thea van Asselt, Frenk Peeters, John Pletzers, Filip Smit, Marc Koopmanschap, and Jorne Grolleman for their help on specific questions.

The trial is financed by ZonMw (Netherlands Organisation for Health Research and Development; project number 945-04-417), research institute EPP and research institute CAPHRI. Municipalities Eijsden, Meerssen, Sittard-Geleen, Valkenburg and Maastricht sponsored the study. 


\section{References}

1. Bijl RV, Ravelli A, van Zessen G. Prevalence of psychiatric disorder in the general population: Results of the Netherlands Mental Health Survey and Incidence Study (NEMESIS). Soc Psychiatry Psychiatr Epidemiol 1998;33(12):587-595.

2. Bijl RV, Ravelli A. Current and residual functional disability associated with psychopathology: findings from the Netherlands Mental Health Survey and Incidence Study (NEMESIS). Psychol Med 2000;30:657668.

3. Kruijshaar ME, Hoeymans N, Bijl RV, Spijker J, Essink-Bot ML. Levels of disability in Major Depression. Findings from the Netherlands Mental Health Survey and Incidence Study (NEMESIS). J Affect Disord $2003 ; 77(1): 53-64$.

4. Slobbe LCJ, Kommer GJ, Smit JM, Groen J, Meerding WJ, Polder JJ. Kosten van Ziekten in Nederland 2003; Zorg voor euro's - 1 [Costs of illness in the Netherlands 2003]. Bilthoven: Rijksinstituut voor Volksgezondheid en Milieu, 2006.

5. Cuijpers P, Smit F, Oostenbrink J, de Graaf R, Ten Have M, Beekmand A. Economic costs of minor depression: a population-based study. Acta Psychiatr Scand 2007;115:229-236.

6. Sobocki P, Jönsson B, Angst J, Rehnberg C. Cost of Depression in Europe. J Ment Health Policy Econ 2006;9(2):87-98.

7. Stewart WF, Ricci JA, Chee E, Hanh SR, Morganstein D. Cost of lost productive work time among US workers with depression. JAMA 2003;289(23):3135-3144.

8. Luppa M, Heinrich S, Angermeyer MC, König HH, Riedel-Heller SG. Cost-of-illness studies of depression. A systematic review. J Affect Disord 2007;98:29-43.

9. Kendrick T, Chatwin J, Dowrick C, Tuylee A, Moriss R, Peveler R, et al. Randomised controlled trial to determine the clinical effectiveness and cost-effectiveness of selective serotonin reuptake inhibitors plus supportive care, versus supportive care alone, for mild to moderate depression with somatic symptoms in primary care: the THREAD (THREshold for AntiDepressant response) study. Health Technol Assess 2009;13(22):1-159.

10. Butler AC, Chapman JE, Forman EM, Beck AT. The empirical status of cognitive-behavioral therapy: A review of meta-analyses. Clin Psychol Rev 2006;26:17-31.

11. Hollon SD, Stewart MO, Strunk D. Enduring effects for cognitive behavior therapy in the treatment of depression and anxiety. Annu Rev Psychol 2006;57:285-315.

12. Hirschfeld RM, Keller MB, Panico S, Arons BS, Barlow D, Davidoff F, et al. The National Depressive and Manic-Depressive Association consensus statement on the undertreatment of depression. JAMA 1997;277(4):333-340.

13. Kaltenthaler E, Brazier J, De Nigris E, Tumur I, Ferriter M, Beverly C, et al. Computerised cognitive behaviour therapy for depression and anxiety update: a systematic review and economic evaluation. Health Technol Assess 2006;10(33):1-186.

14. National Institute for Health and Clinical Excellence. Computerised cognitive behaviour therapy for depression and anxiety. Review of Technology Appraisal 51: NICE, 2006.

15. McCrone P, Knapp M, Proudfoot J, Ryden C, Cavanagh K, Shapiro DA, et al. Cost-effectiveness of computerised cognitive-behavioural therapy for anxiety and depression in primary care: randomised controlled trial. Br J Psychiatry 2004;185:55-62.

16. de Graaf LE, Gerhards SAH, Arntz AR, Riper H, Metsemakers JFM, Evers SMAA, et al. Clinical effectiveness of online computerised cognitive behavioural therapy without support for depression in primary care: a randomised trial. Br J Psychiatry 2009;195(1):73-80.

17. Van der Does AJW. De Nederlandse versie van de Beck Depression Inventory - second edition (BDI-II-NL): Handleiding [The Dutch version of the Beck Depression Inventory - second edition (BDI-II-NL): Manual]. Enschede: The Psychological Corporation, 2002.

18. de Graaf LE, Gerhards SAH, Evers SMAA, Arntz AR, Riper H, Severens JL, et al. Clinical and costeffectiveness of computerised cognitive behavioural therapy for depression in primary care: design of a randomised trial. BMC Public Health 2008;8:224.

19. Riper H, Kramer JJAM. Online zelfhulpcursus www.kleurjeleven.nl. Utrecht: Trimbos-institute, 2004. 
20. СВО. Multidisciplinaire richtlijn depressie: richtlijn voor de diagnostiek en behandeling van volwassen cliënten met een depressie [Multidisciplinary guideline depression: guideline for diagnostics and treatment of adult depression clients]. Utrecht: Trimbos-instituut, 2005.

21. Nederlands Huisartsen Genootschap. NHG-Standaard Depressieve stoornis (depressie) [Dutch College of General Practitioners - Practice guidelines depressive disorder (depression)]. Utrecht, 2003.

22. Drummond MF, Sculpher MJ, Torrance GW, O'Brien B, Stoddart GL. Methods for the Economic Evaluation of Health Care Programmes. Oxford: Oxford University Press, 2005.

23. Oostenbrink JB, Bouwmans CAM, Koopmanschap MA, Rutten FFH. Handleiding voor kostenonderzoek: Methoden en standaard kostprijzen voor economische evaluaties in de gezondheidszorg (Geactualiseerde versie 2004) [Dutch manual for costing: Methods and standard costs for economic evaluations in health care (actualized version 2004)]. Diemen: College voor Zorgverzekeringen, 2004.

24. Oostenbrink JB, Koopmanschap MA, Rutten FFH. Standardisation of Costs. The Dutch Manual for Costing in Economic Evaluations. Pharmacoeconomics 2002;20(7):443-454.

25. Koopmanschap MA. PRODISQ: a modular questionnaire on productivity and disease for economic evaluation studies Expert Review of Pharmacoeconomics and Outcomes Research 2005;5(1):23-28.

26. Koopmanschap M, Meerding WJ, Evers S, Severens J, Burdorf A, Brouwer W. Handleiding voor het gebruik van PRODISQ versie 2.1 [Manual for the use of PRODISQ version 2.1]. Rotterdam/Maastricht: Erasmus MC - Instituut voor Medical Technology Assessment, Instituut Maatschappelijke Gezondheidszorg, Universiteit van Maastricht - Beleid Economie en Organisatie van de Zorg 2004.

27. Koopmanschap MA, Rutten FFH, van Ineveld BM, van Roijen L. The friction cost method for estimating the indirect costs of disease. J Health Econ 1995;14:171-189.

28. College voor Zorgverzekeringen. Farmacotherapeutisch kompas 2008 [Pharmacotherapeutic Compass 2008]. Diemen: College voor Zorgverzekeringen, 2007.

29. Beck AT, Steer RA, Ball R, Ranieri WF. Comparison of Beck Depression Inventories-IA and -II in psychiatric outpatients. J Pers Assess 1996;67(3):588-597.

30. Arnau RC, Meagher MW, Norris MP, Bramson R. Psychometric Evaluation of the Beck Depression Inventory-II With Primary Care Medical Patients. Health Psychol 2001;20(2):112-119.

31. EuroQol Group. EuroQol - a new facility for the measurement of health-related quality of life. Health Policy 1990;16(3):199-208.

32. Brazier J, Usherwood T, Harper R, Thomas K. Deriving a Preference-Based Single Index from the UK SF-36 Health Survey. J Clin Epidemiol 1998;51(11):1115-1128.

33. Brooks R. EuroQol: the current state of play. Health Policy 1996;37(1):53-72.

34. Dolan P. Modeling valuations for EuroQol health states. Med Care 1997;35(11):1095-1108.

35. Lamers LM, McDonnell J, Stalmeier PFM, Krabbe PFM, Busschbach JJV. The Dutch tariff: results and arguments for an effective design for national EQ-5D valuation studies. Health Econ 2006;15:1121-1132.

36. Brazier J, Roberts J, Deverill M. The estimation of a preference-based measure of health from the SF-36. $J$ Health Econ 2002;21:271-292.

37. Brazier JE, Roberts J. The Estimation of a Preference-Based Measure of Health From the SF-12. Med Care 2004;42(9):851-859.

38. Briggs AH, Wonderling DE, Mooney CZ. Pulling cost-effectiveness analysis up by its bootstraps: a nonparametric approach to confidence interval estimation. Health Econ 1997;6(4):405-415.

39. van Asselt ADI, van Mastrigt GAPG, Dirksen CD, Arntz A, Severens JL, Kessels AGH. How to deal with cost differences at baseline. Pharmacoeconomics 2009; 27(6): 519-528.

40. Manca A, Hawkins N, Sculpher MJ. Estimating mean QALYs in trial-based cost-effectiveness analysis: the importance of controlling for baseline utility. Health Econ 2005;14:487-496.

41. Brunenberg DE, van Steyn MJ, Sluimer JC, Bekebrede LL, Bulstra SK, Joore MA. Joint Recovery Programme Versus Usual Care. An Economic Evaluation of a Clinical Pathway for Joint Replacement Surgery. Med Care 2005;43(10):1018-1026.

42. Jacobson NS, Truax P. Clinical significance: a statistical approach to defining meaningful change in psychotherapy research. J Consult Clin Psychol 1991;59(1):12-19.

43. Stinnett AA, Mullahy J. Net Health Benefits: A New Framework for the Analysis of Uncertainty in CostEffectiveness Analysis. Med Decis Making 1998;20(1):S68-S80. 
44. Briggs AH. Handling uncertainty in economic evaluation and presenting results. In: M. D, A. M, eds. Economic evaluation in health care; merging theory with practice. Oxford: Oxford University Press, 2001.

45. Fenwick E, O’Brien BJ, Briggs A. Economic Evaluation. Cost-effectiveness acceptability curves - facts, fallacies and frequently asked questions. Health Econ 2004;13(5):405-415.

46. Fenwick E, Claxton K, Sculpher M. Representing uncertainty: the role of cost-effectiveness acceptibility curves. Health Econ 2001;10:779-787.

47. Raad voor de Volksgezondheid en Zorg. Zinnige en duurzame zorg [Sensible and Sustainable Care]. Zoetermeer, 2006.

48. Pampallona S, Bollini P, Tibaldi G, Kupelnick B, Munizza C. Combined pharmacotherapy and psychological treatment for depression. Arch Gen Psychiatry 2004;61:714-719.

49. Friedman MA, Detweiler-Bedell JB, Leventhal HE, Horne R, Keitner GI, Miller IW. Combined psychotherapy and pharmacotherapy for the treatment of major depressive disorder. Clinical Psychology: Science and Practice 2004;11(1):47-68.

50. van den Brink $M$, van den Hout WB, Stiggelbout AM, van de Velde $\mathrm{CJH}$, Kievit J. Cost Measurement in Economic Evaluations of Health Care. Whom to Ask? Med Care 2004;42(8):740-746.

51. Gyrd-Hansen D. Willingness to pay for a QALY. Health Econ 2003;12:1049-1060.

52. King JT, Tsevat J, Lave JR, Roberts MS. Willingness to Pay for a Quality-Adjusted Life Year: Implications for Societal Health Care Resource Allocation. Med Decis Making 2005;25:667-677.

53. Laupacis A, Feeny D, Detsky AS, Tugwell PX. How attractive does a new technology have to be to warrant adoption and utilization? Tentative guidelines for using clinical and economic evaluations. CMAJ 1992;146(4):473-481.

54. Casparie AF, van Hout BA, Simoons ML. Richtlijnen en kosten [Guidelines and costs]. Ned Tijdschr Geneeskd 1998;142(38):2075-2077.

55. Vuorilehto M, Melartin TK, Rytsälä HJ, Isometsä E. Do characteristics of patients with major depressive disorder differ between primary and psychiatric care? Psychol Med 2007;37:893-904. 


\section{Chapter 4}

\section{Improving adherence and effectiveness of computerised cognitive behavioural therapy without support for depression: a qualitative study on patient experiences}

Gerhards SAH, Abma TA, Arntz A, de Graaf LE, Evers SMAA, Huibers MJH, Widdershoven GAM

In press in Journal of Affective Disorders 2010; doi:10.1016/j.jad.2010.09.012. 


\section{Abstract}

Background: Several studies have evaluated the efficacy and effectiveness of computerised cognitive behavioural therapy (CCBT) for depression, but research on the patient perspective is limited.

Aims: To gain knowledge on patient experiences with the online self-help CCBT program Colour Your Life (CYL) for depression, and find explanations for the low treatment adherence and effectiveness.

Method: Qualitative data were collected through semi-structured interviews with 18 patients. Interviewees were selected from a CCBT trial. An inductive, content analysis of the interviews was performed.

Results: The main theme throughout the interviews concerns barriers and motivators experienced with CCBT. The most important barriers included experiences of a lack of identification with and applicability of CCBT-CYL, lack of support to adhere with the program or to gain deeper understanding, and inadequate computer/Internet skills, equipment, or location. Confusion between CCBT and Internet questionnaires resulted in no CCBT uptake of some study participants. Motivators included experiencing selfidentification and improvement through CCBT-CYL, participating in a scientific study, and the freedom and anonymity associated with online computer self-help. The addition of support to CCBT was suggested as an improvement towards adherence and the course content.

Conclusion: The CCBT program CYL in its current form does not work for a large group of people with depressive symptoms. More tailoring, the provision of support (professional or lay) and good computer conditions could improve CCBT. 


\section{Background}

Depression is a highly prevalent mental health problem in the general population, ${ }^{1}$ with a substantial impact on quality of life ${ }^{2,3}$ and societal costs. ${ }^{4}$ However, many depressed patients in primary care do not receive the care they need. Pharmacotherapy is not always an adequate treatment option: Many patients refuse medication or comply poorly, ${ }^{5}$ and there is only little evidence on the effectiveness of pharmacotherapy for patients suffering from a mild to moderate depression. ${ }^{6,7}$ Psychological treatments in primary care are scarce and costly. ${ }^{8}$ An alternative, more feasible treatment in primary care might be computerised cognitive behavioural therapy (CCBT). Several studies have evaluated the efficacy and effectiveness of CCBT for depression in randomized trials. ${ }^{9-12}$ However, research on the patient perspective of CCBT for depression is limited. In their systematic review, Kaltenthaler et al. ${ }^{13}$ underline the importance of including qualitative studies alongside trials to determine patient acceptability. Previous studies indicate that many study participants allocated to CCBT treatment do not start CCBT. ${ }^{14}$ However, little is known on barriers to CCBT uptake. ${ }^{14}$ Former qualitative research on depression treatment has focused on the patient experience of guided self-help in primary mental health care ${ }^{15}$ and of CBT delivered 'live' online by a psychologist. ${ }^{16}$ But to our knowledge, no previous qualitative research has been conducted on the patient experience of pure self-help online CCBT for depression.

In our CCBT trial, the (cost-)effectiveness of pure self-help online CCBT for depression in primary care was evaluated. ${ }^{17-19,31}$ Results of this trial showed only moderate improvements in depression, ${ }^{17,31}$ and the adherence to treatment was low (only $20 \%$ of all participants receiving log-in codes completed all CCBT sessions, $46 \%$ completed half of the program sessions). ${ }^{32}$ Several explanations for these outcomes have been suggested: it can be either due to characteristics of the patient sample, the way of treatment delivery, or the intervention itself. ${ }^{17}$ In the present study, we used qualitative interviews with trial participants to explore these suggestions. Our research questions were: 1) Why did many participants fail to complete CCBT treatment? 2) How did participants experience CCBT?

\section{Method}

\section{Design of the trial}

Interview participants were recruited from our trial population. Trial inclusion criteria were: age 18-65; at least mild to moderate depressive symptoms (score $\geq 16$ on the Beck Depression Inventory II (BDI-II)); duration of depressive symptoms 3 months or more; no current psychological treatment for depression; no continuous antidepressant treatment for at least 3 months prior to entry; fluent in Dutch language; no alcohol or drug dependence; and no severe psychiatric co-morbidity. Participants were randomly allocated to 1) CCBT, or 2) treatment as usual by a GP (TAU), or 3 ) a combination of both CCBT and TAU (COMBI). Further details on the trial have been described elsewhere. ${ }^{17,18}$ 


\section{Interventions}

CCBT is based on the principles of cognitive behavioural therapy. The CCBT program in our trial (named "Colour Your Life" (CYL)) is an online, multimedia, interactive computer program for depression. The program consists of eight weekly sessions and a ninth booster session. Each session contains video fragments to illustrate the theory. In total, 13 homework-assignments are given. The program offers the option to keep a 'mood diary'. CCBT was offered as a self-help intervention, no professional assistance was offered. Patients could reach the program wherever they had a computer with Internet access. The usage and acceptability of the CCBT program have been presented elsewhere. ${ }^{32}$

Participants in the COMBI group were also advised to contact their own GP for depression treatment. GPs were recommended to follow the depression guideline of the Dutch College of General Practitioners. ${ }^{20}$

\section{Selection of participants for the qualitative study}

Interview participants were recruited from the CCBT and COMBI groups of the trial. The selection of interview participants was based on maximal variation to get as many perspectives as possible. ${ }^{21}$ Participants were selected, based on age, sex, treatment group (CCBT/COMBI), time period between the inclusion in the research project and the moment of the interview, and adherence to CCBT. The selection was done by assessing which trial participants fulfilled certain characteristics according to the maximal variation principle. Potential participants were contacted and informed by phone. If willing to cooperate, the participant received an information letter and an appointment was made for an interview at home or at the university.

\section{Participants}

Table 1 shows the characteristics of the 18 interview participants, compared with the trial sample consisting of 200 participants. Based on the socio-demographic characteristics and $\mathrm{BDI}-\mathrm{Il}$ scores, the interviewees seem rather representative for the trial population. 
Table 1: Characteristics of the interview participants versus trial sample

\begin{tabular}{|c|c|c|}
\hline & $\begin{array}{l}\text { Interview participants } \\
\mathrm{n}=18\end{array}$ & $\begin{array}{l}\text { Trial sample } \\
\mathrm{n}=200\end{array}$ \\
\hline \multicolumn{3}{|l|}{ Treatment group } \\
\hline CCBT, \% (nr) & $50,0(9)$ & $50,0(100)$ \\
\hline COMBI, \% (nr) & $50,0(9)$ & $50,0(100)$ \\
\hline \multicolumn{3}{|l|}{ Socio-demographic characteristics } \\
\hline Sex, male, \% (nr) & $50,0(9)$ & $42,5(85)$ \\
\hline Age, mean (sd) & $43,6(14,5)$ & $44,7(11,3)$ \\
\hline \multicolumn{3}{|l|}{ Education* } \\
\hline Low, \% (nr) & $5,6(1)$ & $17,5(35)$ \\
\hline Medium, \% (nr) & $66,7(12)$ & $53,5(107)$ \\
\hline High, \% (nr) & $22,2(4)$ & $26,0(52)$ \\
\hline Other/unknown, \% (nr) & $5,6(1)$ & $3,0(6)$ \\
\hline \multicolumn{3}{|l|}{ Partner* } \\
\hline Yes, \% (nr) & $77,8(14)$ & $71,5(143)$ \\
\hline No, \% (nr) & $16,7(3)$ & $26,0(52)$ \\
\hline Other/unknown,\% (nr) & $5,6(1)$ & $2,5(5)$ \\
\hline Paid employment, yes, \% (nr) & $61,1(11)$ & $58,0(116)$ \\
\hline \multicolumn{3}{|l|}{ Depression characteristics } \\
\hline \multicolumn{3}{|l|}{ Depression severity (BDI-II; range $0-63$ ) at } \\
\hline Baseline, mean (sd) & $26,5(8,47)$ & $27,8(7,98)$ \\
\hline 2 months, mean (sd) & $17,5(10,44)$ & $21,5(10,23)$ \\
\hline 3 months, mean (sd) & $18,3(12,55)$ & $20,3(11,03)$ \\
\hline 6 months, mean (sd) & $18,4(10,27)$ & $18,1(11,50)$ \\
\hline 9 months, mean (sd) & $15,9(12,60)$ & $17,5(12,28)$ \\
\hline 12 months, mean (sd) & $16,1(13,19)$ & $17,2(11,46)$ \\
\hline \multicolumn{3}{|l|}{ Adherence to CCBT } \\
\hline \multicolumn{3}{|l|}{ CCBT uptake and completion } \\
\hline Did not start, \% (nr) & $16,7(3)$ & $26,0(52)$ \\
\hline Start but did not finish, \% (nr) & $38,9(7)$ & $54,0(108)$ \\
\hline Completed, \% (nr) & $44,4(8)$ & $20,0(40)$ \\
\hline \multicolumn{3}{|l|}{ The interview } \\
\hline \multicolumn{3}{|l|}{ Period between baseline $\&$ interview } \\
\hline$<6$ months, $\%$ (nr) & $33,3(6)$ & \\
\hline 6-12 months, \% (nr) & $27,8(5)$ & \\
\hline$>12$ months, $\%$ (nr) & $38,9(7)$ & \\
\hline \multicolumn{3}{|l|}{ Location } \\
\hline At home, \% (nr) & $55,6(10)$ & \\
\hline At University, \% (nr) & $44,4(8)$ & \\
\hline
\end{tabular}

Note. CCBT, computerised cognitive behavioural therapy; COMBI, combination of CCBT and treatment as usual by a general practitioner; BDI-II, Beck Depression Inventory II.

Figure 1 shows the CCBT adherence of the interview participants. Out of 18 interviewees, 8 had completed all CCBT sessions (completers, COM). Among the 10 non-completers, 3 had never started CCBT nor changed to another form of help (non-starters, NOS), while 7 interviewees had started CCBT. Among these 7 interviewees, 3 experienced CCBT as inconvenient and therefore changed to another form of help for depression symptoms (noncompleter receiving other help, $\mathrm{NOH}$, being face-to-face therapy or participation in a spiritual group), while 4 interviewees did not (non-completer no other help, NON). 


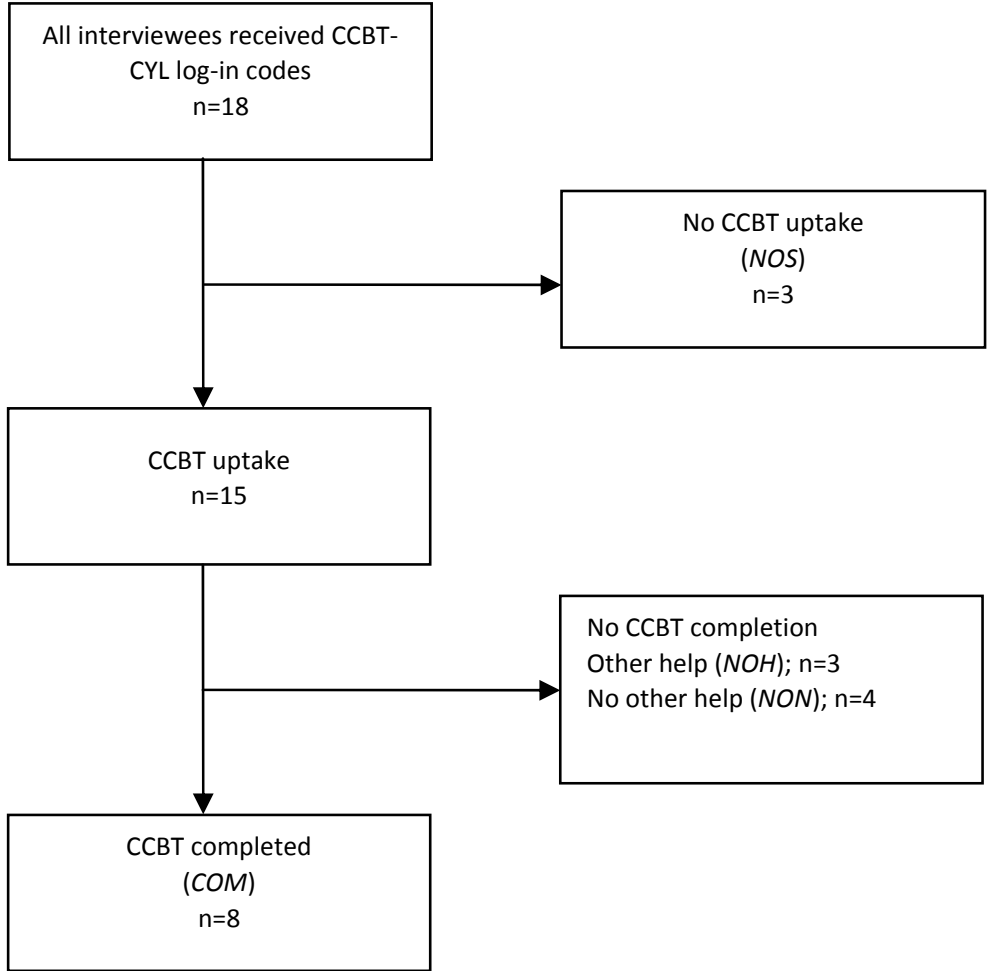

Figure 1: CCBT adherence, flow of the interview participants

\section{The qualitative study}

Qualitative data were collected through semi-structured interviews, with open questions guided by a topic list, between April 2007 and June 2008. The initial topic list was based on issues derived from the research team's experiences with the trial participants using CCBT. After three pilot interviews the initial topic list was adjusted according to relevant emergent topics in the interviews. The average duration of an interview was approximately 55 minutes.

Topic list

The questions in the interview were guided by a topic list. The final topic list covered the following items:

(1) motivators and barriers towards treatment and/or participation in the trial;

(2) recognition of the depressive complaints;

(3) the CCBT/COMBI treatment content, preference, adherence, experience and location (at home versus in a professional's practice);

(4) experienced changes in complaints and factors related to this change;

(5) needs and advices to improve CCBT;

(6) (for participants who were allocated to COMBI) the additional role of TAU next to CCBT, and the contact with the GP;

(7) other depression treatments considered/received, either in the past or next to the current treatment;

(8) the (need for) involvement of the social environment in the complaints and treatment; and

(9) the experience of research activities. 


\section{Analysis}

All interviews were audio-recorded and transcribed. Anonymity was assured by using fictive names and places. A 'member check' was performed: each interviewee received a summary of the transcript of the interview, highlighting the topics identified for further analysis. To check the validity, the interviewee was asked whether he/she agreed with the text. ${ }^{21,22}$ One interviewee did not respond to the member check; it was assumed that this interviewee agreed upon the text.

An inductive, content analysis of the interviews was performed in line with the Grounded Theory approach. ${ }^{23}$ First, the entire interview was read to identify emerging themes and subthemes. Labels were attached to text parts related to a specific (sub)theme. Each interview was first analysed separately. New emerging themes were added to the process of labelling and also adopted to the interviews analysed previously. Next, the data of the different interviews were grouped into clusters based on the main emerging (sub)themes in the interviews. The quotations of different interviewees were compared and citations were identified per theme. To gain further insight into reasons for (non-)adherence to treatment, participants who completed CCBT (completers) were compared to those who did not complete treatment (non-completers). The interviews were performed and analysed by the main researcher (SG). We also used check-coding, meaning that more researchers (i.e. two researchers TA \& GW) were involved in the process of data analysis. ${ }^{21}$

\section{Results}

The main emerging themes of the interviews were the barriers and motivators experienced with CCBT (see figure 2 for an overview). The barriers and motivators were related to the course content and to contextual factors (i.e. social aspects, computer aspects and research aspects). The interviewees' experiences with the course and context are illustrated with quotations, each quotation having a participant identifier, indicating the program and the CCBT compliance (COM, NOH, NON, NOS). Since the experiences of CCBT and COMBI interviewees were similar, the results are not split up between these two groups. 


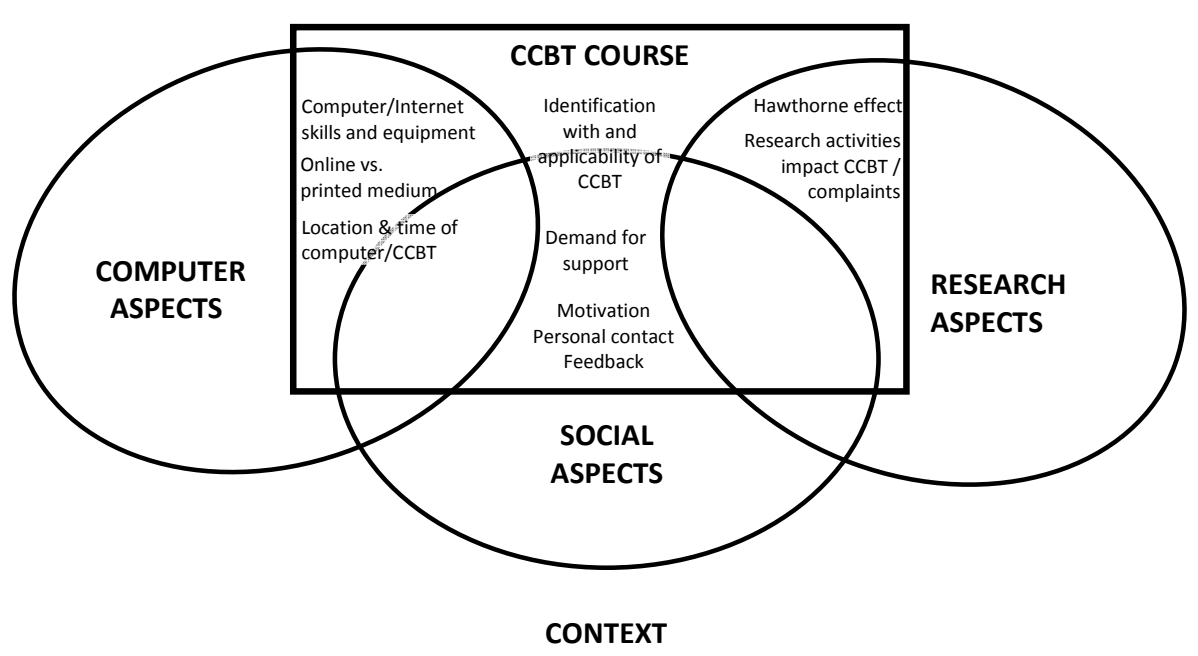

Figure 2: Course and context as motivators and barriers

\section{Experiences of the course content}

An important aspect in the experience with CCBT is to what extent the course is adjusted to the patient's situation. In general, the interviewees experienced the course content positively. The sessions provided them with useful information to create more awareness of the symptoms, and on how their thinking and doing are interrelated with the depression symptoms.

I have noticed that there are many ups and downs in the way you feel. (COMBI05, COM)

It just cleared up a whole lot of things, the course (...) It made me think a bit. (ССВT03, СОM)

I know now how I can keep an eye on my mood. (CCBT10, NON)

Being able to apply the course to one's own situation was generally experienced positively. As such, experiencing self-identification and improvement through CCBT-CYL, was a motivator towards adherence.

That [the theory] was the stimulus to carry on, that it was serious enough because you recognize enough things in yourself, and therefore carry on. (COMBIO5, COM)

And then I started to link the examples in the films to myself, and think about how I could make things better. It kept me occupied the whole week and then I noticed that I felt a bit better and that motivated me to follow the next lesson. (COMBIO7, COM)

For some users, the CCBT-CYL program created curiosity about the next sessions.

Every week I thought it was exciting: like "what are we going to do now?" (COMBIO3, COM) 
However, the examples provided in the sessions, the homework assignments and the mood diary are experienced as either positive or negative. While some interviewees experienced the mood diary as the most essential part of the course for creating awareness, others experienced it as a burden.

I think that I've probably gained more from the mood diaries than from the whole course up until now. (...) Why is it (...) that I get up in a good mood in the morning and then an hour later I'm suddenly in a bad mood. How come? (COMBIO1, NON)

I just thought: I'm just torturing myself, I've had enough, I don't want this anymore (...). To write this feeling down and then at the end of the day to think about how I felt. It made me even more depressed so I just let it go. (CСBTO3, COM)

Many CCBT users had difficulties in translating and applying the homework assignments to their own social situation. The film fragments were partly experienced as good, recognizable examples. However, some CCBT users experienced these examples as incomparable to their own lives, which did not provide appropriate solutions for them personally.

This is distant enough to be used as a mirror, and because it's the same people in the films each time this also gives a feeling of familiarity. (COMBIO6, COM)

Go and find friends. I haven't got any friends (laughs), I don't need any friends. (...) Not for me, the examples were nice. Nice okay, but not for me. (CCBTO2, NON)

The little things that make people depressed, as examples. Making me think "man stop moaning about it and try and get over it". (CCBTO7, COM)

They try to brighten people up with material things. I thought that was a pity, that there was nothing else that could put you in a better mood (...) If I buy something than I only feel better for a moment and then it's gone. Therefore it doesn't really solve the problem. I found that a bit short-sighted. (CCBT10, NON)

Due to negative experiences with some components (e.g. homework or mood diary), completers did not necessarily use all the components of each course session. These completers tailored the CCBT program to their own situation by selecting only those components experienced as beneficial.

The most important thing for me was the theory and I did that in my own way, I did something with it (...) and to also fill in a diary and make tasks, that was too much for me. (COMBIO5, COM)

But negative experiences could also result in not completing the course.

The problem was that the whole computer course didn't fit in with my problems and my feelings. There were often things that I never had any problem with, then I thought this has nothing to do with me and I don't think that I followed the last lessons if I'm honest. Because I just had the feeling that it didn't help me. (CCBT05, $\mathrm{NOH})$

The abovementioned positive and negative aspects of the CCBT content were reported in both groups of CCBT completers and non-completers. However, completers seemed to have more often a positive experience with $\mathrm{CCBT}$, while the inability to identify and apply 
the course content seemed to occur relatively more among the non-completers. Almost all completers experienced an improvement in their depression symptoms which was partly attributed to CCBT and partly to other aspects (e.g. changes in work, at home). Noncompleters who changed to other help did not attribute improvements in symptoms to CCBT. Finally, all non-completers who did not seek other help, reported that they had not experienced a significant improvement.

\section{Computer aspects}

CCBT-CYL requires working on a computer on the Internet. Throughout the interviews, several computer aspects emerged to be important issues for the users including computer/Internet skills and equipment, the location and time of computer/CCBT access, and the reading of an online versus a printed medium.

Not everyone is used to computer work, or has a fast-working computer or Internet connection. Difficulties with computer work were experienced as frustrating, especially when it comes to difficulties in saving homework assignments or mood diaries.

I'm not that great with the computer. Things kept going wrong in the program or something, I don't know. And then I lost everything in the diary that I had just filled in. I was so frustrated that I just thought: I'm not going to do it anymore. (CСBTO3, COM)

In the first weeks, it was so difficult then. I'm not so handy in (shows with hands typing movements). And that's where it begins (CCBTO2, NON)

Moreover, an inconvenient computer location could endanger the experienced accessibility and required privacy to follow the course.

My computer always stood here on the table (...) It was always within reach. But meanwhile we now have a laptop. (...) I only open my post, and do nothing more on the computer. (CCBTO1, NON)

I often argue with my wife. We have a computer and that's in the living room. Everything that I do she can see and I don't like that. So I could only do that program when she was gone. (CCBTO2, NON)

Some interviewees pointed to positive and/or stimulating aspects of doing a therapy in your own time, sitting behind your own home computer. These aspects concerned freedom, enjoying computer work, anonymity and being yourself.

You could make up your own mind when you did something and for how long and what you do. And you're completely free to do whatever you want. (CCBTO3, COM)

The ability to solve it yourself, I think that's a big advantage of such a course. That you can do it in your own way. If you go to the doctor then you have to make an appointment. You go away for a while; if you get a visitor he will hear straightaway where you have gone (...) Whilst with the course, if someone comes in than you push the page away and then later on you just carry on. (COMBIO5, COM) 
If I should go to someone else or go somewhere, than I act differently than when I'm alone in my own surroundings. Here I drop my mask. And I only had that when I sat alone behind the computer, this is me, this is how I feel, and I experience it like this. (CCBTO1, NON)

Holding on to a regular rhythm was sometimes reported as a motivator towards treatment adherence.

I liked it that there was a schedule, a rhythm. Also for yourself. (COMBI05, COM)

Although the program was experienced as clearly written, many interviewees preferred to also have a printed summary version of the course content which was easier to revive as the online version.

I printed everything. (...) And I notice that I pick it up quicker to glance through it again. Easier than the computer and also easier than that book from the last course. (ССBTO3, СOM)

A summary of it all, in a way that you can easily print out. That you have for yourself in any case a sort of checklist of the main points. That is really what I miss. (COMBI05, COM)

The program enables to retrace the items handled in the previous sessions. Some interviewees experienced this as an advantage.

But the course, you can look back on it, you can look and see what it was like again? What did they say there? (COMBIO4, COM)

They gave examples. Of nice things to do, they gave 25 examples. And I like having that list (...) I want to read: 'What must I do?" That really stimulates me. (CCBTO2, NON)

Thus, for an optimal CCBT usage, it is important that the user possesses the right computer skills and equipment.

\section{Social aspects}

Many interviewees reported a preference or need for some kind of support to complete CCBT successfully. The demand for support took three different forms: the main reason for wanting support was to create sufficient discipline to adhere to CCBT.

You haven't really got someone or something forcing you (...) I really need that. I either put it off or I just don't look at it (...) If you're in a bad mood then you really don't feel like it. Yes, that is motivation. Someone should say to me "you have to do it". (CCBTO4, NOH)

Someone who wants to be treated, should just keep to the rules. If you leave it to the patient themselves than they will look for the easiest way. (CCBT10, NON)

Next to self-discipline, a second reason for wanting support was to have personal contact.

I think that that [personal talks] is not so easy to put off. That I put it off less easily.

(...) I think that it is nicer if (...) you can exchange ideas. (CCBT01, NON) 
I need to be with people, I can't just be alone behind my computer screen. (CСBTO9, $\mathrm{NOH})$

Thirdly, some interviewees preferred feedback or wanted to go more in depth into the course through personal support.

That thing doesn't talk back, (...) I haven't got any contact with it. Whereas when I talk to you, then you react, and then you straightaway reach a much deeper level than with the computer. (CCBTO7, COM)

You can't judge whether or not you're doing good. I find that difficult (...) I think that the most important thing is, that you can just ask a question like am I doing it right. Just a bit of confirmation that is actually the only thing. (COMBIO6, COM)

Nearly all non-completers who followed at least one CCBT session indicated a preference or need for support. But also some of the completers preferred some kind of support or argued that other CCBT users could need support. A last finding on support was that the group of $\mathrm{COM}$ and $\mathrm{NOH}$ interviewees differed from the NON interviewees in the experienced support of the social environment. Interviewees from the first group nearly all reported possibilities to discuss their depression symptoms with someone in the near social environment, while nearly all interviewees from the second group did not report this experience. This finding suggests that the near social environment influences depression treatment.

\section{Research aspects}

Research aspects had an unintended motivating impact on treatment adherence. During the trial study, several research activities took place: the screening process consisted of an invitation letter, Internet questionnaires and a face-to-face screening. After inclusion, the participant monthly received Internet questionnaires and reminder e-mails. If a participant failed to fill in the questionnaire, he/she was contacted by phone. Although these activities were no part of CCBT, this distinction between research activities and CCBT was often experienced as less strict. Moreover, there might have been a Hawthorne effect of the research activities, since participating in our trial study might have changed the participant's behaviour.

Firstly, some interviewees would not have had treatment or not have been to the GP if not invited for research participation. The interviews showed several reasons for this finding: the interviewee experienced no need to receive a treatment for the symptoms, or did not want to go to a GP or receive medication for the depression symptoms.

I just didn't think that it was so bad to get treatment for it: "go to the doctor about this, no need". (CСBTO3, COM)

In other cases, the interviewee was not aware of the depression symptoms prior to the research participation. One participant also mentioned a lack of time as the reason for not seeking help on her own. 
Secondly, the fact that CCBT was offered as part of a study was often experienced as stimulating to follow or continue CCBT and/or filling in the questionnaires. This impact varied from routine external discipline to the obligation felt to join the study.

If I take part then I do it wholeheartedly. In the name of science I owe this to them. (COMBI06, COM)

For one interviewee the impact was situated in the belief that CCBT must be good since it is developed by experts as part of a scientific study.

I thought this is something where experts are busy with, something valuable should come out of it. You mustn't just let that pass, therefore I wanted to just finish the lessons. (CCBT10, NON)

Thirdly, the face-to-face screening and the Internet questionnaires were sometimes experienced as part of the treatment. Sometimes, the impact was directly visible: two interviewees confused CCBT with the Internet questionnaires. They thought that the questionnaires were CCBT.

I thought that the computer program was the questionnaire, and the doctor. So however, I read it I thought computer program and doctor. That was it for me: questionnaire and doctor. (COMBIO2, NOS)

But most of the time, the impact emerged rather through the experiences participants expressed regarding the questionnaire and the screening. Screening aspects were often experienced as consciousness-raising or confronting with the depression symptoms.

I found it extremely tiring. You notice that you are not yet over certain things. That there are a lot of things that annoy you unconsciously and annoy you because you haven't done anything with it. (CCBTO1, NON)

The monthly questionnaires were experienced as a reflection on the symptoms. This reflection could work both positively or negatively on the participant's feelings.

When you fill in the questions you notice at a certain time that you aren't on the bottom anymore (...) and that helps you at a certain moment to notice that you are climbing out of it. (COMBIO6, COM)

Then you think that they are all the same questions. Apart from the fact that I don't really think about suicide anymore, it is really the same. (...) If I see that it doesn't really make any difference? Not very motivating. (CCBTO1, NON)

And for some, monthly questionnaires or reminder mails were experienced as helpful towards treatment adherence.

As far as I'm concerned they can higher the frequency of the monthly questionnaires. To rub your face once more in the research (...) It would help me to follow the lessons more regularly. (COMBIO1, NON)

The impact of research aspects was identified through interviews with both completers and non-completers. A difference among both groups was that two of the NOS non-completers confused the CCBT course with the Internet questionnaires. 


\section{Discussion}

\section{Main results}

The interviews pointed out that barriers and motivators experienced within CCBT were related to the course content and to contextual social, computer, and research aspects. The main barriers included: experiencing a lack of identification with and applicability of CCBTCYL, lack of support to adhere to the program or to gain deeper understanding, and inadequate computer/Internet skills, equipment, or location. However, a positive experience with the CCBT course content and reduction of depression were experienced as motivators to adhere to treatment. The opportunity to do the therapy at your own time, pace and place was also experienced positively by some interviewees. Adding support to CCBT was suggested as an improvement towards adherence and the course content.

Research aspects had an unintended impact: Research activities were often experienced as consciousness-raising or as stimulating to start or adhere to CCBT or the research. Confusion with the Internet questionnaires resulted in no uptake of CCBT.

\section{Reflection on trial results and hypotheses}

In the effectiveness study, several explanations for the rather small treatment effect and the low adherence rate have been suggested: characteristics of the patient sample, the way of treatment delivery, or the intervention itself. ${ }^{17}$ As a result of the recruitment strategy, many participants were not active help-seekers. ${ }^{17}$ The interviews confirmed this as part of the participants said not to have gone for treatment, if not invited by the study.

Concerning treatment delivery, we suggested that lack of support might have caused poor adherence and response to CCBT. ${ }^{17}$ This is confirmed by the interviewees who declared that they preferred or needed support. Our interviews though indicate that face-to-face support is not necessarily required to improve adherence. Some interviewees felt motivated through mail messages or Internet questionnaires of the research team. This preference for support is in line with previous research on CCBT in anxiety, depression, and bulimia. ${ }^{14,24,25}$ Moreover, a review and meta-analysis of Internet-delivered treatments for mood and anxiety disorders showed that interventions with support had larger effect sizes compared to interventions not offering support. ${ }^{10,26}$ However, a study on CCBT for bulimia showed no significant differences in treatment uptake, adherence and outcome improvement between a group receiving minimal guidance only, and a group receiving three brief therapist support sessions. ${ }^{27}$

In our study, support might also have been useful in resolving the reported difficulties with CCBT-CYL. The confusion between Internet questionnaires and CCBT could have been discovered earlier, and these participants could have been guided towards properly using CCBT. For participants having difficulties with the course content in self-identification, support could have helped to find more fitting examples. Moreover, support needs not to be restricted to professional help. Previous research indicated lay support to be the most commonly recommended ${ }^{28}$ and used help-form for people with mental health problems. ${ }^{29}$ Adding this to our finding that interviewees of the COMP and NOH group experienced both more depression improvement and more support from their social environment as op- 
posed to the NON interviewees, strengthens the assumption that lay support might play an important role in treatment adherence and depression improvement.

The effectiveness study questioned whether the small effects might be explained by CCBTCYL being less effective than other CCBT programs. ${ }^{17}$ The interviews cannot answer this, as the study did not compare different CCBT programs. This study does demonstrate that some users experienced the examples, homework or mood diary as negative or not helpful, and that non-completers had relatively more difficulties in identifying with and applying the course content. Making CCBT-CYL more patient-tailored can foster the self-identification and applicability to the personal situation and is in line with CYL versions developed for specific target groups, being for people aged $50+,{ }^{12}$ and for adults with diabetes. ${ }^{30}$ But also a variation in the methods might improve CCBT-CYL, as some interviewees strongly disliked the mood diary.

The interviews provide two new possible explanations for low treatment adherence. Firstly, inadequate computer location, skills and equipment can endanger treatment adherence. A second explanation might be confusion between research Internet questionnaires and the online CCBT, which implied that some participants did not even start CCBT.

The finding of an unintended impact of research aspects questions whether these research aspects also had impact on the outcomes of the trial. As research aspects were sometimes experienced as motivators, treatment adherence could have been even lower in this sample.

\section{Recommendations for further research}

To gain more knowledge on the potential gain of adding support, unsupported CCBT should be compared with supported CCBT. This support could take several forms in terms of the level of support (support on demand only or on a regular base), the way of delivery (through mail or Internet chat, telephone or face-to-face), and the person delivering the support (lay persons/personal social network, GP, mental health specialist or assistant). Such studies should take into account that adding support might endanger the appealing aspects of CCBT including low accessibility, low costs, and independence on availability of health care professionals. Moreover, adding professional support (via the computer or face-to-face) might entail other problems, such as difficulties in establishing a therapeutic relationship. ${ }^{16}$ These aspects have to be weighted against the increased benefits in terms of health effects and quality of life.

One of the qualitative study findings is that the groups of COMP and NOH interviewees differ from the NON interviewees in the experienced support of the social environment. Further research on the relation between treatment adherence social support and professional support may guide towards a better match between patient profile and treatment form.

Lastly, we advise further research -especially in the field of self-help interventions- to bear in mind the possible influences of the study design, as participants might experience research aspects as some form of support. Furthermore, to avoid confusion about treatment aspects (e.g. the confusion between questionnaires and CCBT), we advise to first study whether the planned information delivery is understood well enough by people of the intended population. Thus, a formative process evaluation which also takes into account 
the influence of the study design is a crucial element of effect studies of interventions in health care.

\section{Acknowledgements}

We thank Diane Crook for the translation of quotations, Yvonne Gerhards for checking te grammar, Hellen Heutz for her assistance in transcribing the interviews, and Annie Hendriks for assistance in the recruitment of interview participants.

This qualitative study was an addition to a trial financed by ZonMw (Netherlands Organisation for Health Research and Development; project number 945-04-417), research institute EPP and research institute CAPHRI. Municipalities Eijsden, Meerssen, Sittard-Geleen, Valkenburg and Maastricht sponsored the trial study. 


\section{References}

1. Bijl RV, Ravelli A, van Zessen G. Prevalence of psychiatric disorder in the general population: Results of the Netherlands Mental Health Survey and Incidence Study (NEMESIS). Soc Psychiatry Psychiatr Epidemiol 1998;33(12):587-595.

2. Kruijshaar ME, Hoeymans N, Bijl RV, Spijker J, Essink-Bot ML. Levels of disability in Major Depression. Findings from the Netherlands Mental Health Survey and Incidence Study (NEMESIS). J Affect Disord $2003 ; 77(1): 53-64$.

3. Bijl RV, Ravelli A. Current and residual functional disability associated with psychopathology: findings from the Netherlands Mental Health Survey and Incidence Study (NEMESIS). Psychol Med 2000;30:657668.

4. Sobocki P, Jönsson B, Angst J, Rehnberg C. Cost of Depression in Europe. J Ment Health Policy Econ 2006;9(2):87-98.

5. Simon GE, VonKorff M, Heiligstein JH, Revicki DA, Grothaus L, Katon W, et al. Initial antidepressant choice in primary care: Effectiveness and cost of fluoxetine vs tricyclic antidepressants. JAMA 1996;275(24):1897-1902.

6. Kirsch I, Deacon BJ, Huedo-Medina TB, Scoboria A, Moore TJ, Johnson BT. Initial severity and antidepressant benefits: a meta-analysis of data submitted to the food and drug administration. PloS Medicine 2008;5(2):e45.

7. Kendrick T, Chatwin J, Dowrick C, Tuylee A, Moriss R, Peveler R, et al. Randomised controlled trial to determine the clinical effectiveness and cost-effectiveness of selective serotonin reuptake inhibitors plus supportive care, versus supportive care alone, for mild to moderate depression with somatic symptoms in primary care: the THREAD (THREshold for AntiDepressant response) study. Health Technol Assess 2009;13(22):1-159.

8. Bower P, Rowland N, Hardy R. The clinical effectiveness of counseling in primary care: A systematic review and meta-analysis. Psychol Med 2003;33(2):203-215.

9. Kaltenthaler E, Brazier J, De Nigris E, Tumur I, Ferriter M, Beverly C, et al. Computerised cognitive behaviour therapy for depression and anxiety update: a systematic review and economic evaluation. Health Technol Assess 2006;10(33):1-186.

10. Spek V, Cuijpers P, Nyklícek I, Riper H, Keyzer J, Pop V. Internet-based cognitive behaviour therapy for symptoms of depression and anxiety: a meta-analysis. Psychol Med 2007;37(3):319-328.

11. Spek V, Cuijpers P, Nyklícek I, Smits N, Riper H, Keyzer J, et al. One-year follow-up results of a randomized controlled clinical trial on internet-based cognitive behavioural therapy for subthreshold depression in people over 50 years. Psychol Med 2008;38(5):635-639.

12. Spek V, Nyklícek I, Smits N, Cuijpers P, Riper H, Keyzer J, et al. Internet-based cognitive behavioural therapy for subthreshold depression in people over 50 years old: a randomized controlled clinical trial. Psychol Med 2007;37:1797-1806.

13. Kaltenthaler E, Sutcliffe P, Parry G, Beverly C, Rees A, Ferriter M. The acceptability to patients of computerized cognitive behaviour therapy for depression: a systematic review. Psychol Med 2008;38(11):1521-1530.

14. Waller R, Gilbody S. Barriers to the uptake of computerized cognitive behavioural therapy: a systematic review of the quantitative and qualitative evidence. Psychol Med 2009;39(5):705-712.

15. Khan N, Bower P, Rogers A. Guided self-help in primary care mental health. Meta-synthesis of qualitative studies of patient experience. Br J Psychiatry 2007;191:206-218.

16. Beattie A, Shaw A, Kaur S, Kessler D. Primary-care patients' expectations and experiences of online cognitive behavioural therapy for depression: a qualitative study. Health Expect 2009;12:45-59.

17. de Graaf LE, Gerhards SAH, Arntz AR, Riper H, Metsemakers JFM, Evers SMAA, et al. Clinical effectiveness of online computerized cognitive behavioural therapy without support for depression in primary care: a randomized trial. Br J Psychiatry 2009;195(1):73-80. 
18. de Graaf LE, Gerhards SAH, Evers SMAA, Arntz AR, Riper H, Severens JL, et al. Clinical and costeffectiveness of computerised cognitive behavioural therapy for depression in primary care: design of a randomised trial. BMC Public Health 2008;8:224.

19. Gerhards SAH, de Graaf LE, Jacobs LE, Severens JL, Huibers MJH, Arntz A, et al. Economic evaluation of online computerised cognitive-behavioural therapy without support for depression in primary care: randomised trial. Br J Psychiatry 2010;196(4):310-318.

20. Nederlands Huisartsen Genootschap. NHG-Standaard Depressieve stoornis (depressie) [Dutch College of General Practitioners - Practice guidelines depressive disorder (depression)]. Utrecht, 2003.

21. Meadows LM, Morse JM. Constructing Evidence Within The Qualitative Project. In: Morse JM, Swanson JM, Kuzel AJ, eds. The Nature of Qualitative Evidence. Thousand Oaks: Sage, 2001: 187-201.

22. Boeije H. Analyseren in kwalitatief onderzoek: Denken en doen [Analysing in qualitative research: Think and do]. Amsterdam: Boom Onderwijs, 2005.

23. Charmaz K. Grounded Theory, Objectivist and Constructivist Methods. In: Denzin NK, Lincoln YS, eds. Handbook of Qualitative Research. Second Edition. Thousand Oaks: Sage, 2000: 509-535.

24. Murray K, Guadelupe Pombo-Carril M, Bara-Carril N, Grover M, Reid Y, Langham C, et al. Factors Determining Uptake of a CD-ROM based CBT Self-help Treatment for Bulimia: Patient Characteristics and Subjective Appraisals of Self-help Treatment. Eur Eat Disord Rev 2003;11(3):243-260.

25. MacGregor AD, Hayward L, Peck DF, Wilkes P. Empirically Grounded Clinical Interventions Clients' and Referrers' Perceptions of Computer-Guided CBT (FearFighter). Behav Cogn Psychother 2009;37(1):1-9.

26. Palmqvist B, Carlbring P, Andersson G. Internet-delivered treatments with or without therapist input: does the therapist factor have implications for efficacy and cost? Expert Rev Pharmacoecon Outcomes Res 2007;7(3):291-297.

27. Murray K, Schmidt U, Pombo-Carril MG, Grover M, Alenya J, Treasure J, et al. Does therapist guidance improve uptake, adherence and outcome from a CD-ROM based cognitive-behavioral intervention for the treatment of bulimia nervosa? Comput Human Behav 2007;23:850-859.

28. Angermeyer MC, Matschinger H, Riedel-Heller SG. What to do about mental disorder - help-seeking recommendations of the lay public. Acta Psychiatr Scand 2001;103:220-225.

29. Oliver MI, Pearson N, Coe N, Gunnell D. Help-seeking behaviour in men and women with common mental health problems: cross-sectional study. Br J Psychiatry 2005;186:297-301.

30. van Bastelaar KMP, Pouwer F, Cuijpers P, Twisk JWR, Snoek FJ. Web-based cognitive behavioural therapy (W-CBT) for diabets patients with co-morbid depression: Design of a randomised controlled trial. BMC Psychiatry 2008;8:9.

31. de Graaf LE, Gerhards SAH, Arntz A, Riper H, Metsemakers JFM, Evers SMAA, et al. One-year follow-up results of unsupported online computerised cognitive behavioural therapy for depression in primary care: a randomised trial. J Behav Ther Exp Psy. 2010 (in press); doi: 10.1016/j.jbtep.2010.07.003.

32. de Graaf E, Huibers M, Riper H, Gerhards S, Arntz A. Use and acceptability of unsupported online computerized cognitive behavioral therapy for depression and associations with clinical outcome. J Affect Disord 2009;116:227-231. 


\section{Chapter 5 \\ Credibility and expectancy in online self-help depression treatment: impact on depression severity and quality of life}




\begin{abstract}
Background: Computerised cognitive behavioral therapy (CCBT) is a new treatment, which can be offered as a self-help online depression treatment. Gaining insight into determinants through which healthcare interventions influence health outcomes may highlight ways to a more (cost-)effective use of CCBT. Treatment expectancy and credibility might be such determinants.

Objective: To evaluate the role of pre-treatment outcome expectancy and credibility on depression severity and quality of life utility in CCBT.

Method: Trial data were used comparing CCBT with treatment as usual by a GP (TAU) and a combination of CCBT and TAU. The influence of credibility and expectancy on depression severity and utility at 12 months of follow-up was assessed in ANCOVA and regression analyses, while controlling for baseline confounders.

Results: The influence of credibility and expectancy on depression severity was moderated by intervention type, with CCBT showing a higher improvement in health outcome through a higher level of credibility and expectancy. Credibility and expectancy significantly influenced quality of life utility outcome with a higher level of CEQ implying more improvement; this relation was not moderated by the type of intervention.

Conclusion: Taking the patient's pre-treatment expectancy and credibility into account can contribute to a more effective depression treatment. However, the additional explanatory power of credibility and expectancy was rather small, and its impact differed among the interventions. Further insight into the amount of information about the treatment, role expectancy, and control expectancy, could give more explanation to the level of treatment outcome beliefs, and subsequently to health outcomes of CCBT.
\end{abstract}




\section{Introduction}

Depression is a common mental health problem in the general population, ${ }^{1}$ associated with substantial decreases in quality of life ${ }^{2,3}$ and considerable costs. ${ }^{4-8}$ Despite these negative consequences of depression, many patients with depression remain undetected ${ }^{9}$ or do not receive the care they need. ${ }^{10}$ As a possible solution, several computerised forms of depression treatment have been developed, like computerised cognitive behavioural therapy (CCBT). However, it can not be expected that every patient with depressive complaints will benefit from access to a CCBT program. Recently, we studied the clinical effectiveness of unsupported, online CCBT (i.e. Colour Your Life). ${ }^{11}$ Although the majority (53.4\%) of CCBT study participants showed reliable improvements, the effect size and depression severity scores and remission within 12 months indicated the intervention to be rather modest. ${ }^{12}$ Gaining insight into determinants through which healthcare interventions influence health outcomes may highlight ways to a more effective use of CCBT, and in turn to costeffectiveness. Treatment expectancy and credibility might be such determinants. Credibility can be explained as "how believable, convincing, and logical the treatment is", while expectancy refers to "improvements that clients believe will be achieved". ${ }^{13}$ Previous studies have found a relation between patients' treatment outcome expectancy and/or credibility for a wide range of medical and mental conditions, as well as in different face-to-face treatment contexts. ${ }^{14-26}$ However, to our knowledge none of these studies focused on selfhelp or on an e-health intervention for depression. The self-help and the online aspect, as well as the novelty of the CCBT treatment may imply differences in the role of treatment expectancy and credibility as compared with usual treatment practices under supervision of a health care professional. Next to that, most expectancy studies merely focus on outcome in terms of clinical effectiveness (e.g. depression severity), while recently (costleffectiveness studies often include quality of life expressed as a utility as a primary outcome measure. Consequently, information on the influence of credibility and expectancy on utility can be very helpful for future practice, since they might determine which patients will benefit the most from treatment in terms of health outcomes. In the present study, we therefore evaluate the role of pre-treatment expectancy and credibility on depression and quality of life utility using data of our trial studying an e-health self-help intervention for depression. ${ }^{10,11}$

\section{Methods}

\section{Study design}

Data of a randomised trial are used, comparing (1) CCBT, with (2) treatment as usual by a general practitioner (TAU), and (3) a combination of both CCBT \& TAU (COMBI) for depressive symptoms. In the trial, no significant differences were found for the clinical effectiveness of CCBT, TAU and COMBI. ${ }^{10,11}$ 
In total, 303 participants were included in the trial. They were recruited from the general population by means of a large-scale Internet-based screening in the South of the Netherlands. Inclusion criteria were: age 18 to 65; access to the Internet at home (no dial-up connection); at least mild to moderate depressive complaints (BDI-II score $\geq 16$ ); duration of depressive complaints 3 months or more; no current psychological treatment for depression; no continuous antidepressant treatment for at least 3 months prior to entry; fluent in Dutch language; no alcohol and/or drug dependence; and no severe psychiatric comorbidity (e.g. psychotic disorders). During a one-year follow-up period, participants were asked to fill in Internet questionnaires. ${ }^{10,11}$ Further details on the study design have been described elsewhere (see appendix 1 in this thesis).

\section{Treatment allocation procedure}

Preceding treatment allocation, research participants were informed on all three interventions CCBT, TAU and COMBI. For all three interventions, approximately the same amount of information was provided in an information letter and on a website. After written informed consent was obtained, the participants were randomly allocated to CCBT, TAU or COMBI. A brief explanation was given about the TAU treatment, and those receiving CCBT log-in codes were shown on the computer where to find the CYL website, and where to find a demonstration of the course on this CYL website.

\section{Interventions}

CCBT is based on the principles of cognitive behavioural therapy. The CCBT program in our trial (named "Colour Your Life" (CYL, in Dutch "Kleur je Leven")) is an online, multimedia, interactive computer program for depression. ${ }^{27}$ The program consists of eight weekly sessions and a ninth booster session. At the end of each session homework-assignments are given, such as keeping a 'mood diary'. No professional assistance was offered. Patients could reach the CCBT program wherever they had a computer with Internet access.

The GP is the major health care provider involved in the primary TAU of depression. In the Dutch health care system the GP is seen as a gatekeeper, and a key figure in the detection and treatment of depression. ${ }^{28}$ Participants who received TAU were advised to contact their own GP. After inclusion, the participant's GP received an information letter about the participation in the study. In the letter, the GP was advised to follow the depression guideline as described by the Dutch College of General Practitioners. Usual care as such consists of four to five biweekly consultations in combination with antidepressant treatment if indicated. In practice however, usual care is depending on the prescription of the individual's GP. $^{29}$

Participants allocated to COMBI were advised to contact their own GP (TAU) and received log-in codes for the CYL program (CCBT). Further details of the design of the trial, the interventions and the population can be found elsewhere. ${ }^{10,11}$ 


\section{Measures}

\section{Patient characteristics}

Prior to treatment allocation, patients reported socio-demographic information (age, sexe, work status, educational level, and partner).

\section{Credibility and Expectancy Questionnaire}

Credibility and expectancy were assessed after treatment allocation prior to the start of the treatment. Participants completed the Credibility and Expectancy Questionnaire (CEQ), originally developed by Devilly \& Borkovec. ${ }^{30}$ The CEQ is based on the basic scale of Borkovec \& Nau, which is the most frequently used credibility/expectancy measure in therapy research. ${ }^{31}$ The CEQ consists of 6 items, divided into two sets. The first set questions what the patient thinks about the treatment ( 4 items). The second set questions what the patient feels about the treatment ( 2 items). Devilly \& Borkovec found that items one to three from set one load onto the credibility factor, while item four from set one and both items from set two load on the expectancy factor. A composite score can be derived for each factor (expectancy and credibility) by summing the items of each factor, resulting in a range of 3 (low expectancy/credibility) to 27 (high expectancy/credibility). The CEQ demonstrated good psychometric properties. The factors have been found stable across different populations, with high internal consistency within each factor and high test-retest reliability. ${ }^{30}$ In the Netherlands, one study supported the two-factor structure of the CEQ for chronic low back pain patients, ${ }^{20}$ whereas another study identified a single factor structure. ${ }^{43}$

For this study, our group translated the English CEQ into Dutch, adapted it to depression patients, and modified the answer scales of two questions from a $0-100 \%$ to a 9-point Likert scale. These changes were done with advice from Devilly (Grant Devilly, personal communication via e-mail, 2006).

\section{Depression outcome}

The Beck Depression Inventory II (BDI-II) was used to measure depression severity at baseline and at 12 months after baseline. The total score is the sum of 21 items, which results in a range of 0 (no depression) to 63 (severe depression). There has been consistent support for the construct validity and reliability of the BDI-II in various samples. ${ }^{32-34}$

\section{Health-related quality of life: utility}

Health-related quality of life was derived from the Short Form 6D (SF-6D). The SF-6D is based on the health-related quality of life questionnaire 36-item short-form Health Survey (SF-36), measured at baseline and 12 months after baseline. The advantage of the SF-6D, is that it provides one composite score of the separate domains of quality of life. The score is derived from 11 items of the SF-36 and is composed of six dimensions of health (physical functioning, role limitations, social functioning, pain, mental health, and vitality). ${ }^{35}$ The quality of life score of the SF-6D is expressed as a utility. A utility refers to the preference that individuals or society may have for any particular set of health outcomes. It is indicated by a number between 0 (the worst imaginable condition: death) and 1 (perfect health). ${ }^{36}$ The SF-6D utilities were calculated by means of the preference-based UK tariff. This tariff is based on the preferences of a representative sample of the UK general population. ${ }^{35,37}$ 
Although theoretically a utility ranges from 0 to 1 , the SF-6D tariff results in a range from 0.30 to 1 .

\section{Analysis}

All available data were used. Preliminary, the normality of the CEQ data and the treatment outcome variables were assessed by means of histograms, Q-Q plots, and skewness and kurtosis statistics. Group differences in continuous baseline variables and treatment outcome were tested by ANOVA; while the $\chi^{2}$-test was used for dichotomous and categorical variables.

Because we used an adjusted and translated version of the CEQ, the factor structure of the CEQ was first tested. To verify whether the translated version of the CEQ reports the same factor structure as the original CEQ, a Confirmatory Factor Analysis (CFA) was performed using Lisrell. The goodness-of-fit was evaluated by means of (1) the Comparative Fit Index (CFI), (2) the Goodness-of-fit Index (GFI), (3) the Standardised Root Mean Square Residual (SRMR), and (4) the Root Mean Square Error of Approximation (RMSEA). Additionally, the Cronbach's Alpha was computed to assess the internal consistency of the factor(s).

The influence of treatment credibility and expectancy on depression severity and quality of life was evaluated using a univariate analysis of covariance (ANCOVA). The post-treatment health outcome score (being either depression severity or quality of life) was included as dependent variable. The treatment group was entered as a fixed factor. The CEQ and potential confounders (baseline BDI depression score, baseline SF-6D score, gender, age, educational level, work status and partner) were added as covariates. Previous research has shown that these socio-demographic and illness-related characteristics included as covariates can predict outcome of depression treatment, ${ }^{38,39}$ and have sometimes shown to be associated with the level of treatment expectancy. ${ }^{15,17,20}$ Subsequently, an interaction of the interventions with CEQ was added to the model. Regression parameters expressed as standardized Betas of the final model were calculated by means of multiple linear regression analysis. In case of a significant interaction variable between intervention and CEQ ( $p<$ $0.05)$, regression analyses were performed for each intervention separately. Otherwise, the interaction variable was not included in the regression analysis.

The factor analysis was carried out in Lisrel 8.54. All other analyses were carried out using SPSS version 15.0.1 for Windows.

\section{Results}

\section{Population}

303 depressed patients were randomly allocated to CCBT $(n=100)$, TAU $(n=103)$ or COMBI treatment $(n=100)$. Baseline characteristics of the study sample are presented in table 1 . At 12 months after baseline, complete data of follow-up questionnaires were available of 267 research participants (CCBT $n=88$; TAU $n=91$; COMBI, $n=88$ ). Taking into account the incomplete data on the baseline socio-demographic questionnaire (education, partner and employment), regression analyses including all specified variables retained a dataset of 231 
research participants (CCBT $n=81$; TAU $n=72$; COMBI, $n=78$ ) with complete data on all questionnaires.

\section{The expectancy/credibility (CEQ) scores}

The confirmatory factor analysis of the CEQ showed a high level of correlation $(r=0.85)$ between the factors. Moreover a high correlation was found between credibility and expectancy $(r=0.703)$ when calculated as to separate scales. Therefore, we used a onefactor structure of the CEQ. Cronbach's Alpha showed good internal consistency for this factor (Cronbach's Alpha $=0.90$ ).

The CEQ scores ranged from 7 to 53, with a mean score of 36.8 (sd 8.2). Results of ANOVA analysis showed no significant differences between participants allocated to CCBT versus COMBI treatment, and to CCBT versus TAU treatment. However, TAU scored significantly lower on the CEQ as opposed to COMBI with $p<0.05$.

Table 1: Baseline characteristics of the sample $(n=303)$

\begin{tabular}{|c|c|c|c|}
\hline Variable & $\begin{array}{l}\text { CCBT } \\
n=100\end{array}$ & $\begin{array}{l}\text { TAU } \\
n=103\end{array}$ & $\begin{array}{l}\text { COMBI } \\
n=100\end{array}$ \\
\hline Male sex, $\mathrm{nr}(\%)$ & $48(48.0)$ & $46(44.7)$ & $37(37.0)$ \\
\hline Age, $M(s d)$ & $44.3(11.8)$ & $45.1(12.2)$ & $45.2(10.9)$ \\
\hline \multicolumn{4}{|l|}{ Education ${ }^{a}$ : } \\
\hline Low, nr (\%) & $18(18.6)$ & $16(16.2)$ & $17(17.5)$ \\
\hline Medium, nr (\%) & $55(56.7)$ & $55(55.6)$ & $52(53.6)$ \\
\hline High, $\mathrm{nr}(\%)$ & $24(24.7)$ & $28(28.3)$ & $28(28.9)$ \\
\hline Partner, yes, $\mathrm{nr}(\%)^{\mathrm{b}}$ & $72(73.5)$ & $73(72.3)$ & $71(73.2)$ \\
\hline Employed, yes, $\mathrm{nr}(\%)^{\mathrm{c}}$ & $67(72.0)$ & $64(76.2)$ & $69(73.4)$ \\
\hline Credibility and expectancy (CEQ; range 6-54) ${ }^{\mathrm{d}}, \mathrm{M}(\mathrm{sd})$ & $37.1(7.6)$ & $35.2(8.7)$ & $38.2(8.1)$ \\
\hline Depressive severity (BDI-II; range $0-63)^{d}, M(s d)$ & $28.2(7.7)$ & $27.9(7.5)$ & $27.4(8.2)$ \\
\hline $\begin{array}{l}\text { Quality of life utility (SF-6D, U.K. Brazier tariff; range 0.30-1), } \\
\text { M (sd) }\end{array}$ & $0.67(0.08)$ & 0.67 (0.08) & $0.66(0.09)$ \\
\hline
\end{tabular}

Note. CCBT, computerised cognitive behavioural therapy; TAU, treatment as usual by a general practitioner; COMBI, combination of CCBT and TAU; BDI-II, Beck Depression Inventory II; CEQ, Credibility and Expectancy Questionnaire; SF-6D, Short-Form 6D.

${ }^{a}$ data unavailable for 3 persons in CCBT group, 4 persons in TAU group, and 3 persons in COMBI; ${ }^{b}$ data unavailable for 2 persons in CCBT group, 2 persons in TAU group, and 3 persons in COMBI; ${ }^{c}$ data unavailable for 7 persons in CCBT group, 17 persons in TAU group, and 6 persons in COMBI. ${ }^{d}$ Lower scores indicate lower levels of credibility / expectancy / quality of life utility; Higher scores indicate higher levels of credibility / expectancy / quality of life utility.

\section{CEQ predicting depression severity}

The results of the ANCOVA analysis in table 2 indicate that the CEQ had a significant impact on BDI-II depression severity at 12 months follow-up (F-value 8.934, $p=0.003$ ). This influence was moderated by the intervention type (F-value $3.460, p=0.033$ ). The inclusion of CEQ and subsequent inclusion of the interaction between CEQ and intervention added significantly to the explanatory power of the depression severity outcome with respectively $2.9 \%$ and $2.2 \%$ ( $R^{2}$ changes from 0.269 to 0.298 and 0.320 ). 
Table 2: Results ANCOVA test of between-subjects effects on depression severity at 12 months follow-up $(\mathrm{n}=\mathbf{2 3 1})$

\begin{tabular}{|c|c|c|c|c|c|c|}
\hline \multirow[b]{3}{*}{ Variables $^{a}$} & \multirow{2}{*}{\multicolumn{2}{|c|}{ Confounders only }} & \multicolumn{4}{|c|}{ Addition of CEQ } \\
\hline & & & \multicolumn{2}{|c|}{ No Interaction } & \multicolumn{2}{|c|}{ With interaction } \\
\hline & $\mathrm{F}$ & Sig. & $\mathrm{F}$ & Sig. & $\mathrm{F}$ & Sig. \\
\hline Intervention & 1.246 & 0.290 & 0.677 & 0.509 & 3.062 & 0.049 \\
\hline CEQ & & & 8.934 & 0.003 & 9.342 & 0.003 \\
\hline Interaction CEQ * Intervention & & & & & 3.460 & 0.033 \\
\hline Adj. $R^{2}$ & 0.236 & & 0.263 & & 0.279 & \\
\hline $\mathrm{R}^{2}$ & 0.269 & & 0.298 & & 0.320 & \\
\hline
\end{tabular}

Note. BDI-II, Beck Depression Inventory II; CEQ, Credibility and Expectancy Questionnaire; SF-6D, Short-Form 6D.

${ }^{a}$ In all steps controlling for baseline BDI-II depression score, baseline SF-6D utility, sexe, age, educational level, work status, and partner.

The separate regression analyses per intervention group in table 3 indicate that CEQ only significantly influenced treatment outcomes of the CCBT intervention group $(p<0.05)$ while controlling for potential confounders. As shown in the scatterplot in figure 1, a higher CEQ level implied a larger reduction in BDI-II depression severity. All together, the variables included in the regression analysis of CCBT, TAU and COMBI explained respectively $22.2 \%$, $29.0 \%$, and $30.8 \%$ of the variance in depression severity at 12 months.

Table 3: Regression analysis: Influence of expectancy and credibility on depression severity at 12 months follow-up ( $\mathbf{n = 2 3 1 )}$

\begin{tabular}{llll}
\hline Variables & CCBT & Std. Betas & \\
& $(\mathrm{n}=81)$ & TAU & COMBI \\
& $0.294^{* *}$ & $0.386^{* *}$ & 0.131 \\
\hline Baseline BDI score & $-0.220^{*}$ & $-0.257^{*}$ & $-0.472^{* *}$ \\
Baseline SF-6D score & 0.146 & 0.088 & 0.070 \\
Sex (male) & -0.034 & 0.006 & -0.048 \\
Age & -0.189 & -0.048 & -0.135 \\
Education (high) & 0.027 & -0.185 & $-0.299^{* *}$ \\
Education (middle) & -0.032 & -0.021 & 0.001 \\
Partner (yes) & -0.015 & -0.099 & -0.112 \\
Work (yes) & $-0.332^{* *}$ & -0.118 & 0.014 \\
CEQ & 0.222 & 0.290 & 0.308 \\
\hline Adj. $^{2}$ & 0.104 & 0.011 & 0.000 \\
$\mathrm{R}^{2}$ change & $10.743^{\mathrm{a}}$ & 1.124 & 0.018 \\
F change $^{\mathrm{a}}$ & & & \\
\hline
\end{tabular}

Note. Std. Betas, Standardized Betas; CCBT, computerised cognitive behavioural therapy; TAU, treatment as usual by a general practitioner; $C O M B I$, combined treatment of CCBT and TAU; BDI-II, Beck Depression Inventory II; CEQ, Credibility and Expectancy Questionnaire; SF-6D, Short-Form 6D.

${ }^{*} \mathrm{p}<0.10 ;{ }^{* *} \mathrm{p}<0.05$; $^{\mathrm{a}}$ The change of adding the CEQ variable to the model of confounders only. 


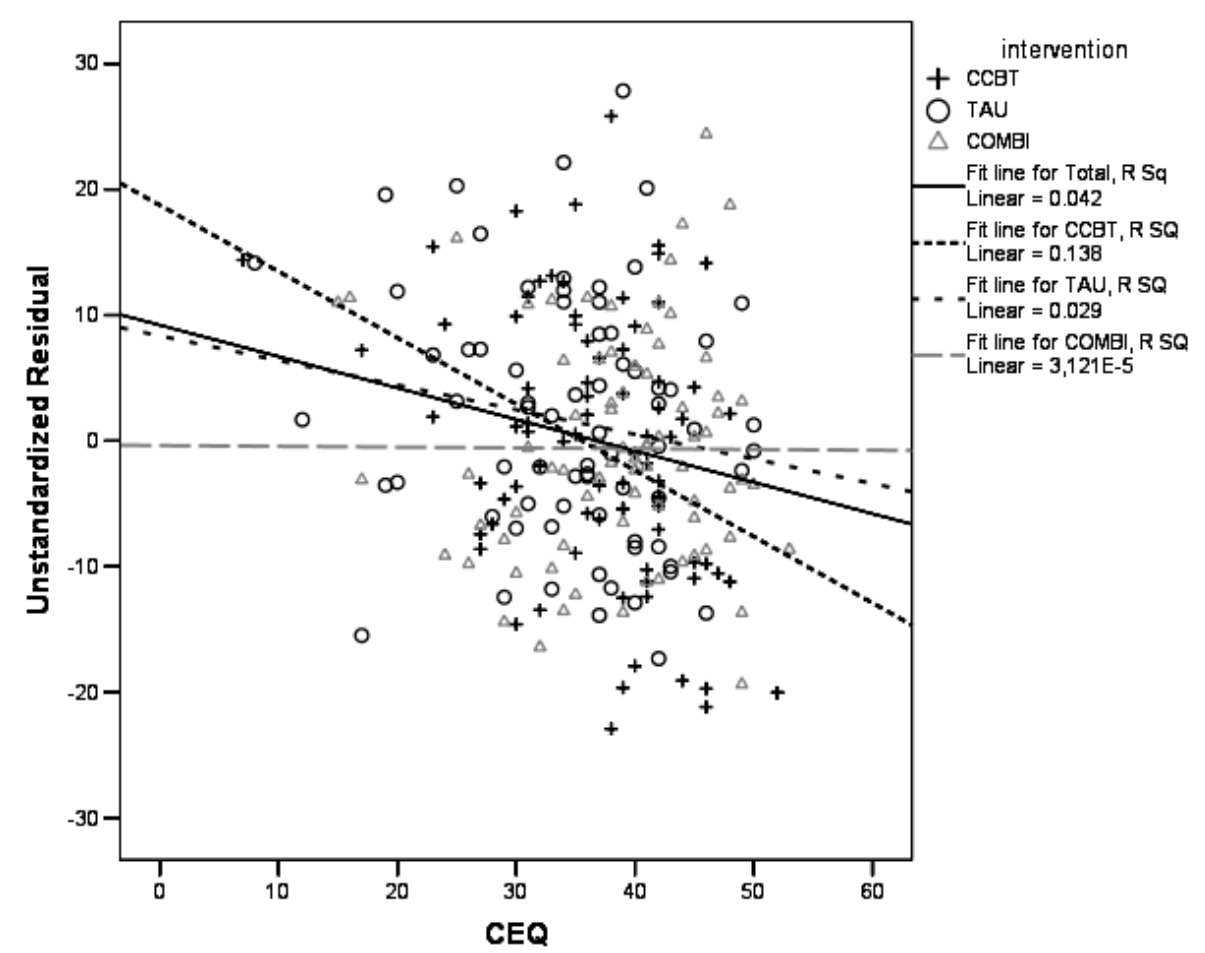

Figure 1: Scatterplots of depression severity at 12 months follow-up (controlling for confounders) related to credibility and expectancy $(n=231)$

Note. CEQ, Credibility and Expectancy Questionnaire; CCBT, computerised cognitive behavioural therapy; TAU, treatment as usual by a general practitioner; COMBI, combined treatment of CCBT \& TAU. The unstandardized residuals are calculated in a regression analysis with BDI-II at 12 months as dependent variable, the following confounders were included as independent variables: baseline BDI-II depression score, baseline SF-6D utility, sexe, age, educational level, work status, and partner.

\section{CEQ predicting quality of life utility}

The results of the ANCOVA analysis in table 4 indicate that the CEQ had a significant impact on SF-6D quality of life utility at 12 months follow-up (F-value 5.349, p 0.022). The inclusion of CEQ added significantly to the explanatory power of the quality of life utility outcome with $1.4 \%$ ( $R^{2}$ changes from 0.441 to 0.455 ). The influence of CEQ on quality of life utility was not moderated by the intervention type (F-value 1.109, p 0.332). The outcomes of the regression in table 5 indicate that a higher CEQ level implied a larger improvement in SF-6D quality of life utility. All together, the variables included in the regression analysis explained $42.7 \%$ of the variance in quality of life utility at 12 months. 
Table 4: Results ANCOVA test of between-subjects effects on quality of life utility at 12 months follow-up (n=231)

\begin{tabular}{lcccccc}
\hline & \multicolumn{2}{c}{ Confounders only } & \multicolumn{4}{c}{ Addition of CEQ } \\
\multicolumn{1}{c}{ Variables $^{\mathrm{a}}$} & & & No Interaction & \multicolumn{2}{c}{ With interaction } \\
& $\mathrm{F}$ & Sig. & $\mathrm{F}$ & Sig. & $\mathrm{F}$ & Sig. \\
\hline Intervention & 0.305 & 0.737 & 0.105 & 0.900 & 1.201 & 0.303 \\
$\mathrm{CEQ}$ & & & 5.349 & 0.022 & 5.305 & 0.022 \\
Interaction CEQ * Intervention & & & & & 1.109 & 0.332 \\
\hline Adj. $\mathrm{R}^{2}$ & 0.416 & & 0.427 & & 0.428 \\
$\mathrm{R}^{2}$ & 0.441 & & 0.455 & & 0.460 \\
\hline
\end{tabular}

Note. BDI-II, Beck Depression Inventory II; CEQ, Credibility and Expectancy Questionnaire; SF-6D, Short-Form 6D.

${ }^{a}$ In all steps controlling for baseline BDI-II depression score, baseline SF-6D utility, sexe, age, educational level, work status, and partner.

Table 5: Regression analysis: Influence of expectancy and credibility on quality of life utility at 12 months follow-up ( $\mathrm{n}=\mathbf{2 3 1})$

\begin{tabular}{ll}
\hline Variables & Std. Betas \\
\hline Baseline BDI score & -0.071 \\
Baseline SF-6D score & $0.561^{* *}$ \\
Sex (male) & -0.079 \\
Age & -0.092 \\
Education (high) & $0.157^{* *}$ \\
Education (middle) & 0.082 \\
Partner (yes) & 0.053 \\
Work (yes) $_{\text {Intervention (CCBT) }}^{\mathrm{a}}$ & 0.069 \\
Intervention (COMBI) $^{\mathrm{a}}$ & -0.011 \\
CEQ & 0.016 \\
\hline
\end{tabular}

Note. Std. Betas, Standardized Betas; BDI-II, Beck Depression Inventory II; CEQ, Credibility and Expectancy Questionnaire; SF-6D, Short-Form 6D; CCBT, computerised cognitive behavioural therapy; COMBI, combined treatment of CCBT and TAU.

${ }^{*} \mathrm{p}<0.10 ;{ }^{* *} \mathrm{p}<0.05$; $^{\mathrm{a}}$ Reference group is TAU (treatment as usual by a general practitioner).

\section{Discussion}

\section{Main results}

Expectancy and credibility had significant influence on the health outcomes of depression patients. Our results showed that the influence of CEQ on depression severity was moderated by the type of intervention. For participants in the CCBT intervention, a higher level of CEQ implied significantly more improvement in BDI-II depression severity. CEQ also significantly influenced quality of life utility outcome with a higher level of CEQ implying more improvement; this relation was not moderated by the type of intervention. 


\section{Reflection on the findings}

The results indicate that credibility and expectancy are associated with CCBT treatment outcome in depression. Regardless of its significance, the CEQ provided rather low percentages of change in variance explained in health outcome. This is in line with Smeets et al. ${ }^{20}$ and Goossens et al. ${ }^{17}$ who identified an explanatory contribution of the CEQ of respectively $2.3 \%$ up to $17.6 \%$, and $1 \%$ to $8 \%$ in several treatment outcome parameters for chronic pain patients. However, as mentioned by Smeets et al., ${ }^{20}$ there is no guideline on which amount of predicted variance by credibility/expectancy is clinically relevant.

While for CCBT, the CEQ factor had significant impact, the COMBI outcomes points towards education as a significant influence on BDI-II depression severity. We therefore additionally assessed whether CEQ interacted with education. However, the addition of an interaction term of CEQ with education did not contribute significantly in explanatory power of the regression models per intervention group ( $p>0.05$ in all analyses).

The finding that CEQ had significant influence on depression severity outcome for the CCBT intervention only, might indicate that credibility and expectancy differ in the impact on different types of depression treatments. The moderating effect of expectancy with intervention might be explained by the baseline differences in CEQ between the three intervention groups, in which TAU scored significantly lower on credibility $(p<0.05)$ and expectancy $(p<0.10)$ as opposed to COMBI. However, this does not explain why our regression results do not show a significant impact of CEQ on depression severity outcome of the COMBI treatment. Perhaps it is not (only) the baseline level of expectancy which explains this moderation, but also the nature of the underlying expectancy which might differ among the three intervention groups. A self-management program such as unsupported CCBT requires the patient to take an active role and control in his treatment all on his own, while credibility and expectancy in treatments involving a health care professional can as well be influenced by the patient's belief in the health care professional's role or in the working of medication. In the absence of a health care professional who can control or reinforce the patient's credibility or expectancy throughout the treatment process, more attention towards the patient's treatment expectancy and credibility at start of treatment might be required.

Moreover, the level of information a patient received about the treatment can also impact pre-treatment expectancy. ${ }^{40,41}$ Although patients of all three intervention groups received the same amount of information during the intake, it could be that patients felt differently informed about COMBI or TAU treatment as opposed to CCBT. In the Netherlands, most people are familiar with GP care, and a part of trial participants have had contact with their GP about depressive complaints prior to their trial participation. CCBT and e-health treatments on the other hand, are new treatment forms in the Netherlands. Consequently patients might have felt more familiar with the TAU intervention compared with online CCBT. However, the content of the CCBT treatment is more pre-defined compared with TAU (which can consist of antidepressant prescription, consultations with the GP, and/or referrals to mental health care specialists), and might consequently as well lead to a different experience of the information level. Another aspect of information is that research participants could not be blinded, while a large part of them had some preferences for treatment allocation. The researchers involved in the intake of patients in the trial ac- 
knowledge that many patients expressed a preference for CCBT or COMBI (41\% preferred CCBT, $33 \% \mathrm{COMBI}, 6 \% \mathrm{TAU}$, and $19 \%$ had no preference at intake). Moreover, a qualitative study on our trial patients' experiences with CCBT has shown that some CCBT and COMBI participants were confused between the online CCBT program and the Internet questionnaire: they thought the Internet questionnaire was the Internet treatment. ${ }^{42}$ This confusion might also be present in their valuation of the CEQ: were these participants valuing their credibility and expectancy of the true CCBT program? Or were they valuing their credibility and expectancy of the Internet questionnaires which they thought to be the treatment? While we did find a significant interaction effect between intervention and CEQ for the BDIII depression severity outcomes, there was no interaction for the SF-6D quality of life utility outcome. A probable explanation for this finding is that the SF-6D showed little change through treatment in all three intervention groups. ${ }^{42}$ This suggestion is supported by the outcomes of the regression analysis which indicated a strong association between baseline and 12-months follow-up SF-6D score.

\section{Methodological considerations}

There were some methodological considerations in this study to bear in mind when interpreting our results. Firstly, the major limitation of our study is its focus on outcome expectancy only, while different types of expectancy can be distinguished. Delsignore \& Schny$\operatorname{der}^{21}$ make a distinction between role expectancy, control expectancy and outcome expectancy. Outcome expectancy is a broad category of patient expectations on how strongly patients believe that treatment will help them get better. Role and control expectancy are as such related to the patient's outcome expectancy, they can partly shape outcome expectancy. ${ }^{21}$ These role and control expectancies might differ between unsupported CCBT, TAU, and $\mathrm{COMBI}$, which might imply differences in the forming and impact of outcome expectancy. For further research, we therefore advise to focus on outcome expectancy as well as control and role expectancy, and the relations between these three types of expectancy and the interventions. Especially qualitative research on pre-treatment expectancy might indicate how people create their (outcome) expectancy. This might explain the differences in CEQ impact we found among the treatment groups, e.g. why especially in CCBT the CEQ had a significant impact.

A second methodological aspect concerns the moment at which credibility and expectancy were assessed. While most studies -including ours- have measured expectancy prior to treatment, some have investigated during-treatment expectancy. ${ }^{19}$ For instance, in Smeets et al. ${ }^{20}$ patients completed the CEQ after the first treatment session. Patients' long-term health outcome is partly determined by fulfillment of patient expectations, ${ }^{16}$ which might change from prior to during treatment. A study on students' attitudes to CCBT for depression showed that filling in the CEQ before versus after a CCBT demonstration impacted the participants' level of CCBT credibility and expectancy. ${ }^{41}$ Our study participants thus might not have been sufficiently able to judge the content of the treatment and the resulting outcomes prior to experiencing the treatment. Measuring the expectancy and credibility after, for instance, the first treatment session, might lead to better-informed patients with more realistic beliefs about the treatment outcome, and may consequently involve an increase in the explanatory power of outcome expectancy and credibility. 
Thirdly, the CEQ we used in this study is supposed to be equivalent to the original version developed by Devilly and Borkovec. ${ }^{30}$ However, the changes we made in our version of the questionnaire might imply some differences from the original English CEQ version administered on paper. Moreover, we used a one-factor structure of the CEQ, whereas Devilly and Borkovec $^{30}$ separated a credibility and expectancy factor. Although the credibility and expectancy do differ somewhat, we found a high correlation between both factors in the confirmatory factor analysis, as well as a high correlation between both credibility and expectancy $(r=0.703)$.

At last, our study sample consisted of participants who were rather severely depressed. ${ }^{12}$ Their complaints were probably too severe for a self-help treatment without guidance, which might have led to only modest effectiveness outcomes of the interventions. In addition, the severity of depression might have resulted in lower expectancy and credibility levels compared with less severely depressed patient groups. Moreover, our recruitment strategy implied that we (partly) included participants who were not active help-seekers, ${ }^{42}$ while a stronger intention for seeking depression help can be expected to create more involvement in (especially self-help) treatment. Perhaps expectancy and credibility would have been stronger predictors in a patient group more suitable for a self-help treatment.

\section{Conclusion}

In conclusion, taking the patient's pre-treatment expectancy and credibility into account can contribute to a more effective depression treatment. Our results show that the explanatory power of pre-treatment credibility and expectancy was rather small though significant, and its impact differed among the interventions. We believe that further insight into other aspects, like the amount of information about the treatment, role expectancy, and control expectancy can give more explanation to the level of treatment outcome beliefs, and subsequently to health outcomes of CCBT, TAU and COMBI.

\section{Acknowledgements}

We thank Annie Hendriks and Greet Kellens for their assistance in the recruitment of trial participants. Rosanne Janssen has developed the infrastructure for the online datacollection. Eric Schouten provided advice on regression and Lisrell analyses. Grant Devilly gave feedback on the adaptation of the CEQ questionnaire in our study.

The trial is financed by ZonMw (Netherlands Organisation for Health Research and Development; project number 945-04-417), research institute Experimental Psychopathology (EPP) and the Care And Public Health Research Institute (CAPHRI). Municipalities Eijsden, Meerssen, Sittard-Geleen, Valkenburg, and Maastricht sponsored the study. 


\section{References}

1. Bijl RV, Ravelli A, van Zessen G. Prevalence of psychiatric disorder in the general population: Results of the Netherlands Mental Health Survey and Incidence Study (NEMESIS). Soc Psychiatry Psychiatr Epidemiol 1998;33(12):587-595.

2. Bijl RV, Ravelli A. Current and residual functional disability associated with psychopathology: findings from the Netherlands Mental Health Survey and Incidence Study (NEMESIS). Psychol Med 2000;30:657668.

3. Kruijshaar ME, Hoeymans N, Bijl RV, Spijker J, Essink-Bot ML. Levels of disability in Major Depression. Findings from the Netherlands Mental Health Survey and Incidence Study (NEMESIS). J Affect Disord 2003;77(1):53-64.

4. Slobbe LCJ, Kommer GJ, Smit JM, Groen J, Meerding WJ, Polder JJ. Kosten van Ziekten in Nederland 2003; Zorg voor euro's - 1 [Costs of illness in the Netherlands 2003]. Bilthoven: Rijksinstituut voor Volksgezondheid en Milieu, 2006.

5. Cuijpers P, Smit F, Oostenbrink J, de Graaf R, Ten Have M, Beekmand A. Economic costs of minor depression: a population-based study. Acta Psychiatr Scand 2007;115:229-236.

6. Sobocki P, Jönsson B, Angst J, Rehnberg C. Cost of Depression in Europe. J Ment Health Policy Econ 2006;9(2):87-98.

7. Stewart WF, Ricci JA, Chee E, Hanh SR, Morganstein D. Cost of lost productive work time among US workers with depression. JAMA 2003;289(23):3135-3144.

8. Luppa M, Heinrich S, Angermeyer MC, König HH, Riedel-Heller SG. Cost-of-illness studies of depression. A systematic review. J Affect Disord 2007;98:29-43.

9. Kessler RC, Berglund P, Demler O, Jin R, Koretz D, Merikangas KR, et al. The epidemiology of major depressive disorder. Results from the National Comorbidity Survey Replication (NCS-R). JAMA 2003;289(23):3095-3105.

10. de Graaf LE, Gerhards SAH, Evers SMAA, Arntz AR, Riper H, Severens JL, et al. Clinical and costeffectiveness of computerised cognitive behavioural therapy for depression in primary care: design of a randomised trial. BMC Public Health 2008;8:224.

11. de Graaf LE, Gerhards SAH, Arntz AR, Riper H, Metsemakers JFM, Evers SMAA, et al. Clinical effectiveness of online computerised cognitive behavioural therapy without support for depression in primary care: a randomised trial. Br J Psychiatry 2009;195(1):73-80.

12. de Graaf LE, Gerhards SAH, Arntz A, Riper H, Metsemakers JFM, Evers SMAA, et al. One-year follow-up results of unsupported online computerised cognitive behavioural therapy for depression in primary care: a randomised trial. J Behav Ther Exp Psy. 2010 (in press); doi: 10.1016/j.jbtep.2010.07.003.

13. Kazdin AE. Therapy outcome questions requiring control of credibility and treatment-generated expectancies. Behavior Therapy 1979;10:81-93.

14. Mondloch MV, Cole DC, Frank JW. Does how you do depend on how you think you'll do? A systematic review of the evidence for a relation between patients' recovery expectations and health outcomes. CMAJ Canadian Medical Association journal 2001;165(2):174-179.

15. Moses T, Leuchter AF, Cook I, Abrams M. What Shapes Depressed Individuals' Pre-Treatment Expectation in Antidepressant Clinical Trials? The Internet Journal of Mental Health 2007;3(2).

16. Meyer B, Pilkonis PA, Krupnick JL, Egan MK, Simmens SJ, Sotsky SM. Treatment Expectancies, Patient Alliance, and Outcome: Further Analyses From the National Institute of Mental Health Treatment of Depression Collaborative Research Program. J Consult Clin Psychol 2002;70(4):1051-1055.

17. Goossens ME, Vlaeyen JW, Hidding A, Kole-Snijders A, Evers SM. Treatment expectancy affects the outcome of cognitive-behavioral interventions in chronic pain. The Clinical Journal of Pain 2005;21(1):18-26.

18. Ilardi SS, Craighead WE. The Role of Nonspecific Factors in Cognitive-Behavior Therapy for Depression. American Psychological Association 1994;1(2):138-156.

19. Greenberg RP, Constantino MJ, Bruce N. Are patient expectations still relevant for psychotherapy process and outcome? Clin Psychol Rev 2006;26:657-678. 
20. Smeets RJEM, Beelen SPT, Goossens MEJB, Schouten EGW, Knottnerus JA, Vlaeyen JWS. Treatment Expectancy and Credibility Are Associated With the Outcome of Both Physical and Cognitive-behavioral Treatment in Chronic Low Back Pain. The Clinical Journal of Pain 2008;24 (4):305-315.

21. Delsignore A, Schnyder U. Control expectancies as predictors of psychotherapy outcome: A systematic review. British Journal of Clinical Psychology 2007;46:467-483.

22. Glass CR, Arnkoff DB, Shapiro SJ. Expectations and preferences. Psychotherapy 2001;38(4):455-461.

23. Cole DC, Mondloch MV, Hogg-Johnson S. Listening to injured workers: how recovery expectations predict outcomes - a prospective study. CMAJ Canadian Medical Association journal 2002;166(6):749754.

24. Holm LW, Carroll L, Cassidy JD, Skillgate E, Ahlbom A. Expectations for Recovery Important in the Prognosis of Whiplash Injuries. PLoS medicine 2008;5(5):1-8.

25. Krell HV, Leuchter AF, Morgan M, Cook IA, Abrams M. Subject Expectations of Treatment Effectiveness and Outcome of Treatment With an Experimental Antidepressant. The Journal of Clinical Psychiatry 2004;65(9):1174-1179.

26. Yee A, Adjei N, Do J, Ford M, Finkelstein J. Do Patient Expectations of Spinal Surgery Relate to Functional Outcome? Clin Orthop 2008;466(5):1154-1161.

27. Riper H, Kramer JJAM. Online zelfhulpcursus www.kleurjeleven.nl. Utrecht: Trimbos-institute, 2004.

28. CBO. Multidisciplinaire richtlijn depressie: richtlijn voor de diagnostiek en behandeling van volwassen cliënten met een depressie [Multidisciplinary guideline depression: guideline for diagnostics and treatment of adult depression clients]. Utrecht: Trimbos-instituut, 2005.

29. Nederlands Huisartsen Genootschap. NHG-Standaard Depressieve stoornis (depressie) [Dutch College of General Practitioners - Practice guidelines depressive disorder (depression)]. Utrecht, 2003.

30. Devilly GJ, Borkovec TD. Psychometric properties of the credibility/expectancy questionnaire. Journal of Behavior Therapy and Experimental Psychiatry 2000;31:73-86.

31. Borkovec TD, Nau SD. Credibility of analogue therapy rationales. Journal of Behavior Therapy and Experimental Psychiatry 1972;3(257-260).

32. Beck AT, Steer RA, Ball R, Ranieri WF. Comparison of Beck Depression Inventories-IA and -II in psychiatric outpatients. J Pers Assess 1996;67(3):588-597.

33. Arnau RC, Meagher MW, Norris MP, Bramson R. Psychometric Evaluation of the Beck Depression Inventory-II With Primary Care Medical Patients. Health Psychol 2001;20(2):112-119.

34. Van der Does AJW. De Nederlandse versie van de Beck Depression Inventory - second edition (BDI-II-NL): Handleiding [The Dutch version of the Beck Depression Inventory - second edition (BDI-II-NL): Manual]. Enschede: The Psychological Corporation, 2002.

35. Brazier J, Roberts J, Deverill M. The estimation of a preference-based measure of health from the SF-36. $J$ Health Econ 2002;21:271-292.

36. Drummond MF, Sculpher MJ, Torrance GW, O'Brien B, Stoddart GL. Methods for the Economic Evaluation of Health Care Programmes. Oxford: Oxford University Press, 2005.

37. Brazier JE, Roberts J. The Estimation of a Preference-Based Measure of Health From the SF-12. Med Care 2004;42(9):851-859.

38. Jarrett RB, Eaves GG, Granneman BD, Rush AJ. Clinical, cognitive, and demographic predictors of response to cognitive therapy for depression: a preliminary report. Psychiatry Res 1991;37:245-260.

39. Wolf NJ, Hopko DR. Psychosocial and pharmacological interventions for depressed adults in primary care: a critical review. Clin Psychol Rev 2008;28:131-161.

40. Horvath $P$. Treatment expectancy as a function of the amount of information presented in therapeutic rationales. J Clin Psychol 1990;46(5):636-642.

41. Mitchell N, Gordon PK. Attitudes Towards Computerized CBT for Depression Amongst a Student Population. Behav Cogn Psychother 2007;35:421-430.

42. Gerhards SAH, Abma TA, Arntz A, de Graaf LE, Evers SMAA, Huibers MJH, et al. Improving adherence and effectiveness of computerised cognitive behavioural therapy without support for depression: A qualitative study on patient experiences. J Affect Disord 2010 (in press); doi: 10.1016/j.jad.2010.09.012.

43. Leeuw M, Goossens MEJB, van Breukelen, GJP, de Jong JR, Heuts PHTG, Smeets RJEM, et al. Exposure in vivo versus operant graded activity in chronic low back pain patients: Results of a randomized controlled trial. Pain 2008; 138:192-207. 



\section{Part 2}

\section{Utility instruments in depression}





\section{Chapter 6}

\section{The responsiveness of quality of life utilities to change in depression: a comparison of instruments (SF-6D, EQ-5D and DFD)}

Gerhards SAH, Huibers MJH, Theunissen KATM, de Graaf LE, Widdershoven GAM, Evers SMAA

Submitted for publication. 


\begin{abstract}
Background: Utilities are often a main outcome parameter in economic evaluations. Since depression has a large impact on quality of life aspects, it is expected that utilities are responsive to changes in depression.

Objective: To evaluate the change in utility derived from different instruments in depression, being: the Short Form 6D (SF-6D), the Euroqol based on the UK (EQ-5D $\mathrm{UK}_{\mathrm{UK}}$ ) and Dutch tariff $\left(E Q-5 D_{N L}\right)$, and utilities derived from the depression severity questionnaire Beck Depression Inventory Second Edition (BDI-II) using the Depression-Free-Day (DFD) method (DFDu).

Method: This study evaluated the responsiveness, the minimally important difference (MID), and the agreement in utility change derived from the different instruments.

Results: The SF-6D, EQ-5D $\mathrm{UK}_{\mathrm{U}}$ and EQ-5D $\mathrm{D}_{\mathrm{NL}}$ showed to be responsive. The MID values are in line with previous studies about 0.3. The DFDu nearly always resulted in positive utility changes, even for subgroups which had no change or deterioration in health status or depression. There was poor agreement between utility changes of the SF-6D, EQ-5D (either EQ-5D $\mathrm{DK}_{\mathrm{UK}}$ or EQ-5D $\mathrm{D}_{\mathrm{NL}}$ ) and DFDu.

Conclusion: The SF-6D, EQ-5D $\mathrm{UK}_{\mathrm{K}}$ and EQ-5D $\mathrm{D}_{\mathrm{NL}}$ seem responsive and thus adequate for estimating utility in depression treatment. We do not recommend the use of the DFD method. The low agreement between utility changes indicates that outcomes of the different instruments are incomparable.
\end{abstract}




\section{Background}

Measuring health-related quality of life is relevant in patients with depression, since depression has a large impact on the physical, social and emotional aspects of the patient's well-being. ${ }^{1,2}$ In the field of economic evaluation, generic health-related quality of life (e.g. Euroqol (EQ-5D), Short form 6D (SF-6D)) is often one of the main outcome parameters. These instruments express health-related quality of life in utilities, which theoretically can range from 0 (the worst imaginable condition: death) to 1 (perfect health). Utilities are mainly used in economic evaluation and health technology assessment (HTA). These fields of study are to help policymakers in resource allocation decisions. ${ }^{3}$ Therefore, it is important that these utilities are responsive to changes in health status. However, in our randomised trial comparing three depression treatments, we found improvement in depression, but no improvement in utilities measured by the EQ-5D and SF-6D. ${ }^{4}$ This raises questions on the responsiveness of these measures for use in depression studies. As suggested by McCrone et al. ${ }^{5}$ and others, ${ }^{6}$ a likely limitation of the existing utility measures might be their large focus on physical health.

As stated above, depression has impact on several domains of quality of life, and consequently the utility measures should be responsive to changes in depression. Another aspect besides responsiveness is the question what utility change constitutes a relevant change. Calculation of the minimally important difference (MID) in utility change might be helpful here. The MID has been defined as "the smallest difference in score in the domain of interest that patients perceive as important, either beneficial or harmful, and which would lead the clinician to consider a change in the patient's management". ${ }^{7}$

This study evaluates change in utility during a 12 month follow-up period for patients with depression complaints. Utilities are calculated using the EQ-5D and SF-6D questionnaires, but also derived from depression severity questionnaires such as the Beck Depression Inventory Second Edition (BDI-II) using the Depression-Free-Day (DFD) method. ${ }^{8,9}$ Since several cost-effectiveness studies of depression treatments have used this approach to derive health-related quality of life from the $\mathrm{BDI}-\mathrm{II}^{10-12}$ or other depression questionnaires, ${ }^{13-21}$ this study included the DFD-derived utility (DFDu). Although the DFD method might give similar cost-utility ratios as generic instruments, recent studies have shown that these DFD-based quality-adjusted life years (QALYs) are significantly higher ${ }^{8}$ and have a poor to moderate agreement with QALYs derived from the SF-6D and EQ-5D. ${ }^{22}$ Therefore, this study will evaluate the responsiveness, the MID, and the agreement in utility change derived from the EQ-5D, SF-6D, as well as the DFDu.

\section{Method}

\section{Design and participants}

Data are used of a randomised trial comparing (1) computerised cognitive behavioral therapy (CCBT), with (2) treatment as usual by a general practitioner (TAU), and (3) a com- 
bination of both CCBT \& TAU for people with depressive complaints (BDI-II score $\geq 16$; age 18 to 65$)$. In the trial, 303 participants were recruited from the general population in the South of the Netherlands by means of a large-scale Internet-based screening. During a oneyear follow-up period, participants were asked to fill in Internet questionnaires. Further details of the design of the trial, the interventions and the population can be found elsewhere. $^{23,24}$

\section{Depression severity}

Depression severity was measured with the BDI-II. The total score is the sum of the 21 items with a range of 0 (no depression) to 63 (severe depression). There has been consistent support for the construct validity and reliability of the BDI-II in various samples. ${ }^{25-27}$

\section{Utility instruments}

Utilities were derived from the EQ-5D and the SF-6D. A utility refers to the preference that individuals or society have for any particular set of health outcomes. ${ }^{3}$ The EQ-5D consists of five health state dimensions (mobility, self-care, usual activity, pain/discomfort, and anxiety/depression) on which the respondent has to indicate his own health status choosing from three levels (no problem, some problems, and major problems). ${ }^{28,29}$ Standardized value sets are available to calculate the utility based on the EQ-5D. This study used the UK tariff (EQ-5D $\mathrm{UK}_{\mathrm{UK}}$ ) and the Dutch tariff (EQ-5D $\left.\mathrm{NL}_{\mathrm{NL}}\right)^{30,31}$

The SF-6D is a utility instrument based on the health-related quality of life questionnaire 36-item short-form Health Survey (SF-36). The utility is derived from 11 items of the SF-36 and is composed of six dimensions of health (physical functioning, role limitations, social functioning, pain, mental health, and vitality). The SF-6D utilities were derived by means of the preference-based UK tariff, ${ }^{32,33}$ no Dutch tariff is available.

Although theoretically a utility ranges from 0 (the worst imaginable condition: death) to 1 (perfect health), the EQ-5D UK tariff results in a range from -0.59 to 1, EQ-5D Dutch tariff results in a range from -0.33 to 1 , and the SF-6D tariff results in a range from 0.30 to 1 .

\section{DFD-derived utility (DFDu)}

The DFD method was originally developed by Lave et al. ${ }^{9}$ By means of this method, disease specific symptom severity information from the BDI-II and the Hamilton Rating ScaleDepression is converted into DFDs and subsequently transformed into a utility-weighted score to estimate QALYs. ${ }^{8,9}$ Since we only had data on the BDI-II, we derived the DFD from the BDI-II outcomes. The DFD attaches utility weights in a range of 0.6 to 1.0 at the BDI-II outcome. For all BDI-II scores below 9, the derived utility is 1.0 since the person is considered not depressed. For all BDI-II scores above 21 , the derived utility is 0.6 since this person is considered depressed. The derived utility for BDI-II scores from 9 until 21 is calculated proportionally. ${ }^{8}$ 


\section{Analysis}

All available data of the baseline and 12-months follow-up period were used. Data of patients lost to follow-up were not imputed. Change scores in utility from baseline to twelve months follow-up were calculated. Preliminary, the normality of the data was assessed by means of histograms and skewness and kurtosis statistics. To facilitate interpretation of the findings, change scores on the BDI-II and utility measures were calculated such that a positive change score reflects an improvement, and a negative change score reflects a deterioration. To evaluate the responsiveness of the SF-6D, EQ-5D $D_{\mathrm{UK}}, E Q-5 D_{\mathrm{NL}}$ and DFDu utilities, we used two different approaches: an anchor-based approach and a linear regression analysis.

All analyses were carried out using SPSS version 15.0.1 for Windows.

\section{Anchor-based subgroups}

For the anchor-based approach of responsiveness we followed the recommendations of Revicki et al. ${ }^{34}$ In this approach, the population is divided in several subgroups based on certain criteria. These criteria, or 'anchors' indicate whether patients have improved or worsened over time. The anchors are external indicator; e.g. clinical endpoints, or patientbased ratings of change can be used as an anchor. As it is recommended to use multiple independent anchors to confirm responsiveness, ${ }^{34}$ we used two BDI-II-based anchors and one retrospective self-report anchor.

For the BDI-II-based anchor, we used the methodology of Jacobson and Truax to determine clinically meaningful changes on the BDI-II. ${ }^{35,36}$ This approach is based on two components: (1) reliable change $(\mathrm{RC})$, being the extent to which the pre-to-post-difference score is reliable taking into account the measurement variability of the instrument; and (2) clinically significant change (CSC), being the extent to which post-treatment scores are clinically meaningful. In our population, the RC was calculated as a change of at least 9 points during follow-up, and the CSC as a follow-up score below 12 on the BDI-II. ${ }^{23}$ Based on the RC, the following three subgroups were created: deterioration (i.e. deterioration by at least 9 points on the BDI-II), no change, and improvement (i.e. an improvement with at least 9 points on the BDI-II). Based on the CSC, the population was divided in two subgroups: improvement and no improvement (i.e. still depressed, a BDI-II score $\geq 12$ ).

For retrospective self-report, the SF-36 health change item was used as an anchor. This item is a global rating of change (GRoC) scale and consists of the question "Compared to one year ago, how would you rate your health in general now?" The population is divided into five subgroups, based on the answers given on a 5-point Likert scale (5. Much better now / 4. Somewhat better now / 3. About the same / 2. Somewhat worse / 1 . Much worse than 1 year ago). The GRoC item is not included in the SF-6D.

As recommended by Revicki et al., ${ }^{34}$ the correlation between the anchor and the change in utility (SF-6D, EQ-5D $D_{U K}, E Q-5 D_{N L}$ and DFDu) was assessed. A correlation of 0.30 to 0.35 was used as a threshold to define an acceptable association. ${ }^{34}$ Due to non-normality of the data, the Spearman correlation was used. 
MID

The MID in utility change was calculated according to the anchor-based approach. The GRoC was used as anchor, assuming that patients who score 4 or 2 have experienced some change equivalent to the MID. ${ }^{37,38}$ The MID was calculated separately for respondents who rated their health to be somewhat better (item 4) and respondents who rated their health somewhat worse (item 2) than one year ago.

\section{Responsiveness: anchor-based approach}

Responsiveness to change within each anchor-based subgroup was based on statistical indicators, being the standardized response mean (SRM) and the effect size (ES). ${ }^{34,39}$ The method to calculate the $S R M$ was $S R M=M_{\text {follow-up }}-M_{\text {baseline }} / S D_{\text {change, }}$ where $M_{\text {baseline }}$ is the mean score at baseline, $\mathrm{M}_{\text {follow-up }}$ is the mean score at the follow-up moment, and $\mathrm{SD}_{\text {change }}$ is the standard deviation of the change in score. ${ }^{40}$ The method to calculate ES was ES=M $\mathrm{M}_{\text {follow- }}$ up $-M_{\text {baseline }} / S_{\text {baseline, }}$ where $M_{\text {baseline }}$ is the mean score at baseline, $M_{\text {follow-up }}$ is the mean score at the follow-up moment, and $\mathrm{SD}_{\text {baseline }}$ is the pooled standard deviation at baseline. ${ }^{41}$ The interpretation of the SRM and ES is based on Cohen's guidelines, where a score $<|0.20|$ is considered trivial, from $\geq|0.20|$ to $<|0.50|$ small, from $\geq|0.50|$ to $<|0.80|$ medium, and from $\geq|0.80|$ large change scores. ${ }^{41}$ The SRM and ES of each anchor-based subgroup (i.e. $\mathrm{RC}, \mathrm{CSC}$, and $\mathrm{GRoC}$ ) were calculated.

\section{Responsiveness: regression approach}

For evaluating responsiveness using regression analysis, we first calculated the correlation between the BDI-II change and utility change from baseline to 12 months follow-up. In a scatterplot, the change in BDI-II was related to the change in utility. In linear regression analysis, the relation between utility change (dependent variable) and BDI-II change (independent variable) was assessed. The correlation, scatterplot and linear regression analysis were performed for each of the utility measures (SF-6D, EQ-5D $D_{\mathrm{UK}}, \mathrm{EQ}-5 \mathrm{D}_{\mathrm{NL}}$ and DFDu) separately.

\section{Agreement between utility changes}

To study the agreement between the different measures' utility changes from baseline to 12 months follow-up, Spearman correlations and intraclass coefficients (ICC) were calculated. A two-way mixed effect model was used to calculate the ICC for full agreement. ${ }^{42} \mathrm{An}$ ICC below 0.40 implies poor reliability, between 0.40 and 0.75 moderate reliability, and above 0.75 indicates good agreement. ${ }^{43,44}$

\section{Results}

\section{Population}

In total, data of 267 trial participants were available at 12 months follow-up. Table 1 presents the baseline characteristics of these participants. The distribution of responses to the EQ-5D and SF-6D items at baseline and 12-months follow-up are presented in figures 1 and 2. At baseline, problems were mainly reported on the EQ-5D items anxiety/depression 
(80.5\%), pain/discomfort (60.7\%) and usual activities (59.6\%), and less on the items mobility (19.9\%) and self-care (2.2\%). After 12 months follow-up, there were some changes on all items. The item anxiety/depression showed a clear improvement (from 19.5\% to $44.9 \%$ having no problems), and the item usual activities seemed to show small improvement (from $40.4 \%$ to $49.1 \%$ having no problems). The items mobility, self-care and pain/discomfort showed no change to some small worsening in experienced problems.

The participants seemed to have responded differently on the SF-6D dimensions: for each dimension a majority of patients reported to have at least some problems $(>72.3 \%)$. Whereas there seemed to be some improvement in the domains role limitation, social functioning, mental health, and vitality (an increasing group answering level 1 or 2 from baseline to follow-up), there was no change or even a small worsening in the physical functioning and pain domain.

Table 1: Baseline characteristics of participants $(n=267)$

\begin{tabular}{ll}
\hline Characteristic & Descriptive statistic \\
\hline Sex, male, nr (\%) & $118(44 \%)$ \\
Age, M (SD) & $45.0(11.5)$ \\
Educational level & \\
$\quad$ Low, nr (\%) & $48(19 \%)$ \\
$\quad$ Middle, nr (\%) & $140(54 \%)$ \\
$\quad$ High, nr (\%) & $72(28 \%)$ \\
Partner, yes, nr (\%) & $187(72 \%)$ \\
Employed, yes, nr (\%) & $174(65 \%)$ \\
BDI-II, M (SD) & $27.7(7.6)$ \\
SF-6D, M (SD) & $0.66(0.08)$ \\
EQ-5D & $0.71(0.20)$ \\
EQ-5D $(S D)$ & $0.71(0.18)$ \\
DFDu, M (SD) & $0.62(0.05)$ \\
\hline
\end{tabular}

Note. BDI-II, Beck Depression Inventory Second Edition; SF-6D, Short-Form 6D utility derived by the UK tariff; EQ-5D $\mathrm{UK}_{\mathrm{K}}$, Euroqol 5D utility derived by the UK tariff; EQ-5D $\mathrm{NL}_{\mathrm{N}}$, Euroqol 5D utility derived by the Dutch tariff; DFDu, Depression Free Days derived utility derived from the BDI-II; M, mean; SD, standard deviation; $\mathrm{nr}$, number.

${ }^{a}$ Data unavailable for 7 persons; ${ }^{b}$ Data unavailable for 7 persons; ${ }^{c}$ Data unavailable for 28 persons. 


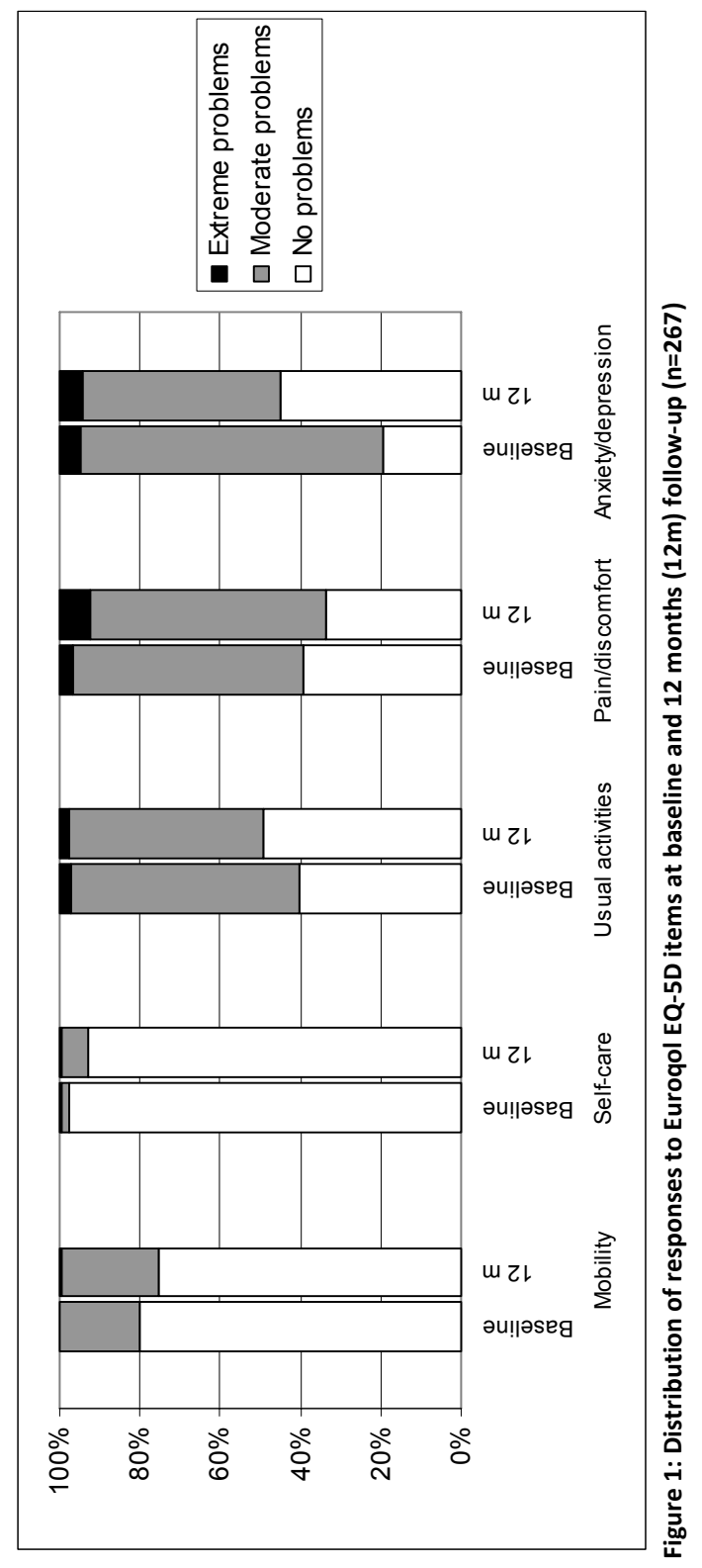




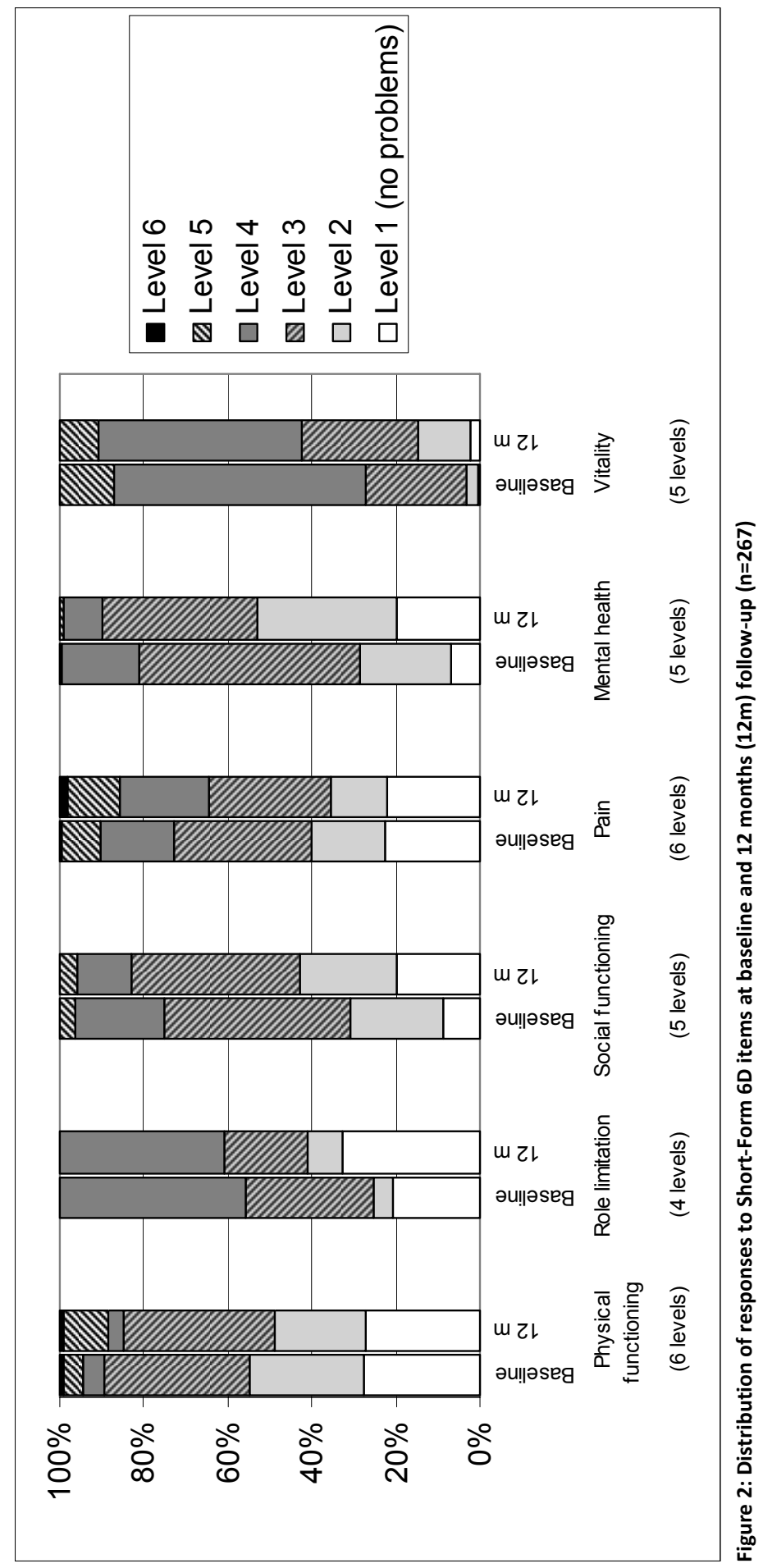




\section{Anchor-based subgroups}

According to the recommendations of Revicki et al., ${ }^{34}$ a correlation of at least 0.30 to 0.35 between the anchor and the change in utility was required to use the anchor as a threshold. As presented in table 2, the association between the anchors and the utility change scores from baseline to 12 months was of an acceptable level, with all three anchors showing significant medium correlations in the range of 0.309 to 0.472 , except for the high correlations of 0.722 and 0.793 between the DFDu and the RC and CSC anchor.

Table 2: Spearman correlations between anchors and utility change from baseline to 12 months follow-up ( $\mathrm{n}=\mathbf{2 6 7 )}$

\begin{tabular}{llll}
\hline Utility change & \multicolumn{2}{c}{ Anchor } \\
\cline { 2 - 4 } & RC & CSC & GRoC \\
\hline SF-6D & 0.368 & 0.334 & 0.437 \\
EQ-5D & 0.355 & 0.309 & 0.386 \\
EQ-5D $_{\mathrm{NL}}$ & 0.398 & 0.330 & 0.379 \\
DFDu & 0.722 & 0.793 & 0.472 \\
\hline
\end{tabular}

Note. SF-6D, Short-Form 6D utility derived by the UK tariff; EQ-5D UK, Euroqol 5D utility derived by the UK tariff; EQ- $5 \mathrm{D}_{\mathrm{NL}}$, Euroqol 5D utility derived by the Dutch tariff; DFDu, Depression Free Days derived utility derived from the BDI-II; RC, reliable change on the BDI-II (i.e. a decrease of at least 9 points during followup); CSC, clinically significant change on the BDI-II (i.e. a follow-up score below 12); GRoC, global rating of change.

All correlations are significant at the 0.01 level.

\section{Responsiveness: anchor-based approach}

The SF-6D, EQ-5D $\mathrm{UK}_{\mathrm{K}}, \mathrm{EQ}-5 \mathrm{D}_{\mathrm{NL}}$, and DFDu utilities at baseline and 12 months follow-up, their change scores, SRM and ES are presented in table 3.

DFDu

Regarding the DFDu, the direction of the SRM and ES did not always correspond with the direction of change according to the anchor. The DFDu showed medium to large positive SRM and ES for all anchor subgroups (i.e. improvement, no change and deterioration), with only exception of the RC subgroup with deterioration.

SF-6D, EQ-5D $D_{U K}$, and $E Q-5 D_{N L}$

For the RC anchor, all three generic measures SF-6D, EQ-5D $\mathrm{UK}_{\mathrm{U}}$, and EQ-5D $\mathrm{DL}_{\mathrm{NL}}$ showed large SRM and ES for the deterioration subgroup, and small to medium changes for the improvement subgroup. In the RC subgroup without reliable change, the SRM and ES did show small negative changes for the EQ-5D $\mathrm{UK}_{\mathrm{K}}$ and $\mathrm{EQ}-5 \mathrm{D}_{\mathrm{NL}}$.

In the CSC improvement subgroup, the SRM and ES showed small to large improvements on all three utility measures. For the subgroup without improvement, the SRM and ES of the SF-6D and EQ-5D $D_{\mathrm{NL}}$ and the SRM of the EQ-5D $\mathrm{UK}_{\mathrm{UK}}$ did not show substantial changes in utility. The ES of the EQ-5D $D_{U K}$, showed a small decrease in utility. 


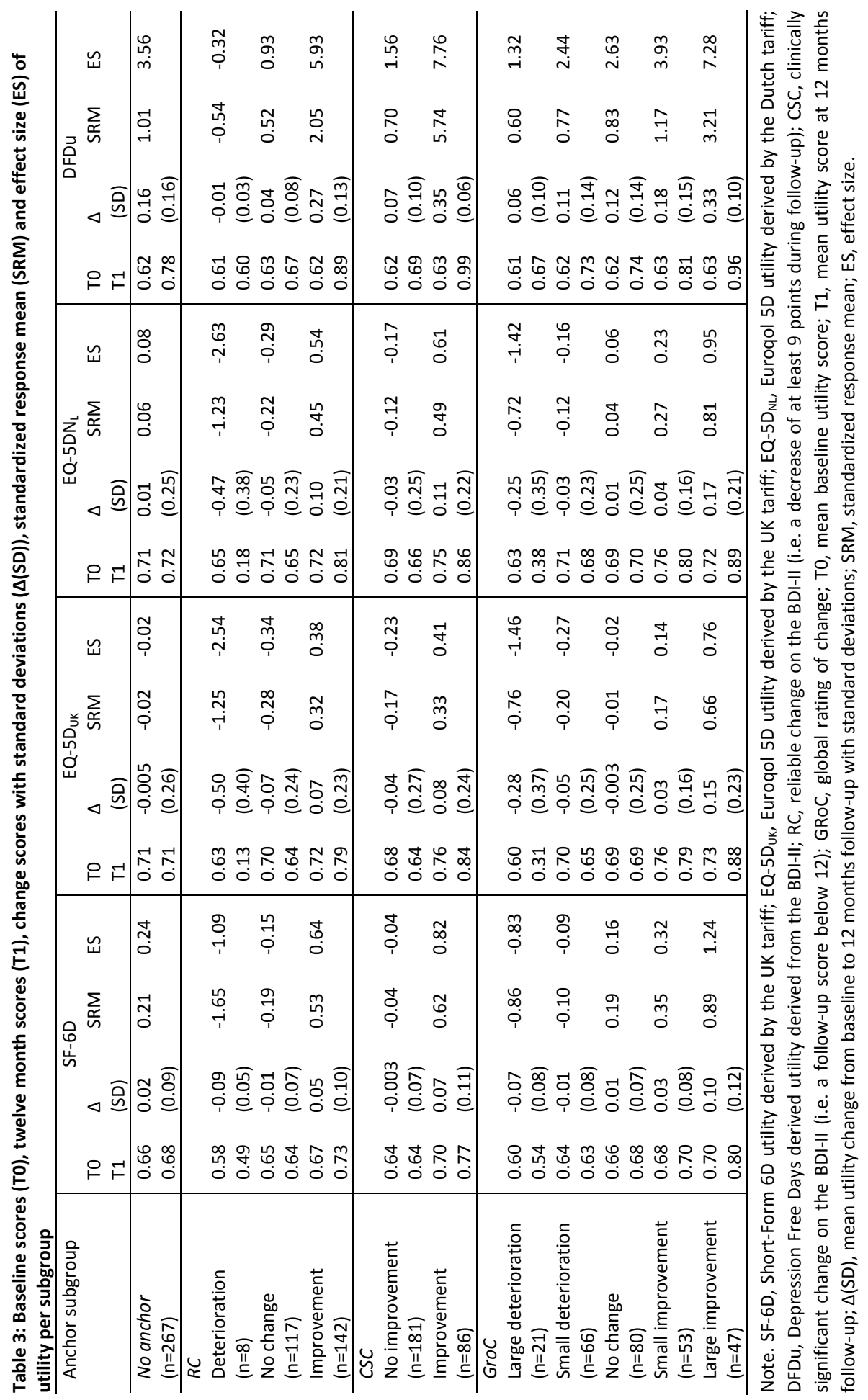


For the GRoC anchor, the subgroups with large deterioration/improvement, showed medium to large SRM and ES on all utility measures. For the no change GRoC subgroup, there were no substantial changes in utility found on all SRM and ES outcomes. Although small improvements on the GRoC were related with SRM and ES showing small improvements in SF-6D and EQ-5D $D_{N L}$, no substantial improvements were detected for the EQ-5D $D_{U K}$ changes. Conversely, the EQ-5D $D_{U K}$ SRM and ES showed small utility changes for the GRoC subgroup with small deterioration, while no substantial changes were detected in SF-6D and EQ-5D $D_{\mathrm{NL}}$. Comparing these three instruments, the SRM and ES of improvement subgroups were highest for the SF-6D, and lowest for EQ-5D $D_{U K}$, while all three utility measures showed large SRM and ES values for (large) deterioration subgroups. The standard deviations of the baseline utility and the utility change from baseline to follow-up were lower for the SF-6D as opposed to the EQ-5D $D_{U K}$ and EQ-5D $D_{\mathrm{NL}}$, which can explain the larger SRM and ES values of the SF-6D.

\section{MID}

The MID based on the GRoC can be read from table 3 as being $-0.01,-0.05$, and -0.03 for respectively the SD-6D, EQ- $5 D_{\mathrm{UK}}$, and $\mathrm{EQ}-5 \mathrm{D}_{\mathrm{NL}}$ in the 'small deterioration' subgroup, and respectively $0.03,0.03$, and 0.04 in the 'small improvement' subgroup. 


\section{Responsiveness: regression approach}

The scatterplots of figure 3 indicate that for each of the utility instruments a large number of respondents showed no change (i.e. SF-6D, EQ-5D $D_{\mathrm{UK}}, E Q-5 D_{\mathrm{NL}}$ and DFDu change of 0.00 ). However, there seems to be a trend that an improvement in utility change is associated with an improvement of depression symptoms measured by the BDI-II. This is confirmed by the correlations between utility changes and depression severity changes shown in table 5 : significant correlations of a medium size were found for the BDI-Il change with SF-6D $(r=0.447), E Q-5 D_{U K}(r=0.414)$, and EQ-5D $D_{N L}(r=0.472)$ change. A large correlation was found for BDI-II change with DFDu change $(r=0.829)$. The outcomes of the regression analyses presented in table 4 also indicate that the change in utility is significantly associated with change in depression severity, whereby an improvement in BDI-II is related with an improvement in utility. The BDI-II change had highest explanatory power in predicting utility change of the DFDu, followed by the SF-6D, EQ-5D $\mathrm{NL}_{\text {and }}$ aQ- $5 \mathrm{D}_{\mathrm{UK}}$ (Adj. $\mathrm{R}^{2}$ of respectively $0.618,0.255,0.232$, and 0.198 ).

Table 4: Regression analyses with change in depression severity (independent variable) and change in utility (dependent variable) from baseline to 12 months follow-up ( $n=267$ )

\begin{tabular}{|c|c|c|c|c|c|c|}
\hline \multirow[t]{2}{*}{$\begin{array}{l}\text { Dependent } \\
\text { variable }\end{array}$} & \multirow[t]{2}{*}{$\begin{array}{l}\text { Independent } \\
\text { variable }\end{array}$} & \multicolumn{2}{|c|}{$\begin{array}{l}\text { Unstandardized } \\
\text { Coefficients }\end{array}$} & \multirow{2}{*}{$\begin{array}{l}\text { Standardized } \\
\text { Coefficients } \\
\beta\end{array}$} & \multirow[t]{2}{*}{$\mathrm{R}^{2}$} & \multirow[t]{2}{*}{$\begin{array}{l}\text { Adj. } \\
R^{2}\end{array}$} \\
\hline & & B & Std. Error & & & \\
\hline \multirow[t]{2}{*}{ SF-6D change } & & -0.025 & 0.007 & & & \\
\hline & BDI-Il change & 0.004 & 0.000 & 0.508 & 0.258 & 0.255 \\
\hline \multirow[t]{2}{*}{$E Q-5 D_{U K}$ change } & & -0.116 & 0.020 & & & \\
\hline & BDI-II change & 0.011 & 0.001 & 0.448 & 0.201 & 0.198 \\
\hline \multirow[t]{2}{*}{$E Q-5 D_{N L}$ change } & & -0.101 & 0.019 & & & \\
\hline & BDI-II change & 0.011 & 0.001 & 0.484 & 0.235 & 0.232 \\
\hline \multirow[t]{2}{*}{ DFDu change } & & 0.043 & 0.008 & & & \\
\hline & BDI-II change & 0.011 & 0.001 & 0.787 & 0.619 & 0.618 \\
\hline
\end{tabular}

Note. BDI-II, Beck Depression Inventory Second Edition; SF-6D, Short-Form 6D utility derived by the UK tariff; EQ-5D $D_{U K}$, Euroqol 5D utility derived by the UK tariff; EQ-5D $D_{\mathrm{NL}}$, Euroqol 5D utility derived by the Dutch tariff; DFDu, Depression Free Days derived utility derived from the BDI-II; St. Error = Standard error; Adj. $R^{2}$, Adjusted $\mathrm{R}^{2}$.

All coefficients are significant with $\mathrm{p}=0.000$.

For interpretation of the coefficients: Both BDI-II and utility changes were calculated such that positive change scores reflect an improvement, whereas negative change scores reflect a deterioration in the health status. 

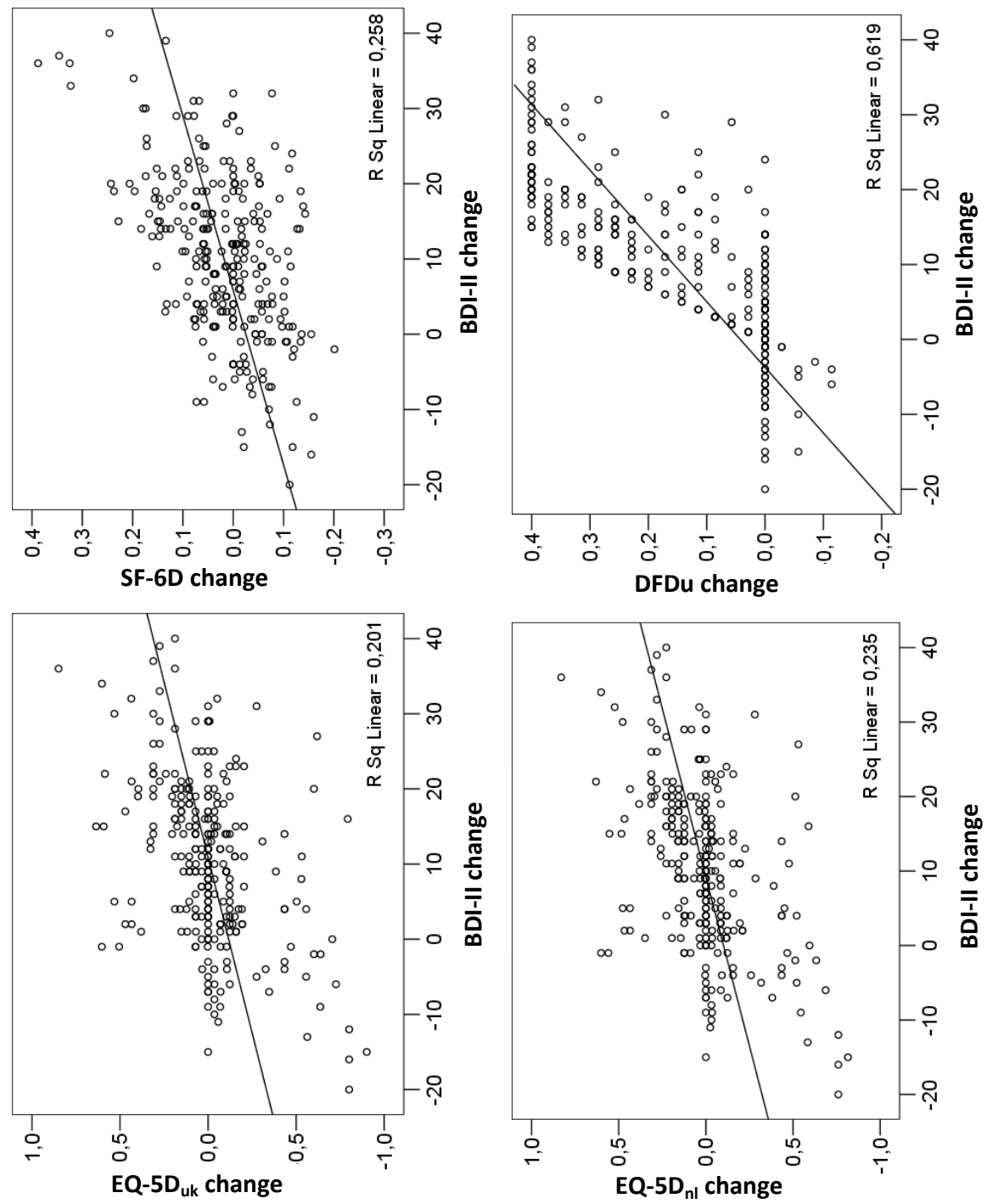

Figure 3: Scatterplots of the change in depression severity related to the change in utility from baseline to 12 months follow-up ( $n=267$ )

Note. BDI-II, Beck Depression Inventory Second Edition; SF-6D, Short-Form 6D utility derived by the UK tariff; EQ-5D $\mathrm{UK}_{\mathrm{K}}$, Euroqol 5D utility derived by the UK tariff; EQ-5D $\mathrm{NL}_{\mathrm{NL}}$ Euroqol 5D utility derived by the Dutch tariff; DFDu, Depression Free Days derived utility derived from the BDI-II.

For interpretation of the scatterplots: Both BDI-II and utility changes were calculated such that positive change scores reflect an improvement, whereas negative change scores reflect a deterioration in the health status. 


\section{Agreement between utility changes}

Table 5 presents the correlations and ICCs of the utility changes derived from the different instruments used in this study. All correlations and ICCs were significant. Correlations with the DFDu were medium (0.397-0.449), correlations of the SF-6D with the EQ- $5 D_{U K}$ and EQ$5 D_{N L}$ were large $(0.538-0.548)$, and the correlation between the EQ-5D $D_{U K}$ and EQ-5D $D_{N L}$ was very large (0.969). All ICC values showed poor agreement between the instruments (0.221$0.356)$, with exception of the strong agreement between the EQ-5D $\mathrm{UK}_{\mathrm{K}}$ and $\mathrm{EQ}-5 \mathrm{D}_{\mathrm{NL}}(0.984)$.

Table 5: ICC agreement and Spearman correlation between utility change scores, and Spearman correlation between utility change and depression severity change from baseline to 12 months follow-up ( $n=267$ )

\begin{tabular}{|c|c|c|c|c|c|}
\hline & \multicolumn{4}{|c|}{$\begin{array}{c}\text { Utility change } \\
\text { Spearman correlation } \\
\text { ICC } \\
(95 \% \mathrm{Cl})\end{array}$} & $\begin{array}{l}\text { Depression severity change } \\
\text { Spearman correlation }\end{array}$ \\
\hline & SF-6D & $E Q-5 D_{U K}$ & $E Q-5 D_{N L}$ & DFDu & BDI-II \\
\hline \multirow[t]{3}{*}{ SF-6D } & & 0.548 & 0.538 & 0.403 & 0.447 \\
\hline & & 0.346 & 0.356 & 0.226 & \\
\hline & & $(0.236 ; 0.447)$ & $(0.247 ; 0.457)$ & $(-0.032 ; 0.437)$ & \\
\hline \multirow[t]{3}{*}{$E Q-5 D_{U K}$} & & & 0.969 & 0.397 & 0.413 \\
\hline & & & 0.984 & 0.221 & \\
\hline & & & $(0.972 ; 0.990)$ & $(0.047 ; 0.372)$ & \\
\hline \multirow[t]{3}{*}{$E Q-5 D_{N L}$} & & & & 0.449 & 0.472 \\
\hline & & & & 0.267 & \\
\hline & & & & $(0.082 ; 0.422)$ & \\
\hline DFDu & & & & & 0.829 \\
\hline
\end{tabular}

Note. BDI-II, Beck Depression Inventory Second Edition; SF-6D, Short-Form 6D utility derived by the UK tariff; EQ-5D $D_{\mathrm{uK}}$, Euroqol 5D utility derived by the UK tariff; EQ-5D $\mathrm{NL}_{\mathrm{N}}$, Euroqol 5D utility derived by the Dutch tariff; DFDu, Depression Free Days derived utility derived from the BDI-II; ICC, intraclass coefficient; $\mathrm{Cl}$, confidence interval.

All correlations and ICCs are significant at the 0.01 level.

For interpretation of the correlations: Both BDI-II and utility changes were calculated such that positive change scores reflect an improvement, whereas negative change scores reflect a deterioration in the health status.

\section{Discussion}

\section{Main results}

The utility instruments SF-6D, EQ-5D $D_{\mathrm{UK}}, E Q-5 D_{\mathrm{NL}}$, and DFDu showed to be responsive to changes in depression severity measured by the BDI-II. However, the direction of the SRM and ES of the DFDu changes often did not correspond with the change according to the anchors. That is, the DFDu SRM and ES nearly always provided moderate to large positive changes in utility, even for subgroups which reported no change and some deterioration subgroups (i.e. the CSC and GRoC anchors). Therefore, the DFDu seems less suited in capturing negative quality of life changes. 
When comparing the SRM, ES and regression outcomes of the SF-6D, EQ-5D $\mathrm{UK}_{\mathrm{UK}}$, and EQ-5D $\mathrm{D}_{\mathrm{NL}}$, the SF-6D is most responsive, followed by the EQ-5D $D_{\mathrm{NL}}$. The ICC showed a poor agreement between the utility changes derived from the different instruments.

\section{Responsiveness and MID of utility measures}

This study showed the SF-6D, EQ- $5 D_{U K}, E Q-5 D_{N L}$ to be responsive to changes in depression. This seems to be in contradiction with earlier findings from the trial from which the current data derive: The (cost-)effectiveness findings of our trial showed some improvement in depression in the three treatment groups, but no changes in quality of life utility. ${ }^{4,23}$ This contradiction between the BDI-II outcomes versus the SF-6D, EQ-5D $D_{\mathrm{UK}}$, and EQ-5D $\mathrm{NL}_{\mathrm{NL}}$ outcomes can be explained from two different perspectives: either the overall change in depression of one treatment group was not large enough to generate a substantial change in utility for the respective treatment group, or the utility instrument -though responsivemight be less able to capture smaller group changes in depression severity. Further exploration on the relation between depression severity and utility might focus on the question from which point on a utility instrument responds to a change in depression, e.g. how much change in depression severity results in a change in utility, and whether this differs among depression severity groups? It should be noted that we did not use the DFD-method to derive utilities or QALYs in the cost-effectiveness study.

The SF-6D responsiveness seems higher compared to the EQ-5D. In accordance with the findings of Lamers et al. ${ }^{46}$ the lower standard deviations of the SF-6D utility change resulted in higher SRM scores compared to the EQ-5D. This difference in standard deviations might be a result of differences between the two instruments valuations and descriptive system. Previous research indicated that much of the discrepancy between both measures stems from differences in the valuation of the health states. ${ }^{47}$ And the descriptive system of the SF-6D is more detailed towards depression changes as opposed to the EQ-5D: Each of the five EQ-5D domains is based on only one question with three answer options. And only the domains 'anxiety/depression' and 'usual activities' of the EQ-5D can be considered directly influenced by changes in depression. The SF-6D is derived from the SF-36 and includes six domains based on eleven questions with each more than three answer options. Besides the mental health domain, the questions used to derive the SF-6D explicitly mention the aspect 'emotional problems' in the domains social functioning and role limitation, and include a domain on 'vitality'. Only the SF-6D domains 'physical functioning' and 'pain' focus specifically on physical health.

The higher responsiveness of the EQ- $5 \mathrm{D}_{\mathrm{NL}}$ as opposed to the EQ-5D $\mathrm{D}_{\mathrm{UK}}$ might be explained by the tariff: The time-trade-off value set of the UK tariff attaches lower values to the anxiety/depression domain compared with the Dutch tariff. ${ }^{30,31,48}$ Thus, a change on the anxiety/depression domain will have more impact on the EQ-5D $D_{\mathrm{NL}}$ than on the EQ-5D $\mathrm{DK}_{\mathrm{UK}}$.

Our MID findings for the SF-6D and EQ-5D are rather close to the 0.03 utility change which is -based on the studies of Walters and Brazier ${ }^{37,38}$ - often considered as a MID cut-off. ${ }^{\text {e.g. }}$ ${ }^{49,50}$ These studies of Walters and Brazier on the anchor-based MID using the GRoC SF-36 item in various patient groups, found SF-6D changes ranging from 0.010 to $0.097,,^{37,38}$ and EQ-5D changes ranging from -0.011 to 0.14 to be important. ${ }^{37} \mathrm{~A}$ recent study on spinal cord injury using the same anchor, found an MID of 0.03 for the SF-6D. ${ }^{51}$ 
As argued by Brazier and Deverill, ${ }^{52}$ a larger ES does not necessarily imply a better utility instrument. Within economic evaluation, it is the change in preferences that matters. "ES or clinical changes do not reflect the importance of a change to patients. It is the sensitivity or responsiveness to changes in preferences that is required for economic evaluation. ${ }^{52,}$ From this point of view, we can argue the GRoC anchor to be more relevant as opposed to the CSC or RC anchor for health-related quality of life, as the GRoC refers to the patient's subjective experienced change in quality of life, subjective experience of whether the health status is valued better, equal or worse as opposed to the health status one year before.

Although using general population preference-based utility tariffs, the anchors used for calculating the responsiveness and MID are not defined from a general population valuation. The results on responsiveness outcomes are calculated only using patient-based and distribution-based anchors. Other studies also used a clinician-based anchor to estimate responsiveness. The MID is only based on a patient-based anchor, whereas also distribution-based methods can be used. However, as mentioned by Revicki et al., ${ }^{34}$ the distribution-based approach will provide change scores that are clinically significant and meaningful, but these are not necessarily minimal. We therefore decided to limit the MID analysis to the anchor-based approach using the GRoC based on the SF-36. But the use of the GRoC questions also has its disadvantages. Recall bias of respondents can be expected in comparing today's health with their health state of one year ago. ${ }^{53}$ Research also indicated that patients' retrospective estimates of health change are highly correlated with their present health state. ${ }^{54}$ The patient's valuation of quality of life might shift over time due to adaptation to the disorder. Experiencing changes in health may change people's internal standards, values and/or conceptualization of health-related quality of life.$^{55}$ Consequently, our data (not only the GRoC anchor, but also the utility and BDI-II data) might be subjected to this response shift.

A limitation of this study is that some of the subgroups were rather small (e.g. RC deterioration group, GRoC large deterioration subgroup). Moreover, the data we used were trial data, which were randomised into treatment groups. This means that the subgroups created on the GRoC, CSC and RC anchors sometimes differ with respect to baseline characteristics.

Another point of attention is that this study indirectly assumes a concurrent relation between utility change from baseline to 12 months follow-up and depression change: the RC and CSC anchors reflect the change in depression severity from baseline to 12 months follow-up. Since the utility instruments measure a patient's subjective well-being, it can be expected that change in quality of life is preceded by clinical change. It might take some time before the patient comes to realize how his changes in complaints affect his life in general. Therefore, not only the concurrent relation between change in depression and utility, but also the temporal relation between these changes could be of interest in studying responsiveness.

\section{Utility agreement}

In this study, the ICC indicated a rather low agreement between the utility changes from the SF-6D, EQ-5D (either UK or Dutch tariff) and DFDu. These differences in utility changes 
might be explained by the differences in mean changes and/or the related standard deviations between the instruments. Likely explanations are the difference in the range of utilities which can be achievied through the instruments, and -as mentioned above- the differences in descriptive system and tariffs.

Only one other study compared outcomes derived from the SF-6D, EQ-5D $D_{\mathrm{NL}}, E Q-5 D_{\mathrm{UK}}$, and the DFD. In accordance with our findings, Jonkers et al. ${ }^{22}$ found a large agreement between the QALYs based on the EQ-5D $\mathrm{NL}_{\mathrm{NL}}$ and EQ-5D $\mathrm{DK}_{\mathrm{UK}}$, and a poor agreement of the QALY based on the DFD method with QALYs derived from either the SF-6D, EQ-5D $\mathrm{NL}_{\mathrm{NL}}$ or EQ-5D $\mathrm{D}_{\mathrm{UK}}$. However, studies of Jonkers et al., ${ }^{22}$ Barton et al., ${ }^{56}$ and Brazier et al. ${ }^{57}$ mostly found better agreement between the SF-6D and EQ-5D compared to our study (i.e. ICC agreement of 0.47 to 0.53 between QALYs, ${ }^{22}$ Pearson correlations about 0.7 to 0.8 between utilities, ${ }^{56}$ and/or ICC agreement of 0.5 to $0.7,^{56}$ respectively 0.3 to $0.5^{57}$ between utilities). This might be explained by our focus on depressive complaints, while Barton et al. ${ }^{56}$ and Brazier et al. ${ }^{57}$ did not specifically focus on mental health complaints, and Jonkers' study consisted of chronically ill elderly with co-occurring depression. A study of Kontodimopoulos et al. ${ }^{58}$ indeed found an ICC value for depression of 0.441 , whereas for most other clinical (not specifically mental) conditions a somewhat higher ICC agreement of about 0.5 was found. The finding of a poor agreement between different utility instruments implies that utilities derived from different instruments can not be used interchangeably: utility changes derived from one instrument can not be compared directly with utilities changes derived from another utility instrument.

Furthermore, while we focused on agreement in utility change, previous studies assessed agreement in utility ${ }^{56-58}$ or QALY. ${ }^{22}$ Our reason for using utility change instead of QALY was that we were interested in measuring whether the instruments are responsive (i.e. can show changes). In our study, calculating the QALY during the one-year follow-up period would mean that we adjusted the length of the follow-up period by the utility value of both the baseline and follow-up period. The inclusion of the baseline utility value in the QALY would mean that it shows less change than looking at the difference between the follow-up and the baseline utility. Moreover, an advantage of the QALY is that it simultaneously combines morbidity and mortality. ${ }^{3}$ But in our study there was no mortality.

\section{Limitations of the DFDu instrument}

Based on our outcomes, the DFD seems not suited for deriving utility (and subsequently calculating QALY) in depression. The positive and large SRM and ES of the DFDu might be explained by the range of the DFD. The DFD attaches utility weights in the range of 0.6 to 1.0 to the BDI-II score of respectively $>21$ and $<9 .{ }^{8}$ At baseline, the required BDI score of our trial participants was at least 16 , while the actual mean BDI score was 27.7 . In total $78 \%$ of all trial participants had a baseline score above 21 (DFDu of 0.6 ), meaning that they could not show a decrease in DFD derived utility during the follow-up period. The DFDu of this $78 \%$ could only remain constant at 0.6 or improve towards 1.0 , whereas an increase in depression severity (BDI-II) could not be projected in their DFDu. This also resulted in small standard deviations of the baseline DFDu and of change in DFDu, leading to very large SRM's and ES's. The DFDu does give high correlations with the BDI-II, and a high predictive 
power from the BDI-II. But these findings are less than surprising since the DFDu is derived from the BDI-II.

Although we do not recommend the DFD method based on our outcomes, this conclusion must be drawn with caution since we only used one manner to calculate the DFDu based on only one dataset. Broadening the ranges of the BDI-II and utilities in the calculation of the DFDu might overcome some of the DFDu limitations. Some economic evaluation studies adopted the method of Lave et al. ${ }^{9}$ to calculate DFD-based QALYs. ${ }^{10,12}$ However, other studies deriving utilities and/or QALYs from the DFD-method have used a different range then the 0.6 to 1.0 utility, varied the BDI-II or Hamilton Rating Scale-Depression score to attach the minimal and maximal utility, and/or used another depression questionnaire instead of the BDI-II or Hamilton Rating Scale-Depression. ${ }^{11,13-21}$ Thus, different studies used different methods to calculate the utility and/or QALY through the DFD method. These variations might improve the DFD method and imply differences in the utility outcomes. However, the comparability of the DFD-derived quality of life outcomes with the outcomes of generic utility instruments may still cause problems since the DFD method attaches utility weights to depression severity outcome alone. The DFD-derived QALY or utility thus might not take into account possible changes in other health-related quality of life aspects resulting through side-effects of treatment or co-morbidity of depression.

\section{Conclusion}

Based on our results, the SF-6D, EQ-5D $\mathrm{D}_{\mathrm{UK}}$, and $\mathrm{EQ}-5 \mathrm{D}_{\mathrm{NL}}$ are responsive to changes related to depression severity and health status, and thus seem adequate for estimating utility in depression treatment. We do not recommend the use of the DFD method. For respondents reporting no change or a worsening of their health status or depression severity according to the CSC or GRoC anchor, the SRM and ES of the DFDu even reported an improvement in quality of life. Since the agreement between the generic utility changes (i.e. SF-6D, EQ-5D $D_{U K}$, and $E Q-5 D_{\mathrm{NL}}$ ) and the DFDu changes as well as between the SF-6D and EQ-5D was poor, the utilities from these instruments seem not comparable.

\section{Acknowledgements}

We thank Annie Hendriks and Greet Kellens for their assistance during the study and Rosanne Janssen for the development of the infrastructure for online data-collection.

The trial is financed by ZonMw (Netherlands Organisation for Health Research and Development; project number 945-04-417), research institute EPP and research institute CAPHRI. Municipalities Eijsden, Meerssen, Sittard-Geleen, Valkenburg and Maastricht sponsored the study. 


\section{References}

1. Bijl RV, Ravelli A. Current and residual functional disability associated with psychopathology: findings from the Netherlands Mental Health Survey and Incidence Study (NEMESIS). Psychol Med 2000;30:657668.

2. Kruijshaar ME, Hoeymans N, Bijl RV, Spijker J, Essink-Bot ML. Levels of disability in Major Depression. Findings from the Netherlands Mental Health Survey and Incidence Study (NEMESIS). J Affect Disord 2003;77(1):53-64.

3. Drummond MF, Sculpher MJ, Torrance GW, O'Brien B, Stoddart GL. Methods for the Economic Evaluation of Health Care Programmes. Oxford: Oxford University Press, 2005.

4. Gerhards SAH, de Graaf LE, Jacobs LE, Severens JL, Huibers MJH, Arntz A, et al. Economic evaluation of online computerised cognitive-behavioural therapy without support for depression in primary care: randomised trial. Br J Psychiatry 2010;196(4):310-318.

5. McCrone P, Patel A, Knapp M, Schene A, Koeter M, Amaddeo F, et al. A Comparison of SF-6D and EQ-5D Utility Scores in a Study of Patients with Schizophrenia. J Ment Health Policy Econ 2009;12:27-31.

6. Günther $\mathrm{OH}$, Roick $\mathrm{C}$, Angermeyer $\mathrm{MC}$, König $\mathrm{HH}$. The responsiveness of EQ-5D utility scores in patients with depression: A comparison with instruments measuring quality of life, psychopathology and social functioning. J Affect Disord 2008;105(81-91).

7. Guyatt GH, Osoba D, Wu AW, Wyrwich KW, Norman GR, Group tCSCM. Methods to Explain Clinical Significance of Health Status Measures. Mayo Clin Proc 2002;77(4):371-383.

8. Pyne JM, Tripathi S, Williams DK, Fortney J. Depression-Free Day to Utility-Weighted Score. Is it Valid? Med Care 2007;45(4):357-362.

9. Lave JR, Frank RG, Schulberg HC, Kamlet MS. Cost-effectiveness of Treatments for Major Depression in Primary Care Practice. Arch Gen Psychiatry 1998;55:645-651.

10. McCrone P, Knapp M, Proudfoot J, Ryden C, Cavanagh K, Shapiro DA, et al. Cost-effectiveness of computerised cognitive-behavioural therapy for anxiety and depression in primary care: randomised controlled trial. Br J Psychiatry 2004;185:55-62.

11. Sava FA, Yates BT, Lupu V, Szentagotai A, David D. Cost-effectiveness and cost-utility of cognitive therapy, rational emotive behavioural therapy, and fluoxetine (Prozac) in treating depression: $A$ randomized clinical trial. J Clin Psychol 2009;65(1):36-52.

12. Jonkers CCM, Lamers F, Evers SMAA, Bosma H, Metsemakers JFM, Van Eijck JTM. Economic evaluation of a minimal psychological intervention in chronically ill elderly patients with minor or mild to moderate depression: A randomized trial (the DELTA-study). Int J Technol Assess Health Care 2009;25(4):497-504.

13. Katon W, Unützer J, Fan MY, Williams JW, Schoenbaum M, Lin EHB, et al. Cost-effectiveness and netbenefit of enhanced treatment of depression for older aduts with diabetes and depression. Diabetes Care 2006;29(2):265-270.

14. Katon WJ, Schoenbaum M, Fan MY, Callahan CM, Williams J, Hunkeler E, et al. Cost-effectiveness of Improving Primary Care Treatment of Late-Life Depression. Arch Gen Psychiatry 2005;62:1313-1320.

15. Domino ME, Foster EM, Vitiello B, Kratochvill CJ, Burns BJ, Silva SG, et al. Relative cost-effectiveness of treatments for adolescent depression: 36-week results from the TADS randomized trial. J Am Acad Child Adolesc Psychiatry 2009;48(7):711-720.

16. Lynch FL, Hornbrook M, clarke GN, Perrin N, Polen MR, O'Connor E, et al. Cost-effectiveness of an intervention to prevent depression in at-risk teens. Arch Gen Psychiatry 2005;62(11):1241-1248.

17. Revicki DA, Siddique J, Frank L, Chung JY, Green BL, Krupnick J, et al. Cost-effectiveness of evidencebased pharmacotherapy or cognitive behavior therapy compared with community referral for major depression in predominantly low-income minority women. Arch Gen Psychiatry 2005;62:868-875.

18. Trivedi MH, Wan GJ, Mallick R, Chen J, Casciano R, Geissler EC, et al. Cost and effectiveness of venlafaxine extended-release and selective serotonin reuptake inhibitors in the acute phase of outpatient treatment for major depressive disorder. J Clin Psychopharmacol 2004;24(5):497-506. 
19. Simon GE, Katon WJ, VonKorff M, Unützer J, Lin EHB, Walker EA, et al. Cost-effectiveness of a collaborative care program for primary care patients with persistent depression. Am J Psychiatry 2001;158(10):1638-1644.

20. Simon GE, von Korff M, Ludman EJ, Katon WJ, Rutter C, Unützer J, et al. Cost-effectiveness of a program to prevent depression relapse in primary care. Med Care 2002;40(10):941-950.

21. Simon GE, Manning WG, Katzelnick DJ, Pearson SD, Henk HJ, Helstad CP. Cost-effectiveness of systematic depression treatment for high utilizers of general medical care. Arch Gen Psychiatry 2001;58:181187.

22. Jonkers CCM, Lamers F, Evers SMAA, Bosma H, van Eijck JTM. Cost-utility estimates in depression: does the valuation method matter? . In: Jonkers CCM, ed. Emotional support for chronically ill elderly persons: Feasibility, effectiveness and cost-effectiveness of a minimal psychological intervention (PhD Dissertation). Maastricht: Universitaire Pers Maastricht, 2009.

23. de Graaf LE, Gerhards SAH, Arntz AR, Riper H, Metsemakers JFM, Evers SMAA, et al. Clinical effectiveness of online computerized cognitive behavioural therapy without support for depression in primary care: a randomized trial. Br J Psychiatry 2009;195(1):73-80.

24. de Graaf LE, Gerhards SAH, Evers SMAA, Arntz AR, Riper H, Severens JL, et al. Clinical and costeffectiveness of computerised cognitive behavioural therapy for depression in primary care: design of a randomised trial. BMC Public Health 2008;8:224.

25. Beck AT, Steer RA, Ball R, Ranieri WF. Comparison of Beck Depression Inventories-IA and -II in psychiatric outpatients. J Pers Assess 1996;67(3):588-597.

26. Arnau RC, Meagher MW, Norris MP, Bramson R. Psychometric Evaluation of the Beck Depression Inventory-II With Primary Care Medical Patients. Health Psychol 2001;20(2):112-119.

27. Van der Does AJW. De Nederlandse versie van de Beck Depression Inventory - second edition (BDI-II-NL): Handleiding [The Dutch version of the Beck Depression Inventory - second edition (BDI-II-NL): Manual]. Enschede: The Psychological Corporation, 2002.

28. Brooks R. EuroQol: the current state of play. Health Policy 1996;37(1):53-72.

29. EuroQol Group. EuroQol - a new facility for the measurement of health-related quality of life. Health Policy 1990;16(3):199-208.

30. Dolan P. Modeling valuations for EuroQol health states. Med Care 1997;35(11):1095-1108.

31. Lamers LM, McDonnell J, Stalmeier PFM, Krabbe PFM, Busschbach JJV. The Dutch tariff: results and arguments for an effective design for national EQ-5D valuation studies. Health Econ 2006;15:1121-1132.

32. Brazier J, Roberts J, Deverill M. The estimation of a preference-based measure of health from the SF-36. $J$ Health Econ 2002;21:271-292.

33. Brazier JE, Roberts J. The Estimation of a Preference-Based Measure of Health From the SF-12. Med Care 2004;42(9):851-859.

34. Revicki D, Hays RD, Cella D, Sloan J. Recommended methods for determining responsiveness and minimally important differences for patient-reported outcomes. J Clin Epidemiol 2008;61:102-109.

35. Jacobson NS, Truax P. Clinical significance: a statistical approach to defining meaningful change in psychotherapy research. J Consult Clin Psychol 1991;59(1):12-19.

36. Evans $\mathrm{C}$, Margison F, Barkham M. The contribution of reliable and clinically significant change methods to evidence-based mental health. Evid Based Ment Health 1998;1(3):70-72.

37. Walters SJ, Brazier JE. Comparison of the minimally important difference for two health state utility measures: EQ-5D and SF-6D. Qual Life Res 2005;14:1523-1532.

38. Walters SJ, Brazier JE. What is the relationship between the minimally important difference and health state utility values? The case of the SF-6D. Health Qual Life Outcomes 2003;1(4).

39. Husted JA, Cook RJ, Farewell VT, Gladman DD. Methods for assessing responsiveness: a critical review and recommendations. J Clin Epidemiol 2000;53(5):459-468.

40. Liang MH, Fossel AH, Larson MG. Comparisons of Five Health Status Instruments for Orthopedic Evaluation. Med Care 1990;28(7):632-642.

41. Cohen J. Statistical power analysis for the behavioral sciences. Hillsdale, NJ: Erlbaum, 1988.

42. McGraw KO, Wong SP. Forming Inferences About Some Intraclass Correlation Coefficients. Psych Methods 1996;1(1):30-46.

43. Fleiss JL. Statistical methods for rates and proportions. New York Wiley, 1981. 
44. Portney LG, Watkins MP. Foundations of Clinical Research: Applications to Practice. 2 ed. New Jersey: Prentice-Hall, 2000.

45. de Graaf LE, Gerhards SAH, Arntz A, Riper H, Metsemakers JFM, Evers SMAA, et al. One-year follow-up results of unsupported online computerised cognitive behavioural therapy for depression in primary care: a randomised trial. J Behav Ther Exp Psy. 2010 (in press); doi: 10.1016/j.jbtep.2010.07.003.

46. Lamers LM, Bouwmans CAM, van Straten A, Donker MCH, Hakkaart L. Comparison of EQ-5D and SF-6D utilities in mental health patients. Health Econ 2006;15:1229-1236.

47. Bryan S, Longworth L. Measuring health-related utility: Why the disparity between EQ-5D and SF-6D? Eur J Health Econ 2005;50:253-360.

48. Knies S, Evers SMAA, Candel MJJM, Severens JL, Ament AJHA. Utilities of the EQ-5D. Transferable or Not? Pharmacoeconomics 2009;27(9):767-779.

49. Barton GR, Sach TH, Doherty M, Avery AJ, Jenkinson C, Muir KR. An assessment of the discriminative ability of the EQ-5Dindex, SF-6D, and EQ VAS using sociodemographic factors and clinical conditions. Eur $J$ Health Econ 2008;9:237-249.

50. Marra CA, Woolcott JC, Kopec JA, Shojania K, Offer R, Brazier JE, et al. A comparison of generic, indirect utility measures (the HUI2, HUI3, SF-6D, and the EQ-5D) and disease-specific instruments (the RAQoL and the HAQ) in rheumatoid arthritis. Soc Sci Med 2005;60:1571-1582.

51. Lee BB, King MT, Simpson JM, Haran MJ, Stockler MR, Marial O, et al. Validity, Responsiveness, and Minimal Important Difference for the SF-6D Health Utility Scale in a Spinal Cord Injured Population. Value Health 2008;11(4):680-688.

52. Brazier J, Deverill M. A checklist for judging preference-based measures of health related quality of life: Learning from psychometrics. Health Econ 1999;8:41-51.

53. Ross M. Relation of Implicit Theories to the Construction of Personal Histories. Psychol Rev 1989;96(2):341-357.

54. Norman GR, Stratford P, Regehr G. Methodological Problems in the Retrospective Computation of Responsiveness to Change: The Lesson of Cronbach. J Clin Epidemiol 1997;50(8):869-879.

55. Schwartz CE, Sprangers MAG, eds. Adaptation to changing health: response shift in quality-of-life research. Washington: American Psychological Association, 2000.

56. Barton GR, Sach TH, Avery AJ, Jenkinson C, Doherty M, Whynes DK, et al. A comparison of the performance of the EQ-5D and SF-6D for individuals aged $\geq 45$ years. Health Econ 2008;17:815-832.

57. Brazier J, Roberts J, Tsuchiya A, Bussbach J. A comparison of the EQ-5D and SF-6D across seven patient groups. Health Econ 2004;13:873-884.

58. Kontodimopoulos N, Pappa E, Papadopoulos AA, Tountas Y, Niakas D. Comparing SF-6D and EQ-5D utilities across groups differing in health status. Qual Life Res 2009;18:87-97. 


\section{Chapter 7}

\section{Change in the course of depression severity (BDI-II) and quality of life utility (SF-6D): evidence for a temporal relation?}

Gerhards SAH, Theunissen KATM, Evers SMAA, de Graaf LE, Widdershoven, GAM, Huibers $\mathrm{MJH}$

Submitted for publication. 


\begin{abstract}
Background: Although the responsiveness of quality of life utility instruments in depression has been studied, it has not yet been studied whether there is a temporal relation between change in depression severity and change in quality of life utility.

Objective: To explore whether there is a temporal relation between change in depression severity and change in quality of life utility.

Method: Data come from a randomised trial on depression treatment, with measurements on baseline, three, and twelve months follow-up. Depression severity is measured using the Beck Depression Inventory Second Edition. Quality of life utility is measured using the Short-Form 6D questionnaire. Stepwise regression analyses are used to assess the relation between depression severity and utility, while controlling for baseline confounders and treatment group. In case of a temporal relation, change in utility (three to twelve months) is preceded by change in depression severity (baseline to three months), or vice versa.

Results: In the regression analyses, addition of the preceded change (baseline to three months) of respectively depression severity or utility did not contribute significantly to the explained variance of respectively utility or depression severity change (three to twelve months). The addition of concurrent change however did imply a significant and major contribution in explained variance.

Conclusion: No temporal, but rather a concurrent relation could be observed between change in quality of life utility and depression severity, which might be explained by a close relatedness between the concepts or the instruments used to assess depression severity and quality of life utility.
\end{abstract}




\section{Background}

Measuring health-related quality of life is relevant in patients with depression, since depression has a large impact on the physical, social and emotional aspects that are relevant and important to a patient's well-being. ${ }^{1,2}$ In the field of economic evaluation, generic health-related quality of life is often one of the main outcome parameters. This generic quality of life can be measured by means of multi-attribute questionnaires which express health-related quality of life in utilities (e.g. Short form 6D (SF-6D)). A utility theoretically can range from 0 (the worst imaginable condition: death) to 1 (perfect health). These instruments look at quality of life in a generic and not in a disease-specific manner: they target several health-related quality of life domains which are not necessarily related to the disorder at issue. This broad perspective facilitates comparisons between different disorders and interventions. ${ }^{3}$ Being a base for policy decisions on resource allocation, it is thus important that these utilities are responsive to changes in health status supposed to be of influence on the subject's quality of life.

In a recent study, we found that health-related quality of life utility changes were responsive to changes in depression severity. The methods we used implicitly assume a concurrent relation between utility change and depression severity change. ${ }^{4}$ However, whether there is a concurrent or a temporal relation remains to be evaluated. Since the utility instruments measure a patient's subjective well-being, it could for instance be expected that change in quality of life is preceded by change in depression. It is not unlikely that a recovery from depression leads to a higher quality of life in general: first depression complaints improve, which is followed by improved well-being on other aspects. For clinical practice, this temporal relation would mean that treatment should focus on the depressive complaints, and that improvement in depression severity would imply an additional effect in quality of life. Reversely, a change in utility might precede change in depression when improvements in other life domains spiral more healthy behavior that affects the depression. This temporal relation would indicate that clinical practice should also target other domains of health besides depressive complaints to treat depression, since a change in generic quality of life would imply an improvement in depression. Therefore, not only the concurrent relation between change in depression and utility, but also the temporal relation (changes occurring in a sequential order, implying a causal pathway) can be of interest in studying responsiveness. To our knowledge, no previous studies have evaluated temporal relations between changes in depression severity and changes in quality of life utility. In this study, we explored whether there is a temporal relation between change in depression severity and change in quality of life utility. Depression severity is measured using the Beck Depression Inventory Second Edition (BDI-II). Utility is measured using the SF-6D questionnaire. 


\section{Method}

\section{Design and participants}

Data come from a randomised trial comparing (1) computerised cognitive behavioral therapy (CCBT), with (2) treatment as usual by a general practitioner (TAU), and ( 3 ) a combination of both CCBT and TAU for depression. In the trial, 303 participants were recruited from the general population in the South of the Netherlands by means of a large-scale Internetbased screening. The main trial inclusion criteria were: age 18 to 65; at least mild to moderate depressive complaints (BDI-II score $\geq 16$ ) during at least 3 months or more; and no severe psychiatric co-morbidity. During a one-year follow-up period, participants were asked to fill in Internet questionnaires. Further details of the design of the trial, the interventions and the population can be found elsewhere (see appendix 1 in this thesis). ${ }^{5,6}$ The trial results did not show differences between the three interventions groups in depression severity or quality of life outcome.

\section{Depression severity}

Depression severity was measured with the BDI-II. The total score is the sum of the 21 items with a range of 0 (no depression) to 63 (severe depression). There has been consistent support for the construct validity and reliability of the BDI-II in various samples. ${ }^{9-11}$

\section{Utility instruments}

Utilities were derived from the SF-6D. A utility refers to the preference that individuals or society may have for any particular set of health outcomes. The SF-6D instrument is based on the health-related quality of life questionnaire 36-item short-form Health Survey (SF36). The utility is derived from 11 items of the SF-36 and is composed of six dimensions of health (physical functioning, role limitations, social functioning, pain, mental health, and vitality). The SF-6D utilities were derived by means of the preference-based UK tariff, ${ }^{12,13}$ no Dutch tariff is available. Although theoretically a utility ranges from 0 to $1,{ }^{3}$ the SF-6D tariff results in a range from 0.30 to 1 .

\section{Analysis}

All available data were used. We calculated change scores in depression severity and utility from baseline to 3 months, from 3 months to 12 months and from baseline to 12 months follow-up. To facilitate interpretation of the findings, change scores on the depression severity and quality of life measures were calculated in such a way that a positive change score always reflects improvement, and a negative change score always reflects deterioration. Preliminary, the normality of the data was assessed by means of histograms and skewness and kurtosis statistics. 


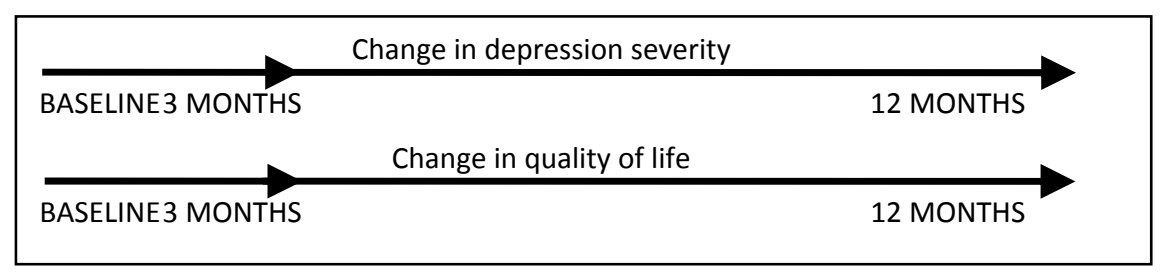

Concurrent relation

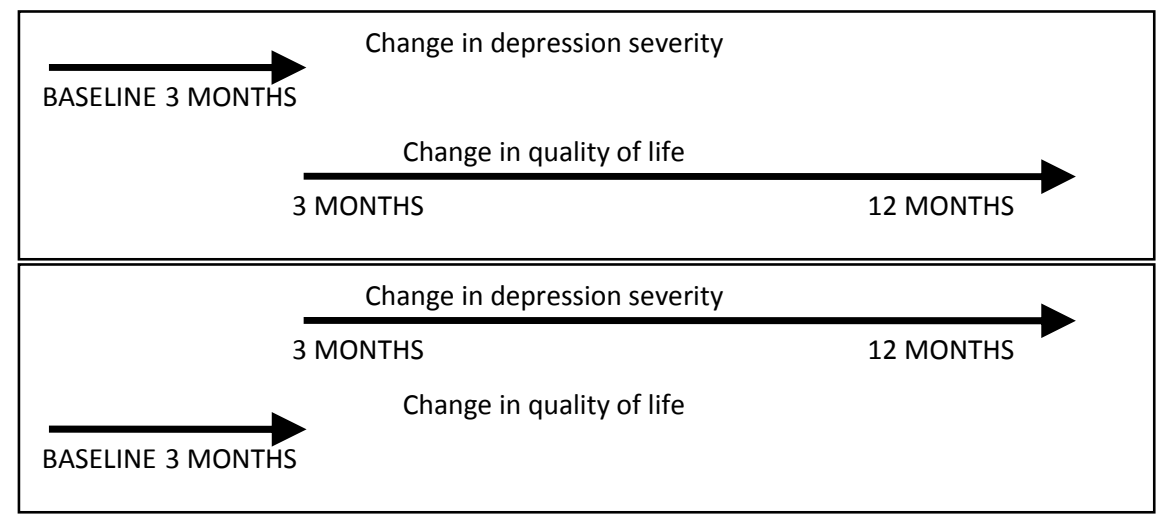

Temporal relation

Figure 1: The relation between change in depression severity and change in utility

To evaluate the relation between BDI-II change and the SF-6D utility change, we used correlation and regression analysis. ${ }^{14}$ In case of a temporal relation, the change in quality of life is preceded or followed by change in depression severity. In case of no temporal, but a concurrent relation, the simultaneous change scores are expected to show highest associations. The concept of concurrent and temporal relations is illustrated in figure 1 . The Pearson correlations between the BDI-II point scores (baseline, 3 months, and 12 months), the $\mathrm{BDI}-\mathrm{II}$ change scores (from baseline to 3 months, from 3 months to 12 months and from baseline to 12 months), the quality of life point scores (baseline, 3 months and 12 months) and the quality of life change scores (from baseline to 3 months, from 3 months to 12 months and from baseline to 12 months) were calculated. A correlation coefficient of \pm 0.1 is considered to be a small effect, while coefficients of \pm 0.3 and \pm 0.5 signify a medium and a large effect respectively.

In multiple regression analysis exploring whether change in quality of life was preceded by change in depression severity, we used the change from 3 to 12 months in quality of life utility (SF-6D) as dependent variable. The regression analysis consisted of four blocks. In the first block (block 1), only the treatment group and the potential confounders (baseline BDI depression score, baseline quality of life utility score, gender, age, educational level, work status and partner) were added to the model as confounders. Previous research has shown that these socio-demographic and illness-related characteristics can predict outcome of depression treatment ${ }^{15,16}$ and we therefore included them as confounders. In the second block we also controlled for change in quality of life from baseline to 3 months (block 2), after which the BDI-II change from baseline to 3 months (block 3 ) and the BDI-II change 
from 3 to 12 months (block 4) were added to the model. It was assessed which BDI-II change contributed most in explaining quality of life change from 3 to 12 months. In case of a temporal relation the BDI-II change from baseline to 3 months (block 3 ) should be the main significant contributor, and for a concurrent relation the BDI-II change from 3 to 12 months (block 4).

To explore the reverse temporal relation - whether change depression severity was preceded by change in quality of life utility (SF-6D) - we performed regression analyses with change from 3 to 12 months in depression severity as dependent variable. In the first block (block 1), only the treatment group and the potential confounders were added to the model. In the second block, we controlled for change in depression severity from baseline to 3 months (block 2), after which the quality of life utility change from baseline to 3 months (block 3 ) and the quality of life utility change from 3 to 12 months (block 4) were added to the model. It was assessed which quality of life utility change contributed most in explaining quality of life change from 3 to 12 months. In case of a temporal relation, the quality of life utility change from baseline to 3 months (block 3 ) should be the main significant contributor, and for a concurrent relation the quality of life utility change from 3 to 12 months (block 4).

In a first set of analyses, we used the complete dataset to perform regression analyses. In a second set of analyses, we only used data of subgroups of our patient sample which experienced an important change. Study participants differed in the amount of change in depression severity and utility. Not every participant in our sample had an important or reliable change in depression severity or utility during the follow-up period, ${ }^{4,5,7,8}$ while a temporal relation between change scores requires that there needs to be some change in the parameter of interest. Therefore we created subgroups based on cut-off points indicating important or reliable change from baseline to three months follow-up. For the BDI-II we used the methodology of Jacobson and $\operatorname{Truax}^{17,18}$ to calculate the reliable change index (RC) from baseline to three months follow-up. In our population, the RC was defined as a decrease of at least 9 points during follow-up. ${ }^{5}$ Based on the RC, a subgroup of participants with reliable improvement was created. ${ }^{4}$ For utility, we used the minimally important difference as a cut-off indicating an important change in utility from baseline to three months follow-up. We used a MID of 0.03 , based on previous research of Walters and Brazier, ${ }^{19,20}$ and in line with our own MID findings. ${ }^{4}$

In all regression analyses, the assumptions of normality of the error terms (using histogram and normal probability plots of the residuals), homoscedasticity and linearity (using plots of the standardized residuals against standardized predicted values), no collinearity (the Variance Inflation Factor < 10 and the Tolerance scores $>0.2$ ), no outliers (Cook's Distance $<1$ ) and independent error terms (Durbin-Watson between 1 and 3) were assessed. All analyses were carried out using SPSS version 15.0.1 for Windows. 


\section{Results}

\section{Population}

In total, data of 267 trial participants were available at 12 months follow-up. Table 1 presents the baseline characteristics of these participants, and the mean depression severity and utility scores at baseline, 3 and 12 months follow-up.

Table 1: Characteristics of participants $(n=267)$

\begin{tabular}{ll}
\hline Characteristic & Descriptive statistic \\
\hline Sex, male, $\mathrm{nr}(\%)$ & $118(44 \%)$ \\
Age, M (SD) & $45.0(11.5)$ \\
Educational level $^{\mathrm{a}}$ & \\
$\quad$ Low, $\mathrm{nr}(\%)$ & $48(19 \%)$ \\
$\quad$ Middle, $\mathrm{nr}(\%)$ & $140(54 \%)$ \\
$\quad$ High, $\mathrm{nr}(\%)$ & $72(28 \%)$ \\
Partner, yes, $\mathrm{nr}(\%)^{\mathrm{b}}$ & $187(72 \%)$ \\
${\text { Employed, yes, } \mathrm{nr}(\%)^{\mathrm{c}}}_{\text {BDI-II, baseline, M (SD) }}$ & $174(65 \%)$ \\
BDI-II, 3 months, M (SD) & $27.7(7.66)$ \\
BDI-II, 12 months, M (SD) & $20.23(11.01)$ \\
SF-6D, baseline, M (SD) & $17.21(11.46)$ \\
SF-6D, 3 months, M (SD) & $0.66(0.08)$ \\
SF-6D, 12 months, M (SD) & $0.66(0.10)$ \\
\hline
\end{tabular}

Note. BDI-II, Beck Depression Inventory Second Edition; SF-6D, Short-Form 6D utility derived by the UK tariff; $\mathrm{M}$, mean; SD, standard deviation; $\mathrm{nr}$, number.

${ }^{\mathrm{a}}$ Data unavailable for 7 persons; ${ }^{\mathrm{b}}$ Data unavailable for 7 persons; ${ }^{\mathrm{c}}$ Data unavailable for 28 persons.

\section{Correlations}

Table 2 shows the correlation between the depression severity and quality of life utility scores. When evaluating the correlations between the BDI-II and SF-6D instruments, highest correlations were found for the concurrent relations with significant medium to large correlations (figures in bold). These correlations show that a higher level of depression severity is associated with a lower level of quality of life utility (for the negative correlations between the point scores), and that an improvement in depression severity is related with an improvement in quality of life utility (for the positive correlations between the change scores). The non-simultaneous relation between BDI-II and SF-6D scores resulted in smaller albeit mostly significant correlations. Remarkably, the correlations between the nonsimultaneous change scores resulted in significant negative correlations (BDI-II $0 \rightarrow 3$ with SF-6D $3 \rightarrow 12, r=-0.197$; SF-6D $0 \rightarrow 3$ with BDI-II $3 \rightarrow 12, r=-0.166$; BDI-II $0 \rightarrow 3$ with BDI-II $3 \rightarrow 12, r=-0.420$; SF-6D $0 \rightarrow 3$ with SF-6D $3 \rightarrow 12, r=-0.405$ ), which indicates that an improvement in either depression severity or utility from baseline to 3 months follow-up is related with a deterioration in either depression severity or utility from 3 to 12 months follow-up, and vice versa. 


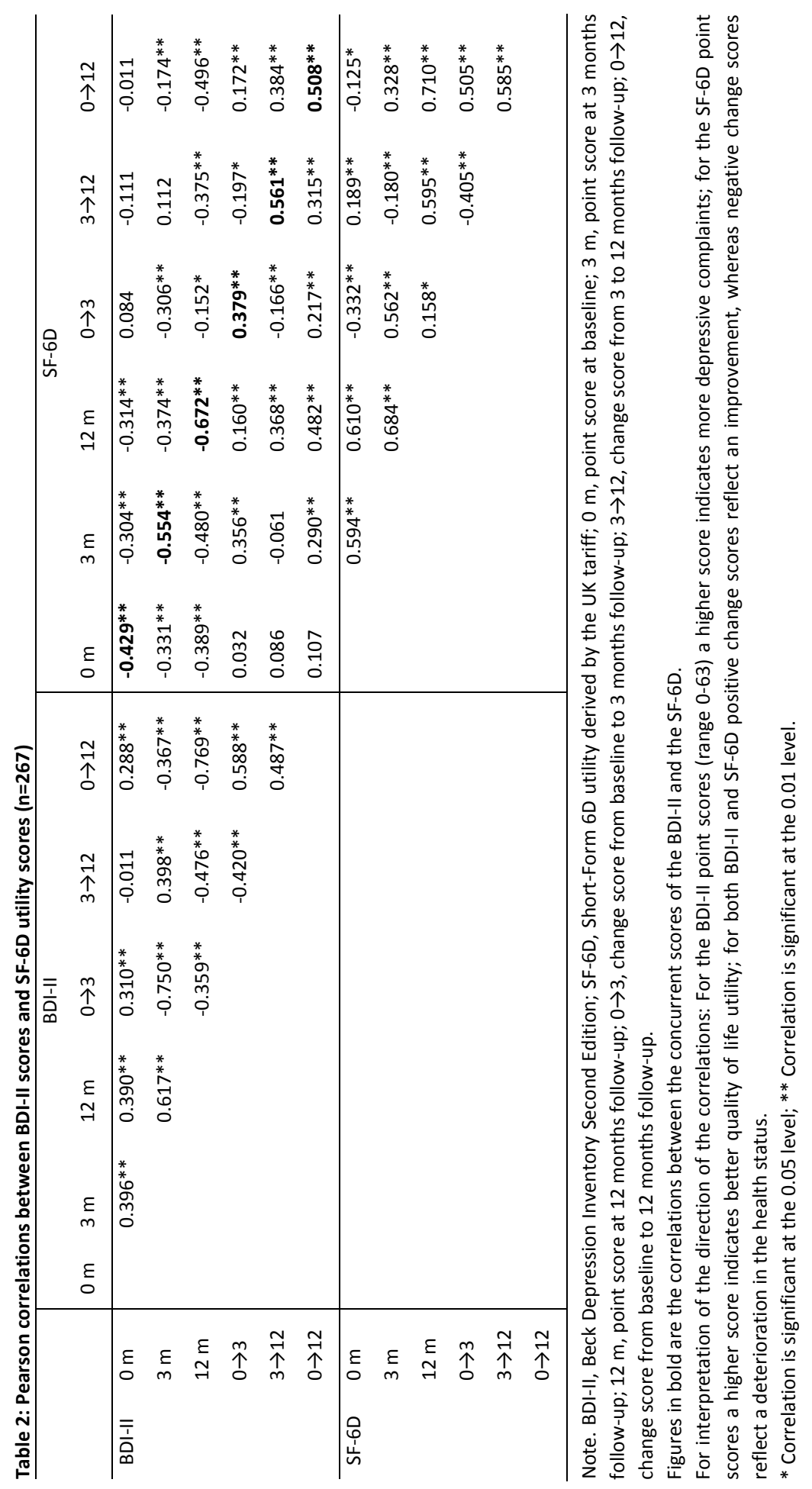




\section{Regression analyses of temporal relation depression $\rightarrow$ utility}

The results of the regression analyses exploring whether change in quality of life utility is preceded by change in depression severity are presented in table 3 . While controlling for baseline confounders, treatment group, baseline quality of life utility and quality of life utility change from baseline to three months follow-up, the inclusion of the preceded change in severity of depression (in block 3 ) did not contribute significantly to the explained variance of the quality of life utility change from 3 to 12 months follow-up. The addition of concurrent change in severity of depression (in block 4) did imply a significant increase in the explained variance of the quality of life utility change from 3 to 12 months for both the complete sample and the RC improvement subgroup. This indicates that the relation between quality of life utility and depression severity is concurrent, and not temporal. In block 4, the explained variance reaches high levels, with a rather high addition in predictive power after adding the variable 'change in depression severity from 3 to 12 months': The adjusted $\mathrm{R}^{2}$ indicates an increase from block 3 to block 4 from $14.1 \%$ to $46.5 \%$ of variance explained for the complete sample, and from $7.6 \%$ to $40.0 \%$ of variance explained for the RC improvement subgroup.

Table 3: Stepwise regression analysis evaluating the temporal relation BDI-Il change $\rightarrow$ SF-6D change (Standardized $\beta$ 's)

\begin{tabular}{l|lll|lll}
\hline \multicolumn{1}{c}{ Variables entered $^{\text {a }}$} & \multicolumn{3}{c}{ Complete sample } & \multicolumn{2}{c}{ Subgroup RC improvement } \\
\cline { 2 - 6 } & \multicolumn{3}{c}{$\mathrm{n}=227$} \\
& Block 2 & Block 3 & Block 4 & \multicolumn{1}{c}{ Block 2 } & Block 3 & Block 4 \\
\hline SF-6D baseline & 0.026 & 0.042 & -0.127 & 0.048 & 0.113 & -0.067 \\
SF-6D change $0 \rightarrow 3$ & $-0.400^{* *}$ & $-0.381^{* *}$ & $-0.441^{* *}$ & $-0.270^{*}$ & -0.221 & $-0.400^{* *}$ \\
BDI-II change 0 $\rightarrow 3$ & & -0.039 & $0.315^{* *}$ & & -0.235 & 0.044 \\
BDI-II change 3 $\rightarrow 12$ & & & $0.642^{* *}$ & & & $0.605^{* *}$ \\
\hline Adj. $\mathrm{R}^{2}$ & 0.144 & 0.141 & 0.465 & 0.050 & 0.076 & 0.400 \\
\hline $\mathrm{R}^{2}$ change & & 0.001 & $0.309^{* *}$ & & 0.033 & $0.287^{* *}$ \\
\hline
\end{tabular}

Note. BDI-II, Beck Depression Inventory Second Edition; SF-6D, Short-Form 6D utility derived by the UK tariff; $0 \rightarrow 3$, change from baseline to 3 months follow-up; $3 \rightarrow 12$, change from 3 to 12 months follow-up; $0 \rightarrow 12$, change from baseline to 12 months follow-up; Adj. $R^{2}$, Adjusted $R^{2}$.

** significant beta / F-change at the 0.01 level; * significant beta / F-change at the 0.05 level.

${ }^{a}$ The exploratory variable is SF-6D utility change from 3 to 12 months follow-up. In all steps controlling for baseline BDI-II depression score, baseline SF-6D utility, gender, age, educational level, work status, partner and treatment group.

\section{Regression analyses of temporal relation utility $\rightarrow$ depression}

The results of the regression analyses exploring whether change in quality of life utility is followed by change in depression severity are presented in table 4 . While controlling for baseline confounders, treatment group, baseline depression severity and change in depression severity from baseline to three months follow-up, the inclusion of the preceded change in quality of life utility (in block 3 ) did not contribute significantly to the explained variance of change in depression severity from 3 to 12 months follow-up. The addition of 
concurrent change in quality of life utility (in block 4) did imply a significant increase in the explained variance of the change in depression severity from 3 to 12 months for both the complete sample and the MID improvement subgroup. This indicates that the relation between quality of life utility and depression severity is concurrent, and not temporal. In block 4 , the explained variance reaches high levels, with a rather high addition in predictive power after adding the variable 'quality of life utility change from 3 to 12 months': The adjusted $\mathrm{R}^{2}$ indicates an increase from block 3 to block 4 from $20.9 \%$ to $50.7 \%$ of variance explained for the complete sample, and from $7.8 \%$ to $54.0 \%$ of variance explained in the MID improvement subgroup.

Table 4: Stepwise regression analysis evaluating the temporal relation SF-6D change $\rightarrow$ BDI-II change (Standardized $\beta^{\prime}$ 's)

\begin{tabular}{|c|c|c|c|c|c|c|}
\hline \multirow[t]{3}{*}{ Variables entered $^{\text {a }}$} & \multicolumn{4}{|c|}{ Complete sample } & \multicolumn{2}{|c|}{ Subgroup MID improvement } \\
\hline & \multicolumn{3}{|c|}{$n=227$} & \multicolumn{3}{|c|}{$\mathrm{n}=74$} \\
\hline & Block 2 & Block 3 & Block 4 & Block 2 & Block 3 & Block 4 \\
\hline BDI-II baseline & $0,205^{* *}$ & $0.226 * *$ & $0.272 * *$ & $0.412^{*}$ & $0.406^{*}$ & $0.379 * *$ \\
\hline BDI-II change $0 \rightarrow 3$ & $-0.508 * *$ & $-0.552 * *$ & $-0.528 * *$ & $-0.472^{*}$ & $-0.502^{*}$ & $-0.544 * *$ \\
\hline SF-6D change $0 \rightarrow 3$ & & 0.094 & $0.319 * *$ & & 0.069 & $0.219 *$ \\
\hline SF-6D change $3 \rightarrow 12$ & & & $0.591^{* *}$ & & & $0.675^{* *}$ \\
\hline Adj. $R^{2}$ & 0.206 & 0.209 & 0.507 & 0.089 & 0.078 & 0.540 \\
\hline $\mathrm{R}^{2}$ change & & 0.006 & $0.284^{* *}$ & & 0.003 & $0.392 * *$ \\
\hline
\end{tabular}

Note. BDI-II, Beck Depression Inventory Second Edition; SF-6D, Short-Form 6D utility derived by the UK tariff; $0 \rightarrow 3$, change from baseline to 3 months follow-up; $3 \rightarrow 12$, change from 3 to 12 months follow-up; $0 \rightarrow 12$, change from baseline to 12 months follow-up; Adj. $R^{2}$, Adjusted $R^{2}$.

** significant beta / F-change at the 0.01 level; * significant beta / F-change at the 0.05 level.

${ }^{a}$ The exploratory variable is BDI-II change from 3 to 12 months follow-up. In all steps controlling for baseline BDI-II depression score, baseline SF-6D utility, gender, age, educational level, work status, partner and treatment group.

\section{Additional analyses}

Additional regression analyses deriving health-related quality of life utility from the Euroqo5D (EQ-5D) instrument yielded similar results as mentioned for the SF-6D. Moreover, we also created subgroups that had a RC deterioration on the BDI-II or a MID deterioration on the SF-6D or EQ-5D. The RC deterioration subgroup however was too small $(n=12)$ to perform regression analysis. For the MID deterioration subgroups similar results were found as mentioned above for the MID improvement subgroup.

\section{Discussion}

We found no indication for a temporal relation between changes in quality of life utility and depression severity, but rather a concurrent relation. One possible explanation is that the time interval between the measurement moments was too long to detect a temporal relation. Another explanation is that either there is no temporal relation between these two concepts, or the instruments we used were unable to detect a temporal relation. It is 
still possible that changes in the subjective experienced quality of life are preceded by changes in depression, or vice versa. But since the BDI-II and SF-6D both are self-report questionnaires, they both tap into the patient's subjective experience of health status. The hypothetical time lag between objectively assessed clinical change and the subject's experience of change might consequently be present, but is likely to merge into a subjective rating of well-being when assessed by self-report.

However, in light of our results, we believe that the main reason for our findings is that the $\mathrm{BDI}-\mathrm{II}$ is closely related to health-related quality of life. The variance in utility explained by the concurrent change in BDI-II (and vice versa the variance in BDI-II explained by the concurrent change in utility) is rather high, which indicates a strong relation between and/or important joint underlying concept within both measures. Since the BDI-II consists of several dimensions - items can for instance be divided into a cognitive dimension (e.g. feelings of worthlessness or excessive guilt) and a somatic-affective dimension (e.g. tiredness or fatigue, loss of energy) $)^{11,21,22}$-, this strong relation between changes in depression severity and changes in quality of life might not be surprising. Given the broad range of complaints included in the BDI-II, one might argue that it also is a quality of life instrument. Further research on temporal relations between quality of life and other disorders might therefore yield other results. Moreover, as was found in one of our previous studies, ${ }^{4}$ it should be noted that the changes on the SF-6D domains of our study participants were mainly found on the domains role limitation, social functioning, mental health, and vitality, and not or less on the domains physical functioning and pain. ${ }^{4}$

Remarkable findings in our study were the significant negative correlations between the non-simultaneous change scores of and within the BDI-II and the SF-6D, which indicate that an improvement in either depression severity or utility from baseline to 3 months follow-up is related with a deterioration in either depression severity or utility from 3 to 12 months follow-up, and vice versa. These negative correlations explain why some of the Betas of the variables 'BDI-II change $0 \rightarrow 3$ ' and/or 'SF-6D change $0 \rightarrow 3$ ' in the regression analyses are negative. However, it is not clear what caused this negative relation. Further exploration of the data revealed that several subgroups can be distinguished in the data: 1) those who improved both from baseline to 3 months and from 3 to 12 months follow-up, 2) those who deteriorated both from baseline to 3 months and from 3 to 12 months follow-up, 3) those who improved from baseline to 3 months and deteriorated from 3 to 12 months follow-up, 4) those who deteriorated from baseline to 3 months and improved from 3 to 12 months follow-up, 5) those who did not show change from baseline to 3 months or from 3 to 12 months follow-up. Apparently about half of the respondents belong to subgroup 3 or 4 . Consequently, some of these respondents might have improved in the first period and relapsed during the second period; while others deteriorated in the first period, but experienced some recovery during the next period. However, the terms 'relapse' or 'recovery' might not be adequate in this situation: Results might also be explained by the fact that after improving during the first period, there is less room left for improvement during a second period, meaning that the chance for a decrease in the second period might increase (and similarly a deterioration in the first period implies more chance for an increase in the second period).

A methodological consideration is that we used data of a treatment study comparing pure self-help CCBT, TAU by a GP, and a combination of CCBT and TAU., ${ }^{5,6}$ The different treat- 
ments can differ in their attention towards depressive complaints only and towards the broader quality of life aspects. The treatments thus might have influenced our outcomes. However, in previous studies no differences in depressive severity and quality of life between the three interventions were observed. ${ }^{5,7,8}$ Moreover, the treatment adherence was rather low. ${ }^{23}$ Consequently, it is hard to say to what extent the treatment really targeted the complaints or broader quality of life aspects.

A criticism on our study might be that we used quality of life expressed as a utility. The calculation of a utility is done by means of general population tariffs. Using patient tariffs might have yielded other, more patient-subjective results. However, there is no patient tariff to calculate the utility. And using other quality of life sum scores might not be a solution: scoring tariffs of questionnaires pretending to represent the patient experience are at least partly based on some general population or researchers' view since the different items or domains of which the overall score is composed do not necessarily get the weight a patient would give. Moreover, one might question whether our utility instruments really reflect the concept 'quality of life'. Different researchers use different definitions for quality of life and some dispute that health status measures (such as SF-36, EQ-5D) are used as quality of life measures. ${ }^{24,25}$

Assuming that the concurrent relation is mainly based on a close relatedness between the concepts depression severity and generic quality of life, our findings can be translated into implications for clinical practice. For clinical practice, this would imply that an overall treatment - focusing on depression complaints as well as on other health-related quality of life aspects - is most likely to lead to an improvement in the patient's situation: Changes in both concepts may foster each other.

\section{Acknowledgements}

We thank Annie Hendriks and Greet Kellens for their assistance in recruitment and datacollection, Rosanne Janssen for the development of the infrastructure for online datacollection, and Eric Schouten for his advice on statistical questions.

This study was an addition to a trial financed by ZonMw (Netherlands Organisation for Health Research and Development; project number 945-04-417), research institute EPP, and research institute CAPHRI. Municipalities Eijsden, Meerssen, Sittard-Geleen, Valkenburg and Maastricht sponsored the trial study. 


\section{References}

1. Bijl RV, Ravelli A. Current and residual functional disability associated with psychopathology: findings from the Netherlands Mental Health Survey and Incidence Study (NEMESIS). Psychol Med 2000;30:657668.

2. Kruijshaar ME, Hoeymans N, Bijl RV, Spijker J, Essink-Bot ML. Levels of disability in Major Depression. Findings from the Netherlands Mental Health Survey and Incidence Study (NEMESIS). J Affect Disord 2003;77(1):53-64.

3. Drummond MF, Sculpher MJ, Torrance GW, O'Brien B, Stoddart GL. Methods for the Economic Evaluation of Health Care Programmes. Oxford: Oxford University Press, 2005.

4. Gerhards SAH, Huibers MJH, Theunissen KATM, de Graaf LE, Widdershoven GAM, Evers SMAA. The responsiveness of quality of life utilities to change in depression: a comparison of instruments (SF-6D, EQ-5D and DFD). submitted.

5. de Graaf LE, Gerhards SAH, Arntz AR, Riper H, Metsemakers JFM, Evers SMAA, et al. Clinical effectiveness of online computerised cognitive behavioural therapy without support for depression in primary care: a randomised trial. Br J Psychiatry 2009;195(1):73-80.

6. de Graaf LE, Gerhards SAH, Evers SMAA, Arntz AR, Riper H, Severens JL, et al. Clinical and costeffectiveness of computerised cognitive behavioural therapy for depression in primary care: design of a randomised trial. BMC Public Health 2008;8:224.

7. Gerhards SAH, de Graaf LE, Jacobs LE, Severens JL, Huibers MJH, Arntz A, et al. Economic evaluation of online computerised cognitive-behavioural therapy without support for depression in primary care: randomised trial. Br J Psychiatry 2010;196(4):310-318.

8. de Graaf LE, Gerhards SAH, Arntz A, Riper H, Metsemakers JFM, Evers SMAA, et al. One-year follow-up results of unsupported online computerised cognitive behavioural therapy for depression in primary care: a randomised trial. J Behav Ther Exp Psy. 2010 (in press); doi: 10.1016/j.jbtep.2010.07.003.

9. Beck AT, Steer RA, Ball R, Ranieri WF. Comparison of Beck Depression Inventories-IA and -II in psychiatric outpatients. J Pers Assess 1996;67(3):588-597.

10. Arnau RC, Meagher MW, Norris MP, Bramson R. Psychometric Evaluation of the Beck Depression Inventory-II With Primary Care Medical Patients. Health Psychol 2001;20(2):112-119.

11. Van der Does AJW. De Nederlandse versie van de Beck Depression Inventory - second edition (BDI-II-NL): Handleiding [The Dutch version of the Beck Depression Inventory - second edition (BDI-II-NL): Manual]. Enschede: The Psychological Corporation, 2002.

12. Brazier J, Roberts J, Deverill M. The estimation of a preference-based measure of health from the SF-36. $J$ Health Econ 2002;21:271-292.

13. Brazier JE, Roberts J. The Estimation of a Preference-Based Measure of Health From the SF-12. Med Care 2004;42(9):851-859.

14. Husted JA, Cook RJ, Farewell VT, Gladman DD. Methods for assessing responsiveness: a critical review and recommendations. J Clin Epidemiol 2000;53(5):459-468.

15. Jarrett RB, Eaves GG, Granneman BD, Rush AJ. Clinical, cognitive, and demographic predictors of response to cognitive therapy for depression: a preliminary report. Psychiatry Res 1991;37:245-260.

16. Wolf NJ, Hopko DR. Psychosocial and pharmacological interventions for depressed adults in primary care: a critical review. Clin Psychol Rev 2008;28:131-161.

17. Jacobson NS, Truax P. Clinical significance: a statistical approach to defining meaningful change in psychotherapy research. J Consult Clin Psychol 1991;59(1):12-19.

18. Evans $C$, Margison F, Barkham M. The contribution of reliable and clinically significant change methods to evidence-based mental health. Evid Based Ment Health 1998;1(3):70-72.

19. Walters SJ, Brazier JE. Comparison of the minimally important difference for two health state utility measures: EQ-5D and SF-6D. Qual Life Res 2005;14:1523-1532.

20. Walters SJ, Brazier JE. What is the relationship between the minimally important difference and health state utility values? The case of the SF-6D. Health Qual Life Outcomes 2003;1(4). 
21. Steer RA, Ball R, Ranieri WF, Beck AT. Dimensions of the Beck Depression Inventory-II in clinically depressed outpatients. J Clin Psychol 1999;55:117-128.

22. Storch EA, Roberti JW, Roth DA. Factor structure, concurrent validity, and internal consistency of the Beck Depression Inventory-second edition in a sample of college students. Depress Anxiety 2004;19:187189.

23. de Graaf E, Huibers M, Riper H, Gerhards S, Arntz A. Use and acceptability of unsupported online computerized cognitive behavioral therapy for depression and associations with clinical outcome. $J A f$ fect Disord 2009;116:227-231.

24. van Heck GL. Verwarring rondom Kwaliteit van Leven: beter ten halve gekeerd, dan ten hele gedwaald [Confusion concerning Quality of Life: a fault confessed is half redressed]. Psychologie en Gezondheid 2008;36(2):72-78.

25. Sanderman R. Over de afschaffing van het begrip kwaliteit van leven - overwegingen bij Van Heck (2008) [About abandoning the term Quality of Life - reflecting on Van Heck (2008)]. Psychologie en Gezondheid 2008;36(5):297-301. 


\section{Chapter 8}

\section{Discrepancy in rating health-related quality of life of depression between patient and general population}




\begin{abstract}
Objective: To compare the quality of life valuation of a hypothetical depression health state between a general population versus a patient population, and within a patient population. Method: In a self-administered Internet questionnaire both patient and general population groups filled in the Euroqol 5D (EQ-5D) questionnaire for a hypothetical depression health state describing mild $(\mathrm{N}=740)$, moderate $(\mathrm{N}=691)$, or severe depression $(\mathrm{N}=670)$, and valued it using a Rating Scale (RS). The 'patient' group consisted of people reporting depressive complaints on the Internet questionnaire, subdivided into three depression severity groups (mild, moderate, severe) based on the Beck Depression Inventory Second Edition (BDI-II) and two groups according to self-perceived duration ( $\leq 3$ months, $\geq 4$ months) of depressive complaints (SPDD).

Results: Significant differences were found between the patient and general population and within the patient population on RS outcomes and on the Euroqol domains usual activities, pain/discomfort, and anxiety/depression. The direction of the differences shows that subgroups with higher severity or longer duration of depressive complaints value depression health states worse compared with subgroups with less severe complaints, a shorter duration, or no depressive complaints. Moreover, the discrepancy in valuation of a health state between different subgroups changes according to the severity of the health state described.

Conclusion: There are discrepancies in the valuation of a hypothetical depression health state between a patient and general population, whereby depression leads to a worse valuation. But also within the patient population the valuation differs according to depression severity and duration. Identification with the hypothetical health state description might explain the varying differences found between subgroups for the different hypothetical health state descriptions.
\end{abstract}




\section{Background}

Many studies have shown that depression has an important influence on a patient's healthrelated quality of life. ${ }^{1-6}$ Health-related quality of life is often a main outcome parameter in economic evaluations of health care interventions (i.e. cost-utility analysis). However, there is no agreement on who should value the health state's quality of life: the general population, the patient, or some other rater group (e.g. health professionals). ${ }^{7}$ One might argue that quality of life should be valued by a patient population, since they really know what it is like to be in that health state, and consequently are the only ones who express the 'true' preference over different health states. ${ }^{8}$ Nevertheless, a consensus panel of the United States Public Health Service recommended using valuations of a representative sample of the general population. In short, the Panel claims that, since the public bears the costs associated with health care decisions, they ought also to have some say in the determination of benefits. ${ }^{8,9}$

Literature indicates that cost-utility studies indeed increasingly rely on general population preferences. ${ }^{10}$ These cost-utility studies often use multi-attribute utility methods whereby the patient only fills in a questionnaire on his/her health state, while numbers from the general population are used to value the patient's health state. For several questionnaires general population value sets are available (e.g. Euroqol 5D (EQ-5D), Short-Form 6D, Health Utility Index). These values, also called preferences or utilities, are quantitative expressions for certain health states, expressed on a scale of 0 (worst imaginable health state, death) to 1 (most optimal health state, full health). ${ }^{11}$ As stated earlier, these preferences can be obtained from a patient population, a general population, or some other rater group. ${ }^{7}$

As all raters have their pros and cons, the question remains who should value a health state and what the differences are between raters. Furthermore, there might be differences between several types of disorders. In this study, we focus on depression. We are aware of only one study on depression comparing a patient population with general population's valuation of a hypothetical health state. ${ }^{12}$ This study on depression found a discrepancy between preferences of the patient and general population: patients reported lower preferences - indicating that patients perceived depression worse than the general population - and there was a trend for a decreasing preference as the depression severity of the patient increased. ${ }^{12}$ This seems in contradiction to previous research on other disorders: while many studies showed a general tendency that general population scored higher preferences for a health state than patients, ${ }^{7}$ others concluded that overall there are no significant differences. ${ }^{13}$

Explanations of the potential differences between general population and patient preferences refer to three factors which we briefly describe below, being: the failure to rate the same health state (description), the failure to use the same measuring sticks, and actual differences of opinion. ${ }^{14}$ First, health state descriptions are always incomplete. Therefore, even when both patients and the general population are asked to rate an identical health state description, they might fill up the incomplete information (e.g. onset, presence of comorbidities) using for instance own experiences or stereotypes. The failure to rate the same health state thus might arise because patients and the public interpret health state 
descriptions differently. Secondly, even when this failure to rate the same health state could be eliminated, patients might still use different measurement sticks compared to the general population: there might be a discrepancy in interpretation of health-related quality of life. This discrepancy might for instance be caused through response shift: Changes in health might imply changes in the internal standards used to evaluate the health state due to changes in social comparisons (e.g. some patients might be comparing their health state to other patients instead of healthy people) or changes in the health expectations due to illness. But also recall error might influence the patient's valuation: they might better remember the strongest feelings experienced during a day (e.g. pain, fatigue) instead of the average feelings. Thus, the patients might attach more importance on the peak intensity while the general public bases its estimates on their prediction of patients' overall averages. Thirdly, discrepancies between the patient and general population might also arise due to real differences in opinion. These differences can exist through patients adapting physically (e.g. a blind patient has learned to read Braille) and emotionally (e.g. the inability to perform certain activities has lead to the patient preferring alternative activities) to their health states, while the general public fails to predict the adaptation in their valuation of the health state. Other causes might be contrast effects (e.g. people who experienced negative life events will be less bothered by less severe negative events) or a shift of interand intra-personal comparisons (e.g. not comparing the health status to their own previous healthier condition, but with e.g. other patients whom might have a more severe condition). ${ }^{14}$

Besides the differences between a patient and a general population, there might also be differences within a patient group while valuing the same health state description. Previous studies have shown that the severity of illness can lead to differences within a patient group. ${ }^{12,15}$

In this study we compare the view of a patient versus general population group on a hypothetical depression health state, whereas the patient group consists of people reporting to have depressive complaints. Both groups are asked to fill in the EQ-5D questionnaire for a hypothetical depression health state, and to value this hypothetical health state using a rating scale (RS). We subdivided the patient population into subgroups based on severity and duration of depressive complaints; and we varied the hypothetical health state describing either mild, moderate or severe depressive complaints. Based on previous research which found a lower valuation by the depressed patient population, ${ }^{12}$ and on the fact that depression implies more negative thoughts, we expect the patient group to value the hypothetical depressive health states worse as opposed to the general population.

\section{Method}

\section{Recruitment of participants}

Data were collected as part of a large-scale screening to recruit participants for a trial study on depression treatment. ${ }^{16-18} \mathrm{~A}$ random selection of individuals in the general population (age 18-65) was sent an invitation letter with unique login codes to complete a screening 
questionnaire via the Internet. Six municipalities in the Southern part of the Netherlands cooperated by providing names and addresses of their residents.

The screening questionnaire consisted of questions concerning depression, dysfunctional attitudes and socio-demographics. The additional data for the current study (i.e. valuation of a hypothetical depression state) were collected from December $19^{\text {th }} 2006$ until March $14^{\text {th }} 2007$, and are based on questionnaires placed after the screening questionnaires. Respondents were asked at the end of the screening to additionally fill in these questions.

\section{Creation of the health state descriptions}

For this study, three hypothetical depression states were created and described: (1) mild depressive complaints, (2) moderate depressive complaints, and (3) severe depressive complaints. These hypothetical states were described by means of the DSM-criteria, ${ }^{19}$ and created based on data of the first 8,916 screening respondents gathered through the Internet screening questionnaire: It was assessed whom of them had depressive complaints (i.e. a cut-off score of 4 on the Beck Depression Inventory for Primary Care ${ }^{20}$ and having complaints for at least 3 months), and their data regarding the nine depression complaints according to the DSM-IV criteria and severity of depression (complaints and severity assessed by the Diagnostic Inventory for Depression ${ }^{21,22}$ ) were used to compile the three different hypothetical depression states. The four most prevalent complaints of the screening respondents with mild complaints $(n=140)$ were used to compose the hypothetical mild depression state. The six most prevalent complaints of the screening respondents with moderate complaints $(n=260)$ were used to compose the hypothetical moderate depression state. And finally, the hypothetical severe depression state was composed by all depression complaints of the DSM-IV. ${ }^{19}$

\section{Valuation procedure}

Those respondents which were approached to value a hypothetical depression state were only presented one of the health states: mild, moderate or severe depression (see figure 1). After a description and explanation of the questionnaire, the respondent was asked to fill in the EuroQol for that hypothetical health state.

The EuroQol consists of five health state dimensions (mobility, self-care, usual activity, pain/discomfort and anxiety/depression) on which the respondent has to indicate the health state choosing from three levels (no problem, some problems, and major problems). ${ }^{23,24}$

Besides the five dimensions, a last question of the EuroQol is a visual analogue scale (EQVAS). This is a vertical rating scale thermometer ranging from 0 (worst) to 100 (most optimal) on which respondents have to indicate how good or bad the health state is. Due to limitations of the computer system in use, we were unable to present the vertical thermometer of the EQ-VAS. Therefore, an adjusted version of the VAS was used, being a rating scale (RS): a question to give a rating between 0 and 100 that indicates how good or bad the presented health state description is, whereby 100 means the most optimal and 0 means the worst imaginable health state. 
Health state description of severe depression

A person is having / suffering from severe depressive complaints. Almost daily he is having a depressed mood and almost no interest or pleasure in (almost) all activities. Besides, he is having the following complaints:

- Problems with appetite or changes in weight

- Problems with sleeping

- Restlessness or being inhibited

- Fatigue, loss of energy

- Feelings of worthlessness or excessive guilt

- Diminished ability to think or concentrate, indecisiveness

- Recurrent thoughts of death or suicide

Health state description of moderate depression

A person is having / suffering from moderate depressive complaints. Almost daily he is having a depressed mood. Besides, he is having the following complaints:

- Problems with sleeping

- Restlessness or being inhibited

- Fatigue, loss of energy

- Feelings of worthlessness or excessive guilt

- Diminished ability to think or concentrate, indecisiveness

\section{Health state description of mild depression}

A person is having / suffering from severe depressive complaints. Almost daily he is having a depressed mood. Besides, he is having the following complaints:

- Restlessness or being inhibited

- Fatigue, loss of energy

- Diminished ability to think or concentrate, indecisiveness

Figure 1: Hypothetical health state descriptions

\section{Defining general population and patient subgroups}

General population and patient subgroups were created according to two different perspectives: A division was made based on depression severity measured by a standardized questionnaire, and based on the participant's self-perceived duration of complaints. Depression severity was measured with the Beck Depression Inventory Second Edition (BDIII). The total score of the BDI-II is the sum of the 21 items with a range of 0 (no depression) to 63 (severe depression). There has been consistent support for the construct validity and reliability of the BDI-II in various samples ${ }^{25-27}$. For patients, diagnosed with depression a BDI-II score of 0-13 is categorised 'minimal', 14-19 'mild', 20-28 'moderate severe', and 29-

63 'severe' depression. ${ }^{27}$ Based on these cut-off scores, we divided study participants into four groups: (0) those without depressive complaints (i.e. the general population) and those with (1) mild, (2) moderate, and (3) severe complaints.

The BDI-II however, does not imply information on the duration of the depressive complaints, and does not necessarily correspond with self-perceived depressive complaints. Therefore participant's self-perceived duration of depressive complaints (SPDD) was used as a second indicator of depressive complaints. This SPDD was measured by the question: Are you suffering from sadness or depression? The answers on this question were divided 
into three groups: (0) no complaints (i.e. the general population), (1) depressive complaints up to about 3 months, and (2) depressive complaints for longer than 3 months.

\section{Analysis}

All available data were used. Preliminary, the normality of the data was assessed by means of histograms and skewness and kurtosis statistics. In the first part, analyses are preformed on the BDI-II based subgroups, and the second part consists of analyses on the SPDD based subgroups. Analyses of both the BDI-II- and SPDD-based subgroups of all three hypothetical depression health states consisted of the following three aspects. First the sociodemographic characteristics of the subgroups were evaluated (mean and standard deviation, or percentage scores). Secondly the scores on the Euroqol dimensions of each subgroup are graphically presented in a bar chart, and differences between subgroups are tested by the $\mathrm{Chi}^{2}$ test. Thirdly, the RS scores of the different subgroups are evaluated (mean score and standard deviation) and differences between subgroups are tested by the Mann-Whitney test $(p<0.05)$. All analyses were carried out using SPSS version 15.0.1 for Windows.

\section{Results BDI-II subgroups}

\section{Study participants}

In total, 2,101 respondents completed the questionnaire on the hypothetical health state. 670 of them were presented the severe health state, 691 were presented the moderate health state, and 740 were presented the mild health state. Table 1 presents the baseline characteristics of these participants per BDI-II-based subgroup. The figures in table 1 indicate that subgroups without depressive complaints have relatively more male, employed, higher educated respondents with partner as opposed to the subgroups with depressive complaints. 


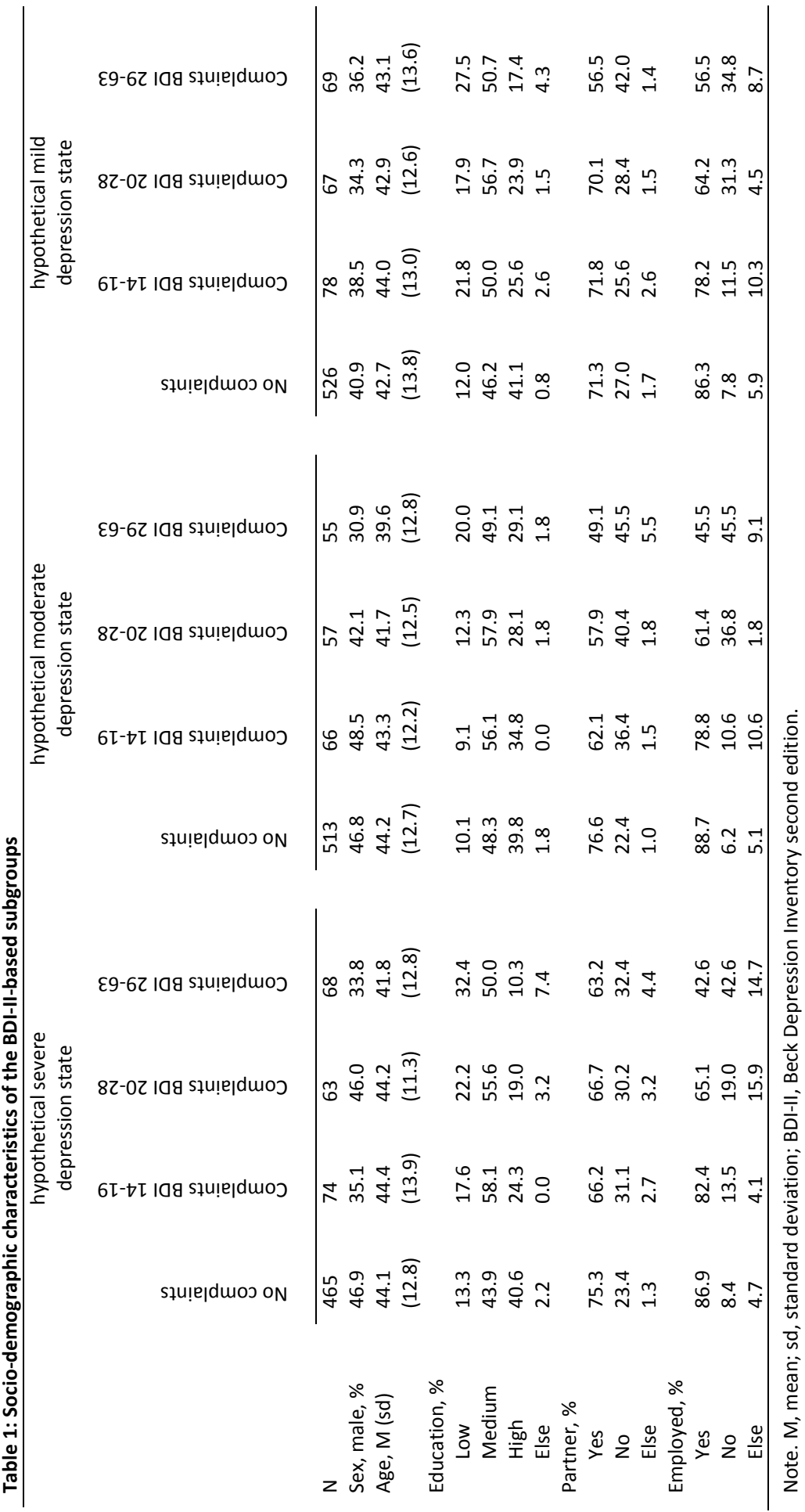




\section{Differences in Euroqol domain scores}

Figures $2 \mathrm{a}, 2 \mathrm{~b}$, and $2 \mathrm{c}$ present the domain scores of the Euroqol. The figures and $\mathrm{p}$-values indicate that the higher the BDI-II score of the subgroups' respondents, the more problems are reported on the domains 'usual activities', 'pain/discomfort', and 'anxiety/depression'. However, for the domain 'self-care' there seems to be a tendency that subgroups with a higher BDI-II score report less problems on this domain compared with subgroups with a lower BDI-II score. The subgroups do not show significant differences on the domain 'mobility'. 


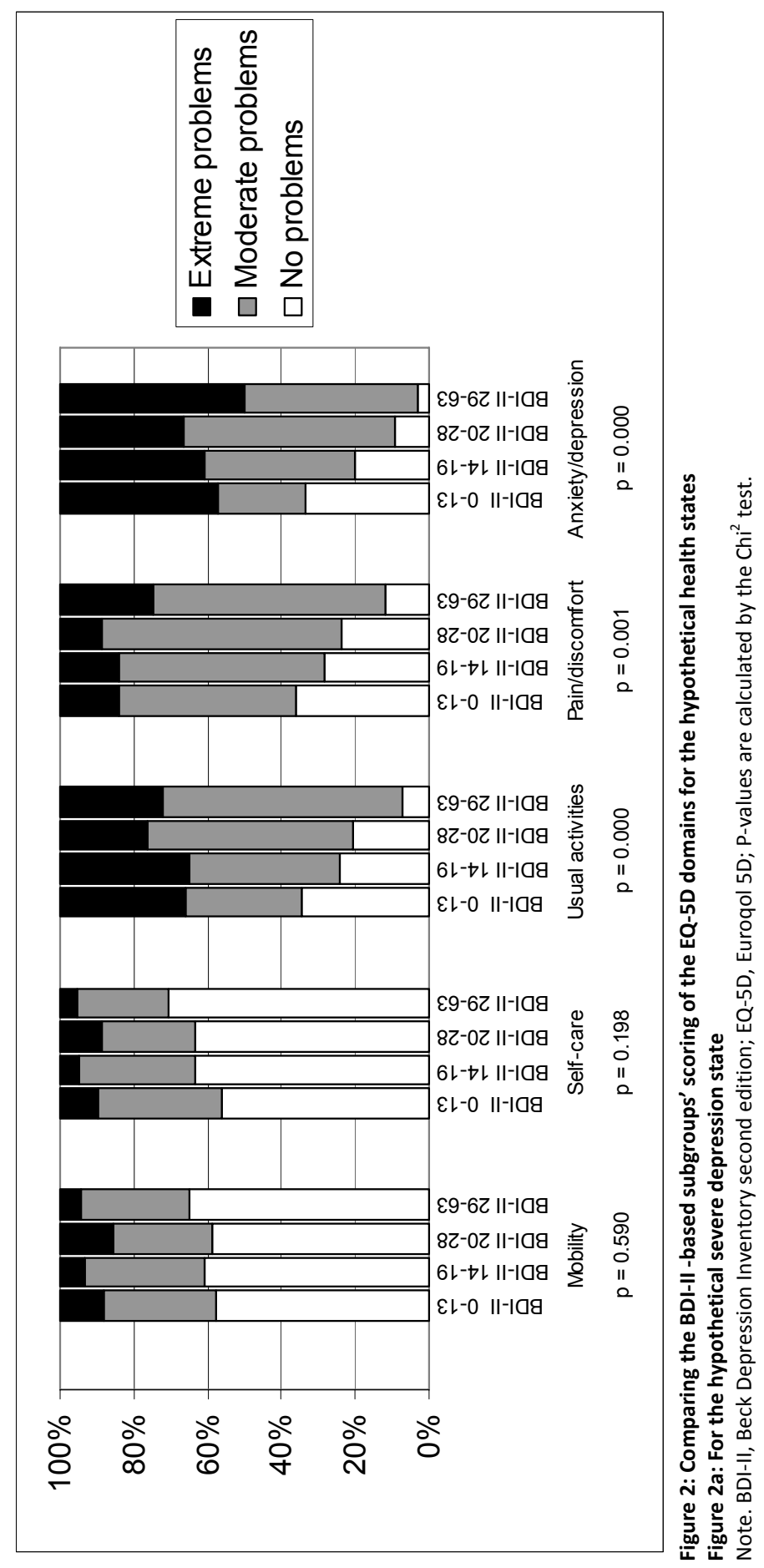




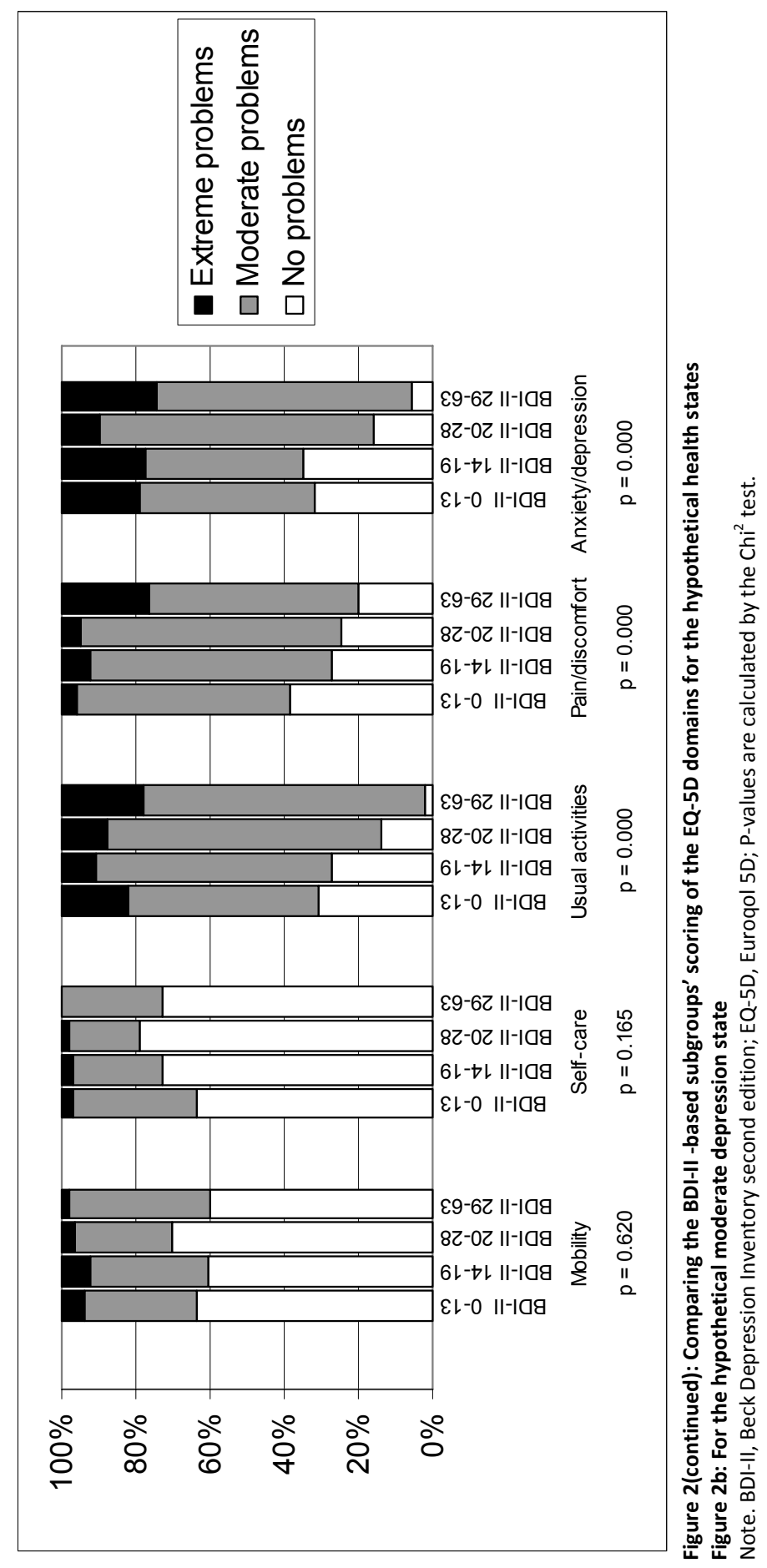




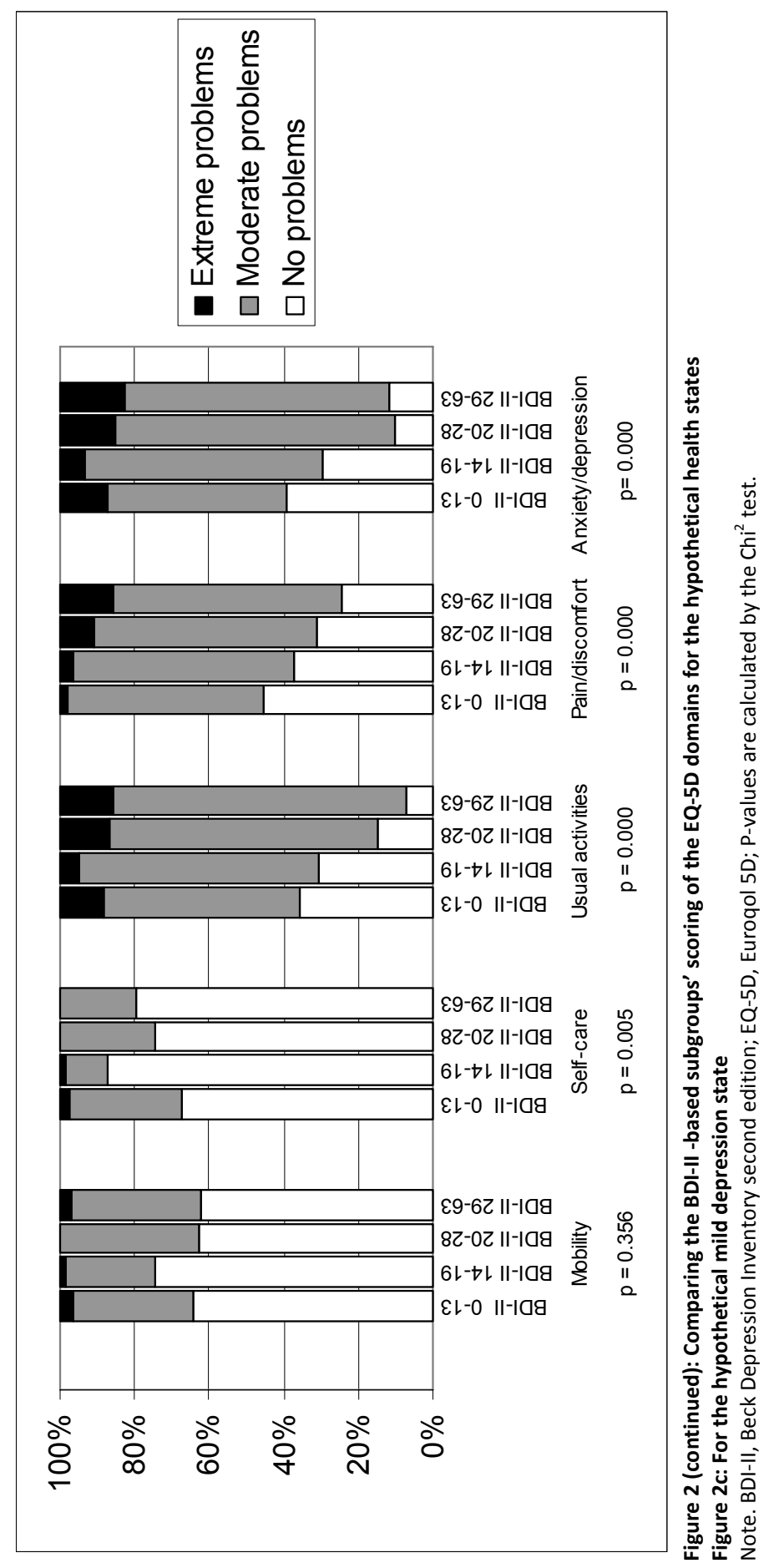




\section{Differences in RS}

Table 2 presents the mean RS outcomes for each hypothetical health state per BDI-II based subgroup. Results indicate that a more severe health state is given relatively lower RS scores compared with a less severe hypothetical depression state. The RS outcome for the severe health state description does not differ significantly between the subgroups, although there is a trend towards significance when comparing the severely depressed subgroup with the subgroup with mild complaints $(p=0.051)$ or the subgroup without complaints $(p=0.053)$. For the moderate health state description, the outcomes of the severely depressed subgroup (BDI-II 29-63) differ significantly from all other subgroups (all $p<0.05)$. And for the mild health state description, the RS outcomes from the severely depressed subgroup (BDI-II 29-63) and the moderately depressed subgroup (BDI-II 20-28) differ significantly from the subgroup without complaints and from the subgroup with mild complaints (BDI 14-19). 


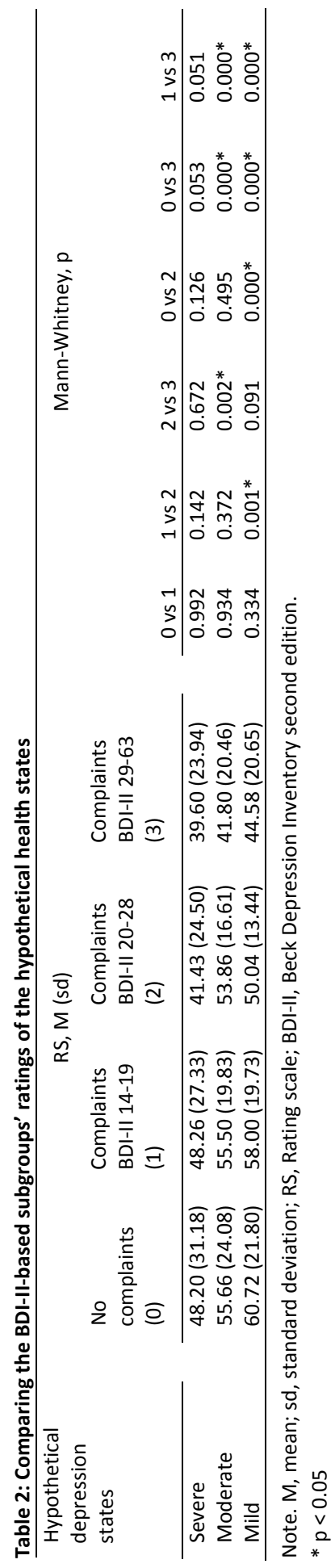




\section{Results SPDD subgroups}

\section{Study participants}

Table 3 presents the baseline characteristics of the participants per SPDD-based subgroup. The figures in table 3 indicate that the subgroups without depressive complaints have relatively more male, employed, higher educated respondents with partner as opposed to the subgroups with depressive complaints.

Table 3: Socio-demographic characteristics of the SPDD-based subgroups

\begin{tabular}{|c|c|c|c|c|c|c|c|c|c|}
\hline & \multicolumn{3}{|c|}{$\begin{array}{l}\text { hypothetical severe } \\
\text { depression state }\end{array}$} & \multicolumn{3}{|c|}{$\begin{array}{l}\text { hypothetical moderate } \\
\text { depression state }\end{array}$} & \multicolumn{3}{|c|}{$\begin{array}{l}\text { hypothetical mild } \\
\text { depression state }\end{array}$} \\
\hline & 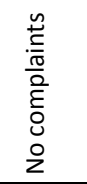 & 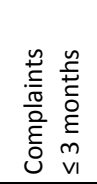 & 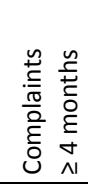 & $\begin{array}{l}\frac{n}{\frac{\pi}{\pi}} \\
\frac{\pi}{0} \\
\frac{0}{E} \\
0 \\
0 \\
0 \\
z\end{array}$ & 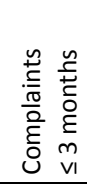 & 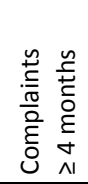 & 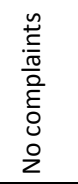 & 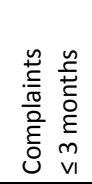 & 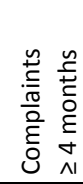 \\
\hline $\mathrm{N}$ & 362 & 126 & 182 & 372 & 150 & 169 & 418 & 144 & 178 \\
\hline Sex, male, \% & 46.7 & 38.1 & 43.4 & 47.0 & 42.0 & 44.4 & 41.4 & 38.9 & 36.0 \\
\hline Age, M (sd) & $\begin{array}{l}45.4 \\
(12.6)\end{array}$ & $\begin{array}{l}40.4 \\
(12.9)\end{array}$ & $\begin{array}{l}43.4 \\
(12.7)\end{array}$ & $\begin{array}{l}44.8 \\
(12.4)\end{array}$ & $\begin{array}{l}40.4 \\
(13.3)\end{array}$ & $\begin{array}{l}43.5 \\
(12.4)\end{array}$ & $\begin{array}{l}43.3 \\
(13.8)\end{array}$ & $\begin{array}{l}40.0 \\
(13.2)\end{array}$ & $\begin{array}{l}44.3 \\
(13.0)\end{array}$ \\
\hline \multicolumn{10}{|l|}{ Education, \% } \\
\hline Low & 14.6 & 18.3 & 19.2 & 10.8 & 10.7 & 11.8 & 11.7 & 18.8 & 19.7 \\
\hline Medium & 45.0 & 39.7 & 56.6 & 48.7 & 48.0 & 54.4 & 44.0 & 53.5 & 52.8 \\
\hline High & 39.0 & 37.3 & 20.9 & 39.0 & 39.3 & 32.5 & 43.5 & 26.4 & 24.7 \\
\hline Else & 1.4 & 4.8 & 3.3 & 1.6 & 2.0 & 1.2 & 0.7 & 1.4 & 2.8 \\
\hline \multicolumn{10}{|l|}{ Partner, \% } \\
\hline Yes & 78.5 & 65.9 & 64.3 & 80.4 & 60.0 & 62.1 & 72.0 & 66.0 & 68.0 \\
\hline No & 20.4 & 30.2 & 33.5 & 18.8 & 38.7 & 34.9 & 26.1 & 31.9 & 30.9 \\
\hline Else & 1.1 & 4.0 & 2.2 & 0.8 & 1.3 & 3.0 & 1.9 & 2.1 & 1.1 \\
\hline \multicolumn{10}{|l|}{ Employed, \% } \\
\hline Yes & 86.7 & 77.8 & 67.6 & 91.1 & 82.0 & 62.1 & 85.4 & 84.0 & 66.9 \\
\hline No & 8.6 & 16.7 & 20.9 & 5.1 & 10.7 & 29.6 & 8.6 & 9.7 & 25.3 \\
\hline Else & 4.7 & 5.6 & 11.5 & 3.8 & 7.3 & 8.3 & 6.0 & 6.3 & 7.9 \\
\hline
\end{tabular}

Note. M, mean; sd, standard deviation; BDI-II, Beck Depression Inventory second edition.

\section{Differences in Euroqol domain scores}

Figures $3 a, 3 b$, and $3 c$ present the domain scores of the Euroqol. The figures and $p$-values indicate that subgroups with self-perceived depression complaints and/or a longer duration of complaints report more problems on the domains 'usual activities', 'pain/discomfort', and 'anxiety/depression' as opposed to the subgroup who has no self-perceived depression complaints or a shorter duration of complaints. However, for the domain 'self-care' subgroups with self-perceived depression complaints report less problems as opposed to the subgroup who has no self-perceived depression complaints. The subgroups do not show significant differences on the domain 'mobility'. 


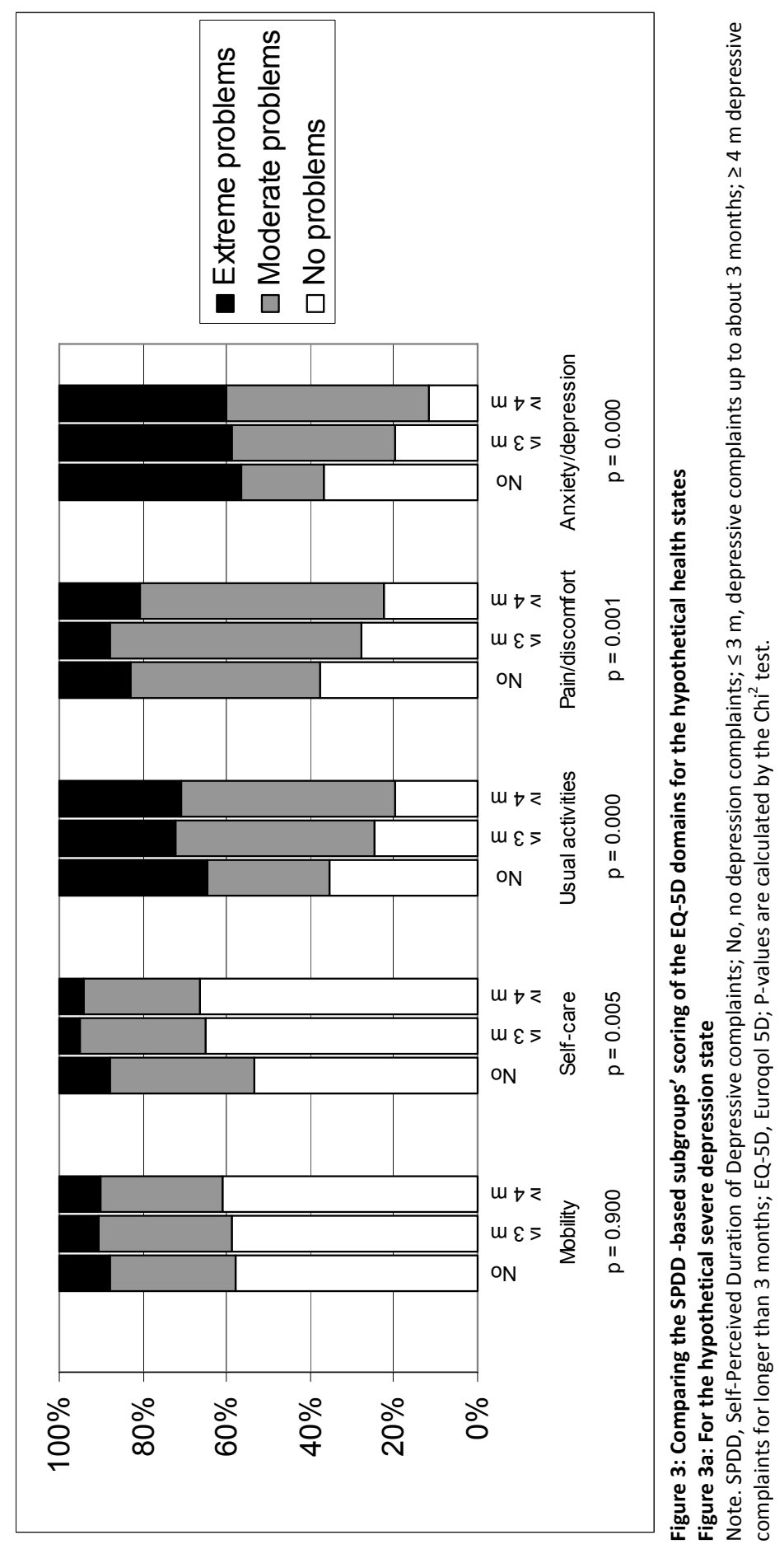




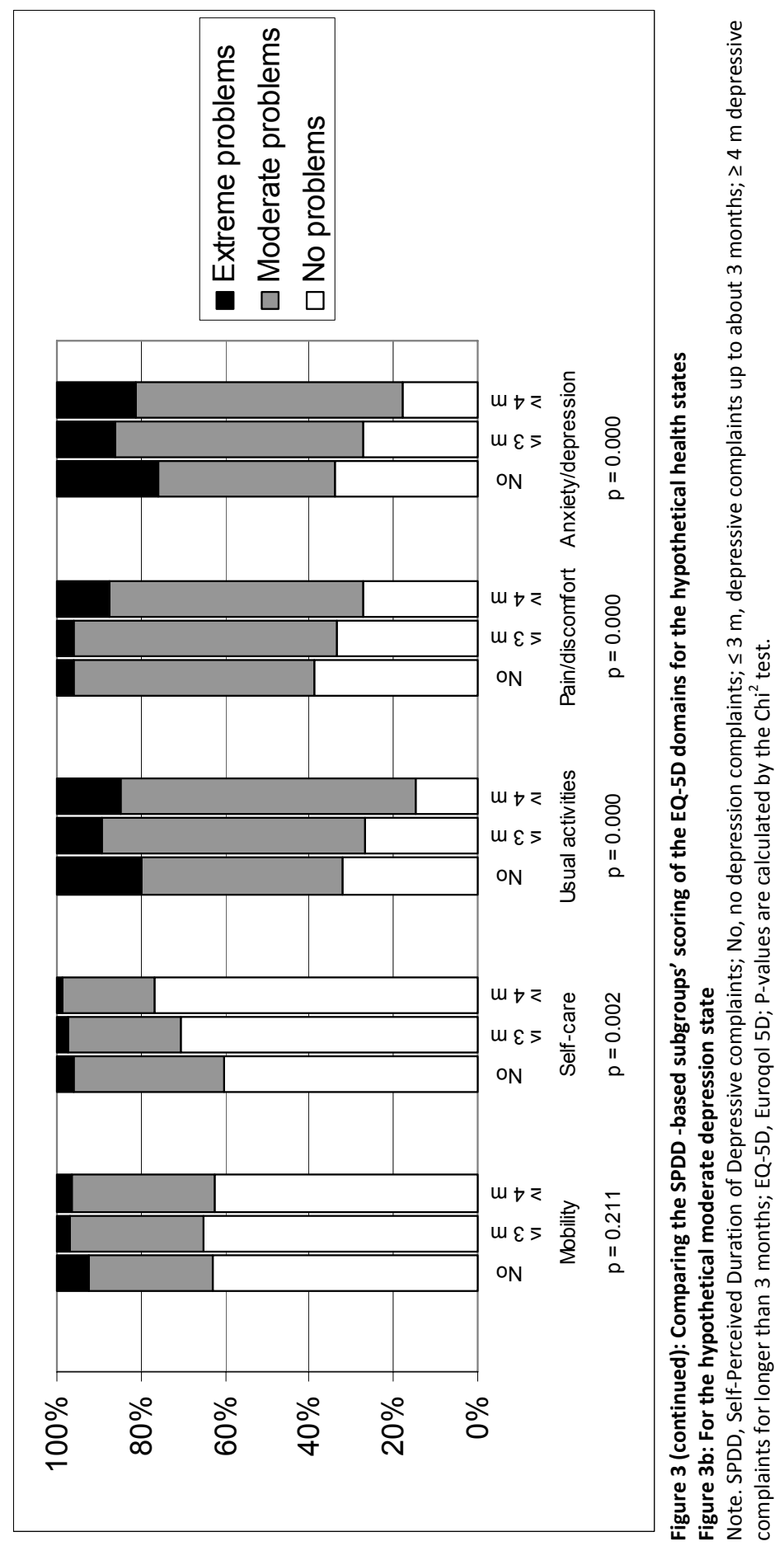




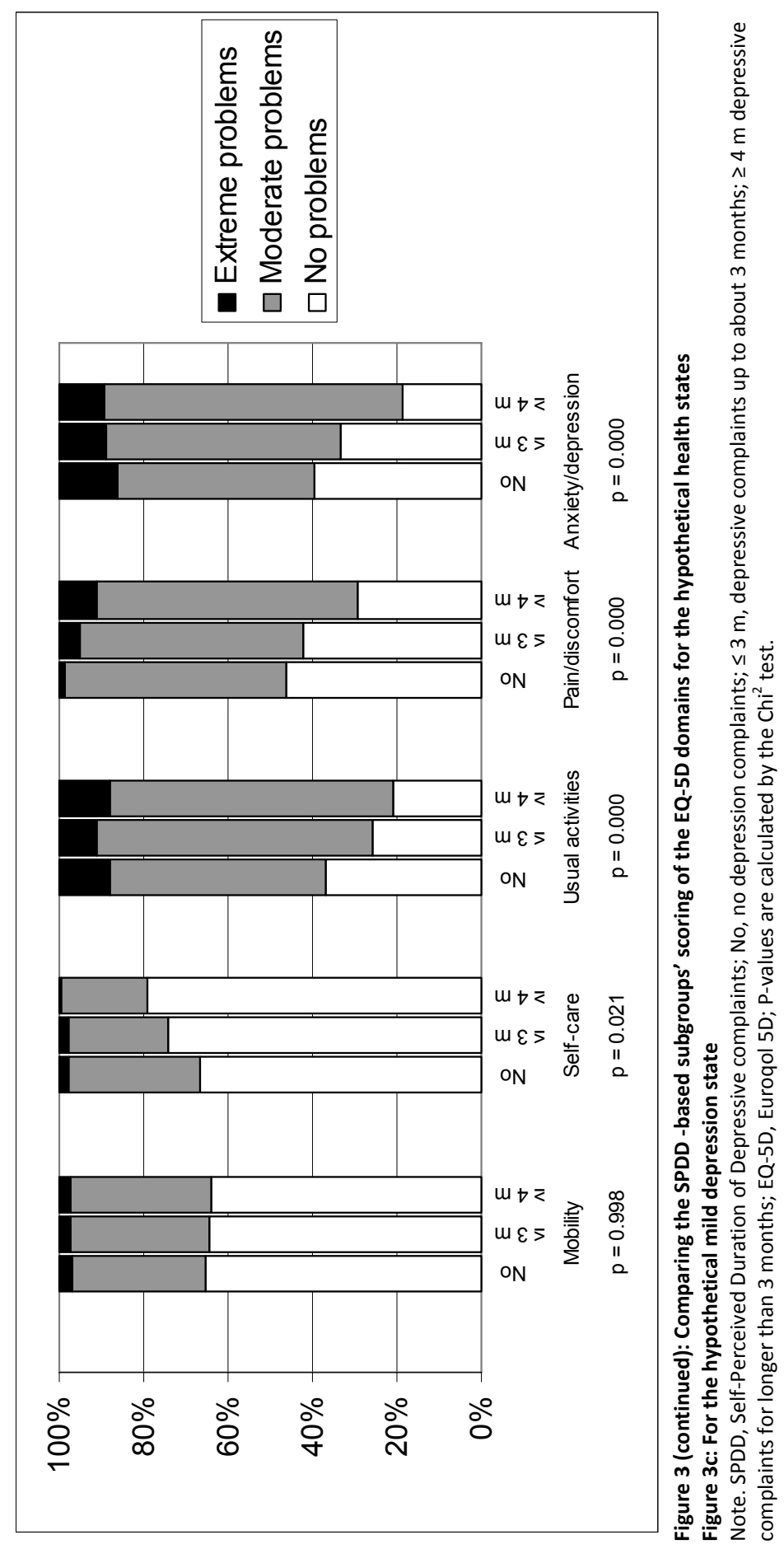




\section{Differences in RS}

Table 4 presents RS outcomes for each hypothetical health state per SPDD based subgroup. Results indicate that a more severe health state is given relatively lower ratings compared with a less severe hypothetical depression state. For the severe health state description, the outcomes of the Mann-Whitney test show that there are no significant differences between the three subgroups. For the moderate health state description, the RS scores of the subgroup with complaints $\geq 4$ months differ significantly from the subgroup with complaints $\leq 3$ months $(p=0.002)$ and from the subgroup without complaints $(p=0.003)$. For the mild health state description, the RS outcomes of the subgroup $\geq 4$ months as well differ significantly from the subgroup with complaints $\leq 3$ months $(p=0.008)$ and from the subgroup without complaints $(p=0.000)$.

Table 4: Comparing the SPDD-based subgroups' ratings of the hypothetical health states

\begin{tabular}{|c|c|c|c|c|c|c|}
\hline \multirow{2}{*}{$\begin{array}{l}\text { Hypothetical } \\
\text { depression states }\end{array}$} & \multicolumn{3}{|c|}{ RS, M (sd) } & \multicolumn{3}{|c|}{ Mann-Whitney, p } \\
\hline & $\begin{array}{l}\text { No complaints } \\
\text { (0) }\end{array}$ & $\begin{array}{l}\text { Complaints } \\
\leq 3 \text { months } \\
\text { (1) }\end{array}$ & $\begin{array}{l}\text { Complaints } \\
\geq 4 \text { months } \\
(2)\end{array}$ & 0 vs 1 & 1 vs 2 & 0 vs 2 \\
\hline Severe & $48.74(32.02)$ & $44.29(28.17)$ & $44.30(25.21)$ & 0.153 & 0.962 & 0.150 \\
\hline Moderate & $55.75(24.94)$ & $56.80(20.70)$ & $49.26(20.34)$ & 0.714 & $0.002 *$ & $0.003 *$ \\
\hline Mild & $60.89(21.74)$ & $57.17(21.61)$ & $51.72(19.37)$ & 0.130 & $0.008^{*}$ & $0.000 *$ \\
\hline
\end{tabular}

Note. M, mean; sd, standard deviation; SPDD, Self-Perceived Duration of Depressive complaints; RS, Rating scale.

$* p<0.05$

\section{Discussion}

\section{Main results}

This study showed that there are discrepancies in the valuation of a hypothetical depression health state between a patient and general population. However, not only between the patient and the general population, also within the patient population discrepancies can exist between subgroups based on depression severity (BDI-II) and on duration of the complaints (SPDD). Moreover, the severity of complaints in the health state description also impacts the differences between the patient and general population and within the patient population.

The direction of the differences shows that patients value the hypothetical state worse compared to the general population, while within the patient groups those with more severe or a longer duration of complaints value the hypothetical state worse compared to those with less severe or a shorter duration of complaints (for the RS score and the Euroqol domains usual activities, pain/discomfort, and anxiety/depression). 


\section{Reflection on the findings}

In the differences between the subgroups' valuation of the health states, there seems to be a relation between the severity of the respondents' own depression complaints and the severity of the hypothetical health state description to be valued. The point from which on groups differ in the valuation of the description changes with the severity of complaints described: For the mild health state description a significant difference from the general population RS score is found for respondents with at least moderate complaints, for the moderate health state description this difference is found for respondents with at least severe complaints, and for the severe health state description this difference is not found for any subgroups. This might indicate that identification has a role in the valuation: Those with at least moderate complaints might recognise themselves in the description of mild depression, those with severe complaints recognise themselves in the description of moderate depression, while the description of severe depression might be too severe for identification in all subgroups.

The fact that differences were also found between the SPDD-based patient subgroups indicates that there are differences in the interpretation or valuation based on the duration of complaints. This might be related to the aspects of adaptation, response shift or shift in internal standards which are often given as possible explanations for differences in valuations between a patient and general population: Patients who experience complaints for a longer period of time, might have more adaptation or shifted further opposed to those who only recently started to experience the health complaints.

Previous studies on different disorders which found a discrepancy in patient and general population studies mostly showed that patients give higher values for a health status compared with the general population. ${ }^{7}$ However, the findings of our study are in line with the only study focusing on depression, being that patients report lower preferences and thus perceive depression worse than the general population, and that the preference score decreases as the depression severity of the respondent increases. ${ }^{12}$ It is not clear whether our results reflect an overestimation by the general population, or an underestimation by the patient population. Assuming an underestimation of the patient population could reflect a tendency of negative thinking. While most of the time adaptation or shifts in the patients' interpretation, valuation or opinion of the health state are explained in terms of patients giving higher valuations opposed to the general population, our results seem to suggest that these can also imply a worse valuation by the patient population. For instance, adaptation in the case of depression might not mean that the patient focuses on what he still can do or on the alternatives, but rather through his depressed mood, loss of interest, feelings of worthlessness etc. focuses on the things he can not do or does not enjoy anymore. At the other hand, several studies have suggested that depressed people have a more accurate perception of reality compared with non-depressed people. ${ }^{28}$ In case of this so-called 'depressive realism', it would not be the patient population which underestimates the depressive health status, but the general population which gives an overestimation of the hypothetical health states presented in this study. Assuming that our results indicate an overestimation by the general population could imply that the general population is not sufficiently experienced or informed to truly understand what it means to have depressive complaints. Many studies have shown that mental disorders in general - but also specific 


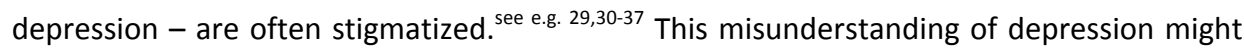
have caused an overestimation of RS for depression.

\section{Methodological considerations and limitations}

A first methodological consideration concerns our composition of the 'general population' and the 'patient population'. Our patient group consists of respondents who reported depressive complaints on a self-report Internet questionnaire. These respondents thus have not been diagnosed as depressed by a professional. Moreover, there is no information on co-morbidity, and in case of co-morbidity the depressive complaints might not be the main complaint but a consequence of another disorder. On the other hand, our general population might not be truly representative for the general population since respondents reporting depressive complaints have been filtered out of the group and placed in the patient group. This might have led to an overestimation of the discrepancy between the patient population and the general population. Moreover, recruitment took place in the open population aged 18-65 years, but it might be expected that those who participated in this study are people who are relatively more interested and/or familiar with depression or mental health and more familiar with computer work.

A second methodological consideration is that results indicate that there might be some crucial baseline differences between the subgroups in socio-demographic characteristics for which no corrections have been done. However, the differences between the subgroups are as expected: the subgroups with (increased/longer) depressive complaints are composed of relatively more female, unemployed, lower educated respondents without a partner as opposed to the subgroups without depressive complaints, with less severe complaints, or complaints since a short term. The mentioned socio-demographic aspects have been demonstrated as related to depression. ${ }^{38}$ Except for sex, these characteristics might be either cause or consequence of depressive complaints. Therefore, we believe that correcting for these differences would be inappropriate.

A third consideration of our study concerns the valuation of the severe hypothetical depression state description, which includes having suicidal thoughts. Suicidal thoughts might imply that a person prefers being dead over living. In that case, the health condition might be valued as worse than death. The health state preferences theoretically range from 0 to 1 , whereby 0 means the worst imaginable health state or death. ${ }^{11}$ But as shown by Macran and Kind, ${ }^{39}$ there are people who place a relatively high value to the state 'death' compared with other health states. However, the RS in our study had a range of 0 to 100 , and in our questionnaire it was not possible for the respondent to give a rating below 0 . Moreover, the 0 was explained as the worst imaginable health state, not mentioning 'death'.

A limitation of our study is that we have not elicited choice-based preferences (e.g. through Standard Gamble (SG) or Time Trade-Off (TTO)), which are considered more appropriate compared with RS or VAS. ${ }^{11,40}$ Within our self-administered Internet questionnaire in the absence of an interviewer, a SG or TTO might have been too complex for the respondent. Research has shown that SG and TTO are feasible in a self-completed format, although the performances in a postal format are relatively unproven. There is evidence for using the VAS technique in postal surveys. ${ }^{40,41}$ Previous studies however showed that preferences derived through VAS/RS provided lower valuations compared to TTO or SG preferences. ${ }^{7}$ 
Moreover, our RS is probably not directly comparable to VAS outcomes since there was no visual thermometer shown in the questionnaire.

Another limitation is that respondents only valued one health state on the RS. Consequently, there is no comparison made with other health states which are perceived by the respondent as most optimal or worst. The RS is subject to end-of-scale bias, meaning that respondents tend to not use the end of the scales. ${ }^{11}$

Moreover, the valuation of a hypothetical health state might be different from the valuation of an identical actual own health state. Unfortunately, we did not obtain data which make this direct comparison possible.

A last limitation of this study, is that we did not assess the contribution of severity and duration simultaneously. We found large Spearman correlations between the SPDD and BDI-II variables subdivided into the subgroup categories presented in this study $(r=0.684$, 0.600 , and 0.641 for respectively the severe, moderate, and mild health state description). However, since each severity category can be combined with each duration category, integrating the severity and duration categories would imply a larger number of subgroups and lead to some very small subgroups.

\section{Conclusion}

People with a higher severity or longer duration of depressive complaints value depression health states worse compared with people with less severe complaints, a shorter duration, or no depressive complaints. Moreover, the discrepancy in valuation of a health state between different subgroups changes according to the severity of the health state described, which might be explained by identification with the health state described.

\section{Acknowledgements}

We thank Esther de Graaf, Annie Hendriks and Greet Kellens for their assistance in recruitment and data-collection, and Rosanne Janssen for the development of the infrastructure for online data-collection.

This study collected data within the screening for a trial financed by ZonMw (Netherlands Organisation for Health Research and Development; project number 945-04-417), research institute EPP and research institute CAPHRI. Municipalities Eijsden, Meerssen, SittardGeleen, Valkenburg and Maastricht sponsored the trial study. 


\section{References}

1. ten Doesschate MC, Koeter MWJ, Bockting CLH, Schene AH, Group TDS. Health related quality of life in recurrent depression: A comparison with a general population sample. J Affect Disord 2010;120:126132.

2. Bijl RV, Ravelli A. Current and residual functional disability associated with psychopathology: findings from the Netherlands Mental Health Survey and Incidence Study (NEMESIS). Psychol Med 2000;30:657668.

3. Kruijshaar ME, Hoeymans N, Bijl RV, Spijker J, Essink-Bot ML. Levels of disability in Major Depression. Findings from the Netherlands Mental Health Survey and Incidence Study (NEMESIS). J Affect Disord 2003;77(1):53-64.

4. Creed F, Morgan R, Fiddler M, Marshall S, Guthrie E, House A. Depression and anxiety impair healthrelated quality of life and are associated with increased costs in general medical inpatients. Psychosomatics 2002;43(4):302-309.

5. Rapaport $\mathrm{MH}$, Clary C, Fayyad R, Endicott J. Quality-of-life impairment in depressive and anxiety disorders. Am J Psychiatry 2005;162(6):1171-1178.

6. Sobocki P, Ekman M, Agren H, Krakau I, Runeson B, Martensson B, et al. Health-related quality of life measured with EQ-5D in patients treated for depression in primary care. Value Health 2007;10(2):153160.

7. de Wit GA, Bussbach JJV, De Charro FT. Sensitivity and perspective in the valuation of health status: Whose values count? Health Econ 2000;9:109-126.

8. Drummond M, McGuire A. Economic evaluation in health care: Merging theory with practice. New York: Oxford University Press, 2001.

9. Gold MR, Siegel JE, Russell LB, Weinstein MC. Cost-effectiveness in Health and Medicine. New York: Oxford University Press Inc, 1996.

10. Brauer $C A$, Rosen $A B$, Greenberg D, Neumann PJ. Trends in the measurement of health utilities in published cost-utility analyses. Value Health 2006;9(4):213-218.

11. Drummond MF, Sculpher MJ, Torrance GW, O'Brien B, Stoddart GL. Methods for the Economic Evaluation of Health Care Programmes. Oxford: Oxford University Press, 2005.

12. Pyne JM, Fortney JC, Tripathi S, Feeny D, Ubel P, Brazier J. How bad is depression? Preference score estimates from depressed patients and the general population. Health Serv Res 2009;44(4):1406-1423.

13. Dolders MGT, Zeegers MPA, Groot W, Ament A. A meta-analysis demonstrates no significant differences between patient and population preferences. J Clin Epidemiol 2006;59:653-664.

14. Ubel PA, Loewenstein G, Jepson C. Whose quality of life? A commentary exploring discrepancies between health state evaluations of patients and the general public. Qual Life Res 2003;12:599-607.

15. Lenert LA, Treadwell JR, Schwartz CE. Associations between health status and utilities: Implications for policy. Med Care 1999;37(5):479-489.

16. Gerhards SAH, de Graaf LE, Jacobs LE, Severens JL, Huibers MJH, Arntz A, et al. Economic evaluation of online computerised cognitive-behavioural therapy without support for depression in primary care: randomised trial. Br J Psychiatry 2010;196(4):310-318.

17. de Graaf LE, Gerhards SAH, Evers SMAA, Arntz AR, Riper H, Severens JL, et al. Clinical and costeffectiveness of computerised cognitive behavioural therapy for depression in primary care: design of a randomised trial. BMC Public Health 2008;8:224.

18. de Graaf LE, Gerhards SAH, Arntz AR, Riper H, Metsemakers JFM, Evers SMAA, et al. Clinical effectiveness of online computerised cognitive behavioural therapy without support for depression in primary care: a randomised trial. Br J Psychiatry 2009;195(1):73-80.

19. American Psychiatric Association. DSM-IV-TR. Diagnostic and Statistical Manual of Mental Disorders. 4th ed. Washington, DC: American Psychiatric Press, 2000.

20. Steer RA, Cavalieri TA, Leonard DM, Beck AT. Use of the Beck Depression Inventory for Primary Care to Screen for Major Depressive Disorders. General Hospital Psychiatry 1999;21:106-111.

21. Zimmerman M, Sheeran T, Young D. The Diagnostic Inventory for Depression: A self-report scale to diagnose DSM-IV major depressive disorder. Clinical Psychology 2004;60(1):87-110. 
22. Sheeran T, Zimmerman M. Case identification of depression with self-report questionnaires. Psychiatry Res 2002;109:51-59.

23. Brooks R. EuroQol: the current state of play. Health Policy 1996;37(1):53-72.

24. EuroQol Group. EuroQol - a new facility for the measurement of health-related quality of life. Health Policy 1990;16(3):199-208.

25. Beck AT, Steer RA, Ball R, Ranieri WF. Comparison of Beck Depression Inventories-IA and -II in psychiatric outpatients. J Pers Assess 1996;67(3):588-597.

26. Arnau RC, Meagher MW, Norris MP, Bramson R. Psychometric Evaluation of the Beck Depression Inventory-II With Primary Care Medical Patients. Health Psychol 2001;20(2):112-119.

27. Van der Does AJW. De Nederlandse versie van de Beck Depression Inventory - second edition (BDI-II-NL): Handleiding [The Dutch version of the Beck Depression Inventory - second edition (BDI-II-NL): Manual]. Enschede: The Psychological Corporation, 2002.

28. Alloy LB, Abramson LY. Judgement of contingency in depressed and nondepressed students: sadder but wiser? J Exp Psychol Gen 1979;108(4):441-485.

29. Perry BL, Pescosolido BA, Martin JK, McLeod JD, Jensen PS. Comparison of public attributions, attitudes, and stigma in regard to depression among children and adults. Psychiatr Serv 2007;58(5):632-635.

30. Matschinger $\mathrm{H}$, Angermeyer MC. The public's preferences concerning the allocation of financial resources to health care: results from a representative population survey in Germany. European Psychiatry 2004;19:478-482.

31. Angermeyer MC, Dietrich S. Public beliefs about and attitudes towards people with mental illness: a review of population studies. Acta Psychiatr Scand 2006;113:163-179.

32. Link BG, Phelan JC, Bresnahan M, Stueve A, Pescosolido BA. Public conceptions of mental illness: Labels, causes, dangerousness, and social distance. Am J Public Health 1999;89(9):1328-1333.

33. Jorm AF, Korten $A E$, Jacomb PA, Christensen $H$, Rodgers $B$, Pollitt $P$. Public beliefs about causes and risk factors for depression and schizophrenia. Soc Psychiatry Psychiatr Epidemiol 1997;32:143-148.

34. Schomerus G, Matschinger H, Angermeyer MC. Preferences of the public regarding cutbacks in expenditure for patient care. Are there indications of discrimination against those with mental disorders? Soc Psychiatry Psychiatr Epidemiol 2006;41:369-377.

35. van 't Veer JTB, Kraan HF, Drossaert SHC, Modde JM. Determinants that shape public attitudes towards the mentally ill: A Dutch public study. Soc Psychiatry Psychiatr Epidemiol 2006;41:310-317.

36. van 't Veer JTB, Kraan HF, Drossaert SHC, Modde JM. Destigmatisering door deconcentratie? Een Nederlands bevolkingsonderzoek naar het stigma van psychiatrische patiënten [De-stigmatisation through de-concentration? A Dutch population-study of the stigmatisation of psychiatric patients]. Tijdschrift voor de Psychiatrie 2005;47(10):659-669.

37. Barney LJ, Griffiths KM, Jorm AF, Christensen H. Stigma about depression and its impact on help-seeking intentions. Aust N Z J Psychiatry 2006;40(1):51-54.

38. Bijl RV, Ravelli A, van Zessen G. Prevalence of psychiatric disorder in the general population: Results of the Netherlands Mental Health Survey and Incidence Study (NEMESIS). Soc Psychiatry Psychiatr Epidemiol 1998;33(12):587-595.

39. Macran S, Kind P. "Death" and the valuation of health-related quality of life. Med Care 2001;3:217-227.

40. Green C, Brazier J, Deverill M. Valuing health-related quality of life: A review of health state valuation techniques. Pharmacoeconomics 2000;17(2):151-165.

41. Parkin D, Devlin N. Is there a case for using visual analogue scale valuations in cost-utility analysis? Health Econ 2006;15:653-663. 
Chapter 9

General conclusion and discussion 
In this thesis we evaluated online computerised cognitive behavioral therapy (CCBT) offered as pure self-help for depression from different perspectives. In the first part, we focused on the clinical effectiveness, the efficiency, the patient experiences, and the role of credibility and expectancy. In the second part, we evaluated methods to derive utilities in depression treatment, since these utilities are used in cost-utility studies on the efficiency of treatments. In this final chapter, the main findings of these different studies are summarized and integrated: What do these outcomes mean for the future of the CCBT in depression, and for the use of utility in studies on depression treatment? What are the limitations and strengths of this research project? And what further research is still needed? Finally, we will end with a brief general conclusion of this thesis.

\section{Main findings}

Below, the main findings of the studies presented in this thesis are briefly summarized. For a more extended explanation of these findings, we refer to the summary of the thesis or the specific chapter.

- The clinical effectiveness study (chapter 2 and appendix 2) suggested that there are no meaningful differences between CCBT, treatment as usual by a GP (TAU), and a combination of CCBT and TAU (COMBI). We found low treatment adherence and modest improvement in depressive severity for all three interventions.

- The economic evaluation (chapter 3 ) suggested CCBT to be the most efficient treatment strategy.

- The main theme throughout the patient interviews (chapter 4) concerned barriers and motivators experienced with CCBT. The most important barriers included experiences of a lack of identification with and applicability of CCBT, lack of support to adhere with the program or to gain deeper understanding, and inadequate computer/Internet skills, equipment, or location. While participating in a scientific study emerged as a motivator, confusion between CCBT and Internet questionnaires resulted in no CCBT uptake of some study participants.

- Study participants showed a higher improvement in health outcome through a higher level of pre-treatment credibility and/or expectancy (chapter 5 ).

- The utility instruments Short-Form 6D (SF-6D), Euroqol 5D based on the UK (EQ-5D $\mathrm{UK}_{\mathrm{UK}}$ ) and Dutch tariff (EQ-5D $D_{\mathrm{NL}}$ ) were responsive to changes related to depression severity and health status, and thus seem adequate for estimating utility in depression treatment. The utilities derived from the depression severity questionnaire Beck Depression Inventory Second Edition using the Depression-Free-Day method (DFDu) seemed less suited. The agreement between the utility changes derived from the SF-6D, EQ-5D (either UK or Dutch tariff) and DFDu was rather low (chapter 6).

- Although the trial results did not show main effects in utility changes during the followup period (in contrast to changes in depressive symptoms), a further exploration between changes in depression severity and in quality of life utility revealed no temporal, but rather a concurrent relation between these parameters (chapter 7).

- Regarding the valuation of quality of life for a hypothetical depression health state (chapter 8), there is a difference between the patient and general population. People 
with a higher severity or longer duration of depressive complaints value depression health states worse compared with people with less severe complaints, a shorter duration, or no depressive complaints.

\section{Recommendations to optimize CCBT-CYL treatment in depression}

Despite the absence of important differences in effectiveness between the three interventions compared, we found moderate improvements through CCBT, and an indication that CCBT is more efficient due to lower costs. We however believe that the CCBT course "Colour Your Life (CCBT-CYL) has more potential than the improvements found in this study. The different studies in part I of this thesis have indicated possible improvements and pitfalls of the CCBT-CYL potential for depression treatment.

First of all, the adherence to CCBT was low: a substantial part of the study participants did not start CCBT $(26 \%)$, and only a minority completed all CYL sessions $(20 \%)$ within the 12 months follow-up period. Other studies on CCBT-CYL found higher completion rates: Spek et al. ${ }^{1}$ reported that $48 \%$ of the study participants completed the course at post-treatment (i.e. 10 weeks follow-up), while Warmerdam et al. ${ }^{2}$ reported at post-treatment (i.e. 12 weeks follow-up) $39 \%$ to have completed the course, while $9 \%$ had never started. These differences between our study and the studies of Spek et al. ${ }^{1}$ and Warmerdam et al. ${ }^{2}$ might be caused by the higher study attrition rate of the participants in the CCBT-CYL intervention in both studies of respectively $34 \%{ }^{1}$ and $48 \% .{ }^{2}$ Study dropouts might be due to the fact that people are not able to complete the CYL course. Warmerdam et al. ${ }^{2}$ mentioned that reasons for study dropout included, for example, problems understanding the computer program. Moreover, the CYL completion rate in our study was based on computerregistered data of CYL usage, while the study of Spek et al. ${ }^{1}$ used self-report questionnaires, which can be expected more vulnerable to recall error or socially desirable answering by the study participant. Despite these differences in study attrition and CCBT-CYL uptake and completion rate, the findings of all three studies indicate that CCBT-CYL adherence is rather low. This is in accordance with a systematic review on CСBT. ${ }^{3}$ This thesis gives several indications how the CCBT-CYL adherence and - as will be argued later on - subsequent treatment outcome might be improved. As discussed below, adding support, more patienttailoring, optimizing the patient information about CCBT-CYL, and optimizing computer skills, equipment and location can optimize CCBT-CYL.

\section{Adding support to CCBT-CYL}

The addition of some kind of support can improve adherence. Several interviewees declared that they preferred or needed support to improve adherence. However, in order to create more discipline, face-to-face contact is not necessarily required. Some interviewees felt motivated through mail messages or Internet questionnaires of the research team. In the study of Warmerdam et al., ${ }^{2}$ participants received support during the intervention period by email from Master-level students of clinical psychology, and weekly received a standard mail to remind them on the lesson of that week and the date on which the assignments were to be sent. This may have led to higher completion rates compared with 
our study. However, the addition of professional support might imply other treatment difficulties, such as difficulties in establishing a therapeutic relation. A study on online CBT for depression delivered by a psychologist, ${ }^{4}$ showed that most patients were able to establish a good relationship with the therapist via the computer. However, other patients experienced an absence of closeness, and/or expressed a strong preference for a face-toface relationship. Most participants of the latter group did not complete treatment, although they found it difficult to define whether the lack of relationship was either due to the online medium, or a matter of not relating well to the particular therapist. ${ }^{4}$ But not only professional support, also lay support might be an important option to consider. Research has indicated that lay support is the most commonly used help-form by people with mental health problems, ${ }^{5}$ and the general population's primary recommended help-form for depression. ${ }^{6}$ Our patient interviews also seem to suggest that more support from the social environment might play an important role in treatment adherence and depression improvement. A review and meta-analysis of Internet-delivered treatments for mood and anxiety disorders have shown that interventions with therapist support had more effect compared to interventions without support. ${ }^{7,8}$ However, to our knowledge only one study directly compared CCBT with and without support. This study on CD-ROM based CBT for bulimia showed no significant differences in treatment uptake, adherence and outcome improvement between a patient group who received the intervention with minimal guidance only, and a patient group receiving this intervention with three brief therapist support sessions. ${ }^{9}$

\section{From adherence towards effectiveness: More patient-tailoring}

Included in the research project, although not part of this thesis, was a study on the use and acceptability of the CCBT-CYL intervention. ${ }^{10}$ Results of that study indicated that several CCBT-CYL usage indices were related with short-term depression improvement (i.e. 3 months follow-up), whereas only homework was related with long-term improvement (i.e. 9 months follow-up). This is in line with a study on the online CBT program MoodGYM for depression, which showed that completing more site material was associated with better psychological outcomes. ${ }^{11}$ Therefore, we believe that increasing CCBT-CYL adherence (i.e. more usage) will also increase CCBT-CYL performance in terms of effectiveness.

Above, we suggested the addition of support as a means to increase adherence. However, a prerequisite for adherence to result in more effectiveness might be that the adherence implies an active participation in the course, since it is homework only which is related to long-term improvement in our use and acceptability study. ${ }^{10}$ Concerning the active involvement in CCBT-CYL, the patient interviews (chapter 4 ) indicate pitfalls and possible improvement of the current CCBT-CYL program. One of the main problems of the interviewees was a lack of identification with and applicability of CCBT-CYL, which can endanger an active usage. We suggest more tailoring to improve the program on this point. Making CCBT-CYL more patient-tailored can foster the self-identification and applicability to the personal situation and is in line with CYL versions developed for specific target groups, being for people aged $50+,{ }^{1}$ and for adults with diabetes. ${ }^{12}$ Recently, also a Flemish CCBTCYL version has been developed for use in Flanders, Belgium (see www.kleurjeleven.be). The fact that Spek et al. ${ }^{1,13}$ studied a version specified for elderly, might also be one of the 
reasons why they found better adherence rates, and better effectiveness outcomes for CCBT-CYL in relation to their comparator treatment groups. Varying the methods (homework assignments, mood diary) in the program might as well be an improvement of CCBT$\mathrm{CYL}$, as some interviewees strongly disliked the use of the mood diary. But also support can be argued as one form of tailoring, since it could also serve the CCBT user with a deeper understanding of the program.

More tailoring might not only mean adjusting the program toward the patient group, but also matching the patient with the most suitable treatment. According to Christensen and Griffiths, ${ }^{14}$ one of the features of delivering CBT via the Internet, is that the Internet is capable of supporting software applications that are tailored to individual needs, e.g. according to particular risk profiles such as divorce, unemployment or experiencing bereavement. So the Internet has the potential to match a patient profile with specific software. But besides life events, other patient or user characteristics might also show a relation with good treatment outcomes. Two studies have evaluated how patient characteristics (demographic, clinical, cognitive, and personality factors, and short-term improvement) might predict the outcome of CCBT-CYL. ${ }^{15,16}$ Also in this thesis, we showed that pretreatment credibility and expectancy are related to CCBT-CYL outcome. For patients who attach low credibility into the CCBT-CYL program, or who have low expectations of the outcome, CCBT-CYL is probably not the best suited treatment. Those who attach higher credibility and expectancy to CCBT-CYL will rather benefit from the program. Although our study has shed some light on the role of credibility and expectancy, there is still a lot unknown on how these treatment beliefs work. In our study, we only focused on outcome expectancy, while a distinction can be made between role expectancy, control expectancy and outcome expectancy. ${ }^{17} \mathrm{~A}$ self-management program such as CCBT requires the patient to take an active role and control in his treatment on his own, while credibility and expectancy in treatments involving a health care professional can as well be influenced by the patient's belief in the health care professional's role or in the working of medication. Thus, further insight into these different forms of expectancy of CCBT might inform on how realistic the patient's belief about CCBT is, and on what points specific information should be provided such that the user is truly well-informed about the CCBT treatment.

\section{Optimizing patient information about CCBT-CYL}

As mentioned above, the level of information given to a study participant or prospective CCBT user should be adjusted to optimize the treatment credibility and expectancy. But this may also increase the adherence and effectiveness of treatment. The level of information a patient received about CCBT treatment can have impact on pre-treatment expectancy, ${ }^{18,19}$ and consequently on the treatment effectiveness. Our patient interviews indicate that our study participants were not all well-enough informed, since some CCBT and COMBI participants were confused between the online CCBT program and the Internet questionnaire: they believed the Internet questionnaire was the Internet treatment. Showing on a computer where to find the CYL website, and where to find a demonstration of the course on this CYL website thus is not sufficient for some prospective users. CCBT and e-health treatments are new treatment forms. Despite the fact that the content of the CCBT treatment is rather predefined, prospective users might have difficulties in understanding what to 
expect from the treatment. Therefore, special attention should be paid on how to inform prospective CCBT users at best. A better informed patient might have a more realistic treatment credibility and expectancy. Moreover, it is important that the patient has a say in choices on his treatment. An adequate provision of information makes the prospective CCBT user able to make well-informed decisions in his treatment.

\section{Optimizing computer skills, equipment and location}

While some CCBT users in our patient interviews appreciated that they could do the therapy at their own time, pace and place, the online and computer aspects can be a negative experience for those less familiar with computer and/or computer work. An inadequate computer location, computer skills and equipment can endanger treatment adherence and experiences. The prospective CCBT user should possess sufficient computer skills, equipment, and have a location where (s)he feels free and safe to do the CCBT sessions. In some previous studies, CCBT was offered on a computer in a professional setting. ${ }^{20}$ This might be an improvement for those not having an adequate location or adequate equipment, although the CCBT user in that case will be less free in choosing the treatment time.

\section{Attention for the easy accessibility}

One of the strengths of CCBT is its easy accessibility for those feeling reluctant to seek help for their depression complaints. There are however two pitfalls within this CCBT strength. First of all, those feeling reluctant to seek help for their depression complaints, probably include the less active help-seekers. The first question then is how to reach this group of less active or non-active help-seekers. Previous studies on help-seeking behaviour showed that people with mental health problems often do not seek professional help, ${ }^{5,21}$ and our patient interviews indicated - in accordance with other qualitative studies on CCBT for depression and anxiety ${ }^{3}$ - that some participants would not have sought treatment if they would not have been invited for trial participation. Another question is how to stimulate these less active or non-active help-seekers into active CCBT users, since - as mentioned above - a higher usage is related to a better treatment outcome. Moreover, data collected from 2007 to 2009 indicate that in the Netherlands, people with psychological problems hardly seek for help via the Internet medium. ${ }^{22}$

The second pitfall in the easy accessibility of CCBT is that at one hand addition of support might endanger its perceived accessibility, while at the other hand absence of support endangers the adherence and effectiveness of the program. An optimal balance should be found between the need for support and the required accessibility for those who could benefit from CBT treatment. It is however difficult to give concrete recommendations regarding this aspect based on the studies in this thesis.

\section{The impact on CCBT efficiency}

Improvements in the adherence and effectiveness of CCBT-CYL will also impact the efficiency of the program. Chapter 3 suggested CCBT to be the most efficient treatment strategy compared with TAU and $\mathrm{COMBI}$, which was mainly due to the lower societal costs 
related with CCBT. Adding support to the CCBT-CYL program implies that the costs of doing CCBT-CYL will increase. However, increased effectiveness might also result in increased productivity and less health care usage through improved depression complaints, consequently implying a decrease in costs. Prior to our study, only one other study has conducted an economic evaluation of CCBT for depression, wherein CCBT was delivered on a personal computer in a general practice in the UK setting. ${ }^{20}$ Participants in that study thus received some guidance in CCBT. Their economic evaluation showed higher health care costs (although not significant when controlling for baseline differences), lower productivity costs, and higher effectiveness outcomes for the CCBT group as opposed to a treatment a usual group (being whatever treatment the GP prescribed), and concluded that CCBT can be highly cost-effective compared with treatment as usual. ${ }^{20}$ Regarding the CCBT program CYL specifically, two other CYL trial studies ${ }^{1,2}$ also include an economic evaluation. Results are however not yet published but expected on short term.

\section{In conclusion}

In sum, the first part of this thesis suggests the following improvements of CCBT-CYL:

- Addition of support;

- More patient-tailoring;

- Adjusting the patient information about CCBT-CYL;

- Attention for adequate computer skills, equipment and location.

- These aspects may increase the potential of CCBT-CYL through an increase in adherence, effectiveness and patient experience with the CCBT-CYL program.

While the above indicates what to expect from an improved effectiveness of CCBT for costeffectiveness studies, the question remains what to expect for cost-utility studies. In our economic evaluation, we saw that there were moderate improvements in depression severity, but no improvements in utility/QALY. Would a further improvement in depression severity be translated in the utility/QALY outcome parameter? After a short conclusion, the next paragraph will focus on the usage of utility instruments for depression treatments.

\section{The adequateness of utility instruments in depression}

As shown in chapter 6 and 7, the absence of improvements in quality of life utility in the three intervention groups in this thesis could not be attributed to complete unresponsiveness of the utility instruments, nor to a temporal relation whereby the utility changes follow later on in the follow-up period. However, the question remains how responsive the utility measure should be in reflecting changes in the health status, and from which point on a utility instrument responds to a change in depression. The latter might for instance differ according to the size of the change in depression severity, but also according to the level of depression severity. Based on our findings, a first concern about utility in depression treatments thus is how responsive these utility measures should be.

A second aspect about the use of utility in studies on depression treatment concerns how the utility should be derived. First of all, there are differences in the indirect multi-attribute 
utility instruments that can be used. Our cost-utility study showed no changes between using the EQ-5D or the SF-6D instrument to derive utilities. The responsiveness study however showed a rather low agreement between the EQ-5D, SF-6D, and DFD-derived utility. In other words, it does matter which instrument you use to derive utilities and QALYs, and different instruments thus might give different results. Moreover, based on the outcomes of the responsiveness study, we do not recommend using the DFD-method.

But not only did this thesis show differences between the utilities derived from different indirect multi-attribute utility instruments, there are also differences between the patient and the general population, and within the patient population. The question still remains whose valuation is the most adequate to use. Nowadays, studies increasingly use general population preferences. ${ }^{23}$ However, if the general population truly underestimates the quality of life with depression, then using general population's valuation might discriminate depression treatments relative to treatments for other disorders.

A third concern is whether the utility instruments we used in our cost-utility study truly measure health-related quality of life. Different researchers use different definitions for quality of life, and some dispute that health status measures (such as SF-36, EQ-5D) are used as quality of life measures. ${ }^{24,25}$ The WHOQOL which is designed by the World Health Organization Quality of Life (WHOQOL) Group might be a promising instrument. ${ }^{24}$ The WHOQOL defines quality of life as "individuals' perceptions of their position in life in the context of the culture and value systems in which they live and in relation to their goals, expectations, standards and concerns". This "reflects the view that quality of life refers to a subjective evaluation that is embedded in a cultural, social and environmental context", and therefore facilitates comparisons over different cultural settings. ${ }^{26-28}$ However, a disadvantage of the WHOQOL questionnaire (both the WHOQOL-100 and the abbreviated WHOQOL-BREF version) is that there exists no tariff to derive one total sum score or utility in which the different domains are weighted and combined. Although a descriptive system of each domain separately might be preferable for studies focusing on quality of life alone, the absence of such scoring tariff makes it inadequate for use as a parameter in costeffectiveness or cost-utility analysis. The WHOQOL is more and more used to derive quality of life, and we expect that developing such scoring tariff would enhance its use in economic evaluations as well.

We can expect that a WHOQOL-derived utility may differ from other utility instruments. In one study using data of our trial, the WHOQOL-BREF domain scores were compared with the EQ-5D and SF-6D domain scores. ${ }^{29}$ That study showed only weak to moderate correlations between all domain scores of the three instruments, with exception of a strong correlation between the physical and pain domains of the different instruments.

\section{Strengths and limitations of the study}

We believe that the major strength of our evaluation of CCBT-CYL is that the intervention is evaluated from different perspectives. However, there is still one perspective missing in this thesis: the perspective of the health professional. Of course, in this study CCBT was offered as pure self-help without any support from a health care professional. But based on the qualitative interviews with CCBT users, we do recommend adding some kind of support 
(from a health care professional and/or lay support). Moreover, even if offered as unguided self-help, health professionals probably have a major role in guiding persons with depressive complaints towards the CCBT-CYL program. Therefore, a further step into the evaluation of CCBT-CYL should be to explore the health professional's perspective (and in case of lay support also exploring their perspective): what is their attitude towards the CCBT-CYL program for depression.

Another strength of our evaluation is the self-reflection on the influence of research activities on the patient's usage and experience with CCBT-CYL, as indicated by the qualitative interviews. In light of the impact of these activities, our results of the CCBT evaluation have to be nuanced: we probably were not only measuring the impact of treatment, but also the impact of research activities.

A major limitation of our CCBT evaluation was that we only compared patient groups which were allocated to a treatment. In the absences of a no-treatment group, it is hard to say whether our CCBT intervention truly implied improvement in clinical effectiveness. It might just as well have been the natural course of depression, especially when bearing in mind the low treatment adherence found in our study. Moreover, also a comparator group which did receive some support would have given more insight into its potential benefits.

In this study, the match between the patient and treatment was probably not optimal: The depression severity of our study sample was rather high, while our recruitment strategy resulted in a sample which might be less active help-seekers. The findings on depression severity of the sample showed that participants were more severely depressed than in previous CCBT studies for depression. ${ }^{30}$ Given the modest effectiveness of the interventions studied in this thesis, the complaints were probably too severe for a self-help treatment without guidance. A study by de Graaf et al. ${ }^{16}$ indeed indicated that in our trial, more severely depressed individuals were less likely to do well in treatment. Regarding our recruitment of less active help-seekers, the patient interviews indicated that some participants would not have sought for treatment if they would not have been invited for trial participation. Consequently, on their own, these participants would not have found their way to CCBT-CYL. This finding is in accordance with Waller and Gilbody's review of qualitative studies on CCBT for depression and anxiety, which showed that some users would not have otherwise consulted their GP for help. ${ }^{3}$

As mentioned in the previous paragraph, there is a dispute on whether health status measures such as EQ-5D and SF-6D might be called 'quality of life'. However, in this thesis, quality of life remains limited to these instruments (and the DFD-derived utility in chapter 6), although we agree that this is a limited translation of the concept.

We are aware that some might question the appropriateness of a rating scale for deriving utilities (see chapter 8), whereas choice-based preferences (e.g. through Standard Gamble or Time Trade-Off) are considered more appropriate compared with RS or VAS. ${ }^{31,32}$ A study of Pyne et al. ${ }^{33}$ used both a rating scale and standard gamble to compare depression health state preferences. In their study, both rating scale and standard gamble resulted in significant preference differences between a patient and general population. The rating scale however resulted in more differences opposed to the standard gamble. Consequently, it is likely that the standard gamble method in our study as well would have generated somewhat different outcomes. However, due to practical aspects in our study, we limited our 
methods to the rating scale: Within our self-administered Internet questionnaire in the absence of an interviewer, a SG or TTO might have been too complex for the respondent.

\section{Recommendations for further research}

For further research, we have nine main recommendations.

- Firstly, we recommend considering and testing several types and degrees of CCBT support, while paying attention to the impact on treatment accessibility, adherence, effectiveness, experience, and cost consequences. The type of support might be either (different kinds of) professional or lay support; and might range from standardized mail messages till face-to-face contact.

- Secondly, a no-treatment (e.g. waiting list) group should be included to compare the effects of CCBT treatment with the natural course of depression complaints.

- Thirdly, further research should focus on aspects through which CCBT-CYL could be more patient-tailored. This includes both on how the program could be adjusted adequately, but also on what aspects the patient should be matched with the specific CCBT program.

- Fourthly, we recommend more qualitative research on CCBT. Our qualitative study on patient experiences was an enrichment, providing better understanding of the quantitative trial findings. However, qualitative studies should not only focus on experiences while following CCBT. Interviews performed before the start of treatment might give better insight into the credibility and expectancy about CCBT-CYL wherein exploring the role and control expectancy in CCBT.

- Our fifth recommendation is to explore the health professional's perspective on CCBT.

- A sixth recommendation is to explore how the prospective CCBT user can optimally be informed about the treatment, such that ( $s$ )he has a true understanding of the program.

- As a seventh recommendation, we advise to further explore the relation between depression severity and utility instruments: how much change in depression severity results in a change in utility, and does this differ among depression severity groups? Guidance towards how responsive utility measures should be would be helpful to evaluate the appropriateness of the current utility instruments.

- Our eight recommendation is to create a WHOQOL-based utility tariff, since it can be expected that the WHOQOL better reflects quality of life.

- Finally, research on why and what the general population versus patient population takes in consideration when valuing a depression state might give indications on what causes the differences between the populations, and whether these perspectives might be an over- or underestimation. 


\section{General conclusion}

Although results of this thesis only show moderate clinical improvements with CCBT-CYL which are not superior to TAU or COMBI for depression, studies did give indications for improvements of the CCBT-CYL program. Especially addition of support, more patienttailoring, adjusting the patient information about CCBT-CYL, and attention for adequate computer skills, equipment and location might optimize the potential of CCBT-CYL in terms of treatment adherence, treatment outcome and patient experiences. These aspects might also increase the efficiency of CCBT-CYL, although further research on utility instruments has to indicate how depression improvement can be expressed most adequately in costutility studies on depression treatment. 


\section{References}

1. Spek V, Nyklícek I, Smits N, Cuijpers P, Riper H, Keyzer J, et al. Internet-based cognitive behavioural therapy for subthreshold depression in people over 50 years old: a randomized controlled clinical trial. Psychol Med 2007;37:1797-1806.

2. Warmerdam L, van Straten A, Twisk J, Riper H, Cuijpers P. Internet-based treatment for adults with depressive symptoms: Randomized controlled trial. J Med Internet Res 2008;10(4):e44.

3. Waller R, Gilbody S. Barriers to the uptake of computerized cognitive behavioural therapy: a systematic review of the quantitative and qualitative evidence. Psychol Med 2009;39(5):705-712.

4. Beattie A, Shaw A, Kaur S, Kessler D. Primary-care patients' expectations and experiences of online cognitive behavioural therapy for depression: a qualitative study. Health Expect 2009;12:45-59.

5. Oliver MI, Pearson N, Coe N, Gunnell D. Help-seeking behaviour in men and women with common mental health problems: cross-sectional study. Br J Psychiatry 2005;186:297-301.

6. Angermeyer MC, Matschinger H, Riedel-Heller SG. What to do about mental disorder - help-seeking recommendations of the lay public. Acta Psychiatr Scand 2001;103:220-225.

7. Palmqvist B, Carlbring $P$, Andersson $G$. Internet-delivered treatments with or without therapist input: does the therapist factor have implications for efficacy and cost? Expert Rev Pharmacoecon Outcomes Res 2007; 7(3):291-297.

8. Spek V, Cuijpers P, Nyklícek I, Riper H, Keyzer J, Pop V. Internet-based cognitive behaviour therapy for symptoms of depression and anxiety: a meta-analysis. Psychol Med 2007;37(3):319-328.

9. Murray K, Schmidt U, Pombo-Carril MG, Grover M, Alenya J, Treasure J, et al. Does therapist guidance improve uptake, adherence and outcome from a CD-ROM based cognitive-behavioral intervention for the treatment of bulimia nervosa? Comput Human Behav 2007;23:850-859.

10. de Graaf E, Huibers M, Riper H, Gerhards S, Arntz A. Use and acceptability of unsupported online computerized cognitive behavioral therapy for depression and associations with clinical outcome. $J A f$ fect Disord 2009;116:227-231.

11. Christensen H, Griffiths K, Groves C, Korten A. Free range users and one hit wonders: community users of an Internet-based cognitive behaviour therapy program. Aust N Z J Psychiatry 2006;40:59-62.

12. van Bastelaar KMP, Pouwer F, Cuijpers P, Twisk JWR, Snoek FJ. Web-based cognitive behavioural therapy (W-CBT) for diabets patients with co-morbid depression: Design of a randomised controlled trial. BMC Psychiatry 2008;8:9.

13. Spek V, Cuijpers P, Nyklícek I, Smits N, Riper H, Keyzer J, et al. One-year follow-up results of a randomized controlled clinical trial on internet-based cognitive behavioural therapy for subthreshold depression in people over 50 years. Psychol Med 2008;38(5):635-639.

14. Christensen H, Griffiths KM. The prevention of depression using the Internet. Med J Aust 2002;177(7 Suppl):S122-S125.

15. Spek V, Nyklícek I, Cuijpers P, Pop V. Predictors of outcome of group and internet-based cognitive behavior therapy. J Affect Disord 2008;105(1-3):137-145.

16. de Graaf LE, Hollon SD, Huibers MJH. Predicting outcome in computerized cognitive behavioural therapy for depression in primary care: A randomized trial. J Consult Clin Psychol 2010;78(2):184-189.

17. Delsignore A, Schnyder U. Control expectancies as predictors of psychotherapy outcome: A systematic review. British Journal of Clinical Psychology 2007;46:467-483.

18. Horvath P. Treatment expectancy as a function of the amount of information presented in therapeutic rationales. J Clin Psychol 1990;46(5):636-642.

19. Mitchell N, Gordon PK. Attitudes Towards Computerized CBT for Depression Amongst a Student Population. Behav Cogn Psychother 2007;35:421-430.

20. McCrone P, Knapp M, Proudfoot J, Ryden C, Cavanagh K, Shapiro DA, et al. Cost-effectiveness of computerised cognitive-behavioural therapy for anxiety and depression in primary care: randomised controlled trial. Br J Psychiatry 2004;185:55-62.

21. Bebbington PE, Meltzer H, Brugha TS, Farrell M, Jenkins R, Ceresa $C$, et al. Unequal access and unmet need: neurotic disorders and the use of primary care services. Psychol Med 2000;30:1359-1367. 
22. de Graaf R, ten Have M, van Dorsselaer S. De psychische gezondheid van de Nederlandse bevolking. Nemesis-2: Opzet en eerste resultaten. Utrecht: Trimbos-instituut, 2010.

23. Brauer CA, Rosen AB, Greenberg D, Neumann PJ. Trends in the measurement of health utilities in published cost-utility analyses. Value Health 2006;9(4):213-218.

24. van Heck GL. Verwarring rondom Kwaliteit van Leven: beter ten halve gekeerd, dan ten hele gedwaald [Confusion concerning Quality of Life: a fault confessed is half redressed]. Psychologie en Gezondheid 2008;36(2):72-78.

25. Sanderman R. Over de afschaffing van het begrip kwaliteit van leven - overwegingen bij Van Heck (2008) [About abandoning the term Quality of Life - reflecting on Van Heck (2008)]. Psychologie en Gezondheid 2008;36(5):297-301.

26. The WHOQOL Group. Development of the world health organization WHOQOL-BREF quality of life assessment. Psychol Med 1998;28:551-558.

27. Orley JJ, Saxena S, Herman H. Quality of life and mental illness. Reflections from the perspective of WHOQOL. Br J Psychiatry 1998;172(4):291-293.

28. The WHOQOL Group. The World Health Organization Quality of Life Assessment (WHOQOL): Position paper from the World Health Organization. Soc Sci Med 1995;41(10):1403-1409.

29. Janssen DME. Quality of life measures in depression (Bachelor thesis): Maastricht University, 2009.

30. de Graaf LE, Gerhards SAH, Arntz AR, Riper H, Metsemakers JFM, Evers SMAA, et al. Clinical effectiveness of online computerised cognitive behavioural therapy without support for depression in primary care: a randomised trial. Br J Psychiatry 2009;195(1):73-80.

31. Drummond MF, Sculpher MJ, Torrance GW, O'Brien B, Stoddart GL. Methods for the Economic Evaluation of Health Care Programmes. Oxford: Oxford University Press, 2005.

32. Green C, Brazier J, Deverill M. Valuing health-related quality of life: A review of health state valuation techniques. Pharmacoeconomics 2000;17(2):151-165.

33. Pyne JM, Fortney JC, Tripathi S, Feeny D, Ubel P, Brazier J. How bad is depression? Preference score estimates from depressed patients and the general population. Health Serv Res 2009;44(4):1406-1423. 



\section{Summary}

Depression is a common mental health problem in the general population. It is related with considerable costs and decreased quality of life. To reduce the burden and costs of depression, it is important that people suffering from depression are treated adequately. However, many depressed people remain undetected, which might partly be explained by not seeking professional help. But even when the depressive complaints are being recognized by the patient and health care professional, many patients do not receive the care they need because effective treatment is not always available. An effective, acceptable, and feasible solution for depressed patients might be computerised cognitive behavioural therapy (CCBT). There is growing evidence on the effectiveness of CCBT for depression, but research on the efficiency and patient experiences is very limited. Therefore, the first aim of this thesis (part 1) is to evaluate CCBT from a clinical, economic and patient perspective. The CCBT program evaluated here (named "Colour Your Life" (CYL, in Dutch Kleur je Leven)) is an online, multimedia, interactive computer program for depression and is offered as pure self-help.

Economic evaluations assess the efficiency of an intervention and are used as a basis for resource allocation decisions. Often, generic health-related quality of life utility is one of the main outcome parameters in economic evaluation (i.e. cost-utility analysis). However, there still exists uncertainty on the measurement of utility in research on depression treatment. Little is known on the differences between a patient or general population valuation of a depression health state, and whether the utilities derived from existing multiattribute questionnaires are responsive to changes in a depression health state. Therefore, the second aim of this thesis (part 2) is to evaluate methods to derive quality of life utility in research on depression treatment.

Chapter 2 (and appendix 2) studies the clinical effectiveness CCBT, compared with treatment as usual (TAU) by a GP, or a combination of CCBT and TAU (COMBI) for depression. Results suggest that there are no meaningful differences between CCBT, TAU, and COMBI in terms of depressive severity, quality of life, dysfunctional beliefs, and general psychological distress. Since treatment adherence was low in all three interventions, we performed per-protocol analyses between and within groups; but these revealed no differences between the interventions either. Only the outcome parameter social functioning showed a significant effect at three months, which was in favour of the COMBI treatment. Regarding changes in depression severity, we found moderate improvement in depressive severity for all three interventions.

Chapter 3 assesses the cost-effectiveness and cost-utility of CCBT compared with TAU and COMBI. The mean societal costs were lowest in this CCBT group. Various cost-effectiveness and cost-utility scenarios were evaluated. They generally showed that CCBT has higest probability of being the most efficient treatment strategy. Even though CCBT seems to be 
the most efficient treatment strategy, all three interventions showed low adherence rates, do not seem to achieve much improvement in depression or quality of life during the 12month follow-up period, and there are no significant differences in effectiveness or QALY (quality-adjusted life-years) outcomes between the interventions.

Chapter 4 presents a study on the patient experiences with CCBT. The interviews pointed out that barriers and motivators experienced with CCBT were related to the course content and to contextual social, computer, and research aspects. The main barriers of CCBT included: experiences of a lack of identification with and applicability of CCBT-CYL, lack of support to adhere with the program or to gain deeper understanding, and inadequate computer/Internet skills, equipment, or location. However, a positive experience with the CCBT course content and reduction of depression were experienced as motivators to adhere to treatment. Doing therapy at your own time, pace and place were also experienced positively by some interviewees. In the interviews, the addition of (personal) support to CCBT was suggested as an improvement towards adherence and the course content. Moreover, several research aspects had an unintended impact on the experience with treatment and with depression complaints. The screening, questionnaires, contact with the research team and the fact of being a research participant were often experienced as consciousness-raising or as a stimulation to adhere to CCBT or the research. While screening aspects sometimes resulted in taking the step towards treatment within the study, confusion with the Internet questionnaires resulted in no uptake of CCBT of some study participants.

Chapter 5 evaluates the role of pre-treatment outcome expectancy and credibility on depression severity and quality of life utility in CCBT. This study indicates that pretreatment expectancy and credibility had significant influence on the health outcomes at 12 months follow-up of CCBT study participants. A higher level of expectancy or credibility implied significantly more improvement in health outcomes. However, while controlling for other baseline variables, the additional explanatory power of expectancy or credibility was rather small.

Chapter 6 assesses the responsiveness of several utility instruments to changes in depression severity and health status. This study revealed that the SF-6D, EQ-5D $D_{\mathrm{UK}}$, and EQ-5D $\mathrm{NL}_{\mathrm{NL}}$ are responsive to changes, and thus seem adequate for estimating utility in depression treatment. The DFDu seems less suited: this method nearly always showed moderate to large improvements in utility, even for deterioration subgroups and subgroups which reported no change in health status and/or depression severity. Additionally, the agreement between the utility changes derived from the SF-6D, EQ-5D (either UK or Dutch tariff) and DFDu was rather low.

Chapter 7 explores whether there is a temporal relation between change in depression severity and change in utility. This study revealed no temporal, but rather a concurrent relation between these parameters.

Chapter 8 explores whether there is a discrepancy in the valuation of a hypothetical depression health state between a patient population and a general population. Not only between the patient and general population, but also within the patient population discrepancies exist between subgroups based on depression severity or on duration of the complaints. People with a higher severity or longer duration of depressive complaints value depression health states worse compared with people with less severe complaints, a 
shorter duration, or no depressive complaints. Moreover, the discrepancy in valuation of a health state between different subgroups changes according to the severity of the hypothetical health state described.

In chapter 9, the main findings of these different studies are summarized and integrated. It is concluded that - despite the finding of only moderate clinical improvements trough CCBT-CYL which are not superior to TAU or COMBI for depression - the studies of this thesis did give indications on possible improvements of the CCBT-CYL program. Especially addition of support, more patient-tailoring, adjusting the patient information about CCBT$C Y L$, and attention for adequate computer skills, equipment and location might optimize the potential of CCBT-CYL in terms of treatment adherence, treatment outcome and patient experiences. These aspects might also increase the efficiency of CCBT-CYL, although further research on utility instruments has to indicate how depression improvement can be expressed most adequately in cost-utility studies on depression treatment. 



\section{Samenvatting}

Depressie is een veel voorkomende aandoening in de algemene bevolking. Depressie leidt tot hoge kosten en verminderde kwaliteit van leven. Om de ziektelast en kosten van depressie te verminderen, is het belangrijk dat mensen die lijden aan depressie adequaat worden behandeld. Veel mensen met depressieve klachten blijven echter onbehandeld, wat deels verklaard kan worden door het niet zoeken naar professionele hulp. Maar zelfs wanneer de depressieve klachten herkend worden door de patiënt en gezondheidszorg professional, ontvangen veel patiënten niet de zorg die ze nodig hebben omdat effectieve zorg niet altijd beschikbaar is. Gecomputeriseerde cognitieve gedragstherapie (CCGT) kan hierin mogelijk een oplossing bieden. Steeds meer onderzoek bewijst dat CCGT een effectieve behandeling kan zijn voor depressie. Echter nog maar weinig onderzoek is gedaan naar de efficiëntie en patiëntenervaringen met CCGT. Daarom is de eerste doelstelling van dit proefschrift (deel 1) om CCGT te evalueren vanuit een klinisch, economisch en patiëntenperspectief. Hierbij evalueren we het CCGT programma genaamd "Kleur je Leven" (KJL). Dit online, multimedia interactief computerprogramma is gericht op de behandeling van depressieve klachten en in dit onderzoek aangeboden als pure zelfhulpbehandeling.

Economische evaluaties beoordelen de efficiëntie van een interventie en worden gebruikt bij beslissingen betreffende de verdeling van middelen. Een van de meest gebruikte uitkomstparameters bij economische evaluaties (en specifiek in kosten-utiliteit analyses) is generieke gezondheidsgerelateerde kwaliteit van leven uitgedrukt als utiliteit. Er bestaat echter nog veel onzekerheid over het meten van utiliteiten binnen onderzoek naar behandelingen voor depressie. Er is weinig bekend over de verschillen tussen de waardering van een depressieve gezondheidstoestand door een patiëntenpopulatie versus de algemene bevolking, en of de utiliteiten herleid van diverse vragenlijsten responsief zijn voor veranderingen in een depressieve gezondheidstoestand. Daarom is de tweede doelstelling van dit proefschrift (deel 2) een evaluatie van meetinstrumenten waaruit kwaliteit van leven utiliteit wordt herleid binnen onderzoek naar depressiebehandeling.

Hoofdstuk 2 (en appendix 2) beschrijft de klinische effectiviteit van CCGT, vergeleken met gebruikelijke zorg door de huisarts (TAU), en een combinatie van CCGT en TAU (COMBI) voor depressie. De resultaten laten geen statistisch significante of klinisch betekenisvolle verschillen zien in ernst van depressie, kwaliteit van leven, disfunctionele attitudes en psychologische stress tussen CCGT, TAU en COMBI. Omdat de therapietrouw in de drie interventiegroepen laag was, zijn de uitkomsten binnen en tussen de interventiegroepen vergeleken in per-protocol analyses. Ook hierin werden geen verschillen gevonden tussen de interventies. Enkel de uitkomstmaat 'sociaal functioneren' toonde op drie maanden een significant effect ten voordele van de COMBI behandeling. Alledrie de interventies leidden tot een matige verbetering in ernst van depressie. 
Hoofdstuk 3 evalueert de kosten-effectiviteit en kosten-utiliteit van CCGT in vergelijking met TAU en COMBI. De gemiddelde maatschappelijke kosten waren het laagst in de CCGT behandelgroep. Verschillende kosten-effectiviteit en kosten-utiliteit scenario's zijn geëvalueerd, waarbij over het algemeen CCGT de meest efficiënte behandelstrategie bleek te zijn. Alledrie de interventiegroepen kenden echter een lage therapietrouw toonden niet zoveel verbetering in depressieve klachten of kwaliteit van leven gedurende de 12 maanden periode, en er waren geen significante verschillen in effectiviteit of QALY (qualityadjusted life-years) uitkomsten tussen de interventiegroepen.

Hoofdstuk 4 beschrijft een studie naar de patiëntenervaringen met CCGT. De interviews tonen aan dat de ervaren barrières en motivaties in het volgen van CCGT gerelateerd zijn aan de cursusinhoud en contextuele sociale aspecten, computeraspecten en onderzoeksaspecten. De voornaamste barrières betreffen een gebrekkige identificatie met en toepasbaarheid van CCGT-KJL, het ontbreken van ondersteuning om door te zetten met de behandeling of om diepgaander in te gaan op onderwerpen, en inadequate vaardigheden, uitrusting of locatie voor computer/internetgebruik. Een positieve ervaring met de CCGT cursusinhoud en een vermindering van depressieve klachten werden echter ervaren als motiverend tot het volhouden van de behandeling. Ook de mogelijkheden tot het volgen van behandeling in de eigen tijd, eigen tempo en eigen omgeving werden als positief ervaren door sommige onderzoeksdeelnemers. In de interviews wordt het toevoegen van (persoonlijke) ondersteuning aan CCGT voorgesteld als een verbetering voor de therapietrouw en de cursusinhoud. Bovendien bleken sommige onderzoeksaspecten een onbedoelde invloed te hebben op de ervaringen met de behandeling en depressieve klachten. De screening, vragenlijsten, het contact met het onderzoeksteam, en het feit onderzoeksdeelnemer te zijn werden ervaren als bewustmakend of als stimulerend tot het volgen van CCGT of het invullen van onderzoeksvragenlijsten. Screeningsaspecten stimuleerden tot het starten van een behandeling door onderzoeksdeelname, terwijl bij sommige onderzoeksdeelnemers verwarring met de internetvragenlijsten leidde tot het niet starten met CCGT.

De studie in hoofdstuk 5 evalueert welke invloed voorafgaande verwachtingen en geloofwaardigheid van behandeluitkomsten hebben op de behandeluitkomsten (namelijk ernst van depressie en kwaliteit van leven utiliteit) van CCGT. Deze studie toont aan dat verwachtingen en geloofwaardigheid significante invloed hebben op de uitkomsten van CCGT gemeten na 12 maanden. Een hogere mate van verwachting of geloofwaardigheid leidt tot significant hogere verbeteringen in uitkomsten. De toegevoegde verklaarde variantie van verwachtingen en geloofwaardigheid na controle voor andere baseline variabelen was echter relatief klein.

In hoofdstuk 6 wordt beoordeeld in welk mate verschillende utiliteitsinstrumenten responsief zijn voor verandering in ernst van depressieve klachten of in gezondheidstoestand. Deze studie toont aan dat de utiliteiten die afgeleid worden uit de SF-6D, EQ-5D $D_{U K}$, en EQ$5 D_{N L}$ instrumenten responsief zijn voor veranderingen, en dus adequaat lijken te zijn voor het schatten van de utiliteit bij behandelingen voor depressie. De DFDu blijkt minder geschikt: de utiliteitsveranderingen herleid van deze methode toonden vrijwel steeds matige tot grote verbeteringen in utiliteit, zelfs voor subgroepen die geen verandering of een achteruitgang lieten zien in gezondheidstoestand en/of ernst van depressie. Bovendien was de overeenkomst in utiliteitsverandering met de andere instrumenten (SF-6D, -6D, EQ$5 D_{\mathrm{UK}}$, en EQ-5D $\mathrm{NL}_{\mathrm{NL}}$ ) nogal laag. 
Het onderzoek beschreven in hoofdstuk 7 verkent of er een temporele relatie bestaat tussen verandering in ernst van depressie en verandering in utiliteit. Deze studie vond geen temporele relatie, maar een concurrente relatie tussen beide parameters.

De studie in hoofdstuk 8 onderzoekt of er discrepantie bestaat in de waardering van een hypothetische depressieve gezondheidstoestand door een patiëntenpopulatie versus een algemene populatie. Bovendien wordt onderzocht of er binnen de patiëntenpopulatie discrepanties bestaan tussen subgroepen gebaseerd op ernst of duur van de depressieve klachten. De resultaten tonen aan dat mensen met een hogere ernst of langdurigere depressieve klachten de hypothetische depressieve gezondheidstoestand lager waarderen in vergelijking tot mensen met minder ernstige klachten, minder langdurige klachten, of zonder klachten. Bovendien blijkt de discrepantie in waardering tussen de subgroepen te veranderen met de ernst van de klachten beschreven in de hypothetische depressieve gezondheidstoestand.

In hoofdstuk 9 worden de belangrijkste bevindingen van de verschillende hoofdstukken samengevat en geïntegreerd. In conclusie kan gesteld worden dat -ondanks het feit dat de onderzoeksresultaten slechts matige klinische verbeteringen vonden bij CCGT-KJL behandeling- de verschillende studies aanwijzingen geven voor mogelijke verbeteringen van het CCGT-KJL programma. Met name het toevoegen van ondersteuning, meer afstemming op de patiënt, aanpassen van de patiënteninformatie over CCGT-KJL, en aandacht voor vereiste computervaardigheden, -uitrusting, en -locatie kunnen het CCGT-KJL programma optimaliseren door betere therapietrouw, behandeluitkomsten en patiëntenervaringen. Deze aspecten kunnen ook de efficiëntie van CCGT-KJL verhogen. Er is echter verder onderzoek nodig naar utiliteitsinstrumenten om inzicht te krijgen hoe verandering in depressie best uitgedrukt kan worden in kosten-utiliteit studies naar behandelingen voor depressie. 



\section{Appendix 1}

\section{Clinical and cost-effectiveness of computerised cognitive behavioural therapy for depression in primary care: design of a randomised trial}

de Graaf LE, Gerhards SAH, Evers SMAA, Arntz A, Riper H, Severens JL, Widdershoven G, Metsemakers JFM, Huibers MJH

Published in BMC Public Health 2008;8(224). 


\section{Abstract}

Background: Major depression is a common mental health problem in the general population, associated with a substantial impact on quality of life and societal costs. However, many depressed patients in primary care do not receive the care they need. Reason for this is that pharmacotherapy is only effective in severely depressed patients and psychological treatments in primary care are scarce and costly. A more feasible treatment in primary care might be computerised cognitive behavioural therapy. This can be a self-help computer program based on the principles of cognitive behavioural therapy. Although previous studies suggest that computerised cognitive behavioural therapy is effective, more research is necessary. Therefore, the objective of the current study is to evaluate the (costleffectiveness of online computerised cognitive behavioural therapy for depression in primary care.

Methods/Design: In a randomised trial we will compare (a) computerised cognitive behavioural therapy with (b) treatment as usual by a GP, and (c) computerised cognitive behavioural therapy in combination with usual GP care. Three hundred mild to moderately depressed patients (aged 18-65) will be recruited in the general population by means of a large-scale Internet-based screening $(N=200,000)$. Patients will be randomly allocated to one of the three treatment groups. Primary outcome measure of the clinical evaluation is the severity of depression. Other outcomes include psychological distress, social functioning, and dysfunctional beliefs. The economic evaluation will be performed from a societal perspective, in which all costs will be related to clinical effectiveness and health-related quality of life. All outcome assessments will take place on the Internet at baseline, two, three, six, nine, and twelve months. Costs are measured on a monthly basis. A time horizon of one year will be used without long-term extrapolation of either costs or quality of life.

Discussion: Although computerised cognitive behavioural therapy is a promising treatment for depression in primary care, more research is needed. The effectiveness of online computerised cognitive behavioural therapy without support remains to be evaluated as well as the effects of computerised cognitive behavioural therapy in combination with usual GP care. Economic evaluation is also needed. Methodological strengths and weaknesses are discussed. 


\section{Background}

Major depression is a common mental health problem in the general population ${ }^{1}$ and it is reported to be the second most common and costly mental health problem in general practice. $^{2}$ Depression is associated with substantial decreases in quality of life through its impact on physical, social and emotional functioning, and well-being. ${ }^{3,4}$ By 2020 , depression is estimated to be the second leading contributor to the global burden of disease. ${ }^{5}$ Cost-ofillness studies reveal that the economic burden of depression is considerable. ${ }^{6-8}$

\section{Difficulties in the treatment of depression in primary care}

The general practitioner (GP) is the major health care provider involved in the primary care treatment of depression. In the Dutch health care system the GP is seen as a gatekeeper, and as a result patients view their GP as a key figure in the detection and treatment of depression. ${ }^{9}$ Despite this, many depressed patients remain undetected. ${ }^{10-12}$ Even when the depressive complaints are being recognised, many patients in primary care do not receive the care they need. There are several reasons for this. First, time for the management of psychosocial problems is lacking. ${ }^{13}$ Second, pharmacotherapy is only effective in extremely depressed patients, ${ }^{14}$ and many patients refuse medication or comply poorly. ${ }^{15}$ Third, effective non-pharmacological treatment options, such as psychotherapy, in primary care are scarce or not feasible. ${ }^{16}$ Consequently, only a limited group of depressed patients in primary care receives effective treatment.

\section{Computerised cognitive behavioural therapy in primary care}

Cognitive behavioural therapy (CBT) is one the most widely researched forms of psychotherapy. Cognitive behavioural therapy (CBT) has proven to be as effective as pharmacotherapy in the acute phase of mild to severe depression, and seems even more effective in the prevention of recurrence and relapse. ${ }^{17-19}$ Despite its effectiveness, face-to-face CBT in primary care has some major limitations. There are not enough well trained therapists, it is costly, there are waiting lists, and patients may feel reluctant to enter psychotherapy. An alternative treatment in primary care might be computerised cognitive behavioural therapy (CCBT): a computer program based on the principles of CBT. The level of therapist support can vary considerably in CCBT. It can be offered as a self-help intervention without or with only minimal support. Previously, written self-help based on CBT seemed a promising treatment for depression. ${ }^{20}$ In a primary care setting, positive outcomes were found regarding the (cost-) effectiveness of written self-help with minimal contact in subthreshold depression relative to care as usual provided by the GP. ${ }^{21,22}$

CCBT for primary care seems promising; it provides an acceptable alternative to pharmacotherapy, it can save clinicians' time, and the costs are low compared with face-to-face CBT. Furthermore, CCBT has a high accessibility, the number of referrals to secondary care by a GP can be reduced, and waiting lists for traditional CBT can become shorter. ${ }^{23,24}$ Next to that, CCBT may fit very well in a stepped care program, and may function as a first step in 
the treatment of depression. ${ }^{25}$ In a recent systematic review, ${ }^{23}$ it was concluded that CCBT is a feasible, effective and acceptable treatment for depression. However, most research on the efficacy of CCBT has been conducted in the general population or within clinical or specialist settings. To our knowledge, only one study, so far, investigated the efficacy of CCBT for depression in primary care, ${ }^{26}$ and it was shown that CCBT (delivered on a personal computer in the general practice) is more effective than usual care by a GP in mild to moderate depression and anxiety. Furthermore, this intervention seemed promising regarding the cost-effectiveness compared with usual GP care. CCBT was both more effective and more costly compared with usual GP care. When willing to pay for an additional unit of effect, CCBT could be very cost-effective. If a value of $€ 40$ is placed on a unit reduction on the Beck Depression Inventory, the probability of CCBT being cost-effective is in excess of $80 \%$. At a value of $€ 5000$ for 1 quality-adjusted life-year (QALY), the study showed that there is an $85 \%$ chance of CCBT being more cost-effective, and at a value of $€ 15000$ per QALY it exceeds a $99 \%$ chance of being cost-effective. ${ }^{27}$ Nevertheless, more research is necessary; so far only this one study has conducted an economic evaluation of CCBT, and the effects of CCBT in combination with usual care by a GP are still unknown. In addition the efficacy of CCBT via the Internet in primary care remains to be evaluated. The Internet can offer further advantages in comparison to CCBT on a stand-alone computer; it is easily accessible and it can be used at home, anonymously, and it is available $24 / 7$.

\section{Current study}

In the present study we aim to evaluate the (cost-)effectiveness of online CCBT for mild to moderate depression in primary care. In a randomised trial we will compare (a) CCBT with (b) treatment as usual (TAU) by a GP, and (c) CCBT in combination with TAU. In a recent Dutch study of Spek et al., ${ }^{28}$ the same CCBT program has shown to be equally effective as group CBT in people over 50 years old with subthreshold depression. ${ }^{28}$ Based on the results from a recent systematic review ${ }^{\text {i.e. }}{ }^{23}$ we hypothesise that CCBT will be more effective than TAU by a GP. Furthermore, we hypothesise that CCBT in combination with TAU will be more effective than CCBT alone by increasing treatment adherence. Although some studies have shown that for mild depression a combination of pharmacotherapy and psychotherapy does not appear more effective than psychotherapy alone, ${ }^{29}$ other studies suggested that patients receiving combined treatments were more likely to stay in treatment and comply to the treatment protocol. ${ }^{30}$

Regarding the economic evaluation we hypothesise the following. The self-help intervention CCBT alone implies costs of time spent by the patient on the treatment and costs of the development of the program, while the TAU treatment requires costs related to a GP consult and/or medication. We hypothesise that from a societal perspective, these costs of the intervention CCBT are comparable to the costs of the intervention TAU. However, as a consequence of our hypothesis that CCBT is more effective than TAU, we expect that CCBT will be more preventive in health care use and productivity loss during the follow-up period, and thus result in lower costs compared with TAU by a GP. As a consequence of the expected increase of effectiveness (in terms of depression and quality of life) and decrease of costs, we hypothesise that CCBT is more cost-effective than TAU by a GP. Hypotheses 
about the intervention CCBT in combination with TAU are that it is both more costly and more effective compared with stand alone CCBT or TAU.

\section{Methods}

\section{Design}

We will conduct a randomised controlled trial. Patients will be randomly allocated to one of the three following conditions: (a) CCBT, (b) TAU by a GP, and (c) a combination of CCBT and TAU by a GP. The design of the study and the anticipated flow of the participants are graphically shown in figure 1 . The Medical and Ethical Committee of Maastricht University approved the study protocol. The study is registered at the Netherlands Trial Register, part of the Dutch Cochrane Centre (ISRCTN47481236).

\section{Study population}

The patient population we aim to investigate consists of 300 mild to moderately depressed adults. Patients are eligible to participate if they meet the following criteria: age 18 to 65 years; access to the Internet at home; at least mild to moderate depressive complaints (BDI-II score > 16), although a DSM-III-R diagnosis of major depression was not required; duration of depressive complaints 3 months or more; no current psychological treatment for depression; no continuous antidepressant treatment for 3 months or more prior to entry; fluent in Dutch language; no alcohol and/or drug dependence; and no severe psychiatric co-morbidity (e.g. psychotic disorders).

\section{Sample size}

Power calculations are based on elementary head-to-head comparisons of CCBT versus usual care and CCBT versus the combined treatment (t-test). A clinically relevant treatment effect is derived from the only study of CCBT in primary care. ${ }^{26}$ For a mean difference in change scores of 5 (SD 5.25) on the BDI-II, a sample size of 84 participants per group is needed (power $90 \%$, alpha 0.05 ). Adjusting for potential study withdrawal (20\%), we estimate that 100 participants per group are needed. 


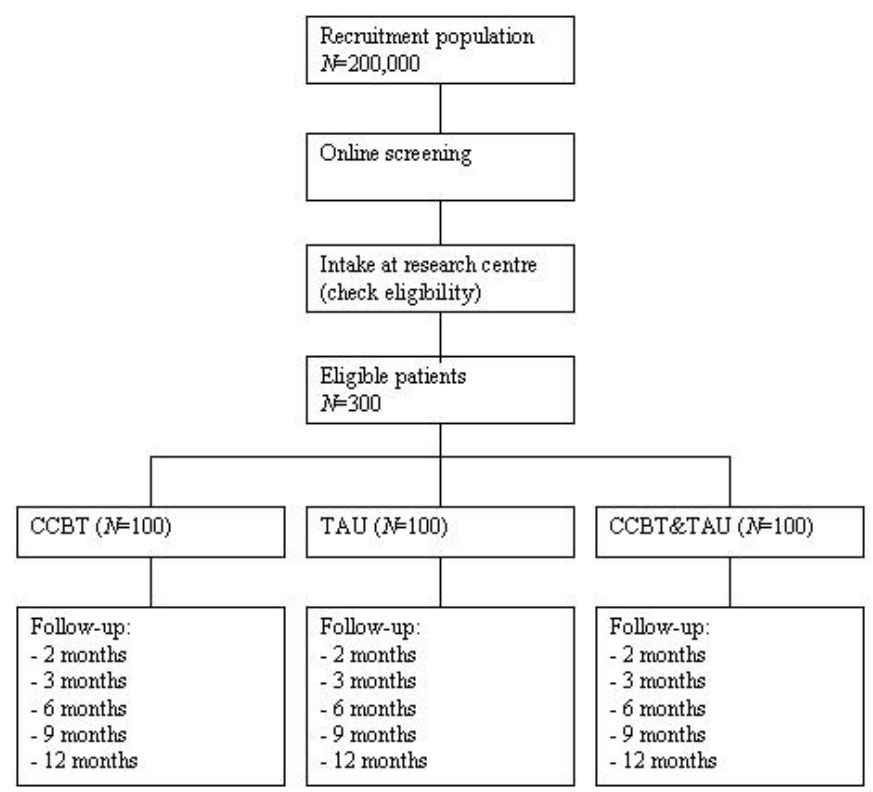

Figure 1: Flow of the participants

\section{Recruitment}

Participants will be recruited in the general population by means of a large-scale Internetbased screening in the South of the Netherlands. A random selection of individuals $(N=$ 200,000 ) will be sent an invitation letter to complete a screening questionnaire (i.e. BDI for primary care) via the Internet. The letters will be sent in weekly badges. Six municipalities cooperate by issuing names and addresses of their residents on a weekly base. The letters will contain information on the study protocol as well as log in codes for the questionnaires on the Internet. Participants who score above the cut-off score of four on the BDI for primary care ${ }^{31}$ will be invited to visit the research centre for an interview where final eligibility will be assessed based on the in- and exclusion criteria. After inclusion we will notify the patients' GP about his or her participation in the study.

\section{Randomisation and procedure}

Randomisation will take place after informed consent is obtained. An independent statistician will develop the randomisation code. Block randomisation will be used to ascertain that each intervention consists of equally large groups. The randomisation code will be given to an independent IT-specialist who will develop a computer program to carry out the group allocation. On entry into the trial the computer program provides the next available number. The randomisation code will not be revealed until participant inclusion is complete. In view of the nature of the treatments, blinding of the participants and researchers is not possible. 
Baseline assessment will take place at the research centre before randomisation. The questionnaires will be administered on a computer. All follow-up assessments will take place at home via the Internet at two, three, six, nine and twelve months after inclusion. Preceding an upcoming assessment point, participants will receive an email alert. If a participant fails to complete the assessment within one week, an email-reminder will be sent. When the participant still fails to fill out the questionnaires, a phone call will be made. Individuals will not be paid for participation, but will receive a small fee for Internet use.

\section{Interventions}

The CCBT program (named "Colour Your Life") is an online, multimedia, interactive, selfhelp computer program for depression, and was developed by Riper and $\mathrm{Kramer}^{32}$ of the Trimbos Institute (the Netherlands Institute of Mental Health and Addiction). The program is based on the principles of CBT and on the Dutch version of the 'coping with depression course' of Lewinsohn. ${ }^{33,34}$ The program consists of eight weekly 30-minute sessions and a ninth booster session, although the duration of sessions can vary among users. At the end of each session homework-assignments are given, such as keeping a 'mood diary'. Patients allocated to the intervention CCBT or the combination CCBT and TAU will be given log in codes by the researchers at inclusion and they will access the program at home. No professional assistance will be offered. The program was originally developed for people over 50years old ${ }^{28}$ and is adapted for an adult population (18 to 65 years) for the current study. GP's of patients allocated to CCBT only will be informed about the participation and treatment allocation of their patient.

In the TAU and CCBT\&TAU group, participants will be advised to contact their own GP. GPs of patients in the TAU and the CCBT\&TAU group will be sent a letter, informing them about their patients' study participation, and advising them to follow the depression guideline as described by the Dutch College of General Practitioners. ${ }^{35}$ This guideline states that treatment should formally consist of four to five biweekly consultations over the course of nine weeks in combination with antidepressant treatment if indicated. In case of suicidal risk, social dysfunction, symptom deterioration or non-improvement in six to twelve weeks time, referral to specialist mental health care settings is recommended. In practice however, usual care is whatever the GP prescribes.

An integrity check will be performed to assess treatment quality and protocol compliance using computer records of the CCBT program and questionnaires assessing use of GP and other health care (i.e. health care use questionnaire).

\section{Instruments}

Instruments will be used for the screening process, the clinical outcome assessment and the economic evaluation. In table 1 an overview of all assessments per time point is shown. 
Table 1: Overview of instruments per time point

\begin{tabular}{|c|c|c|c|c|c|c|c|}
\hline \multirow[t]{2}{*}{ Instrument } & \multirow{2}{*}{$\begin{array}{l}\text { Online } \\
\text { screening }\end{array}$} & \multirow[t]{2}{*}{ Baseline } & \multicolumn{5}{|c|}{ Follow-up months } \\
\hline & & & 2 & 3 & 6 & 9 & 12 \\
\hline Demographic variables & $\mathrm{x}$ & & & & & & \\
\hline Beck Depression Inventory PC & $\mathrm{x}$ & & & & & & \\
\hline Composite International Diagnostic Interview & & $\mathrm{x}$ & & & & & \\
\hline Beck Depression Inventory II & & $\mathrm{x}$ & $\mathrm{X}$ & $x$ & $x$ & $x$ & $x$ \\
\hline Symptom Checklist 90 & & $\mathrm{x}$ & & $\mathrm{x}$ & & & $x$ \\
\hline Work and Social Adjustment Scale & & $\mathrm{x}$ & & $\mathrm{x}$ & & & $x$ \\
\hline Dysfunctional Attitudes Scale & & $x$ & $\mathrm{X}$ & $\mathrm{x}$ & $x$ & $x$ & $x$ \\
\hline WHOQOL-BREF & & $\mathrm{X}$ & & $\mathrm{x}$ & & & $x$ \\
\hline EuroQol & & $x$ & & $\mathrm{x}$ & $x$ & $x$ & $x$ \\
\hline Productivity and disease questionnaire & & $\mathrm{X}$ & & $x$ & $x$ & $\mathrm{x}$ & $x$ \\
\hline
\end{tabular}

Note. In addition to the regular follow-up measurements, each month the health care use questionnaire will be administered.

\section{BeckDepression Inventory for Primary Care}

The Beck Depression Inventory for Primary Care (BDI-PC) is a screening instrument for depression consisting of seven items derived from the Beck Depression Inventory II. Each item is assessed at a 4-point Likert-scale (range $0-4$ ). Several studies have proven its sound psychometric properties. ${ }^{31,36,37}$ A cut-off score of 4 was used in the current study, since this has excellent sensitivity and specificity for identifying a diagnosis of major depression. ${ }^{31}$

\section{Composite International Diagnostic Interview}

To determine in- and exclusion criteria the computerised Composite International Diagnostic Interview (CIDI-auto) will be used. The CIDI is an extensive, fully structured diagnostic interview to assess lifetime and 12-month DSM-III-R diagnoses. The CIDI can be used by layinterviewers and has acceptable reliability and validity. ${ }^{38,39}$

\section{Beck Depression Inventory Second Edition}

The Beck Depression Inventory II (BDI-II) will be used to measure depressive severity. The total score is the sum of the 21 items with a range of 0 (no depression) to 63 (severe depression). There has been consistent support for the construct validity and reliability of the BDI-II in various samples. ${ }^{40-42}$

\section{Functional impairment}

Functional impairment will be assessed with the SF-36 Health Survey (SF-36), which consists of 36 items measuring 8 multi-item scales. For each subscale items are coded, summed, and transformed on to a scale from 0 (worst possible health state measured by the questionnaire) to 100 (best possible health state). The SF-36 has good psychometric properties in terms of validity, reliability, and scale structure. ${ }^{43-45}$ Additionally, the economic evaluation will use the SF-6D utility, which is a quality of life measure derived from the SF-36. ${ }^{46}$

\section{Psychological distress}

The Symptom Checklist (SCL-90) is a self-report symptom inventory of psychopathology. The SCL-90 consists of 90 items, each rated on a five-point scale of distress from 'not at all' 
to 'extremely'. ${ }^{47,48}$ The total score of the SCL-90 can be used as an index of severity for general psychological distress (score range 90-450). ${ }^{49}$ The SCL-90 has a high degree of reliability and support has been found for the validity. ${ }^{47}$

\section{Social functioning}

The Work and Social Adjustment Scale (WSAS) is a self-report scale of functional impairment attributable to an identified problem. The WSAS consists of five items measured on an 8-point Likert-scale (0 to 8). A high score indicates severe impairment. It has good psychometric properties. ${ }^{50}$

\section{Dysfunctional attitudes}

The Dysfunctional Attitude Scale form A (DAS-A) is a self-report scale designed to measure the presence and intensity of dysfunctional attitudes. The DAS-A consists of 40 items and each item consists of a statement and a 7-point Likert-scale ( 7 = fully agree; 1 = fully disagree). The higher the score, the more dysfunctional attitudes an individual reports. ${ }^{51}$

\section{Quality of life measures for the economic evaluation}

Measuring health-related quality of life is relevant in patients with depression, since depression has a large impact on the physical, social and emotional aspects that are relevant and important to a patient's well-being. ${ }^{3,4}$ An intervention aimed at treating depression is therefore expected to have an impact on the perceived quality of life. In addition, measuring generic quality of life facilitates the comparison of the effects on quality of life of our intervention program with that of other interventions. ${ }^{52}$ Quality of life will be measured in three different ways in this study by using the WHOQOL-BREF, the EuroQol and the SF-6D.

The WHOQOL includes a broader range of mental health aspects in its psychological domain compared to other quality of life instruments and is therefore more feasible to use in this study. ${ }^{53}$ The WHOQOL-BREF is an abbreviated version of the WHOQOL-100, which has proven to be a valid and reliable alternative. ${ }^{54,55}$ The WHOQOL-BREF measures four domains related to quality of life (physical health, psychological health, social relationships and environment) and includes two questions on overall quality of life and general health. ${ }^{55}$ Generic quality of life will be derived by means of the EQ-5D of the EuroQol group. The EQ5D consists of five health state dimensions (mobility, self-care, usual activity, pain/discomfort and anxiety/depression) on which the respondent has to indicate his own health state. ${ }^{56,57}$ The EuroQol will be assessed since it is a validated and widely used quality of life instrument, both nationally and internationally. ${ }^{58}$ An advantage of the EuroQol is that it is short and that an overall utility score for population-based quality of life can be obtained, which facilitates comparisons with other interventions and health states in other disease areas. A utility refers to the preference that individuals or society may have for any particular set of health outcomes. It is indicated by a number between 0 (the worst imaginable condition: death) and 1 (perfect health). ${ }^{52}$ Standardised value sets are available to calculate the utility based on the EQ-5D. This study will use the Dutch tariff and the original UK tariff to value generic quality of life. ${ }^{58-60}$ The utility scores of the EQ-5D will be used to calculate the quality adjusted life year (QALY) during the follow-up period by adjusting the length of time affected through the health outcome by the utility value. ${ }^{52}$ 
An adapted version of the EuroQol is the EQ-5D+C, in which a sixth domain (cognitive functions referring to memory, concentration, coherence and IQ-level) is added to the five existing domains of the EQ-5D..$^{61-63}$ This sixth domain of the EQ-5D+C is also included in the questionnaire to provide additional information on quality of life. However, since there is no tariff developed to compute utility scores for the EQ-5D+C, utility scores and QALYs will only be calculated based on the five domains of the EQ-5D.

The SF-6D is a utility instrument based on the health-related quality of life questionnaire SF-36. The utility score is derived from 11 items of the SF-36 and is composed of six dimensions of health (physical functioning, role limitations, social functioning, pain, mental health, and vitality). The SF-6D utilities will be derived by means of the preference-based UK tariff. ${ }^{46}$

Costs

Costs will be defined from the societal perspective. Within our study we distinguish three cost-categories: health care sector costs, costs for the patient and family, and productivity costs. $^{52}$

A health care use questionnaire will be developed to measure the psychological, paramedical, medical, paid and informal care, participation in a self-help group, and alternative treatments received by the patient on a monthly base. This health care use questionnaire will be based on an existing cost diary ${ }^{64}$ and retrospective cost questionnaires, ${ }^{65,66}$ and is adapted to depressive patients. This questionnaire will provide information to calculate health care sector costs by measuring the volume of care provided, and out-of-pocket expenses, which are part of the costs for the patient and family. The other part of the patient and family costs will concern costs of travelling and lost time due to the primary care intervention TAU and/or CCBT. The time spent by a patient on CCBT will be tracked by means of the computer-registered login and logout data of the program. In the health care use questionnaire the duration of a GP consult will be registered by the patient. The number of GP consults informs on the number of travels from/to the GP, and will be linked to average distances from/to a GP. Dutch guideline prices will be used to value the costs of the health care items. ${ }^{67}$ If for specific cost-categories cost guidelines are unavailable, average tariffs or shadow prices will be used. The standard cost prices and tariffs of health care practitioners include the integral costs, being all costs directly and indirectly attributable to the cost unit.

For the measurement of production losses, the patient modules $B, C, D$ and $E$ of the PROductivity and DISease Questionnaire (PRODISQ) will be used. ${ }^{68,69}$ These modules consist of questions concerning the profession, working situation, income, absence from work, compensation mechanisms in case of absence for paid work and productivity costs at work (efficiency loss) of the patient. Productivity costs will be calculated according to the friction cost approach, ${ }^{67,69}$ using one general cost price per lost hour of productivity. ${ }^{67}$ 


\section{Analyses}

\section{Clinical analyses}

Data-analysis will include intention-to-treat analysis and per-protocol analysis. Analysis will include elementary head-to-head comparisons of the intervention groups as well as more complicated multi-level analysis incorporating patients and time measurements if necessary. An integrity check and a process evaluation will be performed using qualitative methods of analysis. In case of missing data, we will impute intermittent missing data using the mean of the values of a previous and a subsequent time point. Other missing data (i.e. missing values due to lost to follow-up) will only be imputed when more then $15 \%$ of the data are missing.

To test the main hypotheses, difference scores for all outcome variables will be calculated $\left(t_{0}\right.$ minus $t_{k}$ ) and compared between the three groups using ANOVA. In case of violation of assumptions, robust ANOVA can be used. ${ }^{70}$ We will then compute improvement effect sizes and between-group effect sizes ${ }^{71}$ or robust equivalents. ${ }^{72}$ Next, we will calculate the number of patients who showed reliable and clinically significant change on the BDI-II using the method of Jacobson and Truax. ${ }^{73}$ This calculation is based on two components: (1) the extent to which the pre-to-post-difference score is reliable taking into account the measurement variability of the instrument (reliable change; RC), and (2) the extent to which post-treatments scores are clinically meaningful (clinically significant change; CSC). ${ }^{74}$ Chisquare tests will be used to test the frequency differences in RC, CSC and RC+CSC between the three groups.

\section{Economic evaluation}

Since the follow-up period lasts one year and no extrapolation over time will be executed, discounting of costs is not necessary. All costs will be indexed to the year 2007 by means of the price indexes of the Dutch Central Bureau of Statistics (CBS).

For each patient, volumes of care, travels, lost time for receiving care and lost productivity hours will be multiplied by the prices determined for each cost item. Based on the costs per item, costs during the follow-up period will be calculated as the cumulative costs per patient. The costs at baseline and during the follow-up period of the three groups will be compared by the non-parametric bootstrapping method with confidence intervals in percentiles. By bootstrapping, samples of the same size as the original data are drawn with replacement from the observed data. ${ }^{75}$ The quality of life and clinical outcome variables will be compared between the three groups at baseline and during the follow-up period using ANOVA.

In case of baseline differences of costs, effectiveness, or utility scores between the patient groups, corrections will be performed. ${ }^{76-78}$ The economic evaluation will consist of a basecase cost-effectiveness and cost-utility analysis, and sensitivity analyses. Uncertainty of parameter estimates of the base-cases will be dealt with by these sensitivity analyses. ${ }^{52}$ In the base-cases, data will be analysed according to the intention-to-treat principle. Incremental cost-effectiveness ratios (ICERs) will be determined on the basis of incremental costs and incremental effects ${ }^{52}$ of (a) stand alone CCBT compared with (b) usual GP care, or (c) a combination of CCBT and usual GP care. The primary outcome measure for the costeffectiveness analysis is depression measured by the BDI-II, and for the cost-utility analysis 
the QALY based on the EQ-5D. The cost-effectiveness ratio will be stated in terms of costs per point improvement on the BDI-II, the cost-utility ratio will focus on the net cost per QALY gained. In our primary analysis QALYs will be derived from the EQ-5D using the UKtariff. Scores on the quality of life domains derived from the WHOQOL-BREF and the sixth domain of the EQ-5D+C will be used to provide in-depth insight into the quality-of-life.

Non-parametric bootstrap re-sampling techniques will be used to explore uncertainty around estimates of cost-effectiveness derived from the study sample ${ }^{75}$ Decision uncertainty will be represented graphically by means of a cost-effectiveness acceptability curve (CEAC) ${ }^{52,79,80}$ In addition, the net monetary benefit (NMB) will be used to present the costeffectiveness and cost-utility results in monetary units. The NMB expresses the difference in effects between the intervention groups in monetary values using the threshold willingness-to-pay for a unit of effect, minus the difference in costs between the interventions. ${ }^{52,81}$ Since the value that society would place on a unit reduction in BDI-II depression score is unknown, different values will be assumed to calculate the NMB. ${ }^{27}$ Regarding the QALY, the Dutch Council of Public Health and Care suggested in 2006 a ceiling of $€ 80.000$ per QALY per year. ${ }^{82}$ Alternative values, ranging to $€ 80.000$ per QALY, will be used to estimate the NMB.

The alternative threshold values of the NMB will be analysed in sensitivity analyses. Other aspects that can be part of a sensitivity analysis are: varying the utility outcome measure by using the SF-6D or alternative tariffs to value the EQ-5D utility (Dutch tariff instead of the UK tariff), or including other effectiveness measures used in the clinical evaluation. Cost prices will be varied as minimum and maximum cost price estimates. Next to the intentionto-treat analysis, a per-protocol analysis can be performed.

\section{Collaboration}

The current study will be conducted in collaboration with several disciplines. The Trimbos Institute (the Netherlands Institute of Mental Health and Addiction) will be involved in the development and dissemination of CCBT. The Pandora foundation (patient organization) acts as an advisor on the design of the study and the dissemination of the results. Several members of the project group work as clinicians in secondary mental health care institutions and have substantial professional contacts in the field. The Dutch College of General Practitioners (NHG) has been informed about our plans and supports our initiative. Additional research projects will be conducted in collaboration with the Department of Health, Ethics and Society/Metamedica and the Department of Health Organization, Policy and Economics of the Maastricht University. For instance, these projects will focus on topics like the patient perspective on CCBT and quality of life aspects of depression.

\section{Discussion}

Although in the last two decades research attention for CCBT has grown, research on the effectiveness of CCBT for depression in primary care is still in its infancy, especially CCBT offered via the Internet. More research evaluating such interventions is necessary. Therefore, in the current study we will evaluate the (cost-)effectiveness of an online CCBT self- 
help program for mild to moderate depression in primary care. We will compare CCBT with treatment as usual by a GP, and with a combination of both treatments.

\section{Why do we need more research on CCBT in primary care?}

There are several reasons why we are conducting this study. First, the only study so far on CCBT in primary care used a program that was delivered on a computer in the general practice. ${ }^{26}$ Since the Internet can increase the accessibility of such an intervention, we will offer the CCBT program on the Internet. In the Netherlands, almost all of the general adult population has access to Internet, and this will only increase in the next decade. ${ }^{83}$ Second, in the only other study on CCBT in primary care, ${ }^{26}$ a nurse provided practical support at the start and end of each session. We will study the effectiveness of CCBT as a pure self-help intervention; no support or guidance will be given to the patient. Third, the effects of a combined treatment (i.e. both CCBT and treatment as usual by a GP) still need to be evaluated. We think this might have extra effects in terms of improvement in depressive severity and quality of life. Although the GP is not directly involved in the CCBT program, a combined treatment might also increase adherence to the intervention. Previous studies already showed that minimal therapist contact could increase the adherence to Internetbased interventions, ${ }^{84,85}$ a result which was recently confirmed in a meta-analysis. ${ }^{86}$ Next to that, the GP can monitor the progress of the patient and can pay attention to non-verbal signals of the patient. Finally, only one study so far has conducted an economic evaluation of $\mathrm{CCBT}{ }^{27}$

\section{Methodological considerations}

Our study has several strengths. First, we will recruit patients from the general population. Unlike in samples selected in general practices or clinics, no biases will occur due to help seeking behaviour of patients and illness recognition by physicians, which is often a problem in depression. ${ }^{10}$ Another strength is that we will make full use of the Internet infrastructure by administering all questionnaires online. This reduces the risk of making mistakes while filling out or scoring the questionnaires.

Several limitations of the present study should also be noted. All our outcomes will be measured online and one may question the equality of computerised questionnaires and paper-and-pen versions. However, there are sufficient indications that computerised and paper-and-pen questionnaires show similar construct validity. ${ }^{87,88}$ Furthermore, all the outcomes at follow-up will be measured by self-report and as a result information on actual DSM-III diagnoses of depressive episodes at follow-up will be lacking.

\section{Conclusion}

CCBT is a new treatment format with interesting possibilities. It might offer a solution to the current undertreatment of depression. It is a promising treatment for depression in primary care, but more research needs to be done before it can be disseminated and implemented in the current health care system. The current study contributes to the growing literature on the clinical and cost-effectiveness of online CCBT. 


\section{Acknowledgements}

We thank Annie Hendriks and Greet Kellens for their assistance during the study and Rosanne Janssen for the development of the infrastructure for online data-collection.

The trial is financed by ZonMw (Netherlands Organisation for Health Research and Development; project number 945-04-417), research institute EPP and research institute CAPHRI. Municipalities Eijsden, Meerssen, Sittard-Geleen, Valkenburg and Maastricht sponsored the study. 


\section{References}

1. Bijl RV, Ravelli A, van Zessen G. Prevalence of psychiatric disorder in the general population: Results of the Netherlands Mental Health Survey and Incidence Study (NEMESIS). Soc Psychiatry Psychiatr Epidemiol 1998;33(12):587-595.

2. Stewart WF, Ricci JA, Chee E, Hanh SR, Morganstein D. Cost of lost productive work time among US workers with depression. JAMA 2003;289(23):3135-3144.

3. Bijl RV, Ravelli A. Current and residual functional disability associated with psychopathology: findings from the Netherlands Mental Health Survey and Incidence Study (NEMESIS). Psychol Med 2000;30:657668.

4. Kruijshaar ME, Hoeymans N, Bijl RV, Spijker J, Essink-Bot ML. Levels of disability in Major Depression. Findings from the Netherlands Mental Health Survey and Incidence Study (NEMESIS). J Affect Disord 2003;77(1):53-64.

5. Murray CL, Lopez AD. Global mortality, disability, and the contribution of risk factors: Global Burden of Disease Study. Lancet 1997;349:1436-1442.

6. Cuijpers P, Smit F, Oostenbrink J, de Graaf R, Ten Have M, Beekmand A. Economic costs of minor depression: a population-based study. Acta Psychiatr Scand 2007;115:229-236.

7. Luppa M, Heinrich S, Angermeyer MC, König HH, Riedel-Heller SG. Cost-of-illness studies of depression. A systematic review. J Affect Disord 2007;98:29-43.

8. Slobbe LCJ, Kommer GJ, Smit JM, Groen J, Meerding WJ, Polder JJ. Kosten van Ziekten in Nederland 2003; Zorg voor euro's - 1 [Costs of illness in the Netherlands 2003]. Bilthoven: Rijksinstituut voor Volksgezondheid en Milieu, 2006.

9. CBO. Multidisciplinaire richtlijn depressie: richtlijn voor de diagnostiek en behandeling van volwassen cliënten met een depressie [Multidisciplinary guideline depression: guideline for diagnostics and treatment of adult depression clients]. Utrecht: Trimbos-instituut, 2005.

10. Paykel ES, Tylee A, Wright A, Priest RG. The Defeat Depression Campaign: Psychiatry in the public arena. Am J Psychiatry 1997;154(6, suppl):59-65.

11. Spijker J, Bijl RV, De Graaf R, Nolen WA. Care utilization and outcome of DSM-III-R major depression in the general population. Results from the Netherlands Mental Health Survey and Incidence Study (NEMESIS). Acta Psychiatr Scand 2001;104:19-24.

12. Tiemens BG, Ormel J, Simon GE. Occurrence, recognition, and outcome of psychological disorders in primary care. Am J Psychiatry 1996;153:636-644.

13. Van Schaik DJF, Van Marwijk HWJ, Van der Windt DAWM, Beekman ATF, De Haan M, Van Dyck R. De effectiviteit van psychotherapie in de eerste lijn bij patiënten met een depressieve stoornis. Tijdschrift voor Psychiatrie 2002;9:609-619.

14. Kirsch I, Deacon BJ, Huedo-Medina TB, Scoboria A, Moore TJ, Johnson BT. Initial severity and antidepressant benefits: a meta-analysis of data submitted to the food and drug administration. PloS Medicine 2008;5(2):e45.

15. Simon GE, VonKorff M, Heiligstein JH, Revicki DA, Grothaus L, Katon W, et al. Initial antidepressant choice in primary care: Effectiveness and cost of fluoxetine vs tricyclic antidepressants. JAMA 1996;275(24):1897-1902.

16. Bower P, Rowland N, Hardy R. The clinical effectiveness of counseling in primary care: A systematic review and meta-analysis. Psychol Med 2003;33(2):203-215.

17. Butler AC, Chapman JE, Forman EM, Beck AT. The empirical status of cognitive-behavioral therapy: $A$ review of meta-analyses. Clin Psychol Rev 2006;26:17-31.

18. Hollon SD, Stewart MO, Strunk D. Enduring effects for cognitive behavior therapy in the treatment of depression and anxiety. Annu Rev Psychol 2006;57:285-315.

19. Vittengl JR, Clark LA, Dunn TW, Jarrett RB. Reducing relapse and recurrence in unipolar depression: a comparative meta-analysis of cognitive-behavioral therapy's effects. J Consult Clin Psychol 2007;75(3):457-488. 
20. Cuijpers P. Bibliotherapy in unipolar depression: a meta-analysis. Journal of Behavior Therapy and Experimental Psychiatry 1997;28:139-147.

21. Willemse GRWM, Smit F, Cuijpers P, Tiemens BG. Minimal-contact psychotherapy for sub-threshold depression in primary care. Br J Psychiatry 2004;185:416-421.

22. Smit F, Willemse G, Koopmanschap M, Onrust S, Cuijpers P, Beekman A. Cost-effectiveness of preventing depression in primary care patients. Br J Psychiatry 2006;188:330-336.

23. Kaltenthaler E, Brazier J, De Nigris E, Tumur I, Ferriter M, Beverly C, et al. Computerised cognitive behaviour therapy for depression and anxiety update: a systematic review and economic evaluation. Health Technol Assess 2006;10(33):1-186.

24. Titov N. Status of computerized cognitive behavioural therapy for adults. Aust N Z J Psychiatry 2007;41(2):95-114.

25. Scogin FR, Hanson A, Welsh D. Self-Administered Treatment in Stepped-Care Models of Depression Treatment. J Clin Psychol 2003;59(3):341-349.

26. Proudfoot J, Ryden C, Everitt B, Shapiro DA, Goldberg A, Mann A, et al. Clinical efficacy of computerised cognitive-behavioural therapy for anxiety and depression in primary care: randomised controlled trial. Br J Psychiatry 2004;185:46-54.

27. McCrone P, Knapp M, Proudfoot J, Ryden C, Cavanagh K, Shapiro DA, et al. Cost-effectiveness of computerised cognitive-behavioural therapy for anxiety and depression in primary care: randomised controlled trial. Br J Psychiatry 2004;185:55-62.

28. Spek V, Nyklícek I, Smits N, Cuijpers P, Riper H, Keyzer J, et al. Internet-based cognitive behavioural therapy for subthreshold depression in people over 50 years old: a randomized controlled clinical trial. Psychol Med 2007;37:1797-1806.

29. Hirschfeld RM, Keller MB, Panico S, Arons BS, Barlow D, Davidoff F, et al. The National Depressive and Manic-Depressive Association consensus statement on the undertreatment of depression. JAMA 1997;277(4):333-340.

30. Edlund MJ, Wang PS, Berglund PA, Katz SJ, Lin E, Kessler RC. Dropping out of Mental Health Treatment: Patterns and Predictors Among Epidemiological Survey Respondents in the United States and Ontario. Am J Psychiatry 2002;159(5):845-851.

31. Steer RA, Cavalieri TA, Leonard DM, Beck AT. Use of the Beck Depression Inventory for Primary Care to Screen for Major Depressive Disorders. Gen Hosp Psychiatry 1999;21:106-111.

32. Riper H, Kramer JJAM. Online zelfhulpcursus www.kleurjeleven.nl. Utrecht: Trimbos-institute, 2004.

33. Cuijpers $P$, Bonarius $M$, van den Heuvel $A$. De omgaan met depressie cursus: een handreiking voor begeleiders en organisatoren [The coping with depression course: a manual]. Utrecht: NcGv, 1995.

34. Lewinsohn PM, Antonuccio DO, Steinmetz JL, Teri L. The coping with depression course: a psychoeducational intervention for unipolar depression. Eugene, OR: Castalia Publishing, 1984.

35. Nederlands Huisartsen Genootschap. NHG-Standaard Depressieve stoornis (depressie) [Dutch College of General Practitioners - Practice guidelines depressive disorder (depression)]. Utrecht, 2003.

36. Beck AT, Guth D, Steer RA, Ball R. Screening for major depression disorders in medical inpatients with the beck depression inventory for primary care. Behav Res Ther 1997;35(8):785-791.

37. Winter LB, Steer RA, Jones-Hicks L, Beck AT. Screening for major depression disorders in adolescent medical outpatients with the beck depression inventory for primary care. J Adolesc Health 1999;24:389394.

38. Robins LN, Wing J, Ulrich Wittchen H, Helzer JE, Babor TF, Burke J, et al. The Composite International Diagnostic Interview. Arch Gen Psychiatry 1988;45(12):1069-1077.

39. Wittchen HU. Reliability and validity studies of the WHO-Composite International Diagnostic Interview (CIDI): A critical review. Journal of psychiatry research 1994;28(1):57-84.

40. Arnau RC, Meagher MW, Norris MP, Bramson R. Psychometric Evaluation of the Beck Depression Inventory-II With Primary Care Medical Patients. Health Psychol 2001;20(2):112-119.

41. Beck AT, Steer RA, Ball R, Ranieri WF. Comparison of Beck Depression Inventories-IA and -II in psychiatric outpatients. J Pers Assess 1996;67(3):588-597.

42. Van der Does AJW. De Nederlandse versie van de Beck Depression Inventory - second edition (BDI-II-NL): Handleiding [The Dutch version of the Beck Depression Inventory - second edition (BDI-II-NL): Manual]. Enschede: The Psychological Corporation, 2002. 
43. McHorney CA, Ware JE, Raczek AE. The MOS 36-item short form health survey (SF-36): II. Psychometric and clinical tests of validity in measuring physical and mental health constructs. Med Care 1993;31(3):247-263.

44. Ware JE, Sherbourne CD. The MOS 36-item short-form health survey (SF-36). I. Conceptual framework and item selection. Med Care 1992;30(6):473-483.

45. Aaronson NK, Muller M, Cohen PD, Essink-Bot ML, Fekkes M, Sanderman R, et al. Translation, validation, and norming of the Dutch language version of the SF-36 Health Survey in community and chronic disease populations. J Clin Epidemiol 1998;51(11):1055-1068.

46. Brazier J, Roberts J, Deverill M. The estimation of a preference-based measure of health from the SF-36. $J$ Health Econ 2002;21:271-292.

47. Arrindell WA, Ettema H. Dimensionele sctructuur, betrouwbaarheid en validiteit van de Nederlandse bewerking van de Symptom Checklist (SCL-90); gegevens gebaseerd op een fobische en een 'normale' populatie. Nederlands Tijdschrift voor de Psychologie 1981;36:77-108.

48. Derogatis LR, Rickels K, Rock AF. The SCL-90 and the MMPI: A Step in the Validation of a New Self-Report Scale. Br J Psychiatry 1976;128(280-289).

49. Koeter MWJ, Ormel J, Brink vd, W. Instrumenteel onderzoek: Totaalscore op de SCL-90 als maat voor de ernst van psychopathologie. Nederlands Tijdschrift voor de Psychologie 1988;43:381-391.

50. Mundt JC, Marks IM, Shear MK, Greist JH. The Work and Social Adjustment Scale: a simple measure of impairment in functioning. Br J Psychiatry 2002;180:461-464.

51. Weissman AN, Beck AT. Development and validation of the Dysfunctional Attitude Scale. 1978, Chicago, November.

52. Drummond MF, Sculpher MJ, Torrance GW, O'Brien B, Stoddart GL. Methods for the Economic Evaluation of Health Care Programmes. Oxford: Oxford University Press, 2005.

53. Orley JJ, Saxena S, Herman H. Quality of life and mental illness. Reflections from the perspective of WHOQOL. Br J Psychiatry 1998;172(4):291-293.

54. Trompenaars FJ, Masthoff ED, Van Heck GL, Hodiamont PP, De Vries J. Content validity, construct validity, and reliability of the WHOQOL-Bref in a population of Dutch adult psychiatric outpatients. Qual Life Res 2005;14(151-160).

55. WHOQOL-Group. Development of the World Health Organization WHOQOL-BREF Quality of Life Assessment. Psychol Med 1998;28(551-558).

56. Brooks R. EuroQol: the current state of play. Health Policy 1996;37(1):53-72.

57. EuroQol Group. EuroQol - a new facility for the measurement of health-related quality of life. Health Policy 1990;16(3):199-208.

58. Szende A, Oppe M, Devlin N. EQ-5D Value Sets: Inventory, Comparative Review and User Guide. Dordrecht: Springer, 2007.

59. Dolan P. Modeling valuations for EuroQol health states. Med Care 1997;35(11):1095-1108.

60. Lamers LM, McDonnell J, Stalmeier PFM, Krabbe PFM, Busschbach JJV. The Dutch tariff: results and arguments for an effective design for national EQ-5D valuation studies. Health Econ 2006;15:1121-1132.

61. Hoeymans N, van Lindert H, Westert GP. The health status of the Dutch population as assessed by the EQ-6D. Qual Life Res 2005;14:655-663.

62. Krabbe PFM, Stouthard MEA, Essink-Bot M-L, Bonsel GJ. The Effect of Adding a Cognitive Dimension to the EuroQol Multiattribute Health-Status Classification System. J Clin Epidemiol 1999;52(4):293-301.

63. Stouthard MEA, Essink-Bot ML, Bonel GJ, Barendregt JJ, Kramers PGN, van de Water HPA, et al. Disability Weights for Diseases in the Netherlands. Rotterdam: Department of Public Health, Erasmus University Rotterdam, 1997.

64. Goossens MEJB, Rutten-van Mölken MPMH, Vlaeyen JWS, Van der Linden SMJP. The cost-diary: a method to measure direct and indirect costs in cost effectiveness research. J Clin Epidemiol 2000;53:688-695.

65. Hakkaart-van Roijen L. Trimbos/iMTA questionnaire for Costs associated with Psychiatric Illness (TiC-P). Rotterdam: Institute for Medical Technology Assessment, Erasmus University, 2002.

66. van Asselt ADI, Dirksen CD, Arntz A, Giesen J, van Dyck R, Spinhoven P, et al. Outpatient psychotherapy for borderline personality disorder: the cost-effectiveness of schema-focused therapy versus transference-focused psychotherapy. Br J Psychiatry 2008;192:450-457. 
67. Oostenbrink JB, Bouwmans CAM, Koopmanschap MA, Rutten FFH. Handleiding voor kostenonderzoek: Methoden en standaard kostprijzen voor economische evaluaties in de gezondheidszorg (Geactualiseerde versie 2004) [Dutch manual for costing: Methods and standard costs for economic evaluations in health care (actualized version 2004)]. Diemen: College voor Zorgverzekeringen, 2004.

68. Koopmanschap M, Meerding WJ, Evers S, Severens J, Burdorf A, Brouwer W. Handleiding voor het gebruik van PRODISQ versie 2.1(PROductivity and DISease Questionnaire). Een modulaire vragenlijst over de relatie tussen ziekte en productiviteitskosten. Toepasbaar bij economische evaluaties van gezondheidszorgprogramma's voor patiënten en werknemers., 2004.

69. Koopmanschap MA. PRODISQ: a modular questionnaire on productivity and disease for economic evaluation studies Expert Review of Pharmacoeconomics and Outcomes Research 2005;5(1):23-28.

70. Wilcox RR. Introduction to robust estimation and hypothesis testing. 2 ed. San Diego, CA: Elsevier Academic Press, 2005.

71. Cohen J. Statistical power analysis for the behavioral sciences. Hillsdale, NJ: Erlbaum, 1988.

72. Algina J, Penfield RD, Keselman HJ. An alternative to Cohen's standardized mean difference effect size: a robust parameter and confidence interval in the two independent groups case. Psych Methods 2005;10(3):317-328.

73. Jacobson NS, Truax P. Clinical significance: a statistical approach to defining meaningful change in psychotherapy research. J Consult Clin Psychol 1991;59(1):12-19.

74. Evans C, Margison F, Barkham M. The contribution of reliable and clinically significant change methods to evidence-based mental health. Evid Based Ment Health 1998;1(3):70-72.

75. Briggs $\mathrm{AH}$, Wonderling DE, Mooney CZ. Pulling cost-effectiveness analysis up by its bootstraps: a nonparametric approach to confidence interval estimation. Health Econ 1997;6(4):405-415.

76. Brunenberg DE, van Steyn MJ, Sluimer JC, Bekebrede LL, Bulstra SK, Joore MA. Joint Recovery Programme Versus Usual Care. An Economic Evaluation of a Clinical Pathway for Joint Replacement Surgery. Med Care 2005;43(10):1018-1026.

77. Manca A, Hawkins N, Sculpher MJ. Estimating mean QALYs in trial-based cost-effectiveness analysis: the importance of controlling for baseline utility. Health Econ 2005;14:487-496.

78. van Asselt ADI, van Mastrigt GAPG, Dirksen CD, Arntz A, Severens JL, Kessels AGH. How to deal with cost differences at baseline. Pharmacoeconomics 2009:in press.

79. Briggs $\mathrm{AH}$. Handling uncertainty in economic evaluation and presenting results. In: M. D, A. M, eds. Economic evaluation in health care; merging theory with practice. Oxford: Oxford University Press, 2001.

80. Fenwick E, O’Brien BJ, Briggs A. Economic Evaluation. Cost-effectiveness acceptability curves - facts, fallacies and frequently asked questions. Health Econ 2004;13(5):405-415.

81. Stinnett AA, Mullahy J. Net Health Benefits: A New Framework for the Analysis of Uncertainty in CostEffectiveness Analysis. Med Decis Making 1998;20(1):S68-S80.

82. Raad voor de Volksgezondheid en Zorg [Council for Public Health and Health Care]. Zinnige en duurzame zorg [Sensible and sustainable care]. Zoetermeer: Raad voor de Volksgezondheid en Zorg [Council for Public Health and Health Care], 2006.

83. Statistics Netherlands. www.cbs.nl.

84. Christensen $\mathrm{H}$, Griffiths $\mathrm{KM}$, Jorm AF. Delivering interventions for depression by using the internet: randomised controlled trial. Br Med J 2004;328(265).

85. Andersson G, Bergström J, Holländare F, Carlbring P, Kaldo V, Ekselius L. Internet-based self-help for depression: randomised controlled trial. Br J Psychiatry 2005;187:456-461.

86. Spek V, Cuijpers P, Nyklícek I, Riper H, Keyzer J, Pop V. Internet-based cognitive behaviour therapy for symptoms of depression and anxiety: a meta-analysis. Psychol Med 2007;37(3):319-328.

87. Butcher JN, Perry J, Hahn J. Computers in Clinical Assessment: Historical developments, present status, and future challenges. J Clin Psychol 2004;60(3):331-345.

88. Butcher JN, Perry JN, Atlis MM. Validity and Utility of Computer-Based Test Interpretation. Psychological Assessment 2000;12(1):6-18. 


\section{Appendix 2}

\section{One-year follow-up results of}

unsupported online computerised cognitive behavioural therapy for depression in primary care: a randomised trial

de Graaf LE, Gerhards SAH, Arntz A, Riper H, Metsemakers JFM, Evers SMAA, Severens JL, Widdershoven G, Huibers MJH

In press in Journal of Behavior Therapy and Experimental Psychiatry 2010; doi:10.1016/j.jbtep.2010.07.003. 


\begin{abstract}
Objective: To report the one-year follow-up results of computerised cognitive behavioural therapy (CCBT), offered online without professional support, for depression compared with usual GP care and a combination of both treatments. To explore potential relapse prevention effects of CCBT.

Methods: 303 depressed patients were randomly allocated to (a) unsupported online CCBT (b) treatment as usual (TAU), or (c) CCBT and TAU combined. We had a 12-month follow-up period. Primary outcome measure was the Beck Depression Inventory II. Self-reported health care use was also measured.

Key findings: At 12 months, no statistically significant differences between the three interventions are found in the intention-to-treat population for depressive severity, reliable improvement, remission, and relapse. In the first quarter, differences in health care consumption between the three interventions are significant (i.e. less GP contacts, less antidepressant medication, and less specialist mental health care in the CCBT group), but these differences disappear over time.

Conclusions: Unsupported online CCBT is not superior to TAU by a GP for depression. With equal effects, CCBT alone leads to less health care consumption than TAU and CCBT\&TAU. Overall effects are modest in all interventions, which can be explained by the finding that the use of health care services decreases despite the lack of substantial improvements.
\end{abstract}




\section{Introduction}

Depression is highly prevalent ${ }^{1}$ and relapse and recurrence is very common. ${ }^{2,3}$ It causes considerable suffering ${ }^{4,5}$ and the economic burden on society is substantial. ${ }^{6-8}$ Given the impact of depression, effective treatment is essential. Although cognitive behavioural therapy (CBT) is an effective treatment for depression, ${ }^{9,10}$ many depressed patients in primary care remain untreated. ${ }^{11} A$ possible solution might be computerised CBT (CCBT), in which therapy components are delegated to a computer system. CCBT programmes can vary greatly in terms of technologies used and amount of additional professional support. CCBT seems a feasible, effective, and acceptable treatment for depression. ${ }^{12-14}$ However, only one study so far investigated the efficacy of CCBT for depression in primary care. ${ }^{15}$ It was shown that CCBT (delivered on a personal computer located in the general practice with nurse support) is more effective than usual GP care in mild to moderate depression. We recently evaluated the short-term effectiveness of unsupported online CCBT (i.e. Colour Your Life) for depression in primary care compared with treatment as usual by a GP (TAU) and a combination of both treatments. ${ }^{16}$ The same CCBT intervention proved very efficacious for people over 50 years old. ${ }^{17}$ However, our study revealed no differences in outcome between the three interventions during six months of follow-up, regardless of the amount of treatment adherence. ${ }^{16}$

To date, long-term follow-up results of CCBT for depression have rarely been reported. We are aware of only two studies that have reported one-year follow-up results and they showed promising results for $\mathrm{CCBT} .{ }^{18,19}$ To contribute to these findings, we present the effects of the three interventions after twelve months. Despite the results found during the first six months, we additionally tested whether unsupported online CCBT can prevent depressive relapse. Relapse is very common in depression, ${ }^{2}$ and failing to achieve adequate maintenance treatment has serious personal and economic consequences. ${ }^{3}$ Previous studies have demonstrated that face-to-face CBT prevents future relapse and recurrence, ${ }^{10,20}$ but no such studies have tested this in computer-assisted treatments. In our study a booster session was incorporated into the CCBT program focussing on relapse. Furthermore, we additionally examined the use of antidepressant medication and treatment in specialist mental health care, because the level of health care consumption during the follow-up period might have influenced the outcome and relapse rates.

\section{Method}

\section{Design}

The design of the study was a randomised trial with three conditions: (a) unsupported online CCBT, (b) TAU by a GP, and (c) CCBT and TAU combined. The Medical and Ethical Committee of Maastricht University approved the study protocol. The study is registered at the Netherlands Trial Register (ISRCTN47481236). Full details of the study method have been described elsewhere. ${ }^{21}$ 


\section{Study population}

Participants were recruited in the general population by means of a large-scale Internetbased screening in the South of the Netherlands. A random selection of individuals $(\mathrm{N}=$ $217,816)$ was sent a postal invitation to participate in the online screening. Potentially eligible participants (i.e. a score at least 4 points on the BDI for Primary Care ${ }^{22}$ ) were invited to visit the research centre for an intake to assess final eligibility. Inclusion criteria were: age 18 to 65; access to the Internet at home; at least mild to moderate depressive complaints (BDI-II score > 16); duration of depressive complaints 3 months or more; no current psychological treatment for depression; no continuous antidepressant treatment for at least 3 months prior to entry; fluent in Dutch language; no alcohol and/or drug dependence; and no severe psychiatric co-morbidity (e.g. psychotic disorders).

\section{Procedure}

After written informed consent was obtained, participants were randomly allocated to one of the three interventions. Baseline assessment took place on a computer at the research centre before randomization. All follow-up assessments took place at home via the Internet at two, three, six, nine, and twelve months after inclusion. Preceding an upcoming assessment point, participants received an email alert.

\section{Interventions}

Those in the CCBT and CCBT\&TAU condition were given secure login codes for Colour Your Life, which is an online, multimedia, interactive, self-help computer program for overcoming subthreshold depression. ${ }^{23}$ The program consists of eight sessions and a ninth booster session focussing on relapse prevention. The duration of sessions can vary among users. Participants were advised to complete one session per week. No professional assistance was offered.

Participants in the TAU and CCBT\&TAU condition were advised to contact their own GP. The GPs were advised to follow depression guidelines described by the Dutch College of General Practitioners. ${ }^{24}$ TAU can include four to five biweekly consultations and antidepressant treatment if indicated.

For each patient, it was assessed whether the interventions received were according to 'protocol'. Adherence to CCBT was defined as having completed five or more sessions. Adherence to TAU was defined as having received at least four GP consultations or antidepressant medication. CCBT\&TAU adherence was defined as a combination of both. It should be noted that adherence to TAU cannot only be attributed to the behaviour of the patient. It also depends on the degree to which a GP follows depression guidelines.

\section{Outcomes}

The primary outcome was the severity of depression as measured with the Beck Depression Inventory Second Edition (BDI-II), high scores indicating severe depression (range 0-63). There has been consistent support for its construct validity and reliability in various sam- 
ples. ${ }^{25-27}$ Additionally, a health care use questionnaire was used to measure self-reported use of GP care, antidepressant medication, and specialist mental health care on a monthly base.

\section{Data analyses}

The analyses were based on the intention-to-treat principle. That is, all available data were analyzed, regardless of treatment adherence. Only intermittent missing data were imputed $(n=5)$ by calculating the mean of the values of a previous and a subsequent time point. Missing data due to loss to follow-up were not replaced by imputed values. Preliminary tests for distribution and outliers did not indicate substantial deviations from normality for the BDI-II. We tested all effects at the $p<.05$ level. All analyses were carried out using SPSS (version 15.0.1 for Windows).

First, repeated-measures analyses of variance (ANOVAs) were performed for the BDI-II. Second, improvement effect sizes for the BDI-II scores at 12 months of follow-up were calculated in two ways. We calculated the usual Cohen's $d$ by dividing the pre-post difference by the pooled standard deviation. ${ }^{28}$ As the pooled standard deviation can lead to under- or overestimation of the effect size, we also calculated an alternative effect size. That is, dividing the pre-post difference by the standard deviation of the difference score. Between-group effect sizes were determined by subtracting the improvement effect size of one group from the improvement effect size of another group. This procedure was done for both effect size indices. Third, we determined the proportion of patients who made clinically meaningful changes at 12 months using the methodology of Jacobson and Truax ${ }^{29}:$ (1) reliable improvement, based on the reliable change index (i.e. a decrease of at least 9 points on the BDI-II since baseline), and (2) remission, defined as clinically significant change (i.e. a score below 12 on the BDI-II). Fourth, we calculated the relapse rate in those patients who were reliably improved at 3 months of follow-up, immediately after the CCBT intervention. Relapse was defined as an increase of at least 9 points on the BDI-II from 3 months to either 6,9 , or 12 months of follow-up. Chi-square tests were used to examine frequency differences between the three groups. Finally, to better understand the obtained findings, we examined quarterly health care consumption. This was defined as making at least one visit for depression treatment to either a GP or a specialist in mental health care per quarter, or using antidepressant medication in that quarter. To compare frequency differences across the groups Chi-square tests were used. In case of statistically significant differences, posthoc pairwise Chi-square tests were conducted comparing the scores between each pair of groups. Finally, it is noted that the analyses on relapse and health care consumption were conducted a posteriori and power analyses were lacking for these tests. 


\section{Results}

\section{Participant characteristics}

Three-hundred-and-three participants were enrolled in the study. The flow of the participants is graphically shown in figure 1 . At 12 months of follow-up, data were available for 267 participants (attrition rate $11.9 \%$ ). In contrast to the low attrition rate from data collection, treatment adherence was low in all three groups.

Demographic characteristics have been described in detail elsewhere. ${ }^{16}$ To summarize, mean age for CCBT, TAU, and CCBT\&TAU was respectively 44.3 years (SD =11.8), 45.1 years $(S D=12.2)$, and 45.2 years $(S D=10.9)$. Male gender was not equally distributed despite randomization: CCBT (48\%), TAU (45\%), and CCBT\&TAU (37\%). In a previous paper, ${ }^{16}$ we showed that gender did not confound the outcomes.

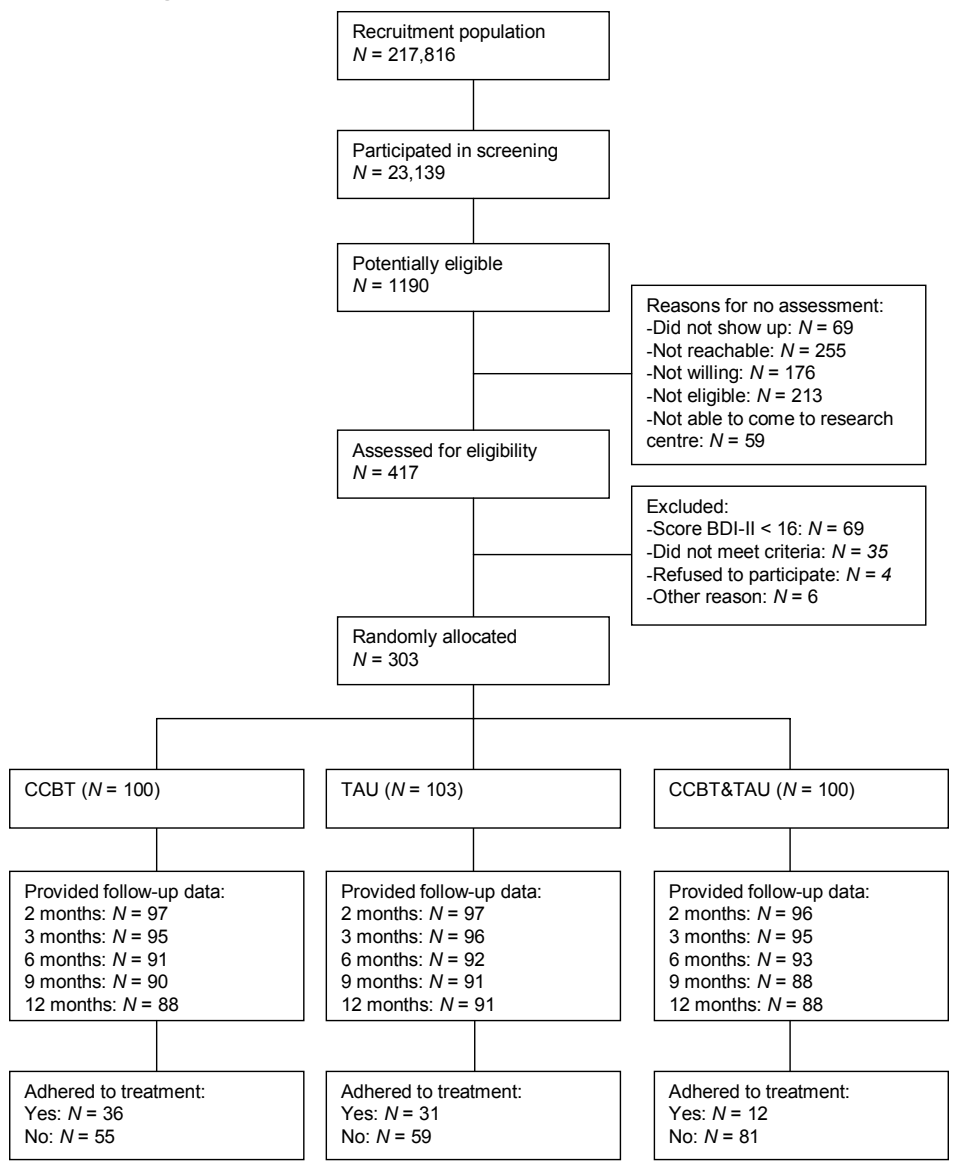

Figure 1: Flowchart

Note. CCBT, online computerised cognitive behavioural therapy (i.e. Colour Your Life) without support; TAU, treatment as usual by a GP. 


\section{Depressive severity}

Mean BDI-II scores are shown in table 1. Repeated measures ANOVA showed that there was a significant time effect, but not a significant group by time interaction on the BDI-II. At 12 months, improvement effect sizes according to Cohen's $d$ were large ( $d=1.26$ for CCBT; $d=1.09$ for TAU; $d=1.11$ for CCBT\&TAU), but the between group effect sizes were small ( $d$ $=0.17$ for CCBT vs. TAU; $d=0.02$ for CCBT\&TAU vs. TAU). The alternative effect sizes in the three groups were all exactly the same ( $d=1.0$ for each group), resulting in between-group effect sizes of zero.

Table 1: Mean scores (SD) for the BDI-II in the intention-to-treat population and results from repeated measures ANOVA

\begin{tabular}{llll}
\hline Time point & CCBT & TAU & CCBT\& TAU \\
\hline Baseline & $28.2(7.7)$ & $27.9(7.5)$ & $27.4(8.2)$ \\
2 months & $\mathrm{n}=100$ & $\mathrm{n}=103$ & $\mathrm{n}=100$ \\
& $20.6(10.4)$ & $22.1(10.2)$ & $21.7(10.1)$ \\
3 months & $\mathrm{n}=97$ & $\mathrm{n}=97$ & $\mathrm{n}=96$ \\
& $20.4(11.2)$ & $21.4(11.0)$ & $19.1(10.9)$ \\
6 months & $\mathrm{n}=95$ & $\mathrm{n}=96$ & $\mathrm{n}=95$ \\
& $17.8(10.6)$ & $18.9(11.8)$ & $\mathrm{n}=93$ \\
9 months & $\mathrm{n}=91$ & $\mathrm{n}=92$ & $17.6(12.8)$ \\
& $15.5(10.8)$ & $18.0(11.8)$ & $\mathrm{n}=88$ \\
12 months & $\mathrm{n}=90$ & $\mathrm{n}=91$ & $16.5(11.1)$ \\
& $16.1(11.1)$ & $17.5(11.1)$ & $\mathrm{n}=88$ \\
\hline & $\mathrm{n}=88$ & $\mathrm{n}=91$ & \\
& Time: $\mathrm{F}_{5,260}=58.9, \mathrm{p}<.001$ & \\
& Group: $\mathrm{F}_{2,264}=0.80, \mathrm{p}=.45$ & \\
& Time $\mathrm{Group}: \mathrm{F}_{10,520}=0.96, \mathrm{p}=.37$ &
\end{tabular}

Note. CCBT, online computerised cognitive behavioural therapy (i.e. Colour Your Life) without support; TAU, treatment as usual by a GP; BDI-II, Beck Depression Inventory II (score range 0 - 63).

\section{Reliable improvement}

Reliable improvement was defined as a decrease of at least 9 points on the BDI-II at 12 months of follow-up since baseline. The number of participants who reliably improved did not significantly differ between the groups $\left(\chi^{2}(2)=2.26, p=.32\right)$. The numbers were: 47 (53.4\%) for CCBT, 46 (50.5\%) for TAU and 54 (61.4\%) for CCBT\&TAU. However, there seems to be a small trend in favour of CCBT\&TAU (see figure 2). Moreover, figure 2 shows a cycliclike pattern for the CCBT\&TAU group; the number of participants with a reliable improvement declines at 9 months and rises again at 12 months. 


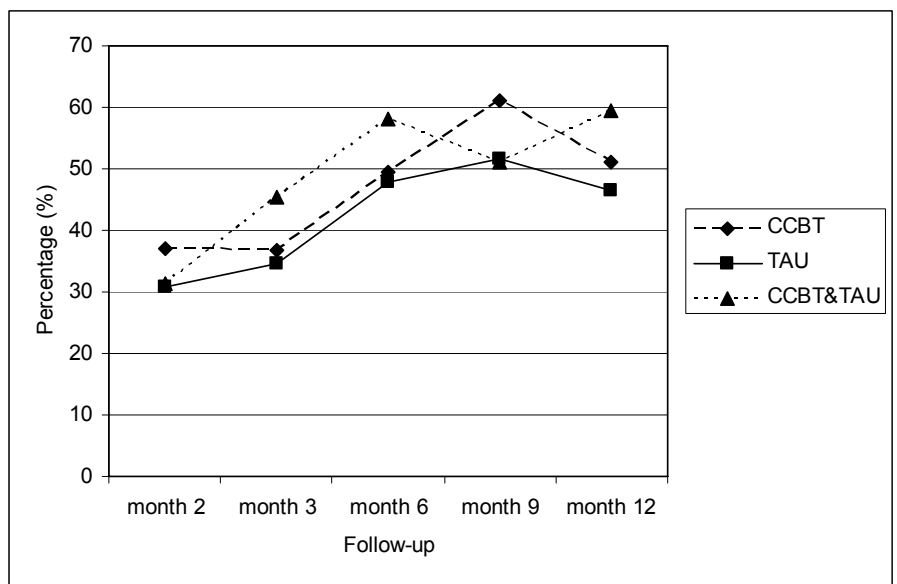

Figure 2: Percentage of patients with reliable improvement (i.e. a reduction of at least 9 points on the Beck Depression Inventory II since baseline)

Note. CCBT, online computerised cognitive behavioural therapy (i.e. Colour Your Life) without support; TAU, treatment as usual by a GP.

\section{Remission}

Remission was defined as a score below 12 on the BDI-II at 12 months of follow-up. There was no significant difference in the number of participants who had remitted $\left(\chi^{2}(2)=0.30\right.$, $p=.86)$. The numbers were: $36(40.9 \%)$ for CCBT, $34(37.4 \%)$ for TAU, and $33(37.5 \%)$ for CCBT\&TAU.

\section{Relapse}

Relapse rates were calculated for those patients that reliably improved at 3 months of follow-up. The number of participants that reliably improved at 3 months of follow-up were: 35,33 , and 43 respectively in the CCBT, TAU, and CCBT\&TAU group. Relapse rates (i.e. an increase of at least 9 points on the BDI-II from 3 months to either 6,9 , or 12 months of follow-up) for these patients were lower in the TAU group $(20.7 \% ; n=6)$ than in the CCBT group (31.3\%; $n=10)$ and the CCBT\&TAU group $(31.0 \% ; n=13)$. However, these differences were not statistically significant $\left(\chi^{2}(2)=1.11, p=.57\right)$.

\section{Health care consumption}

Table 2 shows the quarterly consumption of mental health care. As can be expected from our study design, most statistically significant differences in the consumption of health care between the three interventions occurred during the first quarter. For all significant results pairwise comparisons were conducted, which revealed the following findings. In the first quarter, less patients in the CCBT alone group had depression related GP contact than those in the TAU group $\left(\chi^{2}(1)=46.02, p<.001\right)$ and than those in the CCBT\&TAU group $\left(\chi^{2}(1)=40.55, p<.001\right)$. Furthermore, the CCBT group received less specialist mental health 
care than the TAU group during the first quarter $\left(\chi^{2}(1)=9.83, p<.01\right)$. Also in the first quarter, patients allocated to the CCBT group used antidepressants less frequently than patients in the TAU group $\left(\chi^{2}(1)=5.75, p=.02\right)$. This difference in use of antidepressant medication was again statistically significant in the fourth quarter between the CCBT group and the TAU group $\left(\chi^{2}(1)=4.85, p=.03\right)$ and also between the CCBT group and the CCBT\&TAU group $\left(\chi^{2}(1)=5.29, p=.02\right)$. On average, it was observed that antidepressant use remained fairly stable over time, while GP contact and specialist mental health care decreased. Regarding the use of CCBT, most patients started the intervention, but many did not complete all modules.

Table 2: Quarterly consumption of mental health care and use of CCBT. Data are in numbers (\%).

\begin{tabular}{llllll}
\hline Variable & CCBT & TAU & CCBT\&TAU & $\chi^{2}(\mathrm{df})$ & $\mathrm{p}$ \\
\hline $\begin{array}{l}\text { Depression related GP contact } \\
1^{\text {st }} \text { quarter }\end{array}$ & $19(20.7 \%)$ & $66(70.2 \%)$ & $63(67.0 \%)$ & $57.2(2)$ & $<.001$ \\
2nd quarter & $18(20.0 \%)$ & $23(25.3 \%)$ & $22(23.9 \%)$ & $0.7(2)$ & .68 \\
3rd quarter & $11(12.2 \%)$ & $15(16.5 \%)$ & $12(13.6 \%)$ & $0.7(2)$ & .70 \\
4th quarter & $12(13.6 \%)$ & $15(16.5 \%)$ & $13(14.8 \%)$ & $0.3(2)$ & .87 \\
Use of antidepressants & & & & & \\
1st quarter & $8(8.7 \%)$ & $20(21.3 \%)$ & $17(18.1 \%)$ & $5.9(2)$ & .05 \\
2nd quarter & $10(11.1 \%)$ & $22(24.2 \%)$ & $19(20.7 \%)$ & $5.4(2)$ & .07 \\
3rd quarter & $11(12.2 \%)$ & $20(22.0 \%)$ & $19(21.6 \%)$ & $3.6(2)$ & .16 \\
4th quarter & $8(9.1 \%)$ & $19(20.9 \%)$ & $19(21.6 \%)$ & $6.1(2)$ & .05 \\
Specialist mental health care & & & & & \\
1st quarter & $11(12.0 \%)$ & $29(30.9 \%)$ & $19(20.2 \%)$ & $10.0(2)$ & .01 \\
2nd quarter & $14(15.6 \%)$ & $22(24.2 \%)$ & $13(14.1 \%)$ & $3.7(2)$ & .16 \\
3rd quarter & $15(16.7 \%)$ & $21(23.1 \%)$ & $17(19.3 \%)$ & $1.2(2)$ & .55 \\
4th quarter & $12(13.6 \%)$ & $15(16.5 \%)$ & $8(9.1 \%)$ & $2.2(2)$ & .34 \\
Use of CCBT & & & & & \\
First session completed & $72(72.0 \%)$ & - & $76(76.0 \%)$ & $0.4(1)$ & .52 \\
Last session completed & $14(14.0 \%)$ & - & $26(26.0 \%)$ & $4.5(1)$ & .03 \\
\hline
\end{tabular}

Note. CCBT, online computerised cognitive behavioural therapy (i.e. Colour Your Life) without support; TAU, treatment as usual by a GP. Health care consumption is defined as using antidepressant medication or making at least one visit for depression treatment to either a GP or a specialist in mental health care per quarter.

\section{Discussion}

The one-year follow-up results of the effectiveness of unsupported online CCBT (i.e. Colour Your Life) for depression look fairly similar to the results for six months of follow-up reported in our previous paper. ${ }^{16}$ Reductions in depressive severity were sustained and remained comparable over time between the three interventions (i.e. CCBT, TAU, and CCBT\&TAU).

To be able to compare our effects with the two available studies that reported long-term outcomes of CCBT for depression, we re-calculated the effect sizes from the two studies described below (i.e. the dividing the pre-post difference by the pooled standard deviation). The study of Spek et al. ${ }^{19}$ focused on the efficacy of unsupported CCBT for subthreshold depression in people over 50 years old who were recruited in the general population. 
Spek et al. used a similar intervention as we did (i.e. Colour Your Life) comparing it to group CBT and a waiting list control group. At one-year of follow-up they found a somewhat smaller improvement effect size on the BDI-II for CCBT $(d=1.13)$ than we did $(d=1.26)$. In the Spek study, CCBT did moderately better than both group CBT $(d=0.49)$ and the waiting list $(d=0.54)$. However, Spek et al. conducted baseline assessment of their primary outcome measure after randomisation, which could have violated their results. Mackinnon et al.18 investigated the efficacy of CCBT with support for adults with elevated depression scores. The one-year outcomes of CCBT (i.e. MoodGYM consisting of five modules) were compared with a psycho-education website (i.e. BluePages) and an attention control condition. All participants received weekly telephone support by a lay interviewer to encourage adherence. In the MacKinnon study, CCBT resulted in a medium effect size for the CES-D at twelve months of follow-up $(d=0.73)$, which was much smaller than our improvement effect size. Although their CCBT intervention performed somewhat better than an attention control condition $(d=0.27)$, it surprisingly did a little worse than the psycho-education website $(d=-0.16)$. The finding that our improvement effect size for CCBT was larger than the ones in the two previous might be explained by our more severely depressed sample combined with the fact that higher scores leave more room for improvement. Nevertheless, it is difficult to interpret differences in study outcomes, as any comparison falls short because of differences in patient populations, outcome parameters, CCBT interventions, comparator conditions, and study designs.

The overall effects of our interventions were rather small regarding effect sizes, depressive severity scores at twelve months, and remission. One could argue that these modest improvements are merely the result of regression to the mean and that the interventions were thus ineffective. However, we also used the reliable change index to reduce the influence of regression to the mean and found that half of our participants made reliable improvements. Another explanation for the high depression scores after one year might be that potential effects could have been masked by the low treatment adherence. However, adherence was not found to differentiate the outcomes. ${ }^{16}$ We think that the tested interventions may not have been appropriate for our study population that was more severely depressed than samples in previous CCBT studies. ${ }^{15,17,30}$ In another study, we found that participants with higher depression severity scores were less likely to do well in any of the three treatments. ${ }^{31}$ These more severely depressed patients might require professional support when using CCBT. There are recent indications that therapist support is a crucial element in CCBT as it leads to larger effect sizes. ${ }^{14}$ Our patient might also have fared better in some kind of care management by the GP, or even treatment in secondary mental health care. Furthermore, other sources of referral might improve treatment outcome. Selfreferred patients, as in our study, seem to do less well in CCBT than patients who are referred by their GP. ${ }^{32}$

The finding that depressive severity remained unchanged subsequent to six months in the three groups can be interpreted in two distinct ways. One might argue that depression status was maintained and did at least not deteriorate over time. Alternatively, we would say that no additional improvements were made and patients were still fairly depressed at twelve months of follow-up. This lack of additional improvements might be explained by the high amount of undertreatment in our study. The use of health care services decreased in all groups after the first quarter. This seems to suggest that patients do not step up to a 
more intense treatment when initial treatment proves inadequate. We can only speculate about the causes of undertreatment in the current study. On the one hand, patients themselves might have failed to seek further treatment. Patients might lack awareness and knowledge of the disorder, they might have accepted their lesser state of well-being, or they might have refused further treatment. On the other hand, GPs and professionals in specialist mental health care might not have offered alternative treatments when improvement stayed behind ${ }^{11,33}$ or maybe they were not able to motivate their patients. Taken together, these findings confirm that many depressed patients in primary care remain untreated. ${ }^{11}$ It highlights the importance of supporting and systematic monitoring of depressive patients to improve the quality of care.

Initial depressive severity in our sample was high; even higher than generally seen in depressed primary care patients. ${ }^{34}$ The gap between this high depressive severity and actual treatment received is particularly striking, since we know from previous research that incomplete recovery is a strong predictor of relapse and chronicity. ${ }^{2}$ In case of ongoing symptoms, further treatment is recommended. Since it has been shown that only two depressive symptoms (i.e. psychomotor retardation and suicidal ideation) are associated with treatment seeking behaviour by patients, ${ }^{35}$ public awareness and knowledge of depression should be increased. From a stepped-care perspective, frequent monitoring should be encouraged in order to timely identify those who require stepping up to a higher level of care to ensure full recovery. ${ }^{36}$

Despite the huge under-treatment in our study, we found that with equal effects in depressive severity between the three treatment groups, the CCBT alone group did lead to less health care consumption than the other two groups. Even a small dosage of CCBT was associated with less use of antidepressant medication during the first and fourth quarter, and with less visits to the GP and specialist mental health care during the first quarter. This is in line with our full economic evaluation of this study, which showed that the costs were lowest for CCBT alone (see chapter 3 ). ${ }^{37}$

A small trend (albeit statistically insignificant) was observed in favour of the combination group as opposed to both mono-therapies for reliable improvement. Given the high depressive severity of our sample, this might not seem surprising. For more severely depressed patients, combination treatments have been found to be superior to single treatments. $^{38,39}$

Relapse rates did not significantly differ between the groups. Although the small numbers warrant some caution, a lower relapse rate was found in the TAU only group, indicating a relapse prevention trend in favour of this group. This might be explained by the finding that more patients in the TAU group turned to specialist mental health care than those in the other groups. It is likely that they might have received face-to-face psychotherapy, such as CBT, which is effective in preventing relapse. ${ }^{10,20,40}$ We should note here that defining relapse in improved patients at three months was an arbitrary choice. At three months, not all patients might have finished their treatments yet.

We feel that our results cannot be explained by clear methodological flaws. We feel confident that no biases occurred due to missing data, because of our large sample size and low attrition rate from data collection. Some other methodological issues should also be mentioned here. First, it is notable that relatively many male participants were included in the study (approximately 45\%), more than can be expected based on epidemiological data (the 
female to male ratio is $2: 1$ ). A computerised intervention perhaps appeals more to men than to women. Second, all outcomes were measured via the Internet. One might question the equality of computerised questionnaires and paper-and-pen versions. However, there are sufficient indications that they show similar psychometric properties. ${ }^{41-43}$ Third, as we did not include a no-treatment group in our study, we do not know whether the modest improvements were significantly better than doing nothing. We should keep in mind, however, that the background for our study was to improve patient care. In that sense, comparing a new intervention to usual care is most informative. Finally, we solely relied on self-report measures at follow-up. As a result, we have no information on actual diagnoses of depressive episodes at follow-up. Moreover, health care consumption might have been over- or underestimated by patients.

In conclusion, improvements in depressive severity were maintained during twelve months of follow-up for all groups. Although unsupported online CCBT (i.e. Colour Your Life) was equally effective as TAU or CCBT\&TAU, it led to less health care consumption. The overall effects in all groups were modest, which might be explained by the high illness severity in our sample and the undertreatment we observed. CCBT with professional support or more intense treatment in secondary mental health might have yielded better results in this group of more severely depressed patients. The latter is contrasted by our finding that patients (and GPs and other specialists) seldomly stepped up to more intense treatment when improvement stayed behind, which might reflect barriers to seek or provide additional care. This calls for a need for systematic monitoring of patients to encourage further treatment.

\section{Acknowledgements}

We thank Annie Hendriks and Greet Kellens for their assistance during the study and Rosanne Janssen for the development of the infrastructure for online data-collection. The trial was financed by ZonMw (Netherlands Organisation for Health Research and Development; project number 945-04-417), research institute EPP and research institute CAPHRI. Municipalities Eijsden, Meerssen, Sittard-Geleen, Valkenburg and Maastricht sponsored the study. 


\section{References}

1. Bijl RV, Ravelli A, van Zessen G. Prevalence of psychiatric disorder in the general population: Results of the Netherlands Mental Health Survey and Incidence Study (NEMESIS). Soc Psychiatry Psychiatr Epidemiol 1998;33(12):587-595.

2. Rapaport MH, Judd LL, Schettler PJ, Yonkers KA, Thase ME, Kupfer DJ, et al. A descriptive analysis of minor depression. Am J Psychiatry 2002;159(4):637-643.

3. Keller KE. Dysfunctional attitudes and the cognitive therapy for depression. Cognitive Therapy and Research 1983;7(5):437-444.

4. Bijl RV, Ravelli A. Current and residual functional disability associated with psychopathology: findings from the Netherlands Mental Health Survey and Incidence Study (NEMESIS). Psychol Med 2000;30:657668.

5. Kruijshaar ME, Hoeymans N, Bijl RV, Spijker J, Essink-Bot ML. Levels of disability in Major Depression. Findings from the Netherlands Mental Health Survey and Incidence Study (NEMESIS). J Affect Disord 2003;77(1):53-64.

6. Cuijpers P, Smit F, Oostenbrink J, de Graaf R, Ten Have M, Beekmand A. Economic costs of minor depression: a population-based study. Acta Psychiatr Scand 2007;115:229-236.

7. Luppa M, Heinrich S, Angermeyer MC, König HH, Riedel-Heller SG. Cost-of-illness studies of depression. A systematic review. J Affect Disord 2007;98:29-43.

8. Slobbe LCJ, Kommer GJ, Smit JM, Groen J, Meerding WJ, Polder JJ. Kosten van Ziekten in Nederland 2003; Zorg voor euro's - 1 [Costs of illness in the Netherlands 2003]. Bilthoven: Rijksinstituut voor Volksgezondheid en Milieu, 2006.

9. Butler AC, Chapman JE, Forman EM, Beck AT. The empirical status of cognitive-behavioral therapy: A review of meta-analyses. Clin Psychol Rev 2006;26:17-31.

10. Hollon SD, Stewart MO, Strunk D. Enduring effects for cognitive behavior therapy in the treatment of depression and anxiety. Annu Rev Psychol 2006;57:285-315.

11. Kessler RC, Berglund P, Demler O, Jin R, Koretz D, Merikangas KR, et al. The epidemiology of major depressive disorder. Results from the National Comorbidity Survey Replication (NCS-R). JAMA 2003;289(23):3095-3105.

12. Kaltenthaler E, Brazier J, De Nigris E, Tumur I, Ferriter M, Beverly C, et al. Computerised cognitive behaviour therapy for depression and anxiety update: a systematic review and economic evaluation. Health Technol Assess 2006;10(33):1-186.

13. Kaltenthaler E, Sutcliffe P, Parry G, Beverly C, Rees A, Ferriter M. The acceptability to patients of computerized cognitive behaviour therapy for depression: a systematic review. Psychol Med 2008;38(11):1521-1530.

14. Spek V, Cuijpers P, Nyklícek I, Riper H, Keyzer J, Pop V. Internet-based cognitive behaviour therapy for symptoms of depression and anxiety: a meta-analysis. Psychol Med 2007;37(3):319-328.

15. Proudfoot J, Ryden C, Everitt B, Shapiro DA, Goldberg A, Mann A, et al. Clinical efficacy of computerised cognitive-behavioural therapy for anxiety and depression in primary care: randomised controlled trial. Br J Psychiatry 2004;185:46-54.

16. de Graaf LE, Gerhards SAH, Arntz AR, Riper H, Metsemakers JFM, Evers SMAA, et al. Clinical effectiveness of online computerised cognitive behavioural therapy without support for depression in primary care: a randomised trial. Br J Psychiatry 2009;195(1):73-80.

17. Spek V, Nyklícek I, Smits N, Cuijpers P, Riper H, Keyzer J, et al. Internet-based cognitive behavioural therapy for subthreshold depression in people over 50 years old: a randomized controlled clinical trial. Psychol Med 2007;37:1797-1806.

18. Mackinnon AJ, Griffiths KM, Christensen H. Comparative randomised trial of online cognitivebehavioural therapy and an information website for depression: 12-month outcomes. Br J Psychiatry 2008;192:130-134. 
19. Spek V, Cuijpers P, Nyklíček I, Smits N, Riper H, Keyzer J, et al. One-year follow-up results of a randomized controlled clinical trial on Internet-based cognitive behavioural therapy for subthreshold depression in people over 50-years. Psychol Med 2008;38:635-639.

20. VittengI JR, Clark LA, Dunn TW, Jarrett RB. Reducing relapse and recurrence in unipolar depression: a comparative meta-analysis of cognitive-behavioral therapy's effects. J Consult Clin Psychol 2007;75(3):457-488.

21. de Graaf LE, Gerhards SAH, Evers SMAA, Arntz AR, Riper H, Severens JL, et al. Clinical and costeffectiveness of computerised cognitive behavioural therapy for depression in primary care: design of a randomised trial. BMC Public Health 2008;8:224.

22. Beck AT, Guth D, Steer RA, Ball R. Screening for major depression disorders in medical inpatients with the beck depression inventory for primary care. Behav Res Ther 1997;35(8):785-791.

23. Riper H, Kramer JJAM. Online zelfhulpcursus www.kleurjeleven.nl. Utrecht: Trimbos-institute, 2004.

24. Van Marwijk HWJ, Grundmeijer HGLM, Bijl D, van Gelderen MG, de Haan M, van Weel-Baumgarten EM, et al. NHG-standaard depressieve stoornis (in Dutch) [Depression guideline of the Dutch College of General Practitioners]. Huisarts Wet 2003;46:614-623.

25. Arnau RC, Meagher MW, Norris MP, Bramson R. Psychometric Evaluation of the Beck Depression Inventory-II With Primary Care Medical Patients. Health Psychol 2001;20(2):112-119.

26. Beck AT, Steer RA, Ball R, Ranieri WF. Comparison of Beck Depression Inventories-IA and -II in psychiatric outpatients. J Pers Assess 1996;67(3):588-597.

27. Van der Does AJW. De Nederlandse versie van de Beck Depression Inventory - second edition (BDI-II-NL): Handleiding [The Dutch version of the Beck Depression Inventory - second edition (BDI-II-NL): Manual]. Enschede: The Psychological Corporation, 2002.

28. Cohen J. Statistical power analysis for the behavioral sciences. Hillsdale, NJ: Erlbaum, 1988.

29. Jacobson NS, Truax P. Clinical significance: a statistical approach to defining meaningful change in psychotherapy research. J Consult Clin Psychol 1991;59(1):12-19.

30. Andersson G, Bergström J, Holländare F, Ekselius L, Carlbring P. Delivering cognitive behavioural therapy for mild to moderate depression via the internet: predicting outcome at 6-month follow-up. Verhaltenstherapie 2004;14:185-189.

31. de Graaf LE, Hollon SD, Huibers MJH. Predicting outcome in computerized cognitive behavioural therapy for depression in primary care: a randomized trial. Journal of Consulting and Clinical Psychology 2010, 78(2):184-189.

32. Mataix-Cols D, Cameron R, Gega L, Kenwright M, Marks IM. Effect of referral source on outcome with cognitive-behavior therapy self-help. Comprehensive Psychiatry; 2006;47:241-245.

33. Brugha TS, Bebbington PE. The undertreatment of depression. Eur Arch Psychiatry Clin Neurosci 1992;242:103-108.

34. Vuorilehto M, Melartin TK, Rytsälä HJ, Isometsä E. Do characteristics of patients with major depressive disorder differ between primary and psychiatric care? Psychol Med 2007;37:893-904.

35. Galbaud du Fort G, Newman SC, Boothroyd L, Bland C. Treatment seeking for depression: role of depressive symptoms and comorbid psychiatric diagnoses. J Affect Disord 1999;52:31-40.

36. Bower P, Gilbody S. Stepped care in psychological therapies: access, effectiveness and efficiency. $\mathrm{Br} J$ Psychiatry 2005;186:11-17.

37. Gerhards SAH, de Graaf LE, Jacobs LE, Severens JL, Huibers MJH, Arntz A, et al. Economic evaluation of online computerised cognitive-behavioural therapy without support for depression in primary care: randomised trial. Br J Psychiatry 2010;196(4):310-318.

38. Friedman MA, Detweiler-Bedell JB, Leventhal HE, Horne R, Keitner GI, Miller IW. Combined psychotherapy and pharmacotherapy for the treatment of major depressive disorder. Clinical Psychology: Science and Practice 2004;11(1):47-68.

39. Pampallona S, Bollini P, Tibaldi G, Kupelnick B, Munizza C. Combined pharmacotherapy and psychological treatment for depression. Arch Gen Psychiatry 2004;61:714-719.

40. Paykel ES, Brugha T, Fryers T. Size and burden of depressive disorders in Europe. Eur Neuropsychopharmacol 2005;15:411-423. 
41. Carlbring P, Brunt S, Bohman S, Austin D, Richards J, Öst LG, et al. Internet vs paper and pencil administration of questionnaires commonly used in panic/agoraphobia research. Computers in Human Behavior 2007;23:1421-1434.

42. Garb HN. Computer-administered interviews and rating scales. Psychological Assessment 2007;19(1):413.

43. Schulenberg SE, Yutrzenka BA. Equivalence of Computerized and Conventional Versions of the Beck Depression Inventory-II (BDI-II). Current Psychology 2001;20(3):216-230. 



\section{Dankwoord}

Graag wil ik iedereen bedanken die heeft bijgedragen aan het totstandkomen van dit proefschrift: Mijn (co)promotores Silvia, Marcus, Arnoud en Guy; Het fantastische Depressiedotcom-team Esther, Annie, Rosanne en Greet; Co-auteurs/mede-begeleiders Tineke, Hans, Mariëlle, Heleen; Thesisstudenten Linde, Kevin, Philip en Denise die meewerkten aan de onderzoeken; Alle onderzoeksdeelnemers en deelnemende gemeenten; De leden van de beoordelingscommissie; En alle mensen die direct of indirect een kleinere bijdrage hebben geleverd aan dit proefschrift.

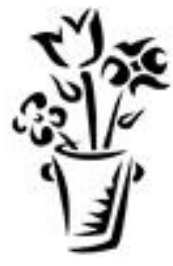

Als laatste wil ik alle (oud-)collega's van CPS en BEOZ, vrienden, familie en in het bijzonder pa, ma, Yvonne, Peter en natuurlijk Dennis bedanken voor hun steun en voor de leuke momenten tijdens de aio-jaren.

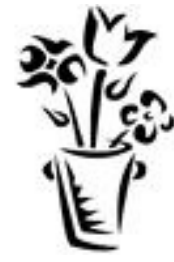

Een kort dankwoord,

Maar een grote BEDANKT aan jullie allen! 



\section{About the author}

Sylvia Gerhards was born on October 27th, 1981 in Tongeren (Belgium). She completed secondary school at the Provinciale Secundaire School in Voeren (Belgium) in 1999, after which she started a study Political and Social Sciences at the Katholieke Universiteit Leuven (Belgium). She graduated in 2004 and received her Master degree in Sociology. That same year she started working as coordinator of an extramural childcare center at the Landelijke Kinderopvang in Voeren (Belgium), and started as part-time student of the Master in Public Health (specialisation Health Policy, Economics and Management) at the Maastricht University (the Netherlands). In 2006 she received her Master degree in Public Health and changed job into PhD Candidate at the department Clinical Psychological Science and the School for Public Health and Primary Care (Caphri) of the Maastricht University (the Netherlands). Her PhD project, which is described in this thesis, consisted of two parts: an evaluation of self-help computerised cognitive behavioural therapy for depression (clinical and economic evaluation, patient experiences) and an evaluation of quality of life utility instruments. In 2009 she received the ISRII (International Society for Research on Internet Interventions) Early Career Researcher Award for her presentation on the economic evaluation study of her project. In addition to her PhD project, she worked voluntary as a member of the Conference Committee of the PhD Academy Maastricht in organising the PhD Conference 2009 on the theme 'Crossing borders'; And she worked voluntary as program coordinator/ supervisor in the project South Africa Xplored 2009 of the foundation OPIN (Stichting OnderwijsProjecten Inter- \& Nationaal). She was lecturer, examiner, and tutor within the modules Sociology and Ethics of the educational program Arts Therapy (Creatieve Therapie / Vaktherapie) at the Hogeschool Zuyd in Heerlen (the Netherlands) from April till July 2010. Since September 2010, she works as a policy-supporting staff member at the outpatient community mental health care institution VGGZ (Vereniging Geestelijke GezondheidsZorg Limburg vzw) in Hasselt (Belgium). 


\section{Publications}

- Gerhards SAH, Abma TA, Arntz A, de Graaf LE, Evers SMAA, Huibers MJH, Widdershoven $G$. Improving adherence and effectiveness of computerised cognitive behavioural therapy without support for depression: A qualitative study on patient experiences. Journal of Affective Disorders 2010 (in press); doi:10.1016/j.jad.2010.09.012.

- Gerhards SAH, Evers SMAA, Sabel PWM, Huibers MJH. Discrepancy in rating healthrelated quality of life of depression between patient and general population. Quality of Life Research 2010 (in press); doi:10.1007/s11136-010-9746-x.

- De Graaf LE, Gerhards SAH, Arntz A, Riper H, Metsemakers JFM, Evers SMAA, et al. Oneyear follow-up results of unsupported online computerised cognitive behavioural therapy for depression in primary care: a randomised trial. Journal of Behavior Therapy and Experimental Psychiatry 2010 (in press); doi:10.1016/j.jbtep.2010.07.003.

- Gerhards SAH, de Graaf LE, Jacobs LE, Severens JL, Huibers MJH, Arntz AA, Riper H, Widdershoven G, Metsemakers JFM, Evers SMAA. Economic evaluation of online computerised cognitive behavioural therapy without support for depression in primary care: randomised trial. British Journal of Psychiatry 2010; 196: 310-318.

- De Graaf LE, Gerhards SAH, Arntz AR, Riper H, Metsemakers JFM, Evers SMAA, et al. Clinical effectiveness of online computerised cognitive behavioural therapy without support for depression in primary care: a randomised trial. British Journal of Psychiatry 2009; 195: 73-80.

- De Graaf E, Huibers M, Riper H, Gerhards S, Arntz A. Use and acceptability of unsupported online computerised cognitive behavioral therapy for depression and associations with clinical outcome. Journal of Affective Disorders 2009; 116: 227-231.

- Van Eijsden MD, Gerhards SA, de Bie RA, Severens H. Cost-effectiveness of postural exercise therapy versus physiotherapy in screen-workers with early non-specific workrelated upper limb disorders (WRULD); a randomised controlled trial. Trials 2009; 10:103.

- De Graaf LE, Gerhards SAH, Evers SMAA, Arntz AR, Riper H, Severens JL, et al. Clinical and cost-effectiveness of computerised cognitive behavioural therapy for depression in primary care: design of a randomised trial. BMC Public Health 2008; 8(224).

- De Graaf LE, Gerhards SAH, Metsemakers JFM, Riper H, Huibers MJH. De computer als hulpverlener bij depressie en angst. Bijblijven 2007; 23(7):41-7.

\section{Manuscripts submitted for publication}

- Gerhards SAH, Theunissen KATM, Evers SMAA, de Graaf LE, Widdershoven GAM, Huibers $\mathrm{MJH}$. Change in the course of depression severity (BDI-II) and quality of life utility (SF-6D): evidence for a temporal relation? 
- Gerhards SAH, Goossens M, Huibers MJH, de Graaf LE, Riper H, Evers SMAA. Credibility and expectancy in online self-help depression treatment: impact on depression severity and quality of life.

- Gerhards SAH, Huibers MJH, Theunissen KATM, de Graaf LE, Widdershoven GAM, Evers SMAA. The responsiveness of quality of life utilities to change in depression: a comparison of instruments (SF-6D, EQ-5D and DFD). 